\title{
Desirables and weeds \\ for roadside management - \\ a northern Rocky Mountain catalogue.
}

Prepared by

Gretchen Meier and

T Weaver

Department of Biology

Montana State University

Bozeman MT 59717

Prepared for

State of Montana Department of Transportation

Research, Development, and Technology Transfer Program

in cooperation with the

US Department of Transportation

Federal Highway Administration

December 1997 
Technical Report Documentation Page

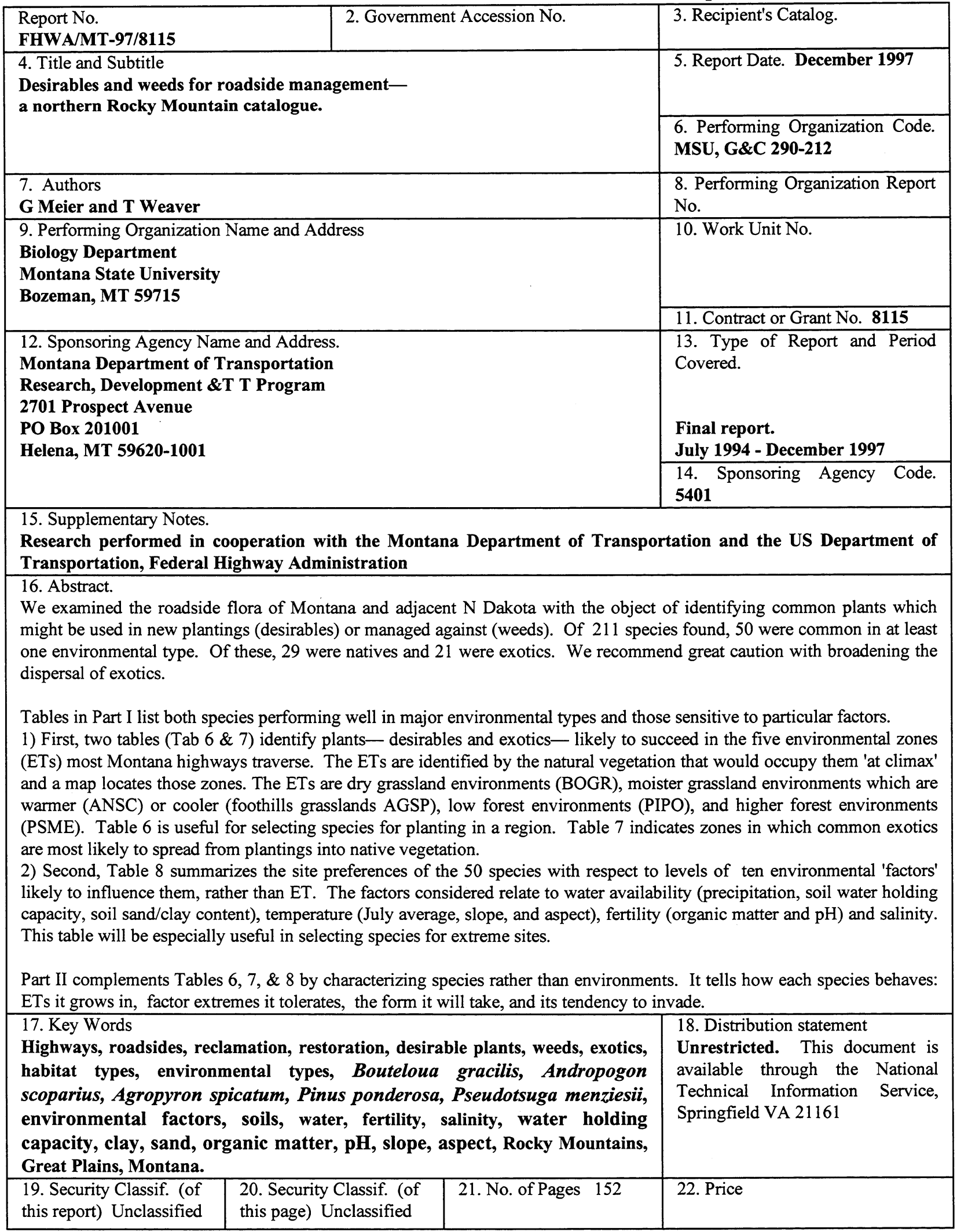




\section{DISCLAIMER}

The opinions, findings, and conclusions expressed in this publication are those of the authors and not necessarily those of the Montana Department of Transportation or the Federal Highway Administration.

\section{ALTERNATE FORMAT STATEMENT}

MDT attempts to provide reasonable accommodations in any service, program or activity of the department. Alternative accessible formats of this document will be provided upon request. For further information call (406) 444-6269 or TTY (406) 444-7696.

\section{ACKNOWLEDGEMENTS}

This manual is the result of a cooperative effort. P Johnson and T Weaver first concieved the project. G Meier gathered the roadside data (Su 1993-1994), identified and filed plants, processed soil samples, filed data, and processed the data. J Rumely helped with the plant identification, $\mathrm{M}$ Taper and S Cherry helped with complex math, and the MSU Soil Testing Lab made the chemical analysis. The synthesis was due to Gretchen, Tad and Phil. MDT provided primary funding, excellent editing (S Sillick) and outstanding project management ( $\mathrm{R}$ Garber). Parallel work in the mountains cross-fertilized with this project; it was supported by the National Park Service/ University of Wyoming Research Center. Thanks to all. 


\begin{abstract}
We examined the roadside flora of Montana and adjacent $\mathrm{N}$ Dakota with the object of identifying common plants which might be used in new plantings (desirables) or managed against (weeds). Of 211 species found, 50 were common in at least one environmental type. Of these, 29 were natives and 21 were exotics. We recommend great caution with broadening the dispersal of exotics.
\end{abstract}

Tables in Part I list both species performing well in major environmental types and those sensitive to particular factors.

1) First, two tables (Tab $6 \& 7$ ) identify plants - desirables and exotics - likely to succeed in the five environmental zones (ETs) most Montana highways traverse. The ETs are identified by the natural vegetation that would occupy them 'at climax' and a map locates those zones. The ETs are dry grassland environments (BOGR), moister grassland environments which are warmer (ANSC) or cooler (foothills grasslands AGSP), low forest environments (PIPO), and higher forest environments (PSME). Table 6 is useful for selecting species for planting in a region. Table 7 indicates zones in which common exotics are most likely to spread from plantings into native vegetation.

2) Second, Table 8 summarizes the site preferences of the 50 species with respect to levels of ten environmental 'factors' likely to influence them, rather than ET. The factors considered relate to water availability (precipitation, soil water holding capacity, soil sand/clay content), temperature (July average, slope, and aspect), fertility (organic matter and $\mathrm{pH}$ ) and salinity. This table will be especially useful in selecting species for extreme sites.

Part II complements Tables $6,7, \& 8$ by characterizing species rather than environments. It tells how each species behaves: ETs it grows in, factor extremes it tolerates, the form it will take, and its tendency to invade.

KEY WORDS: Highways, roadsides, reclamation, restoration, desirable plants, weeds, exotics, habitat types, environmental types, Bouteloua gracilis, Andropogon scoparius, Agropyron spicatum, Pinus ponderosa, Pseudotsuga menziesii, environmental factors, soils, water, fertility, salinity, water holding capacity, clay, sand, organic matter, $\mathrm{pH}$, slope, aspect, Rocky Mountains, Great Plains, Montana. 


\section{TABLE OF CONTENTS}

Part I: Desirables and weeds inhabiting major environments: environmental

types and special conditions .................................................................................................................1

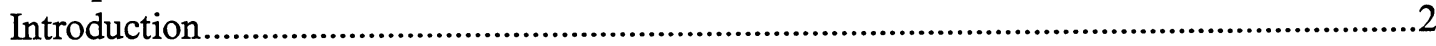

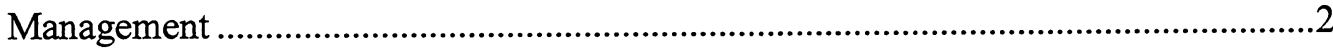

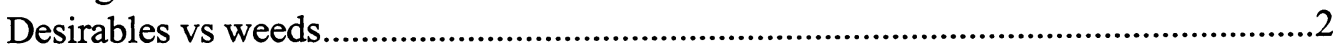

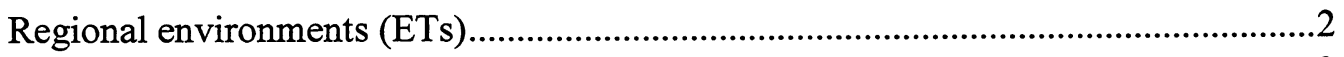

Objectives and presentation .............................................................................

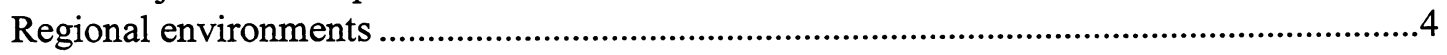

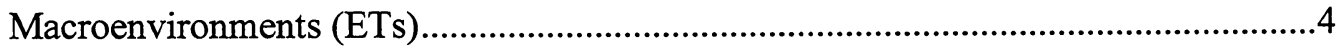

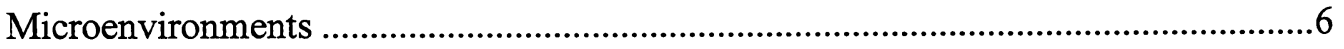

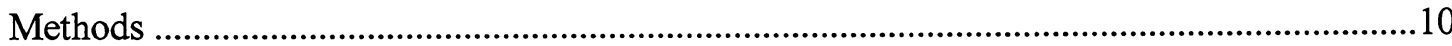

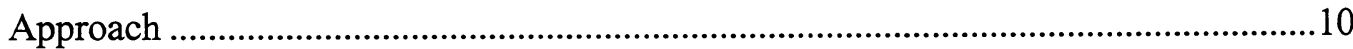

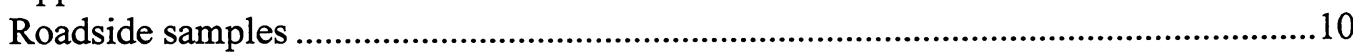

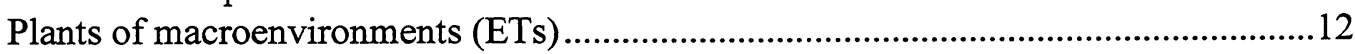

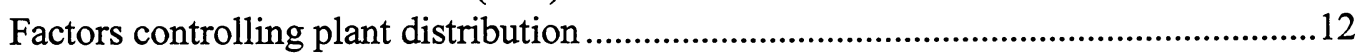

Roadside flora of macroenvironments (ETs) .................................................................... 14

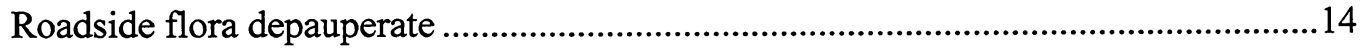

Natives of principle ET's: candidates for seeding......................................................15

Exotics of principle ET's: candidates for management (+ or - ) ..................................18

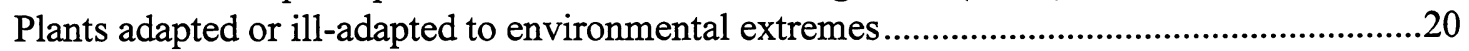

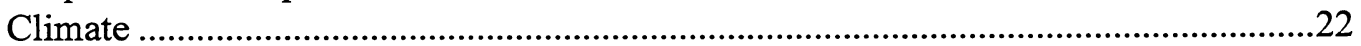

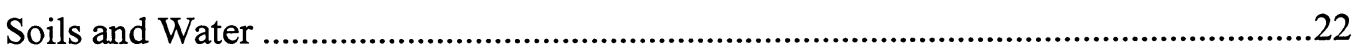

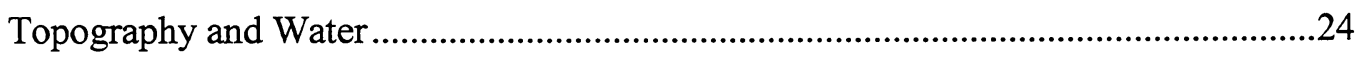

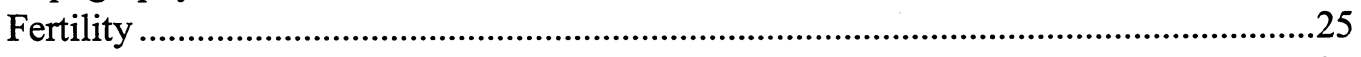

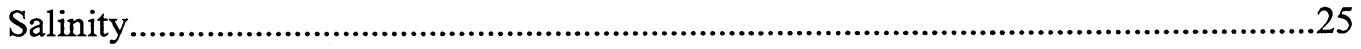

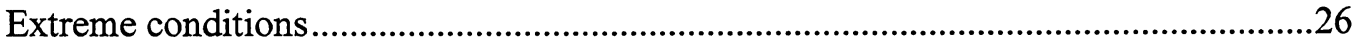

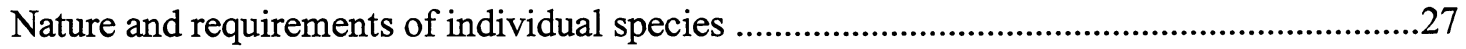

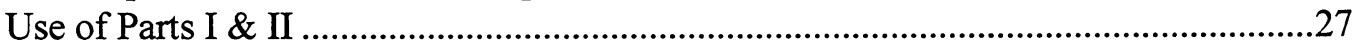

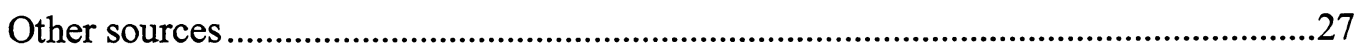

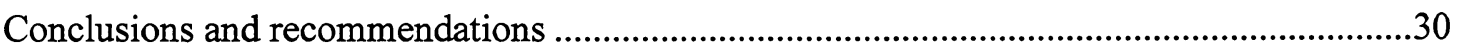

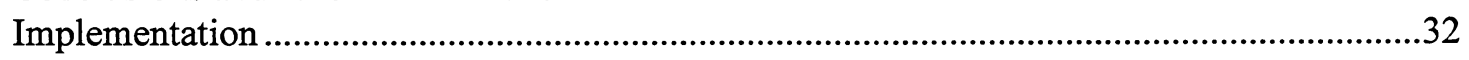

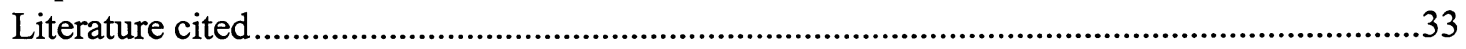

Part II: Nature and requirements of fifty species ..................................................................................36

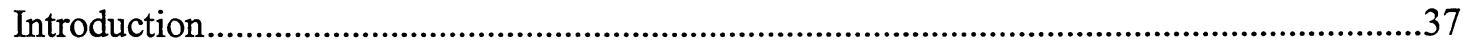

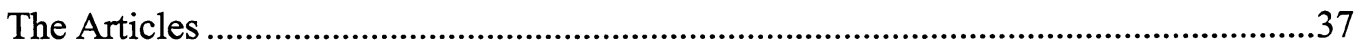

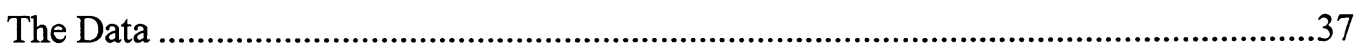

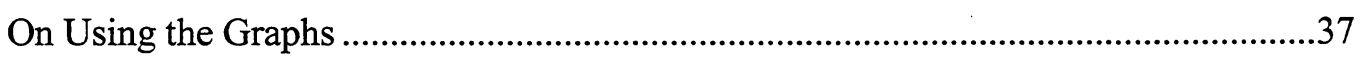

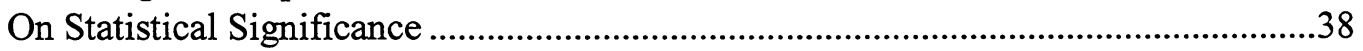

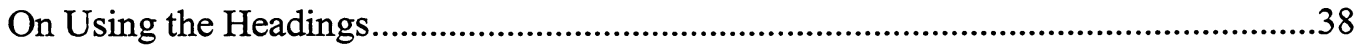

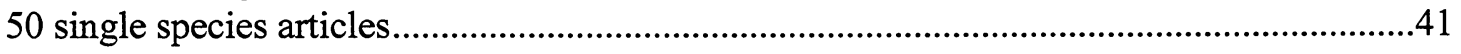

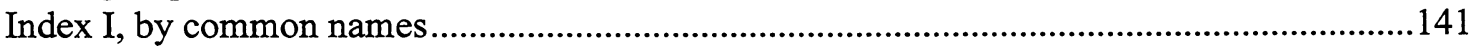

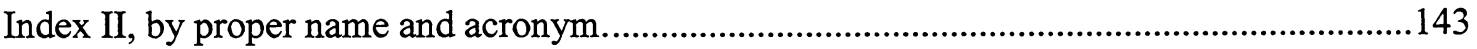

Appendix A. Metric -English conversions (inside back cover) ........................................................145 


\section{LIST OF EXHIBITS}

\section{LIST OF MAPS}

Map 1. Environmental types of the northern Rocky Mountains ..............................................7

Map 2. Study sites in Montana and North Dakota. ..................................................................11

\section{LIST OF TABLES}

Table 1. Changes in environmental characteristics across altitudinal zones (ET's) .....................5

Table 2. Identifying major environmental types (ET's) …......................................................

Table 3. Factors distinguishing macro- and micro-environments.............................................

Table 4. Distribution of sites sampled among environmental types, aspect, and position ............11

Table 5. Richness of roadside flora relative to natural flora in five environmental types.............15

Table 6. Performance of native species on roadsides in five environmental types ......................16

Table 7. Performance of exotic species on roadsides in five environmental types ......................19

Table 8. Positions of common plant species on eight factor gradients .......................................20

Table 9. Characteristics of major species...................................................................................28

Table 10. Conversion of metric and English measures ...............................................................145

\section{LIST OF FIGURES}

Figures 1-50. Distribution of fifty species among five environmental types and on nine factor gradients. Distributions are presented separately for fifty common roadside natives and exotics. The plants are listed alphabetically. 


\section{Part I:}

DESIRABLES AND WEEDS INHABITING MAJOR ENVIRONMENTS: ENVIRONMENTS AND SPECIAL CONDITIONS 


\section{INTRODUCTION}

MANAGEMENT Roadside vegetation is managed for five qualities: high plant cover (i.e., low erosion), attractive appearance, non-attractive to large animals (i.e., low road hazard), and low height (i.e., minimal mowing to prevent fire or obstruction of vision). Managers need communities which establish rapidly and dependably. They also want communities which are stable in the long term (Egler 1975, Niering and Goodwin 1974).

DESIRABLES VS WEEDS To install and manage roadside vegetation, it is necessary to identify and manage two sorts of species: desirables and weeds. 1) 'Desirables', according to the conditions set above, are species which establish easily, spread strongly on-site, are well adapted, remain low, are attractive, are unpalatable, and exclude invaders. A presidential memorandum (Clinton 1994) encourages planting of natives of the region, because they are well adapted, deserve preservation, and, due to their long established place in our vegetation, do not threaten native vegetation. 2) 'Weeds' are unwanted plants because they interfere with establishing vegetation, interfere with established vegetation, or spread from roadsides to vegetation where they are unwanted. Weeds of newly established $\left(1^{\circ}\right.$ seral $)$ vegetation are well studied by agronomists and are not considered here. Plant invaders changing the nature of established roadside vegetation - even if the invasion is natural succession - are considered weedy if they change the nature of suitable vegetation (Egler 1975, Niering and Goodwin 1974). For example, undesirable invaders might lure large mammals (e.g.,legumes), obstruct views (e.g, junipers, pines, or cottonwoods), or litter highways with leaves or branches. Introduced plants (exotics or aliens) - despite sometimes good properties - are looked askance upon because they may move from a planting to degrade natural vegetation - either lateral to the road or down the road corridor.

REGIONAL ENVIRONMENTS Most stretches of highway in the area pass through one of five macroenvironments, each containing a variety of microenvironments. A somewhat different suite of desirables/weeds is expected in each environment. Thus, for the sake of the manager, important $(+/-)$ species are listed separately for each environmental zone. To facilitate identification of the environmental zones, the ETs are listed, characterized, and keyed in the next section of our report. 
OBJECTIVES AND PRESENTATION Species which thrive along roadsides were identified for macro- and micro-environments of the high plains and adjacent mountains. Native species, candidates for seeding after new construction ('desirables') and exotics, questionable for use ('undesirables') are distinguished. The results are presented in two sections. Part I lists species adapted to particular environments - both regional environmental types ( 5 ETs) and environments extreme with respect to ten important factors - and deserving management ( \pm ) there. Part II summarizes information on the nature and environmental requirements of common species, one at a time, rather than across environments. It also characterizes desirables and weeds with respect to invasiveness, form and reproduction, environments occupied, and extremes tolerated. 


\section{REGIONAL ENVIRONMENTS}

The manager must determine the environmental type (ET) of the site being treated to estimate the success of particular species on that site. The first subsection of this section therefore introduces the macro- and microenvironments common along Montana highways. Later sections list species thriving in each of Montana's most widespread macroenvironments (ETs) and use the species' relation to important environmental factors to explain their distribution between ETs and among microenvironments within them.

MACROENVIRONMENTS Major environments of the northern plains and adjacent mountains have been described (Pfister et. al. 1977, Mueggler and Stewart 1980), named for plants dominating at climax, and mapped (Kuchler 1964, Meier 1997). They are presented here as an altitudinal series occupied by grasslands at low elevation, montane forests (ponderosa pine and douglas fir), subalpine forests (subalpine fir), and alpine tundra. Their physical environments are sketched (Table 1) from more detailed climatic (Weaver 1980, 1994) and substrate (Weaver 1979) data. Since climatic data is often unavailable, the one-to-one correspondence between environment and vegetation- especially climax vegetation (Holdridge 1947 and Whittaker 1975) - is also used to map environmental zones from vegetation occupying them.

Highways in our region rarely pass through the alpine and subalpine. Thus, only five environmental zones common at lower altitudes are considered. These include three grassland and two forest types characterized below. These environments (ETs) can be identified with a simple key (Table 2, pg 8). And the areas dominated by each type are mapped (Map 1, Kuchler 1964, pg 7) to provide an alternate or complimentary tool for their identification.

The Shortgrass ET (abbreviated BOGR) is Montana's largest environmental type. It reaches from 0-100 $\mathrm{km}$ west of the Montana/Dakota border around the island mountains nearly to the foot of the main Rocky Mountains, that is, from eastern Montana to a line connecting Billings and Great Falls (Map 1, pg 7). It is noted for low rainfall, a shallow calcic horizon, and the presence of Bouteloua gracilis, especially on heavily grazed sites. Upland areas support grazing and strip farmed wheat. 
Table 1. Changes in environmental characteristics across altitudinal zones (ETs) of the northern Rocky Mountains. Roadside samples were drawn from the first five types.

\begin{tabular}{|c|c|c|c|c|c|c|c|}
\hline \multirow[b]{2}{*}{ variable } & \multicolumn{7}{|c|}{ Environmental Types $^{1}$} \\
\hline & ANSC & BOGR & AGSP & PIPO & PSME & ABLA & ALPN \\
\hline Elevation $(\mathrm{m})^{2}$ & 2200 & 3000 & 4000 & $3-5000$ & $5-7500$ & $7-9000$ & $>9000$ \\
\hline Mean July Temperature $\left({ }^{\circ} \mathrm{C}\right)^{3}$ & 22 & 21 & 20 & 20 & 17 & 14. & 9 \\
\hline Mean Annual Precipitation & 53 & 35 & 38 & 55 & 58 & 82 & $>82$ \\
\hline Sand $(\%)^{3}$ & 4 & $33 \pm 3$ & $36 \pm 4$ & $36 \pm 14$ & $36 \pm 5$ & 52 & 56 \\
\hline Clay $(\%)^{3}$ & 4 & $28 \pm 2$ & $27 \pm 3$ & $28 \pm 8$ & $12 \pm 2$ & 4 & 10 \\
\hline Organic Carbon $(\%)^{3}$ & 4 & $1.5 \pm 0.1$ & $2.8 \pm 0$ & $2.9 \pm 0.5$ & $1.2 \pm 0.2$ & 1.6 & 5.7 \\
\hline $\mathrm{pH}^{3}$ & 4 & $7.4 \pm 0.2$ & $6.5 \pm 0$ & $6.4 \pm 0.3$ & $5.6 \pm 0.3$ & 6.1 & 5.4 \\
\hline
\end{tabular}

${ }^{1}$ Environmental types are ANSC $=$ Andropogon scoparium, BOGR $=$ Bouteloua gracilis, AGSP $=$ Agropyron spicatum, PIPO = Pinus ponderosa $;$ PSME = Pseudotsuga mensizeii, ABLA $=$ Abies lasiocarpa, alpine $=$ ALPN. See text for more information.

${ }^{2}$ Typical elevations of grasslands (Montana Atlas and Gazetteer, 1997) and forests (Pfister et al., 1977). ${ }^{3}$ Soils and climate data from Weaver $(1979,1980)$.

${ }^{4}$ Comparable information is not available.

The Mixed-Grass ET (abbreviated ANSC) lies to the east (Map 1, pg 7). While it was sampled at the northeast corner of Montana, the environment also occurs in SE Montana and extends eastward to the Missouri River (beyond Bismark and Pierre ND, Kuchler 1964). It is noted for somewhat higher rainfall, a deeper calcic horizon, and a greater variety of grass dominants: Agropyrons, Stipas, and traces of Andropogon scoparius. Upland areas support grazing and small grain production, both more productive than the shortgrass prairie. As small grain production increases eastward, the proportion of the landscape which is farmed also increases.

The Foothill Grassland ET (FEID) occupies the first $50 \mathrm{~km}$ east/north of the Rockies and most of the valley bottoms west of the mountains (Map 1, pg 7). It receives slightly more rainfall than the shortgrass prairie and - because of its foothill location - has gravelly soils which absorb water before it evaporates. The resultant increase in water availability favors bunchgrasses- so Agropyron spicatum dominates at lower altitude and fescues (Festuca idahoensis/ F scabrella) dominate at higher altitude (cooler/moister) sites. The calcic horizon in this type is deeper than in the shortgrass ET. Productivity is higher and grazing and wheat production are the dominant land uses. 
The Ponderosa Pine ET (PIPO) covers the lowest forest lands in western Montana (Map 1). Being higher than the foothill grasslands, it receives more precipitation and has stonier soils. Thus it has more effective rainfall, its calcic horizon is deeper, and plant production is higher. The production is, however, non-agricultural, because the slopes are steeper, soils are stonier, and some rock outcrops.

The Douglas Fir ET (PSME) is a second montane forest type (Map 1). In western Montana, it lies above the ponderosa forests. East of the Rockies and north of Casper WY, it is usually the lowest Rocky Mountain forest. Rainfall and stoniness are higher than in the PIPO environments. For the first time on the altitudinal gradient, we see lower temperatures (Table 1, Weaver 1980, 1994). Production is primarily forest, some grazing, and very little crop.

Five other commonly mapped environmental types (ET's) were not sampled because they occupy relatively small areas and contain few roads. 1) A second ponderosa pine environmental type (eastern PIPO) occurs in the Big Timber, Lewistown, Roundup, and Ashland areas of SE Montana (Map 1). Highway 212 passes through this area. While this ET receives less precipitation than the western ponderosa type (Weaver 1980), it is also stony and thus has similar amounts of effective water. Associated plant desirables/ weeds probably resemble those of the mixed grass and/or ponderosa types. 2) Shrublands containing Artemisia species appear in the SE, the SW, and between the mountain ranges south of Great Falls. 3) Riparian environments border the Yellowstone and Missouri Rivers. 4) Subalpine fir forest environments appear at higher altitudes, e.g., near highways 2, 200, and 15 (Map 1). 5) Roadside alpine environments occur only on the Beartooth Plateau, adjacent to highway 212. Roadside plants in the subalpine and alpine are discussed by Weaver et al. $(1989,1993)$.

MICROENVIRONMENTS Just as the flora varies from one climatic region (ET) to another, it varies between microhabitats within environmental types (ETs). Thus, the results section shows individual species' responses to factors which have local effects. These factors may operate through water availability (precipitation, soil texture and stone content, and aspect and position), temperature (altitude and slope/aspect), nutrient availability (organic matter and $\mathrm{pH}$ ), and salinity (conductivity). These factors are defined and discussed in Table 3. 
Table 2. Identifying major environmental types (ETs) of the northern plains and mountains. To use the key, move down the table, choosing one of the (paired) headings at each level of indentation.

I. Sites dominated, at climax, by grassland. If cultivated or heavily grazed, then deduce climax status from nearby environmentally similar and uncultivated sites and/or the map of environments (Map 1).

1. Grassland in the eastern plains.

a. Most sites 50-100 km (30-60 mi) east of the Rockies and 50-100 km (30-60 mi) west of Montana's eastern border (Map 1). Upland sites dominated, at climax, by an open stand of Bouteloua gracilis, Agropyron smithii, and/or Stipa comata. S viridula and/or Andropogon scoparius absent. Grass blades less than $20 \mathrm{~cm}$ (8 in) tall.

SHORTGRASS ET.

b. Site near or east of the Montana border (Map 2). Upland sites dominated, at climax by a moderately dense stand of Agropyron smithii, Bouteloua gracilis, Stipa comata and $S$ viridula. Grass blades usually more than $20 \mathrm{~cm}(8 \mathrm{in})$ tall. Andropogon scoparius on moist sites.

MIXED-GRASS ET.

2. Grassland in the mountains or foothills.

a. Site within approximately $50 \mathrm{~km}$ (30mi) of the mountains (Map 1). Soil usually gravelly. Occupied, at climax, by bunchgrasses, i.e., Agropyron spicatum, Festuca idahoensis, or F scabrella.

\section{FOOTHILL BUNCHGRASS ET.}

b. Rare short-grassy sites above $3000 \mathrm{~m}(10,000 \mathrm{ft})$

\section{ALPINE ET.}

II. Sites dominated, at climax, by forest. If the site has been cleared assign the ET according to vegetation of similar forested sites in the landscape.

1. Site dominated by Pinus ponderosa, often in open stands. Sometimes with Juniperus virginiana or P flexilis; not with P contorta, Pseudotsuga menziesii, or Abies lasiocarpa.

a. West of the Rocky Mountains

b. East of the Rocky Mountains.

Western PINUS PONDEROSA ET.

Eastern PINUS PONDEROSA ET.

2. Site dominated by Pseudotsuga menziesii, at climax. Sometimes with $P$ contorta as a precursor on higher (moister cooler) sites; if the site is dominated by $P$ contorta, PSME seedlings can be found in it.

PSEUDOTSUGA MENZIESII ET.

3. Site dominated by Abies lasiocarpa, at climax. Usually with $P$ contorta as a precursor; if the site is dominated by $P$ contorta, ABLA seedlings can be found in it. Highest general forest vegetation; rare along highways

ABIES LASIOCARPA ET. 
Table 3. Factors distinguishing macro-(ETs) and micro-environments of Montana.

WATER AVAILABILITY

Precipitation Average annual precipitation is used as an index for rainfall deposited at a site. Data from statewide precipitation maps (Caprio et al. 1994).

Sand High sand increases water infiltration. Thus, more summer rainfall will be available on sandy sites. Measured with the hydrometer method (Boyoucos 1962, Tan 1996)

Clay High clay stores winter water and reduces infiltration of summer precipitation. Thus, plants occupying clay rich soils may have a long moist season alternating with drought. Through their shrink-swell and crusting characteristics clays may interfere with seedling establishment. Measured with the hydrometer method.

WHC Water holding capacity of a profile is largely determined by its soil content, and within that soil by clay and organic matter: 15 bar $\mathrm{WHC}=2+0.5$ clay $+0.3 \mathrm{OM}$ and $1 / 3$ bar water $=2 \times 15$ bar water (Decker 1972). Like clay, this factor expresses a soil's capacity to extend spring rainfall into summer. It may share other characteristics with clay.

Aspect/position See 'energy' below.

ENERGY.

Temperature Relative non-dormant season temperatures were indexed with average July temperature. Data from a temperature map (Caprio et al. 1994):

Aspect Slopes facing the sun receive more energy than those facing away from it (Geiger 1966, Frank and Lee 1966). Thus south-facing slopes are generally warmest, andbecause heat evaporates water- they are often driest. Read with a compass.

Position Inslopes differ from backslopes in energy receipt (slope), stability, compaction, disturbance, pollution, distance from weed seed sources (the road) and native seed sources (adjacent vegetation).

NUTRIENT AVAILABILITY.

Organic matter High organic matter (OM) indicates rich conditions, except in permanently flooded conditions. OM is about $50-60 \% \mathrm{C}$ and $5 \% \mathrm{~N}$. It contributes to cation exchange capacity. OC also contributes to soil WHC, see above.

pH. Most nutrient elements are available at $\mathrm{pH}$ 7. Phosphorus, calcium, and magnesium are significantly less available below $\mathrm{pH}$ 6. Iron, manganese, and boron become less available above pH 8 (Truog 1947, Daubenmire 1974). Measured on a 1 soil: 2 water slurry with a pH meter.

SALINITY.

Conductivity. Conductivity indexes salinity. Values below $4 \mathrm{mmhos} / \mathrm{cm}$ are not damaging, values in the 4-15 range exclude most crops, and higher conductivities are tolerated only by halophytes (Richards 1969, Daubenmire 1974). Measured with a wheatstone bridge in a 1 soil: 2 water slurry 


\section{METHODS}

APPROACH We assume that plants comprising established roadside vegetation in a particular environmental type are likely to establish well on newly disturbed sites in that environmental type. Thus, to identify plants that will establish well in a given environment (ET) one should 1) identify that environment and 2) observe what plants occupy established communities in several examples of it. Operationally, points were sampled at regularly spaced intervals along Montana highways, the data was grouped by environmental type (Table 2), and the vegetation data was summarized for each ET separately. This approach may exclude early seral species which invade disturbed sites but are quickly eliminated by the competition with species which eventually dominate. This approach may also exclude any late seral species which have not invaded roadside sites after 10-50 years, or which have invaded and have been managed against.

ROADSIDE SAMPLES Highways of the area are mostly located in five environments, three grassland and two forest environments. These are usually identified by their potential natural vegetation (Daubenmire and Daubenmire 1968), or often less easily, by conditions that determine that vegetation: climate, substrate, topography, and time (Jenny 1980). A map (Map 2) gives general locations of these environmental types. When driving from one environmental type to another, one identifies the transition by changes in the appearance of vegetation on representative uplands.

To determine what roadside plants were common in each of these environmental zones, plant presence was listed at each of many sites (Table 4) in each zone. The basic sampling strategy involved 1) locating sites at approximately 30 mile intervals along major roads crossing the type (Map 2), and at each, 2) sampling slopes on opposite sides of the road, and 3) sampling on both roadbeds (inslope) and road cuts (backslope). North-south and east-west roads were sampled to accumulate samples with all aspects. The ideal of finding undisturbed sites at regular distances, including equal numbers of NSEW aspects and bed/cut sites was not attained, but suitably approximated (Meier 1997). 


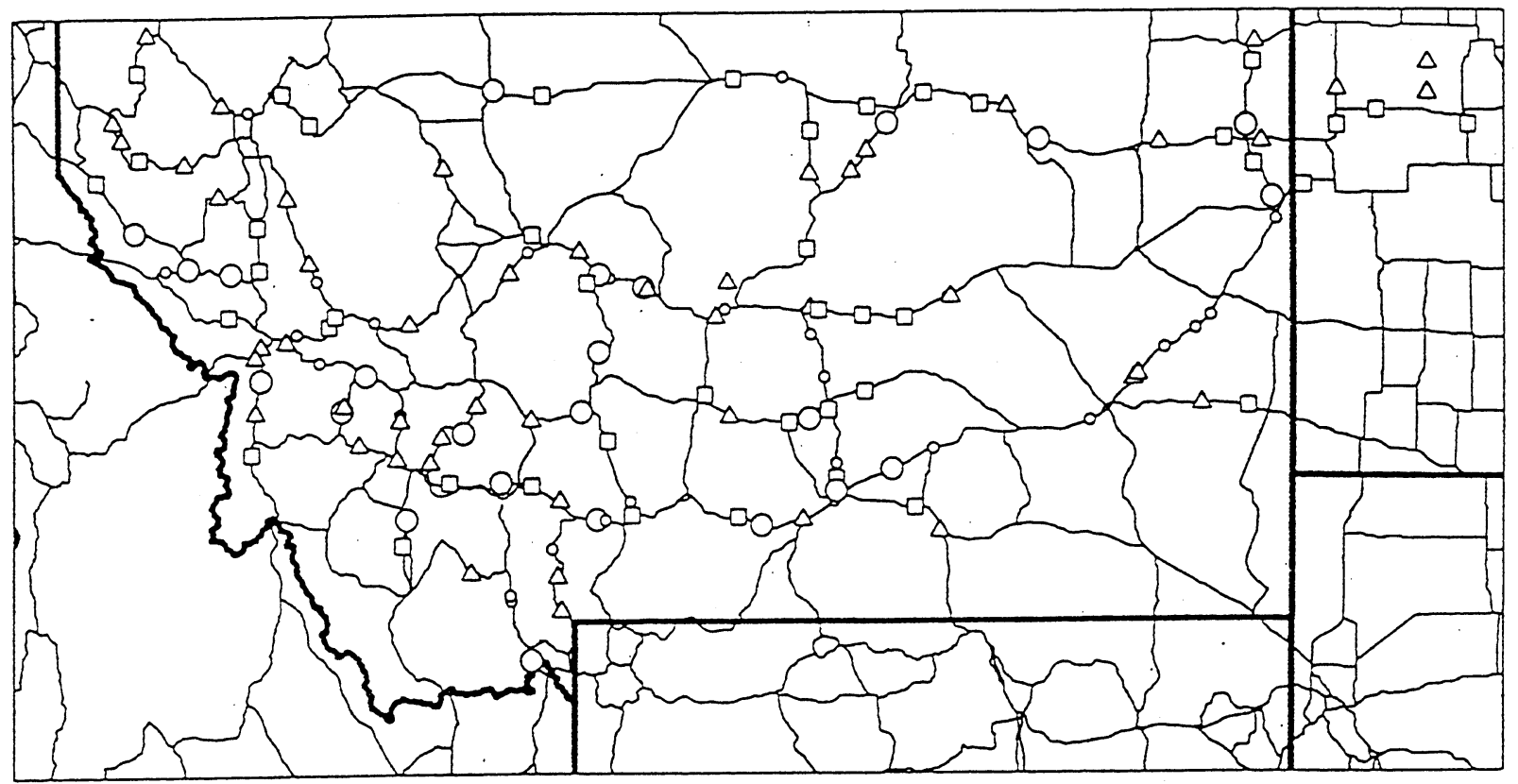

Map 2. Study sites in Montana and North Dakota. Open symbols enclose plot locations. Small circles contain one plot, triangles contain two plots, squares contain three plots, and large circles contain four plots.

The vegetation at each site was described in terms of presence and cover. A quadrat parallel to the road was established; it was ten meters long and as wide as the surface sampled. Quadrats were typically 3$5 \mathrm{~m}$ wide on inslopes and $5-15 \mathrm{~m}$ wide on backslopes. Representative vegetation outside the plots was recorded according to European tradition (Kuchler 1967). Species present in the plots were listed. And the cover of species present in the vegetation was estimated ocularly. Because occular estimates of cover may have little absolute value, we regularly adjusted our ocular estimates to conform to estimates made by point sampling (Evans and Love 1957).

Table 4. Distribution of the sites sampled among environmental types, aspect, and position. Numbers of sites representing each cell are given.

\begin{tabular}{lrrrrrrrr} 
Position & \multicolumn{3}{c}{ Backslope } & \multicolumn{3}{c}{ Inslope } \\
Aspect & N & S & E & W & N & S & E & W \\
\hline ANSC/ mixed grass & 6 & 6 & 7 & 6 & 7 & 7 & 7 & 6 \\
BOGR/ shortgrass & 22 & 19 & 12 & 12 & 22 & 25 & 16 & 13 \\
AGSP / bunchgrass & 5 & 6 & 9 & 9 & 9 & 8 & 14 & 14 \\
PIPO / ponderosa & 4 & 5 & 6 & 5 & 5 & 6 & 6 & 6 \\
PSME / douglas fir & 10 & 8 & 4 & 9 & 7 & 7 & 10 & 8 \\
\hline
\end{tabular}


PLANTS OF MACROENVIRONMENTS (ETs) To identify the successful plants of each environmental type, 370 'random' sites were sampled, the sites were sorted by environmental type, and the plants thriving in each ET were listed separately. First, the samples were sorted into the five environmental types by use of vegetation maps (Map 1 and Kuchler 1964) and vegetation indicators occurring locally (Table 2). Sites of questionable fit were discarded. Second, plants occurring in each environmental type were noted and their constancies (probability of occurrence) in sites of that type were calculated. Analyses were made for the fifty species which occurred in more than $10 \%$ of the sites of at least one environmental type. Third, the performance of each species was contrasted across environmental types (Box et al. 1978). Plants whose cover did vary across environmental types were identified with a Kruskal-Wallis non-parametric analysis of variance. Pairwise comparisons were made to identify the significant variants. The $5 \%$ probability level was used here as a significant deviation from the normal condition; actual probabilities for each test are reported in Meier (1997).

FACTORS CONTROLLING PLANT DISTRIBUTION One expects the performance of individual species to vary both across and within macroenvironments. Tests of species' tolerances for extreme conditions with respect to ten regionally important ecological factors (Table 3) will help the user to understand the distribution of plants among and within ETs, and thus, inform the users selections of plant material for extreme sites.

Thus, for each site, conditions normally influencing plant performance were measured (Table 3).

1) Conditions affecting water availability. Average annual precipitation was read from a precipitation map (Caprio et al. 1994). Soil sand/clay contents of soils passing a $2 \mathrm{~mm}(0.08 \mathrm{in})$ screen were estimated by the hydrometer method (Boyoucos 1962, Tan 1996). Organic matter contents were estimated spectrophotometrically after a wet dichromic acid digestion (Wakley 1947, Sims and Haby 1971). Water holding capacity of the fines was calculated from clay and OM contents (Decker 1972) and corrected for soil gravel contents determined by sieving.

2) Conditions affecting temperature, evaporation, and dryness. Temperature differences among sites is indexed with average July temperature read from a map (Caprio et al. 1994). Aspect was measured with a compass. Position (gentle inslope vs steep backslope) was recorded.

3) Fertility was indexed with $\mathrm{pH}$ and organic carbon. $\mathrm{pH}$ was measured on a 1 soil: 2 water slurry with a pH meter. Organic matter was estimated spectrophotometrically after a wet dichromic acid digestion (Wakley 1947, Sims and Haby 1971). 
4) Salinity was indexed on a 1 soil: 2 water slurry with a conductivity meter.

5) Soil samples for measurement of texture organic matter, $\mathrm{pH}$, and conductivity (salinity) were collected from the top $15 \mathrm{~cm}$ of the soil profile (Meier 1997). The samples were composites from three points evenly spaced on the axis of the plot which paralleled the road. They were dried and sieved to separate material greater or smaller than $2 \mathrm{~mm}$ diameter. Texture, $\mathrm{OM}, \mathrm{pH}$, and conductivity of the latter was measured by the MSU soil testing lab.

Plant response to factors likely to control their distribution (listed in Table 3 and just above) was analyzed separately for each species (50) and factor (10). 1) A frequency diagram plots the number of a species' occurrences at each factor level of eight continuously varying factors (Part II, Fig 1-50). For comparison, the 'general condition' is plotted simultaneously, i.e. the number of sites - with or without the species- is plotted at each factor level. Thus, if the species' plot is skewed with respect to the general condition one concludes that it is especially adapted to that factor. For example, Agropyron cristatum occupies abnormally few cool sites (Part II, Fig 2.2). 2) This conclusion was tested statistically by comparing the means of the two distributions. a) The mean of the plant distribution was calculated. b) From the 370 sites, a sample- with number equal to the number of sites containing the species - is randomly drawn and its mean was calculated. This is repeated 1000 times. Finally, the mean, standard error, and 95\% confidence level across the 1000 samples was calculated. c) If the 'species' mean lies outside the 'normal' confidence interval calculated across all sites the two populations differ (Manley 1991). 3) Note that this test is only a comparison of means and that one may gain additional information about a plant's behaviour under extreme conditions by examining the tails of the distributions (Fig 1-50, Part II). 4) The effects of position and aspect- with discrete values- were analyzed by Kruskall-Wallis/ pairwise comparisons as exactly as the effects of ET were analyzed (see above). 


\section{ROADSIDE FLORA OF MACROENVIRONMENTS (ETs)}

Species distributions are summarized, below, under five subheads. In this section plant communities of major environments are characterized with respect to 1) diversity, 2) native components, and 3) exotic components. This information will guide expectations in revegetation of an area dominated by an environmental type. The two following sections guide expectations based on 4) specific environmental factors and 5) species.

ROADSIDE FLORA DEPAUPERATE Remarkably few species occur along Montana highways. About 2300 species occur in Montana (Dorn 1984). Despite this, examination of roadsides in five of the seven major environmental types produced only 211 species. Many of these were rare. Only 50 species occurred in more than $10 \%$ of the samples in at least one environmental type. Half of these (29) were native and half (21) exotic.

Comparison of roadside floras with floras of native vegetation in the same environments focuses this observation by environmental type. Roadsides in the shortgrass prairie (BOGR), foothills prairie (AGSP), ponderosa pine forest (PIPO), and douglas fir forest (PSME) environmental types supported $36 \%, 24 \%, 80 \%$ and $41 \%$, respectively, as many species as grow in native vegetation adjacent to the road (Table 5). Comparison of our data with that of others (eg, Schmidt 1989) suggests that the paucity of species on roadsides may be a world-wide phenomenon.

Causes for the depauperate nature of roadside vegetation are diverse and vary from site to site. Steep slopes may be unstable and erosive. Their soils may be poorly developed thus containing few fines, little organic matter, or few microbes, such as nitrogen-fixers and mycorrhizae. Propagules for adapted native species or exotics may not have been available from planting or immigration. Seeds of competitive exotics enter down the road corridor. Inslopes are repeatedly disturbed by mowing, herbicides, and traffic. Pollutants including salt, lead, and auto exhaust are applied periodically. The cost of remediation of environmental restraints (reducing slopes, amending soil or exclusion/removal of toxins) may be unacceptably high. The costs of some biological remediation (introducing more plants or microbes) might be more acceptable. 
Table 5. Richness of roadside flora ${ }^{1}$ relative to natural flora ${ }^{2}$ in five environmental types.

\begin{tabular}{llllllll} 
& & Tree & Shrub & Grass & Comp & Other forbs & Total \\
\hline ANSC & $\begin{array}{l}\text { roads } \\
\text { native }\end{array}$ & 0 & 1 & 4 & 1 & 2 & 8 \\
& roads & 0 & 2 & & & & \\
\hline BOGR & native & & $10+3$ & $4+3$ & $3+1$ & $25+8$ & $5+1$ \\
\hline AGSP & roads & 0 & 0 & 7 & 1 & 1 & 9 \\
& native & 0 & $5+2$ & $11+4$ & $13+6$ & $37+12$ & $5+2$ \\
\hline PIPO & roads & 0 & 0 & 5 & 1 & 2 & 8 \\
& native & $3+0$ & $3+1$ & $2+1$ & $1+0$ & $0+1$ & $10+2$ \\
\hline PSME & roads & 0 & 0 & 7 & 1 & 1 & 9 \\
& native & $3+1$ & $5+2$ & $3+1$ & $2+1$ & $3+2$ & $16+5$ \\
\hline
\end{tabular}

${ }^{1}$ Species richness for roadside sites was calculated by averaging richness across the plots sampled in the ET.

${ }^{2}$ Natural species richness for the ET was calculated by averaging richness across habitat types in the ET (or series) considered. Data for these calculations came from Mueggler and Stewart 1980 (grasslands) and Pfister et al. (1977, forests). Comparable data is not available for ANSC. Numbers of habitat types (Mueggler and Stewart 1980, Pfister et al 1977) summarized for BOGR, AGSP, PIPO, and PSME were $2,6,3$, and 8 respectively.

\section{NATIVES OF PRINCIPLE ETs: CANDIDATES FOR SEEDING Natives which establish at} roadsides are clear candidates for seeding, though a manager might reject them at some sites for reasons other than their establishment characteristics. Planting the natives which appear naturally along Montana roadsides (Table 6) would enrich the roadside flora. While many are rarely planted, if seeded, the plants are expected to establish easily on sites where they establish without site preparation. Thus, to identify natives quite likely to succeed in a particular environment, locate the environmental type at the top of Table 6 and list successful species (marked with * and/or A) appearing in the column under it.

Trees are rarely sought for roadside sites. If one were needed, Pinus ponderosa might be planted in the ANSC, PIPO, or perhaps other ETs (Table 6). While our data don't demonstrate this, Juniperus species will surely establish on roadsides in low ( $J$ horizontalis \& $J$ scopulorum) and higher ( $J$ communis) environments. Douglas fir seeds naturally into moister PSME environments. Likewise, Pinus contorta freely invades roadsides in subalpine fir (ABLA) ETs, for example along the roads of Yellowstone Park. Cottonwood and aspen could be used in other moist sites at lower and higher elevations, respectively. 
Table 6. Performance of native species on roadsides in five environmental types. Plants grow best in asterisked sites. Where letters accompany, plant performance drops from environments marked 'A to $B$ to $C$ '. The ampersand ' $\&$ ' points out species disjunct from the eastern plains to the douglas fir zone.

\begin{tabular}{|c|c|c|c|c|c|c|}
\hline \multirow[b]{2}{*}{ Species } & \multirow[t]{2}{*}{ Origin $^{1}$} & \multicolumn{5}{|c|}{ Environmental Type } \\
\hline & & ANSC & BOGR & AGSP & PIPO & PSME \\
\hline \multicolumn{7}{|l|}{ TREES } \\
\hline Pinus ponderosa & $\mathrm{N}$ & $*$ & * & $*$ & $*$ & $*$ \\
\hline \multicolumn{7}{|l|}{ SHRUBS } \\
\hline Opuntia polyacantha & $\mathrm{N}$ & $*$ & $*$ & $*$ & * & * \\
\hline Guterriezia sarothrae & $\mathrm{N}$ & $*$ & $*$ & $*$ & $*$ & $*$ \\
\hline Artemisia tridentata & $\mathrm{N}$ & $*$ & $*$ & $*$ & $*$ & $*$ \\
\hline Artemisia cana & $\mathrm{N}$ & $*$ & $*$ & $*$ & * & $*$ \\
\hline Symphoricarpos albus & $\mathrm{N}$ & $*$ & $*$ & $*$ & $*$ & $*$ \\
\hline Rosa woodsii & $\mathrm{N}$ & $*$ & $*$ & $*$ & $*$ & $*$ \\
\hline \multicolumn{7}{|l|}{ GRASSES } \\
\hline Agropyron spicatum & $\mathrm{N}$ & $*$ & * & $*$ & $*$ & $*$ \\
\hline Bouteloua gracilis & $\mathrm{N}$ & $*$ & $*$ & $*$ & $*$ & $*$ \\
\hline Poa sandbergii & $\mathrm{N}$ & $*$ & $*$ & * & * & $*$ \\
\hline Stipa viridula & $\mathrm{N}$ & $A^{*} \&$ & $A^{*}$ & B & B & $A * \&$ \\
\hline Agropyron smithii & $\mathrm{N}$ & $\mathrm{B}$ & $A^{*}$ & B & $\mathrm{B}$ & $\mathrm{B}$ \\
\hline Hordeum jubatum & $\mathrm{N}$ & $\mathrm{B}$ & $A^{*}$ & B & $\mathrm{AB}$ & $\mathrm{B}$ \\
\hline Koeleria nitida & $\mathrm{N}$ & B & $A^{*} \&$ & B & B & $\mathrm{AB}^{*} \&$ \\
\hline Stipa comata & $\mathrm{N}$ & $\mathrm{BC}$ & $\mathrm{AB}^{*}$ & $A^{*}$ & $\mathrm{C}$ & $\mathrm{BC}$ \\
\hline Festuca scabrella & $\mathrm{N}$ & $\mathrm{B}$ & $\mathrm{B}$ & $A^{*}$ & $\mathrm{~B}$ & $\mathrm{~B}$ \\
\hline Agropyron dasystachyum & $\mathrm{N}$ & $\mathrm{C}$ & B & $A^{*}$ & $A^{*}$ & $A^{*}$ \\
\hline Festuca idahoensis & $\mathrm{N}$ & $\mathrm{C}$ & $\mathrm{C}$ & $\mathrm{BC}$ & $A^{*}$ & $\mathrm{AB}$ \\
\hline Festuca ovina & $\mathrm{N}$ & $\mathrm{C}$ & $\mathrm{C}$ & $\mathrm{BC}$ & $A^{*}$ & $\mathrm{AB}$ \\
\hline \multicolumn{7}{|l|}{ FORBS } \\
\hline Heterotheca villosa & $\mathrm{N}$ & $*$ & $*$ & $*$ & $*$ & $*$ \\
\hline Sphaleracea coccinea & $\mathrm{N}$ & $*$ & $*$ & $*$ & $*$ & $*$ \\
\hline Gaura coccinea & $\mathrm{N}$ & $*$ & $*$ & * & $*$ & $*$ \\
\hline Liatris punctata & $\mathrm{N}$ & $*$ & $*$ & $*$ & $*$ & $*$ \\
\hline Lupinus argenteus & $\mathrm{N}$ & $*$ & $*$ & * & $*$ & $*$ \\
\hline Ratibida columnifera & $\mathrm{N}$ & $*$ & $*$ & $*$ & $*$ & $*$ \\
\hline Dalea purpurea & $\mathrm{N}$ & $A^{*}$ & B & $\mathrm{B}$ & $\mathrm{B}$ & $\mathrm{B}$ \\
\hline Artemisia frigida & $\mathrm{N}$ & $\mathrm{B}$ & $A^{*}$ & $A^{*}$ & $\mathrm{AB}$ & $A^{*}$ \\
\hline Achillea millefolium & $\mathrm{N}$ & $\mathrm{C}$ & $\mathrm{B}$ & $A^{*}$ & $\mathrm{BC}$ & $\mathrm{AB}$ \\
\hline
\end{tabular}

${ }^{1}$ Origin: $\mathrm{N}=$ native, $\mathrm{E}=$ exotic

While shrubs are a major component of both natural and roadside vegetation in the Great Basin, they are rare in Montana's grassy landscape. Shrubs might be used to add 'texture' to plantings, or in some cases, 
to provide patches of dense cover. Six species represented in our samples (Table 6) are listed in order of likely success in progressively moister sites. Opuntia will occupy rough dry sites, should be easily established, and has large attractive flowers. Guterrizia sarothrae, Artemisia tridentata, and Artemisia cana will occupy slightly moister sites; the Artemisias, especially, might be recommended. Chrysothamnus spp and Rhus trilobata might have been expected in this group and, if shrubs are needed, should be tried. On still moister sites one might plant Symphoricarpos alba, spreading to form dense clones, or Rosa woodsii.

Grasses provide the matrix of most plantings because they are low and anchor soils well. Natives that could be used - those establishing naturally - are listed by environmental type (Table 6). Poa sandbergii is an unlikely choice, a low grass ranging from the driest environments to relatively wet ones. Agropyron smithii, Hordeum jubatum, Stipa comata, Koeleria nitida, and Stipa viridula appeared in the driest sites. While it normally dominates native grasslands in this environment and seems like an ideal plant for roadside sites, Bouteloua gracilis is said to establish here with difficulty, perhaps because we have no northern cultivar (ecotype). Moister foothill sites might be seeded with Stipa comata or Agropyron dasystachyum; Agropyron spicatum is an excellent candidate, though not recorded. Festuca scabrella is a good candidate for foothill sites in relatively moist areas, that is, in northern and western of Montana. In the higher (moister) foothill and forest zones Festuca idahoensis and $F$ ovina establish well.

Forbs, like shrubs, add texture to grassy vegetation. Sphaleracea coccinea, Heterotheca villosa, and Gaura coccinea are notable in drier areas; Sphaleracea and Heterotheca have relatively showy flowers and provide ground cover. Liatris, Lupinus and Ratibida, all with attractive foliage and flowers, perform best on slightly moister sites. Achillea millefolium is suitable for foothill and douglas fir ETs. Artemisia frigida, an attractive half-shrub, grew well in most environments; it may fail in mixed-grass prairie because it only competes well in open vegetation. Dalea purpurea performed best in the mixed grass prairie of eastern Montana.

Species successful in several adjacent environmental types (i.e. in adjacent columns of Table 6) have broader environmental tolerances than those successful in a single type. Broader tolerances may be due to phenotypic plasticity or ecotypic (genetic) differentiation. Where broad tolerances are due to plasticity, planting will be facilitated since propagules from one source will be useful over a wider range of environments. On the other hand, where broader tolerances are due to ecotypic variation the 
importance of selecting proper varieties is emphasized. The surprisingly poor performance of Bouteloua gracilis on many range sites may illustrate the problem with use of an inappropriate ecotype. Thus, some knowledge of plastic and genetic variation of potentially seeded species, whether native or exotic, should be developed.

Two native species, Stipa viridula and Koeleria nitida, appear in seemingly unrelated environments, warm dry grasslands and douglas fir forests (PSME). Two exotics (Bromus inermis and Thlaspi arvense), and likely others (Weaver et al. 1993: ALAL, BRTC, BRJP, DEPI, KOSC, POCO, and TRAE) have a similar distribution. This distribution suggests an unexpected environmental similarity. While temperatures, soils, and macro-precipitation are clearly different, canopy catch in douglas fir environments may reduce micro-environment precipitation there to a level supporting dry grassland plants. The mechanism of support is probably elimination of mesic plants that would otherwise compete with the xeric plants.

\section{EXOTICS OF PRINCIPLE ETs: CANDIDATES FOR MANAGEMENT (+OR-)}

To identify exotics which commonly establish in each environmental zone, note the asterisked plants under that heading in Table 7.

Exotics are questionable for seeding-or maintenance- on roadsides if they tend to invade native vegetation either in the ET planted or if they might be transported along the road corridor to ETs supporting native vegetation they can invade. It is difficult to certify that an exotic will not spread.

Our roadside samples contained no exotic trees or shrubs. The entire flora contains relatively few exotic trees (e.g., Eleagnus angustifolia = russian olive and Salix fragilis = brittle willow ) or shrubs (e.g., Tamerix chinensi $s=$ china tamerisk and Lonicera tartarica = tartar honeysuckle), perhaps because, in contrast to crop weeds, appropriate vectors are lacking.

Exotic grasses change as one moves across environmental zones (Table 7). Those common in the driest grassland ETs (BOGR) include Bromus tectorum and Agropyron cristatum. In somewhat moister sites to the east (ANSC), Bromus inermis, Poa pratensis, and Avena sativa show their best performance. On moister foothill ETs to the west (AGSP), Bromus tectorum, Poa pratensis, and Dactylis glomerata occur. Bromus inermis, Poa pratensis, Phleum pratense, Dactylis glomerata are important in forest ETs. Poa 
Table 7. Performance of exotic species on roadsides in five environmental types. Plants grow best in asterisked environments. Where letters accompany, plant performance (cover) decline from environments labeled 'A to $B$ to $C$ '. The ampersand ' $\&$ ' points out species disjunct from the eastern plains to the douglas fir zone.

\begin{tabular}{|c|c|c|c|c|c|c|}
\hline \multirow[t]{2}{*}{ Species } & \multirow[t]{2}{*}{ Invades $^{1}$} & \multicolumn{5}{|c|}{ Environmental Type } \\
\hline & & ANSC & BOGR & AGSP & PIPO & PSME \\
\hline \multicolumn{7}{|l|}{ GRASSES } \\
\hline Avena sativa & - & $A^{*}$ & B & B & B & B \\
\hline Bromus inermis & 4 & $A * \&$ & $\mathrm{BC}$ & $\mathrm{BC}$ & $\mathrm{C}$ & $A B \&$ \\
\hline Poa pratensis & $1-4+$ & $A^{*}$ & $A^{*}$ & $A^{*}$ & $\mathrm{~B}$ & $A^{*}$ \\
\hline Bromus tectorum & 124 & $\mathrm{~B}$ & $A^{*}$ & $A^{*}$ & $A^{*}$ & $\mathrm{AB}$ \\
\hline Agrostis stolonifera & - & B & $A^{*}$ & $\mathrm{~B}$ & $\mathrm{~B}$ & $\mathrm{~B}$ \\
\hline Agropyron cristatum & 12 & $\mathrm{~B}$ & $A^{*}$ & $\mathrm{~B}$ & $\mathrm{C}$ & $\mathrm{C}$ \\
\hline Dactylis glomerata & 4 & $\mathrm{~B}$ & $\mathrm{~B}$ & $A^{*}$ & $A^{*}$ & $A^{*}$ \\
\hline Poa compressa & $34+$ & $\mathrm{C}$ & $\mathrm{C}$ & $\mathrm{B}$ & $A^{*}$ & $\mathrm{BC}$ \\
\hline Phleum pratense & $3-4+$ & $\mathrm{B}$ & $\mathrm{B}$ & $\mathrm{B}$ & $\mathrm{AB}$ & $A^{*}$ \\
\hline \multicolumn{7}{|l|}{ FORBS } \\
\hline Alyssum alyssoides & $1-3$ & $*$ & $*$ & $*$ & $*$ & * \\
\hline Tragopogon dubius & $1-4$ & $*$ & $*$ & * & $*$ & * \\
\hline Centaurea maculosa & $1-3$ & $*$ & $*$ & $*$ & $*$ & * \\
\hline Cirsium arvense & $3+$ & * & * & * & $*$ & $*$ \\
\hline Medicago polymorpha ${ }^{3}$ & - & * & * & * & * & * \\
\hline Medicago sativa & 1 & $*$ & $*$ & * & * & $*$ \\
\hline Trifolium hybridum & - & $*$ & * & * & $*$ & $*$ \\
\hline Verbascum thapsis & 2 & $*$ & * & * & * & $*$ \\
\hline Lactuca serriola & 12 & $A^{*}$ & $\mathrm{~B}$ & $\mathrm{~B}$ & B & $\mathrm{B}$ \\
\hline Thlaspe arvense & 4 & $\mathrm{AB}$ & $A * \&$ & B & $\mathrm{AB}$ & $A^{*} \&$ \\
\hline Melilotus officinalis & $1-3$ & $\mathrm{~B}$ & $\mathrm{AB}$ & $A^{*}$ & $\mathrm{AB}$ & $A^{*}$ \\
\hline Kochia scoparia & 1 & $\mathrm{~B}$ & $\mathrm{~B}$ & $A^{*}$ & $\mathrm{~B}$ & $\mathrm{~B}$ \\
\hline
\end{tabular}

${ }^{1}$ Exotic species may invade undisturbed sites in the BOGR (1), AGSP (2), FEID (3), PSME (4), or cooler moister types (+, Weaver et al. 1989). Invasion of undisturbed sites in the ANSC type was not studied. ${ }^{2}$ Environmental Types are mixed grass (ANSC), shortgrass (BOGR), foothill (AGSP), ponderosa pine (PIPO), and douglas fir (PSME). ${ }^{3}$ Medicago polymorpha $=$ Medicago lupulina.

pratensis, Agrostis stolonifera, and Phlaris arundinaceae - in order of water requirements- occur in wet microsites in relatively dry areas, but spread into normal areas in moister wooded ETs, e.g., PIPO/PSME.

Exotic forbs have broader tolerances and range more widely across environmental types than grasses (Table 7). Alyssum, Tragopogon, and Centaurea may favor drier sites (BOGR/AGSP). Cirsium, Kochia, Medicago, Melilotus, Trifolium, and Verbascum thrive with slightly greater water (AGSP/PIPO). Lactuca also preferred more water (ANSC). 


\section{PLANTS ADAPTED, OR ILL-ADAPTED, TO FACTOR EXTREMES}

The performance of common species varies both across environmental types and within them. The variation in performance is usually due to variation in environmental qualities including temperature, water availability, nutrient availability, and salinity. Knowledge of species adapted to factor extremes will be useful to managers considering extreme sites.

Native species which tolerate extreme conditions - with respect to ten factors (Table 3) presumed to control most of the variation observed- are identified below (Table 8). These species are probably the best (or worst, if they tolerate the opposite extreme) candidates for planting on a site with an extreme condition, whether across ETs or among microsites in an ET. A species is considered 'tolerant of an extreme', if the factor level of its mean site is significantly different from the Montana roadside 'norm'. A more stringent test can be made by comparing the extreme values of the factor tolerated with the range of 'normal' values for the same factor (Part II, Figures 1-50). In the following paragraphs the species are identified with four letter codes keyed to Table 8 and to Part II and decoded easily with either the acronym index (II) or Part II.

Exotic species which tolerate extremes of these environmental factors are also identified (Table 8). This information may be used to combat weeds rather than to vegetate sites. Like the natives identified above, these species will be among the most successful on extreme sites. If they arrive, these species may dominate those sites. Thus, some should never be planted (e.g.,Centaurea maculosa, Phleum pratense, or Poa pratensis). Others might be planted after carefully considering the consequences of possible weediness (e.g., Avena sativa, Medicago polymorpha, M. sativa, or Trifolium hybridum).

Table 8. Positions of 50 common plant species on eight factor gradients. Gradients are listed below. Cases are marked where mean conditions at sites occupied by the plant are significantly $(p<0.05)$ above $(+)$ or below $(-)$ the average roadside condition. Part II, tables 1-50, provide frequency diagrams with numbers of observations at each factor level.

\begin{tabular}{l|c|cccccccc}
\multicolumn{10}{c}{ Environmental variables } \\
\hline Species & $\mathrm{Orgn}^{1}$ & $\mathrm{Temp}^{2}$ & $\mathrm{Pptn}^{3}$ & $\mathrm{WHC}$ & $\mathrm{Clay}^{5}$ & $\mathrm{Sand}^{6}$ & $\mathrm{OC}^{7}$ & $\mathrm{Ph}^{8}$ & $\mathrm{EC}^{9}$ \\
Achillea millefolium & $\mathrm{N}$ & $\cdot$ & + & + & + &. &. & $\cdot$ & + \\
Agropyron cristatum & $\mathrm{E}$ & + & - & + & + & - &. & $\cdot$ & + \\
Agropyron dasystachyum & $\mathrm{N}$ & - & + & - & - & + &. &. & - \\
Agropyron spicatum & $\mathrm{N}$ & + & - &. & + & - &. &. & + \\
\hline
\end{tabular}


Table 8. Continued.

\begin{tabular}{|c|c|c|c|c|c|c|c|c|c|}
\hline \multirow[b]{2}{*}{ Species } & \multirow[b]{2}{*}{ Orgn $^{1}$} & \multicolumn{8}{|c|}{ Environmental variables } \\
\hline & & Temp ${ }^{2}$ & $\mathrm{Pptn}^{3}$ & $\mathrm{WHC}^{4}$ & Clay $^{5}$ & Sand $^{6}$ & $\mathrm{OC}^{7}$ & $\mathrm{Ph}^{8}$ & $\mathrm{EC}^{9}$ \\
\hline Agrostis stolonifera & $E$ & 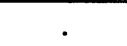 & - & . & 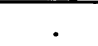 & . & . & . & + \\
\hline Allysum allysoides & $\mathrm{E}$ & ${ }^{\circ}$ & - & . & & ${ }^{\circ}$ & . & - & \\
\hline Artemisia cana & $\mathrm{N}$ & . & - & . & + & - & . & . & + \\
\hline Artemisia frigida & $\mathrm{N}$ & + & - & + & + & - & . & + & + \\
\hline Artemisia tridentada & $\mathrm{N}$ & & • & . & . & - & . & . & . \\
\hline Avena sativa & $\mathrm{E}$ & + & 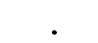 & . & . & . & . & . & . \\
\hline Bouteloua gracilis & $\mathrm{N}$ & + & - & . & . & - & . & . & . \\
\hline Bromus inermis & $\mathrm{E}$ & . & . & • & . & . & . & . & . \\
\hline Bromus techtorum & $\mathrm{E}$ & . & . & - & . & . & . & . & . \\
\hline Centaurea maculosa & $\mathrm{E}$ & - & + & - & - & + & . & - & - \\
\hline Circium arvense & $\mathrm{E}$ & . & . & . & . & . & . & . & . \\
\hline Dactylis glomerata & $\mathrm{E}$ & - & + & - & - & + & . & . & . \\
\hline Dalea punctata & $\mathrm{N}$ & • & . & . & . & - & . & + & . \\
\hline Festuca idahoensis & $\mathrm{N}$ & - & + & - & - & + & . & . & - \\
\hline Festuca ovina & $\mathrm{N}$ & . & + & - & - & + & - & . & - \\
\hline Festuca scabrella & $\mathrm{N}$ & . & 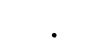 & . & . & . & . & . & . \\
\hline Gaura coccinea & $\mathrm{N}$ & . & . & . & . & . & . & . & . \\
\hline Guterrizia sarothrae & $\mathrm{N}$ & 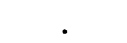 & - & . & . & - & - & . & . \\
\hline Heterotheca villosa & $\mathrm{N}$ & + & - & . & . & . & . & . & + \\
\hline Hordeum jubatum & $\mathrm{N}$ & + & $\cdot$ & . & . & - & . & . & + \\
\hline Koleria nitida & $\mathrm{N}$ & . & - & . & . & . & . & . & + \\
\hline Kochia scoparium & $\mathrm{E}$ & . & - & . & . & . & . & . & . \\
\hline Lactuca serriola & $\mathrm{E}$ & . & . & . & 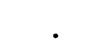 & . & . & . & . \\
\hline Liatris punctata & $\mathrm{N}$ & . & . & . & . & . & . & . & . \\
\hline Lupinus arvense & $\mathrm{N}$ & - & - & • & . & • & . & - & . \\
\hline Medicago polymorpha & $\mathrm{E}$ & - & + & - & - & + & . & . & - \\
\hline Medicago sativa & $\mathrm{E}$ & + & - & + & + & - & 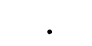 & . & + \\
\hline Melilotus offficinalis & $\mathrm{E}$ & . & + & . & & . & - & . & . \\
\hline Opuntia polycantha & $\mathrm{N}$ & . & - & & + & - & - & . & + \\
\hline Phalaris arundinaceae & $\mathrm{EN}^{10}$ & - & + & - & - & + & . & . & . \\
\hline Phleum pratense & $\mathrm{E}$ & - & + & - & . & + & . & . & - \\
\hline Pinus ponderosa & $\mathrm{N}$ & - & + & & - & . & . & . & - \\
\hline Poa compressa & $\mathrm{E}$ & - & + & - & - & + & . & . & - \\
\hline Poa pratense & $\mathrm{E}$ & . & ${ }^{\circ}$ & - & - & . & . & . & $\cdot$ \\
\hline Poa sandbergii & $\mathrm{N}$ & . & - & . & . & . & . & . & + \\
\hline Ratibida columnifera & $\mathrm{N}$ & . & . & 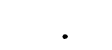 & . & . & . & . & . \\
\hline Rosa woodsia & $\mathrm{N}$ & . & & • & . & • & . & . & . \\
\hline Sphaeralcea coccinea & $\mathrm{N}$ & . & - & . & . & . & . & . & . \\
\hline Stipa comata & $\mathrm{N}$ & . & - & 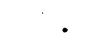 & . & . & . & . & . \\
\hline Stipa viridula & $\mathrm{N}$ & 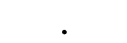 & & 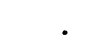 & 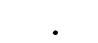 & 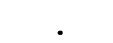 & . & . & . \\
\hline Symphoricarpos albus & $\mathrm{N}$ & . & + & & 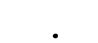 & 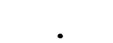 & . & . & . \\
\hline Thlaspi arvense & $\mathrm{E}$ & . & . & + & . & . & . & $\cdot$ & . \\
\hline Tragopogon dubius & $\mathrm{E}$ & . & . & 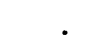 & & 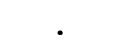 & . & . & . \\
\hline Tryfolium hybridum & $\mathrm{E}$ & - & + & . & . & . & . & - & - \\
\hline Verbascum thapsus & $\mathrm{E}$ & - & + & - & & + & & & - \\
\hline
\end{tabular}

${ }^{1}$ Origin=Exotic/Native species determined by Hitchcock and Cronquist (1973) or McGregor et al.(1986),

${ }^{2} \mathrm{Temp}=$ mean annual July temperature $\left({ }^{\circ} \mathrm{C}\right),{ }^{3} \mathrm{Pptn}=$ mean annual precipitation,

${ }^{4} \mathrm{WHC}=$ water-holding capacity $(\%),{ }^{5} \mathrm{Clay}(\%),{ }^{6} \mathrm{Sand}(\%),{ }^{7} \mathrm{OC}=$ organic carbon(\%), ${ }^{8} \mathrm{Acidity}(\mathrm{pH})$,

${ }^{9} \mathrm{EC}=$ electrical conductivity $(\mathrm{mmhos} / \mathrm{cm})$. ${ }^{10} \mathrm{PHAR}$ is a North American native though roadside areas are usually reclaimed with exotic (European) seed. 
CLIMATE ${ }^{1}$ Adaptation to climate was examined with indices of summer temperature (July mean) and precipitation (annual total).

Temperature: Temperatures are relatively constant across lowland (grassland) environmental types (ETs) and fall with increasing altitude through the forest zone (Table 1). Within an ET, south facing slopes are relatively warm and may thus support plants from warmer macro-environments; north facing slopes, similarly, may support plants from cooler zones. Natives performing best in warm climates are AGSM, ARFR, BOGR, HEVI, and HOJU; exotics are AGCR, AVSA, and MESA (Table 8). Natives performing best (best planted) in cool climates are AGDA, FEID, LUAR, PHAR and PIPO; exotics are CEMA, DAGL, MEPO, PHPR, POCO, TRHY, and VETH (Table 8). Plants occupying especially warm climates are usually poorly adapted to the coolest environments and vice-versa; one can test the breadth of adaptation for any species by examining the range of that species on the factor gradient (Part II).

Precipitation: The effect of rainfall is direct and is a major determinant of plant distribution across environmental types (ETs). Some (15/50) species are likely to do well in high rainfall areas; natives are ACMI, AGDA, FEID, FEOV, PHAR, PIPO, and SYAL; and exotics are CEMA, DAGL, MEPO, MEOF, PHPR, POCO, TRHY, and VETH. Other (16/50) species are associated with low rainfall; natives are AGSM, ARCA, ARFR, BOGR, GUSA, HEVI, KONI, LUAR, OPPO, POSA, SPCO, and STCO; and exotics are AGCR, ALAL, KOSC, and MESA.

Interaction: In the northern Rocky Mountains, cool sites are usually moist and warm sites are usually dry. Thus, corresponding lists (cool/moist and warm/dry) overlap heavily. There will be little confusion in choice of species to plant/control, because the environmental conditions are linked in nature.

SOILS and WATER ${ }^{1}$ Besides precipitation, water availability depends on soil qualities which modify the availability of rainfall. Thus we identify plants which commonly occur on 'droughty' and 'moist' soils as plants which are likely to thrive on such soils. Supporting mean and range data are listed by species in Part II.

\footnotetext{
${ }^{1}$ Adapted plants are listed with four letter codes, see Index II for proper and common names.
} 
Water holding capacity: WHC is the best general indicator of water storage capacity of a soil, because it integrates the effects of stone and organic matter content of the soil with those of texture (clay/sand content, Decker 1972). Plants requiring storage of spring water for summer use should occupy sites with high WHC. A few (4/50) species, including one native (ARFR) and three exotics (AGCR, MESA, THAR), tend to occupy sites with high WHC. Plants (11/50 spp) doing well on low WHC sites include natives (AGDA, FEID, FEOV, and PHAR) and exotics (BRTE, CEMA, DAGL, MEPO, PHPR, POCO, and VETH).

Clay: Water holding qualities of clay rich soils are opposite those of sand rich soils, storing rainyseason water, but running-off water from summer showers. Species expected to grow well on clay $(6 / 50$ species) may depend on its water reserves. Natives are AGSM, ARCA, ARFR, and OPPO; and exotics are AGCR and MESA (Table 8). Species growing poorly on clay (9/50) may depend on summer showers. Natives are AGDA, FEID, FEOV, PIPO, and PHAR; and exotics are CEMA, DAGL, MEPO, and POCO.

Sand: Sand rich soils drain well (and thus store little spring rain water for summer), but are also permeable (and thus capture a large fraction of summer rainfall). Species growing well on sand (10/50 species) may depend on the penetration of summer showers. Natives are AGDA, FEID, FEOV and PHAR; and exotics are CEMA, DAGL, MEPO, PHPR, POCO and VETH (Table 8). Species absent from sand (9/50 spp) may require stored water for summer use. Natives are AGSM, ARCA, ARFR, ARTR, DAPU, GUSA, and OPPO; and exotics are AGCR and MESA (Table 8).

Organic matter: Water holding capacity is also correlated with OM. The four species correlated with low organic matter may tolerate dry conditions. These include three natives (FEOV, GUSA, and OPPO) and one exotic (MEOF, Table 8).

Interactions: Species associated with clays tend to be associated with high WHC (because clays have a high WHC) and those associated with sands are associated with low WHC (because sands have a low WHC). Species associated with clay-rich sites are usually negatively associated with sands, and those associated with sands are negatively associated with clays. This is because a soil is a mixture made up of three components (sands, silts, and clays); the presence of a large quantity of one component thus necessitates relatively small quantities of the other two. 
TOPOGRAPHY and WATER ${ }^{1}$ The two factors analyzed were position and aspect.

Position: The flora of inslopes might differ from backslopes for at least three reasons. Inslopes are moister, both because natural rainfall is supplemented by runoff from the road and because more of the water delivered tends to soak in on gentle inslopes. Inslopes are further from natives dispersing from adjacent vegetation and nearer exotics dispersing along the road. Inslopes and backslopes may have been seeded differently; for example, plantings on inslopes may have included more exotic grasses than those of backslopes (P Johnson, personal communication). Inslopes are more disturbed (Dale and Weaver 1974). Twenty-one of fifty species have a preferred position (inslope vs backslope). Of fourteen natives, most were more important on backslopes (AGSP, ARFR, ARTR, DAPU, GACO, GUSA, KONI, LUAR, OPPO, PHAR, SPCO, STCO) and three were most common on inslopes (AGDA, FEID, and PHAR, Meier 1997). In contrast, of seven exotics one was more common on backslopes (THAR) and most were more common on inslopes (BRIN, DAGL, LASE, PHPR, POCO, and POPR, Meier 1997). Any or all of the factors mentioned above might contribute to the distinct distributions of natives and exotics.

Aspect: Solar radiation absorbed by a slope depends on its angle and aspect. South facing back-slopes (cut-slopes) absorb large amounts of energy, because they are oriented to the sun. North slopes receive less energy because they are oriented away from the sun. Energy receipt affects warmth and, via evaporation, drought. We therefore expect different plants on north and south slopes and especially if the slopes are steep. On backslopes (steep) two species are more common on north than south facing slopes (BOGR and STCO) and one is more common on south facing slopes (KONI, Meier 1997); the opposite distribution was expected. On inslopes, we found no species preferences for N/S slopes.

Our data suggest that some species may prefer EW over NS slopes. On inslopes, three species (AGST, ARCA, and LASE) are favored by east inslopes and four plants seem to be favored by EW inslopes (AGCR, AGSM, AVSA, and POPR). On backslopes three species preferred west facing slopes (AGST, AVSA, BRIN), one species avoided west facing slopes (ARFR), and one species avoided both east and west facing slopes (GUSA). Since the energy received by east/west slopes is intermediate between north and south slopes, energy is probably not the causal factor. More likely, the difference is due to

1 Adapted plants are listed with four letter codes. If these are unfamiliar, see Index II for both proper and common names. 
differences in the construction or seeding of east-west highways (i.e. mostly interstates with NS slopes) and north-south highways (i.e. mostly secondaries with EW slopes).

FERTILITY ${ }^{1}$ We used two indices of fertility. Neither affected many species. Species tending to occupy sites with higher or lower $\mathrm{OM} / \mathrm{pH}$ may be useful on sites with 'abnormal' qualities. In both cases one should use Part II to evaluate candidate species with ranges as well as means (Tables 1-50).

Organic matter: High OM usually indicates high fertility because decomposition releases nutrients from organic matter. The overall $\mathrm{OM}$ average was $2.8 \%$, averages for individual species ranged from $1.8-3.4 \%$. No plants requiring higher than average OM (OM is $50-60 \%$ carbon and $5 \%$ nitrogen, Nelson and Sommers 1982, Jackson 1969) were identified. Three natives (FEOV, GUSA, and OPPO) and one exotic (MEOF) were correlated with low organic matter.

pH: Nutrients present in soils with moderate $\mathrm{pH}$ (5.5-7.5) are available. At lower pH's $\mathrm{P}, \mathrm{K}, \mathrm{S}, \mathrm{Ca}$, and $\mathrm{Mg}$ become less available. At higher $\mathrm{pH}$ 's $\mathrm{Fe}, \mathrm{Mn}, \mathrm{Zn}, \mathrm{Cu}$, and $\mathrm{Bo}$ become less available. The average $\mathrm{pH}$ was 7.5 for roadside soils and averages of sites occupied by individual species ranged from 6.8 to 8.0; only slightly more basic than 'moderate'. Two natives occupied sites with higher than average pH: ARFR and DAPU. One native (LUAR) and three exotics (ALAL, CEMA, and TRHY) occupied sites with lower than average $\mathrm{pH}$. Since $\mathrm{pH}$ 's were measured on a 1:2 (soil/water) suspension, the more alkaline measures are skewed upward.

SALINITY ${ }^{1}$ Elevated salinities might be expected on shoulders of salted roads or on run-in sites in dry regions (e.g.,BOGR ET). Despite this, salinities necessary to affect sensitive crops $(>2 \mathrm{mmhos} / \mathrm{cm}$, Richards 1969), ordinary crops ( $>4)$, or tolerant crops (>8) were rarely observed. The overall mean EC was $0.27 \mathrm{mmhos} / \mathrm{cm}$ and means for various species ranged from $0.13-0.45 \mathrm{mmhos} / \mathrm{cm}$. Species (10/50 spp) occupying low salinity sites included natives (AGDA, FEID, FEOV, and PIPO) and exotics(CEMA, MEPO, PHPR, POCO, TRHY, and VETH). Species (11/50 spp) occupying sites more saline than average included natives (AGSM, ARCA, ARFR, HEVI, HOJU, KONI, OPPO, and POSA) and exotics

1 Adapted plants are listed with four letter codes. If these are unfamiliar, see Index II for both proper and common names. 
(AGCR, AGST, and MESA). The measurements reported were made on a 1:2 (soil/water) slurry; thus they could be as low as 0.25 times measurements made on the preferred saturated paste.

EXTREME CONDITIONS The factor-by-factor analysis presented above is based on comparison of mean conditions on sites where the plant grows and across all sites. Plots of presence or cover against factor levels for individual species (Fig 1-50, Part II) may be more useful in identifying species for extreme sites. That is, when seeking a species for an extreme site, it may be more useful to know whether it occupies extreme sites, rather than whether its mean is high or low. 


\section{NATURE AND REQUIREMENTS OF INDIVIDUAL SPECIES}

USE OF PARTS I \& II The first section of this report lists plants likely to grow on a roadside in a particular environment. That environment might be identified either as a representative of a particular environmental type (ET, Table 2) or as a segment of a particular factor gradient (Table 3).

In contrast, the material in Part II will help the user evaluate a particular plant being considered for introduction to or eliminated from a particular site. The same fifty plants - those appearing in at least $10 \%$ of the sites in at least one environmental type - are considered, each in a short article. The article gives primary names and taxonomic family. It hints at type of cover expected - through notes on plant form and vegetative spread. It lists the environmental types in which the plant was found and which are preferred. It indicates, for ten environmental factors, what position the plant occupies on the gradient from low to high concentration.

Part II's second function is to present data in a form that may support interpretation beyond that in Part I. Specifically, it's data should be more useful for the determination of the tolerance range of a species than the tables in Part I. To illustrate: Part I compares the mean condition on roadsides where the species grows with the mean conditions on all roadsides. In contrast, Part II shows the range of species with respect to environmental conditions. Part II is therefore needed to distinguish between the needs (or limits) of two species which occupy the same average environment, but which have different upper (or lower) limits.

OTHER SOURCES Field data in Part II can be supplemented with information from other sources.

General books on reclamation plantings include Cairns (1988) and Munshower (1994). Two catalogues of plants are especially relevant to our region. Munshower of the MSU reclamation group characterizes grasses (1991) and other plants (1995). Colorado ecologists (Dittberner and Olson 1983) have used library and consulting sources to gather ecological information on 4000 plant species of the Rockies. Table 9 shows the most relevant information to support and extend our observations. Identifying characteristics include proper name, acronym, origin, reproduction, and duration. Ecological headings indicate weediness, disturbance indicator value (mechanical or grazing), growth rate (on shallow or steep slopes), erosion control, and cover expected (immediate, short term, and long term). 
Table 9. Characteristics of major species (const $>\mathbf{1 0} \%$ ) of Montana roadsides as reported by PIN (Ditberner and Olsen 1983). Footnotes elaborate on column heads.

\begin{tabular}{|c|c|c|c|c|c|c|c|c|c|c|}
\hline Scientific name & $\operatorname{Org}^{1}$ & Acronm $^{2}$ & Dist $^{3}$ & $\operatorname{Repr}^{4}$ & $\mathrm{Habt}^{5}$ & Dur $^{6}$ & Weed $^{7}$ & Slop 8 & $\mathrm{Er}^{9}$ & $\mathrm{Cvr}^{10}$ \\
\hline Achillea millefolium & $\mathrm{N}$ & ACMI & - & $\bar{v}$ & $\mathrm{f}$ & $\mathrm{p}$ & $\mathrm{cct}$ & gf & $\mathrm{m}$ & $\mathrm{lhm}$ \\
\hline Agropyron cristatum & $\mathrm{E}$ & AGCR & $\mathrm{mch}$ & - & $\mathrm{g}$ & $\mathrm{p}$ & $\mathrm{cnt}$ & gf & $\mathrm{h}$ & $\operatorname{lmh}$ \\
\hline Agropyron dasystacum & $\mathrm{N}$ & AGDA & - & $\mathrm{v}$ & $\mathrm{g}$ & $\mathrm{p}$ & $\mathrm{cn}$ & gf & $\mathrm{h}$ & $\mathrm{mmh}$ \\
\hline Agropyron smithii & $\mathrm{N}$ & AGSM & - & $\mathrm{v}$ & $\mathrm{g}$ & $\mathrm{p}$ & $\mathrm{cn}+$ & gf & $\mathrm{h}$ & $\mathrm{mmh}$ \\
\hline Agropyron spicatum & $\mathrm{N}$ & AGSP & - & - & $\mathrm{g}$ & $\mathrm{p}$ & $-n+$ & gg & $\mathrm{m}$ & $11 \mathrm{~m}$ \\
\hline Agrostis stolonifera & $\mathrm{E}$ & AGST & mch & $\mathrm{v}$ & g & $\mathrm{p}$ & $\mathrm{cn}$ & $\mathrm{fp}$ & $\mathrm{h}$ & lhh \\
\hline Alyssum alyssoides & $\mathrm{E}$ & ALAL & - & - & $\mathrm{f}$ & $a b$ & $\mathrm{cn}+$ & gf & $\mathrm{m}$ & $\operatorname{lmh}$ \\
\hline Artemisia cana & $\mathrm{N}$ & ARCA & - & - & $\mathrm{s}$ & $\mathrm{p}$ & $-n$ & gf & $\mathrm{m}$ & $\operatorname{lmh}$ \\
\hline Artemisia frigida & $\mathrm{N}$ & ARFR & grz & $\mathrm{v} ?$ & sf & $\mathrm{p}$ & ce & gf & $\mathrm{m}$ & $\operatorname{lmm}$ \\
\hline Artemisia tridentata & $\mathrm{N}$ & ARTR & $?$ & - & $\mathrm{s}$ & $\mathrm{p}$ & $\mathrm{cn}$ & $g f$ & $\mathrm{~m}$ & $11 \mathrm{~m}$ \\
\hline Avena sativa & $\mathrm{E}$ & AVSA & $\mathrm{mch}$ & - & g & a & $\mathrm{cn}$ & $\mathrm{gp}$ & - & $-\mathrm{hl}$ \\
\hline Bouteloua gracilis & $\mathrm{N}$ & BOGR & - & $\mathrm{v}$ & g & $\mathrm{p}$ & $\mathrm{cn}$ & $\mathrm{gp}$ & $\mathrm{m}$ & mlh \\
\hline Bromus inermis & $\mathrm{E}$ & BRIN & $\mathrm{mch}$ & $\mathrm{v}$ & $\mathrm{g}$ & $\mathrm{p}$ & $\mathrm{cn}+$ & gf & $\mathrm{h}$ & $\operatorname{lmh}$ \\
\hline Bromus tectorum & $\mathrm{E}$ & BRTC & grz & - & $\mathrm{g}$ & a & cet & $\mathrm{gf}$ & 1 & $\operatorname{lml}$ \\
\hline Centaurea maculosum & $\mathrm{E}$ & CEMA & mch & - & $\mathrm{f}$ & bp & $\mathrm{cn}$ & gf & - & -11 \\
\hline Cirsium arvense & $\mathrm{E}$ & CIAR & - & $\mathrm{v}$ & $\mathrm{f}$ & $\mathrm{p}$ & $\mathrm{cc}$ & $\mathrm{gp}$ & 1 & $11 \mathrm{~m}$ \\
\hline Dactylis glomerata & $\mathrm{E}$ & DAGL & $?$ & - & g & $\mathrm{p}$ & $\mathrm{cc}$ & gf & $\mathrm{h}$ & $\mathrm{lhm}$ \\
\hline Dalea purpurea & $\mathrm{N}$ & DAPU & - & - & $\mathrm{f}$ & $\mathrm{p}$ & $-n$ & gf & - & - \\
\hline Festuca idahoensis & $\mathrm{N}$ & FEID & - & - & $\mathrm{g}$ & $\mathrm{p}$ & $-n$ & gg & $\mathrm{m}$ & $11 \mathrm{~m}$ \\
\hline Festuca ovina & $\mathrm{N}$ & FEOV & - & - & $\mathrm{g}$ & $\mathrm{p}$ & $-n$ & gf & $\mathrm{m}$ & $\operatorname{llm}$ \\
\hline Festuca scabrella & $\mathrm{N}$ & FESC & - & - & $\mathrm{g}$ & $\mathrm{p}$ & $-n$ & $g f$ & - & $-\mathrm{mh}$ \\
\hline Gaura coccinea & $\mathrm{N}$ & GACO & $?$ & - & $\mathrm{f}$ & $\mathrm{p}$ & $-n$ & $\mathrm{gf}$ & - & -11 \\
\hline Guterriezia sarothre & $\mathrm{N}$ & GUSA & - & - & s & $\mathrm{p}$ & cet & $\mathrm{gf}$ & $\mathrm{m}$ & 111 \\
\hline Heterotheca villosa & $\mathrm{N}$ & HEVI & - & - & $\mathrm{f}$ & $\mathrm{p}$ & $\mathrm{cn}$ & gf & 1 & 111 \\
\hline Hordeum jubatum & $\mathrm{N}$ & HOJU & oth & - & g & $\mathrm{p}$ & $-n$ & $\mathrm{fp}$ & 1 & $\operatorname{lml}$ \\
\hline Kochia scoparia & $\mathrm{E}$ & $\mathrm{KOSC}$ & $\mathrm{mch}$ & - & $\mathrm{f}$ & a & ce & gf & 1 & lhl \\
\hline Koleria nitida & $\mathrm{N}$ & KONI & - & - & g & $\mathrm{p}$ & $-n$ & gf & $\mathrm{m}$ & $1 \mathrm{~lm}$ \\
\hline Lactuca serriola & $\mathrm{E}$ & LASE & - & - & $\mathrm{f}$ & $\mathrm{a}$ & ce & $\mathrm{gp}$ & 1 & $\operatorname{lml}$ \\
\hline Liatris punctata & $\mathrm{N}$ & LIPU & - & $\mathrm{v} ?$ & $\mathrm{f}$ & $\mathrm{p}$ & $-n$ & $\mathrm{gf}$ & - & -11 \\
\hline Lupinus argenteus & $\mathrm{N}$ & LUAR & - & - & $\mathrm{r}$ & $\mathrm{p}$ & $\mathrm{cn}$ & $\mathrm{gf}$ & $\mathrm{m}$ & $11 \mathrm{~m}$ \\
\hline Medicago lupulina & $\mathrm{E}$ & MELU & - & - & $\mathrm{f}$ & $\mathrm{p}$ & ce & $\mathrm{fp}$ & $\mathrm{h}$ & $11 \mathrm{~m}$ \\
\hline Medicago sativa & $\mathrm{E}$ & MESA & $\mathrm{mch}$ & - & $\mathrm{f}$ & $\mathrm{p}$ & ce & $\mathrm{fp}$ & $\mathrm{h}$ & lhh \\
\hline Melilotus officinalis & $\mathrm{E}$ & MEOF & mch & - & $\mathrm{f}$ & $a b$ & cc & gf & $\mathrm{m}$ & $\mathrm{lhm}$ \\
\hline Opuntia polacantha & $\mathrm{N}$ & OPPO & - & $\mathrm{v}$ & $\mathrm{f}$ & $\mathrm{p}$ & ce & $\mathrm{fp}$ & 1 & 111 \\
\hline Phalaris arundinacea & EN & PHAR & - & $\mathrm{v}$ & g & $\mathrm{p}$ & ce & $\mathrm{pp}$ & $\mathrm{h}$ & $\operatorname{lmh}$ \\
\hline Phleum pratense & $\mathrm{E}$ & PHPR & mch & - & $\mathrm{g}$ & $\mathrm{p}$ & $\mathrm{cc}$ & $\mathrm{fp}$ & $\mathrm{m}$ & $\operatorname{lmh}$ \\
\hline Pinus ponderosa & $\mathrm{N}$ & PIPO & - & - & $\mathrm{t}$ & $\mathrm{p}$ & $\mathrm{cn}$ & gf & $\mathrm{m}$ & $11 \mathrm{~m}$ \\
\hline Poa compressa & $\mathrm{E}$ & $\mathrm{POCO}$ & - & $\mathrm{v}$ & $\mathrm{g}$ & $\mathrm{p}$ & $\mathrm{cc}$ & gp & $\mathrm{h}$ & $\operatorname{lmh}$ \\
\hline Poa pratensis & $\mathrm{E}$ & POPR & - & $\mathrm{v}$ & g & $\mathrm{p}$ & $\mathrm{cc}$ & gf & $\mathrm{h}$ & $\operatorname{lmh}$ \\
\hline Poa sandbergii & $\mathrm{N}$ & POSA & - & - & $\mathrm{g}$ & $\mathrm{p}$ & $\mathrm{cn}$ & gf & $\mathrm{m}$ & 111 \\
\hline Ratibida columnifera & $\mathrm{N}$ & RACO & - & - & $f$ & $\mathrm{p}$ & $\mathrm{cc}$ & $\mathrm{fp}$ & - & $-\operatorname{lm}$ \\
\hline Rosa woodsii & $\mathrm{N}$ & ROWO & - & $\mathrm{v}$ & s & $\mathrm{p}$ & $\mathrm{cn}$ & gf & $\mathrm{h}$ & $1 \mathrm{~lm}$ \\
\hline Sphaleraceae coccinea & $\mathrm{N}$ & SPCO & - & $\mathrm{v} ?$ & $\mathrm{f}$ & $\mathrm{p}$ & $\mathrm{cn}$ & $\mathrm{fp}$ & 1 & 111 \\
\hline Stipa comata & $\mathrm{N}$ & STCO & - & - & $\mathrm{g}$ & $\mathrm{p}$ & $\mathrm{cn}$ & gf & $\mathrm{m}$ & $\operatorname{lmh}$ \\
\hline
\end{tabular}


Table 9. Continued.

\begin{tabular}{lllllllllll} 
Scientific name & $\mathrm{Org}^{1}$ & Acronm $^{2}$ & Dist $^{3}$ & Repr $^{4}$ & $\mathrm{Habt}^{5}$ & Dur $^{6}$ & Weed $^{7}$ & Slop $^{8}$ & $\mathrm{Er}^{9}$ & $\mathrm{Cvr}^{10}$ \\
\hline Stipa viridula & N & STVI & - & - & $\mathrm{g}$ & $\mathrm{p}$ & $\mathrm{cn}$ & $\mathrm{gp}$ & $\mathrm{m}$ & $1 \mathrm{hh}$ \\
Symphoricarpos albus & $\mathrm{N}$ & SYAL & - & $\mathrm{v}$ & $\mathrm{s}$ & $\mathrm{p}$ & $\mathrm{cn}$ & $\mathrm{gf}$ & $\mathrm{m}$ & $1 \mathrm{~lm}$ \\
Thlaspi arvense & $\mathrm{E}$ & THAR & - & - & $\mathrm{f}$ & $\mathrm{a}$ & $\mathrm{cx}$ & $\mathrm{fp}$ & 1 & 111 \\
Trifolium hybridum & $\mathrm{E}$ & TRHY & - & $\mathrm{v}$ & $\mathrm{f}$ & $\mathrm{p}$ & $\mathrm{cc}$ & $\mathrm{gp}$ & $\mathrm{m}$ & $1 \mathrm{~lm}$ \\
Tragopogon dubius & $\mathrm{E}$ & TRDU & - & - & $\mathrm{f}$ & $\mathrm{b}$ & $\mathrm{cc}$ & $\mathrm{fp}$ & 1 & 111 \\
Verbascum thapsus & E & VETH & mch & - & $\mathrm{f}$ & $\mathrm{b}$ & $\mathrm{cc}$ & $\mathrm{ff}$ & 1 & $1 \mathrm{~lm}$ \\
\hline
\end{tabular}

${ }^{1}$ Origin: native or exotic

${ }^{2}$ Acronym. Four letter code derived from genus and specific epithet names.

${ }^{3}$ Disturbance: indicates mechanical (mch), heavy grazing (grz) or other (oth), or non-indicator. Species marked with (?) are listed as unknown; all probably indicate competition reducing disurbance.

${ }^{4}$ Reproduction: seed only (-), possibly vegetative (v?) or clearly vegetative (v)

${ }^{5}$ Habit: grass (g), forb (f), shrub (s), tree (t).

${ }^{6}$ Duration: annual (a), biennial (b), perennial (p)

${ }^{7}$ Weediness: 1st letter indicates presence on disturbed places $(c=$ early seral); second letter indicates degree of weediness (not $=\mathrm{n}$, colonizing $=\mathrm{c}$, economic $=\mathrm{e}$, noxious $=\mathrm{x}$ ); a ' + ' after the second letter indicates species whose impact may be greater than the level indicated.

${ }^{8}$ Growth on shallow (1st letter, 9-30\%) and steep slopes (2nd letter, $>30 \%$ ): good (g), fair (f), and poor (p).

${ }^{9}$ Erosion control: low (1), medium (m), high (h), no data (-)

${ }^{10}$ Cover: initial establishment 1 st letter, short term 2 nd letter, long term 3 rd letter. low (l), medium (m), high (h), no data (-) 


\section{CONCLUSIONS AND RECOMMENDATIONS}

1) Despite Montana's large native flora and diverse environments, only 50 species are common on Montana's roadsides. This is probably due to harsh conditions at roadsides. While costs of ameliorating physical conditions may exceed returns, some natural amelioration may occur- especially where slopes are gentle. Some biological amelioration may be feasible.

2) Most segments of Montana's highways lie in one of the five environmental types (Map 1) studied. Since each ET has different plants, plants common in each type are discussed separately.

3) The primary mission of this project was to identify native plants that establish naturally on roadsides in each environmental type. Such plants are well adapted and are thus clear candidates for planting. Despite their adaptation, they might be selected against for various reasons, e.g. attractive to game or obstruction of views. Table 6 provides lists of species common in each ET. Entries in Part II, as well as Table 9 provide information relevant to the use of these species.

The methods used may have undersampled two groups of plants. First, since undisturbed sites were selected, non-competitive pioneers could have been missed. Because these plants are ephemeral, they are undesirable in plantings - except possibly as a nurse crop. Second, since Montana's highways are relatively young, late seral species might have been missed. Such species would be species with either very poor dispersal or species requiring site amelioration.

4) The methods used were not designed to identify desirable natives which do not establish naturally, but which would establish well, if planted. Thus, additional native species with good potential for revegetation of roadside sites exist. These are parallels to exotics which succeed only if planted ( c.f. \#6 below).

5) Methods for establishing natives mentioned above (\#3 and \#4) are incomplete. Developmental plasticity and ecotypic structure of desirable species need study. Seed sources may need to be developed. Planting techniques may need development. 
6) Weedy exotics (Table 7) obviously invade and tolerate their respective environments. Thus our data indicate sites where weed control may be needed. Part II and Table 9 estimate, for each species and ET, expected invasion of disturbed and undisturbed vegetation.

7) Exotics which have been planted on roadside sites (e.g., Agropyron cristatum, Bromus inermis, Dactylis glomerata, Phleum pratense, and Poa pratensis) passed a lesser test of adaptedness than natives or exotics independently invading those sites — because adequate seed was delivered to a prepared bed.

8) We recommend great caution in planting of exotics, since they may spread from the planted site into adjacent native vegetation or along the road to places where they can spread laterally. Examples of serious weeds that were probably intentionally introduced include Poa pratensis, Phleum pratense, Centaurea maculosa, and others. Species-by-species accounts in Part II (as well as Weaver et al. 1989, 1993) indicate environments where specific exotics move into disturbed and undisturbed sites.

9) Both within and across environmental types, a dominant factor can influence the success of either natives or exotics. For this reason, species especially tolerant or intolerant of ten major factors are indicated in Table 8. These factors relate to water availability (precipitation, sand/clay, soil WHC, soil $\mathrm{OM})$, temperature (July average, slope, aspect), nutrient availability ( $\mathrm{OM}$ and $\mathrm{pH})$, and salinity (conductivity).

10) Part II of this report considers the data from the species view point - rather than the environmental point-of-view emphasized in Part I. It summarizes information on 50 common species- form, reproductive qualities, and likelihood of succeeding in particular environments - environmental types or extreme levels of ten factors.

11) Figures in Part II summarize the distribution of the data, including range, rather than summarizing it with a mean as in the previous discussion. This more elaborate summary will be especially useful when seeking a species for an extreme site. In this case, knowledge of a species' capacity to grow in extreme sites is of more use than facts about the average site it occupies. 


\section{IMPLEMENTATION}

The object of this study was to list the most successful plants on roadsides in major enviornments. A list of fifty plants alerts managers to possible planting candidates and to weed management responsibilies.

Half $(30 / 50)$ of the plants identified (Table 6) were natives seen as candidates for planting to enrich the normally depauperate roadside flora. Some candidates (e.g., Agropyron spicatum) seem more attractive than others (e.g.,Hordeum jubatum). That attractiveness varies from site-to-site; for example, while Ponderosa pine does not belong on road shoulders it may be useful at interchanges or on long backslopes. While the plants listed have established naturally, it is desirable to develop seed sources and planting techniques to improve establishment of the most attractive species.

Regional floras contain other attractive natives. While these did not establish naturally, they should be listed — with consideration of seed sources, establishment techniques, and long term behaviour - as additional candidates.

Lists of candidate species (Dittberner and Olson 1983, Munshower 1991 \& 1995, Meier (1997) have concentrated on individual species. Recent (unpublished) studies of European vegetation show that soil erosion and weed resistance vary among communities with different suites of species. The possibility that community complexes — rather than individual species — should be planted might be explored in Montana by reanalysis of this data, followed by testing in roadside plantings.

This report is designed to deliver lists of seeding candidates for specific sites. If it were useful, a compact up-datable computer-intelligent system could be constructed to deliver this information.

Half (20/50) of the plants identified were exotic. Exotics not planted are slightly (e.g., Alyssum alyssoides or Tragopogon dubius) to vigorously (e.g., Centaurea maculosa or Bromus tectorum) weedy. Most of the exotics that were planted are vigorous pasture plants. World wide, native vegetation is being eliminated by introduced pasture plants (e.g., Poa pratensis, Phleum pratense Bromus inermis, Agropyron cristatum, and Melilotus officinalis). These should be battled in proportion to their impact on Montana ecosystems. 


\section{LITERATURE CITED}

Boyoucos, G. J., 1962. Hydrometer method improved for making particle size analysis od soils. Journal of Agronomy. 54:464-465.

Box, G, W Hunter, and J Hunter. 1978. Statistics for experimenters. Wiley. New York NY. 653 pgs.

Cairns, J. 1988. Rehabilitating damaged ecosystems. CRC Press. Boca Raton FL. 2 Volumes.

Caprio, J, D Cooksey, J Jacobsen, G Nielsen, and R Roche. 1994. Maps atlas: a land and climate information system, version 5.0. Extension bulletin 125, Montana State Univ. Bozeman MT. 89 pages and a diskette.

Clinton, W. 1994. Environnmentally and economically beneficial practices on federal landscaped grounds. Memo to heads of executive departments and agencies. The White House, Office of Press Secretary. Washington DC. 2 pgs.

Dale, D and T Weaver. 1974. Trampling effects on vegetation of the trail corridors of northern Rocky Mountain forests. Journal of Applied Ecology 11: 767-772.

Daubenmire, R \& J Daubenmire. 1968. Forest vegetation of eastern Washington and N Idaho. Wash Ag Expt Sta Tech Bull 60. Pullman WA. 104 pgs.

Daubenmire, R. 1974. Plants and environment. J Wiley. New York NY. 422pgs.

Decker, G. 1972. Automatic retrieval and analysis of soil characterization data. Unpublished $\mathrm{PhD}$ dissertation. MSU, Bozeman MT 59717138 pgs. Library of Congress \# Mic 76-621041, Dissertation Abstracts 73-10949.

Dittberner, $\mathrm{P}$ and M Olson. 1983. The plant information network (PIN) data base: Colorado, Montana, N Dakota, Utah, and Wyoming. US Fish Wildlife Service FWS/OBS-83/36. 786 pgs.

Dorn, R. 1984. Vascular plants of Montana. Mountain West Publishing. Cheyenne WY. 276 pgs

Egler, F and Foote S. 1975. The plight of the right-of-way domain. Futura Media Services. Mt Kisco NY. 294 pgs.

Evans, $\mathrm{R}$ and $\mathrm{R}$ Love 1957. The step-point method- a practical tool in range management. J Range Management 10:208-212.

Frank, E and R Lee. 1966. Potential solar beam irradiation on slopes, Tables for $30-50^{\circ}$ latitude. USDA Forest Service Research Paper RM 18. Ft. Collins CO. 116 pgs.

Geiger, R. 1966. The climate near the ground. Harvard University Press. Cambridge MA. 611 pgs.

Hitchcock, C and A Cronquist. 1987. Flora of the Pacific Northwest. University of Washington Press, Seattle WA. 730 pgs. 
Holdridge, L. 1947. Determination of world plant formations from sample climatic data. Science 105: 367-368.

Jackson, M. 1969. Soil chemical analysis. Prentice Hall. Englewood Cliffs NJ. 895 pgs.

Johnson, P. 1997. Personal communication. Montana Department of Transportation. PO Box 201001, Helena MT. 59620.

Jenny, H. 1980. The soil resource: Origin and behaviour. Springer-Verlag. New York NY. 377 pgs.

Kuchler, A. 1964. Potential natural vegetation of the conterminous United States. American Geographical Society Publication \#36. New York NY. 116 pgs.

Kuchler, A. 1967. Vegetation mapping. Kluwer Academic Press. Boston MA. 472 pgs.

Manley, B. 1991. Randomization and Monte Carlo methods in biology. Chapman and Hall, London. 281 pgs.

McGregor, R. T Barkley, R Brooks, E Schofield. 1986. Flora of the Great Plains. University of Kansas Press. Lawrence KS. 1392 pgs.

Meier, G. 1997. The colonization of Montana roadsides by native and exotic plants. Unpublished MS thesis, Montana State University, Bozeman MT. 187 pgs.

Montana Atlas and Gazetter, 2nd edition. 1997. Delorme Publishers. Yarmouth ME. 96 pgs.

Mueggler, W and W Stewart. 1980. Grassland and shrubland habitat types of western Montana. USDA Forest Service Gen Tech Rept INT-66. Ogden UT. 154 pgs.

Munshower, F. 1991. Perennial grasses for revegetation of disturbed lands in the northern Great Plains and intermountain region (3rd ed). Reclamation Research Publication 9101. MSU Bozeman MT. 138 pgs.

Munshower, F. 1994. Practical handbook of disturbed land revegetation. Lewis Publishers, Boca Raton FL. 265 pgs.

Munshower, F. 1995. Forbs, shrubs and trees for revegetation of disturbed lands on the northern Great Plains and adjacent areas (2nd ed.) Reclamation Research Publication 9505. MSU, Bozeman MT. 179 pgs.

Nelson, D and L Sommers. 1982. Total carbon, organic carbon, and organic matter. IN A Page 1982. Methods of soil analysis. Soil Science Society of America, Madison WI. 1159 pgs.

Niering, W and R Goodwin. 1974. Creation of relatively stable shrublands with herbicides: arresting succession on rights-of-way and pastureland. Ecology 55: 784-795.

Pfister, R, B Kovalchik, S Arno and R Presby. 1977. Forest habitat types of Montana. USDA Forest Service Gen Tech Rept INT-34. Ogden UT 174 pgs. 
Richards, L ed. 1969 Diagnosis and improvement of saline and alkali soils. USDA Handbook \#60. 160 pgs.

Schmidt, W. 1989. Plant dispersal by motor cars. Vegetatio 80: 147-152.

Sims, J and V Haby. 1971. Simplified colorimetric determination of soil organic matter. Soil Science 112(2): 137-141.

Tan, K. 1996. Soil sampling, preparation, and analysis. Marcel Dekker. New York NY. 408 pgs.

Truog, E. 1947 Soil reaction influence on availability of plant nutrients. Soil Science Society of America Proceedings 11: 305-308

Wakley, A. 1947. A critical examination of a rapid method for determining organic carbon in soilseffect of variations in digestion conditions and of organic soil constituents. Soil Science. 63: 251-263.

Weaver, T. 1979. Changes in soils along a vegetational (altitudinal) gradient of the northern Rocky Mountains. p14-29 IN: C. Youngberg ed. 1979. Proceedings of the Fifth North American Forest Soils Conference, Soil Science Society of America, Madison, WI.

Weaver, T. 1980. Climates of vegetation types of the northern Rocky Mountains and adjacent plains. American Midland Naturalist 103: 392-398.

Weaver T, D Gustafson, J Lichthardt, and B Woods. 1989. Distribution of exotic plants in the northern Rocky Mountains by environmental type and disturbance condition. MSU Biology Report \#41. Bozeman MT. 91 pgs.

Weaver T, D Gustafson, and J Lichthardt. 1993. Plants colonizing disturbances in 15 Rocky Mountain environments: weeds and reclamation candidates. U Wyoming/ NPS Research Center (Laramie Wyo) 17:20-28.

Weaver, T. 1994. Vegetation distribution and production in Rocky Mountain climates - with emphasis on whitebark pine. 11 pgs $\mathrm{IN} \mathrm{W}$ Schmidt and K Holtmeier eds. 1994. Stone pines and their environments: the status of our knowledge. USDA Forest Service Gen Tech Rept INT-GTR-309. Proceedings of an international workshop 5-11 Sept 1992, San Moritz Switzerland.

Whittaker, R. 1975. Communities and ecosystems. MacMillan. New York NY 385 pgs. 


\section{Part II}

NATURE AND REQUIREMENTS OF FIFTY SPECIES:

NAMES, WEEDINESS, HABIT

ENVIRONMENTAL TYPES OCCUPIED, AND

FACTOR EXTREMES TOLERATED. 


\section{INTRODUCTION}

THE ARTICLES The following articles characterize the fifty plant species occurring most commonly along Montana roadsides. A brief text considers four qualities important to the manager. It provides: 1) three names and the family name; 2) a measure of the species' tendency to colonize unplanted areas (invasiveness); 3) descriptive characteristics useful in choosing species suitable for revegetation, for example, life form, length of life, and vegetative spread and 4) eleven indicators of site qualities that predict success of the species on a site. Most of these qualities were discussed under 'methods (Table 3)', but they are reformatted here to clarify the material in Part II.

THE DATA All quantitative data were gathered as described in Part I. Non-quantative data were drawn from standard taxonomic works such as Hitchcock et al 1987, Dorn 1984 and McGregor et al 1986.

ON USING THE GRAPHS Graphs support most of the conclusions drawn. Three general comments about the graphs may make them more useful.

1) The general environmental range of a species is indicated by its distribution among discrete environmental types (ETs). That range is shown by the first bar graph in the species' article, where 'importance' is plotted against ET (see below). Importance is indexed with the cover rank (KruskalWallis) for that category. 2) The distribution across and within environmental types is largely explained by ten factors. Graphs shown on the second page of the article allow you to evaluate species distribution with respect to eight continuously varying factors. Solid, unconnected points record numbers of the species' appearances at particular factor levels; we assume that the species grows best at factor levels where it is most common. Note logarithmic scales. To recognize special adaptation, one compares the species' distribution on the factor gradient to the normal distribution of conditions there. Thus the number of roadside sites observed at each factor level-regardless of species presence-is plotted (open squares, connected) on the factor scale for comparison. Comparison of means was made statistically, and where significant, the means are given . Other useful comparisons of distribution can 
be made from the graphs. For example, a plant without a deviant mean may have either phenotypic plasticity or ecotypic variation which allows it to occupy an extreme site. 3) Aspect data are analyzed with Kruskal-Wallis ANOVA (Box et al. 1978) and plotted on the first page as bar graphs, just as ET data were.

ON STATISTICAL SIGNIFICANCE The footnote \#2 on a factor heading indicates that the factor has significant effects.

ON USING THE HEADINGS Each single-species article has ten headings followed by notes on characteristics of that species. The following paragraphs will explain and facilitate proper use of the information presented.

Taxonomy: Proper and common names are given. They are followed by family name.

Invasiveness: Species are classified as native or exotic. Natives are considered normal to the vegetation and never invasive. Exotic invasion is undesirable. We therefore indicate environmental types likely to be invaded on disturbed sites (On roadsides...) or on undisturbed sites (Escaping into...). These facts come from Weaver et al (1989 and 1993).

Duration and habit: Expected length of life (annual-perennial), life form (herb-tree) and prevalence of vegetative reproduction (plant's tendency to fill the stand).

Environmental type: Five environmental types were studied. These are named for the climax vegetation occupying them and abbreviated with four letter codes. ANSC is a dry environment dominant in the western Dakotas. Moving up the moisture gradient in Montana one passes through arid grassland (BOGR), moister foothills grassland (AGSP), ponderosa pine (PIPO), and douglas fir (PSME) forest environments. Still higher, but unstudied, are the subalpine fir (ABLA) and the alpine (ALPN) environments. Additional discussion is available in Mueggler and Stewart (1980) and Pfister et al (1977). Refer to text (Pgs 10-12) for a more elaborate explanation of methods. 
Temperature: Mean July temperature $\left({ }^{\circ} \mathrm{C}\right)$ is used as an index for comparing growing season temperatures among environmental types (Caprio et al 1994)

Precipitation: Mean annual precipitation $(\mathrm{cm})$ is used to compare precipitation among environmental types (Caprio et al 1994).

Water-holding capacity: The capacity of a soil to hold water at different tensions. Fifteen bar WHC measures water stored in a dry soil, \% of its dry weight. 1/3 bar WHC (twice 15 bar) is its water content at field capacity. Thus, $1 / 3$ bar WHC - 15 bar WHC indexes the water that can be delivered to plants by a moist soil. WHC was calculated from the clay and $\mathrm{OM}$ content of the soil $(\mathrm{WHC}=2+1 / 3$ $\mathrm{OM}+1 / 2$ OM, Decker 1972)

Clay: Clay content (\% wt) is positively correlated with water storage capacity and negatively correlated with water infiltration.

Sand: Sand content (\%) is negatively correlated with water storage and positively correlated with infiltration.

Organic matter: $\mathrm{OM}$ is $40-60 \%$ carbon and 5\% nitrogen. Organic matter (\%) contributes to total soil WHC ( see WHC above). It also adds to soil fertility-both when nutrients are released by decomposition and through its high cation exchange capacity.

pH: A measure of acidity, nutrient binding, and therefore of fertility. All nutrients are most available at $\mathrm{pH} 7$ and most become less available when $\mathrm{pH}$ deviates significantly.

Conductivity: Electrical conductivity of a 2:1 suspension of soil in water. Indexes salinity. 
Position: On the inslope (between shoulder and ditch) vs. on the backslope (on the roadcut above the ditch and away from the road). No data are presented here; the inslope and backslope graphs (Fig X.1B) cannot be compared because their vertical axes have different scales.

Aspect: Aspect is the compass direction you are facing when your back is to the slope. Slopes chosen to be north, south, east or west-within 5 degrees. An alternative treatment of slope/ aspect may be useful (Meier 1997). 


\section{Achillea millefolium (Acmi)}

Common name: western yarrow

Family: Asteraceae

Invasiveness: Native

Duration and Habit ${ }^{1}$ : Perennial Forb, not vegetatively reproducing.

Environmental Type ${ }^{2}$ : Acmi cover (\%) is highest in the AGSP and PSME types, lower in PIPO and BOGR types and lowest in the ANSC type (Fig. 1.1A).

Temperature: Summer temperature does not differ between average Acmi sites and average roadside sites (Fig. 1.2A).

Precipitation': Annual precipitation is higher on average Acmi than average roadside sites (Fig 1.2B)

Water-holding capacity: WHC does not differ between average Acmi and average roadside sites (Fig. $1.2 \mathrm{C})$.

Clay: Clay does not differ between average Acmi sites and average roadside sites (Fig. 1.2D).

Sand: Sand does not differ between average Acmi sites and average roadside sites (Fig. 1.2E).

Organic matter: Organic matter does not differ between average Acmi sites and average roadside sites (Fig. 1.2F).

pH: $\mathrm{pH}$ does not differ between average Acmi sites and average roadside sites (Fig. 1.2G).

Conductivity: Conductivity does not differ between average Acmi sites and average roadside sites (Fig. 1.2H).

Position ${ }^{3}$ : Performance of Acmi does not vary significantly with position.

Aspect: Performance of Acmi does not vary significantly with aspect (Fig. 1.1B).

\footnotetext{
${ }^{1}$ Refer to the introduction (p37) for a brief discussion (elaborated in Part 1) of each factor.

${ }^{2}$ Species presence varies significantly with this factor.

${ }^{3}$ Inslope/backslope effects cannot be determined from Figure 1.1B below.
}
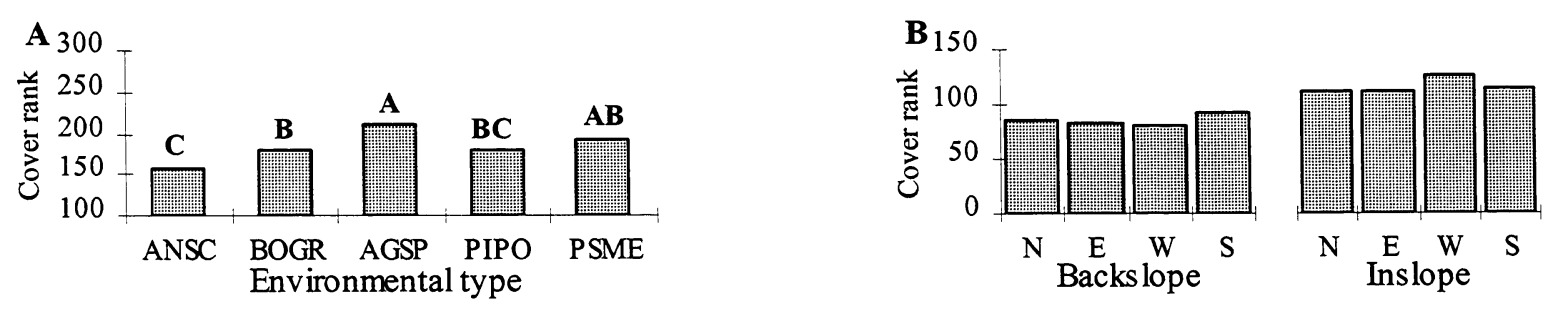

Figure 1.1. A) Relative performance of Achillea millefolium in five environmental types. B) Effect of position and aspect on the performance of Achillea millefolium. Categories sharing a letter are not significantly $(\mathrm{p}<0.05)$ different. 


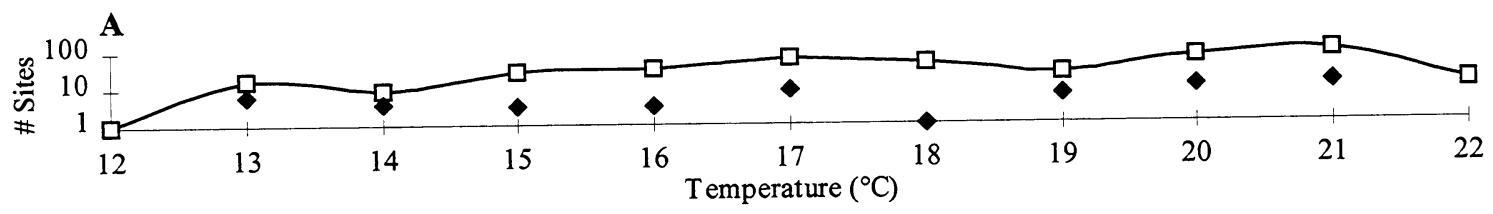

B
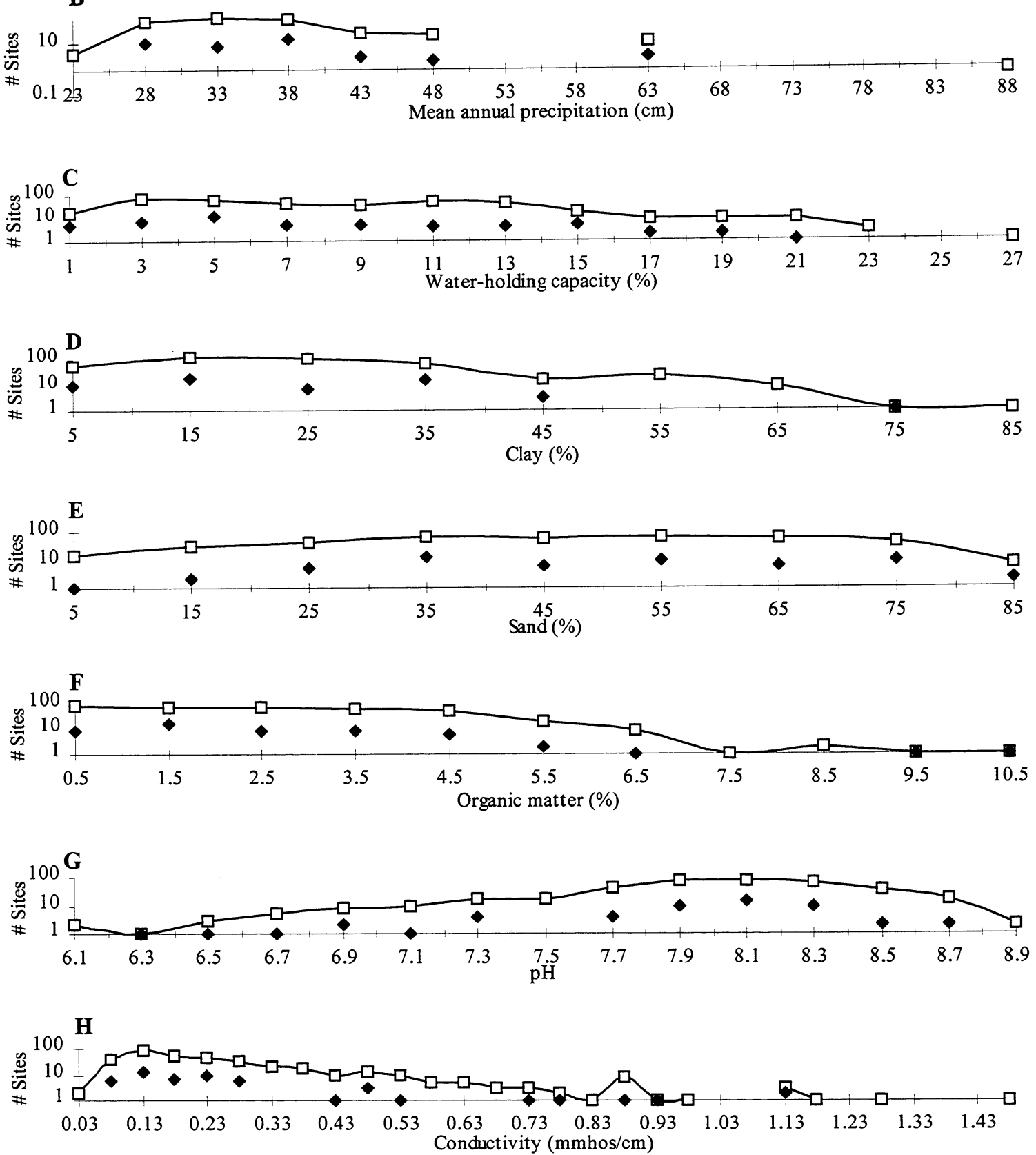

Figure 1.2. The distribution of Achillea millefolium sites (solid diamonds) and all roadside sites (open squares) across nine site characteristics. Where the mean of sites occupied by Achillea millefolium is significantly $(\mathrm{p}<0.05)$ different from the mean of all sites, both are shown in the upper right of the graph. 


\section{Agropyron cristatum (Agcr)}

Common name: crested wheatgrass

Family: Poaceae

Invasiveness: Exotic. On roadsides BOGR-PSME. Escaping in BOGR-AGSP.

Duration and Habit ${ }^{1}$ : Exotic, Perennial grass, not vegetatively reproducing.

Environmental Type ${ }^{2}$ : Agcr cover (\%) is highest in the BOGR type, lower in the ANSC and AGSP types, and lowest in PIPO and PSME types (Fig. 2.1A).

Temperature ${ }^{2}$ : Summer temperature is higher at average Agcr sites than average roadside sites (Fig. 2.2A).

Precipitation ${ }^{2}$ : Annual ppt is lower on average Agcr sites than average roadside sites. (Fig 2.2B)

Water-holding capacity ${ }^{2}$ : WHC at average Agcr sites is higher than at average roadside sites (Fig. 2.2C).

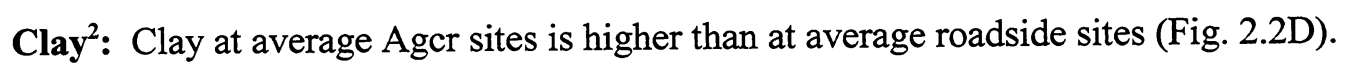

Sand $^{2}$ : Sand at average Agcr sites is lower than at average roadside sites (Fig. 2.2E).

Organic matter: OM does not differ between average Agcr sites and average roadside sites (Fig. 2.2F).

pH: $\mathrm{pH}$ does not differ between average Agcr sites and average roadside sites (Fig. 2.2G).

Conductivity ${ }^{2}$ : Conductivity at average Agcr sites is higher than at average roadside sites (Fig. 2.2H).

Position ${ }^{3}$ : Performance of Agcr does not vary significantly with position.

Aspect $^{2}$ : Agcr performance may decline slightly from $\mathrm{S}$ to $\mathrm{N}$ to WE facing inslopes.

Its cover is essentially constant across aspects on backslopes (Fig 2.1B).

\footnotetext{
${ }^{1}$ Refer to the introduction (p37) for a brief discussion (elaborated in Part 1) of each factor.

${ }^{2}$ Species presence varies significantly with this factor.

${ }^{3}$ Inslope/backslope effects cannot be determined from Figure 2.1B below.
}
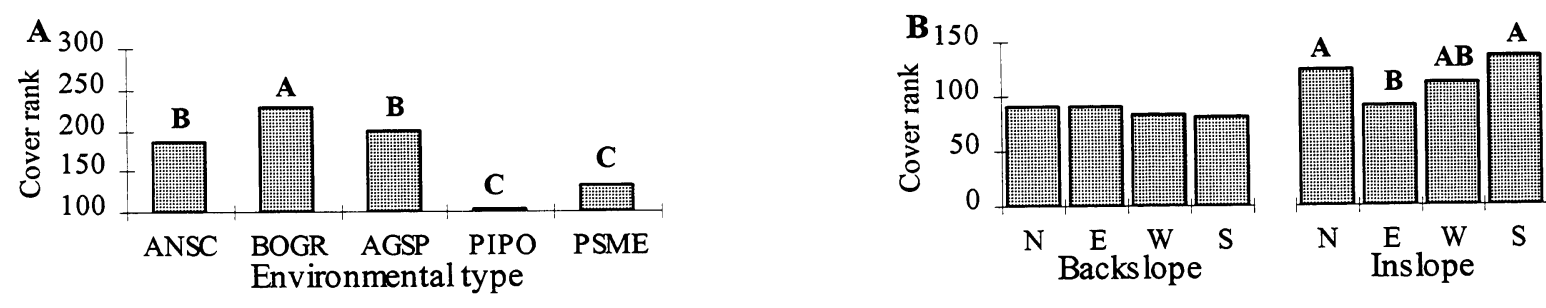

Figure 2.1. A) Relative performance of Agropyron cristatum in five environmental types. B). Effect of position and aspect on the performance of Agropyron cristatum. Categories sharing a letter are not significantly $(\mathrm{p}<0.05)$ different. 

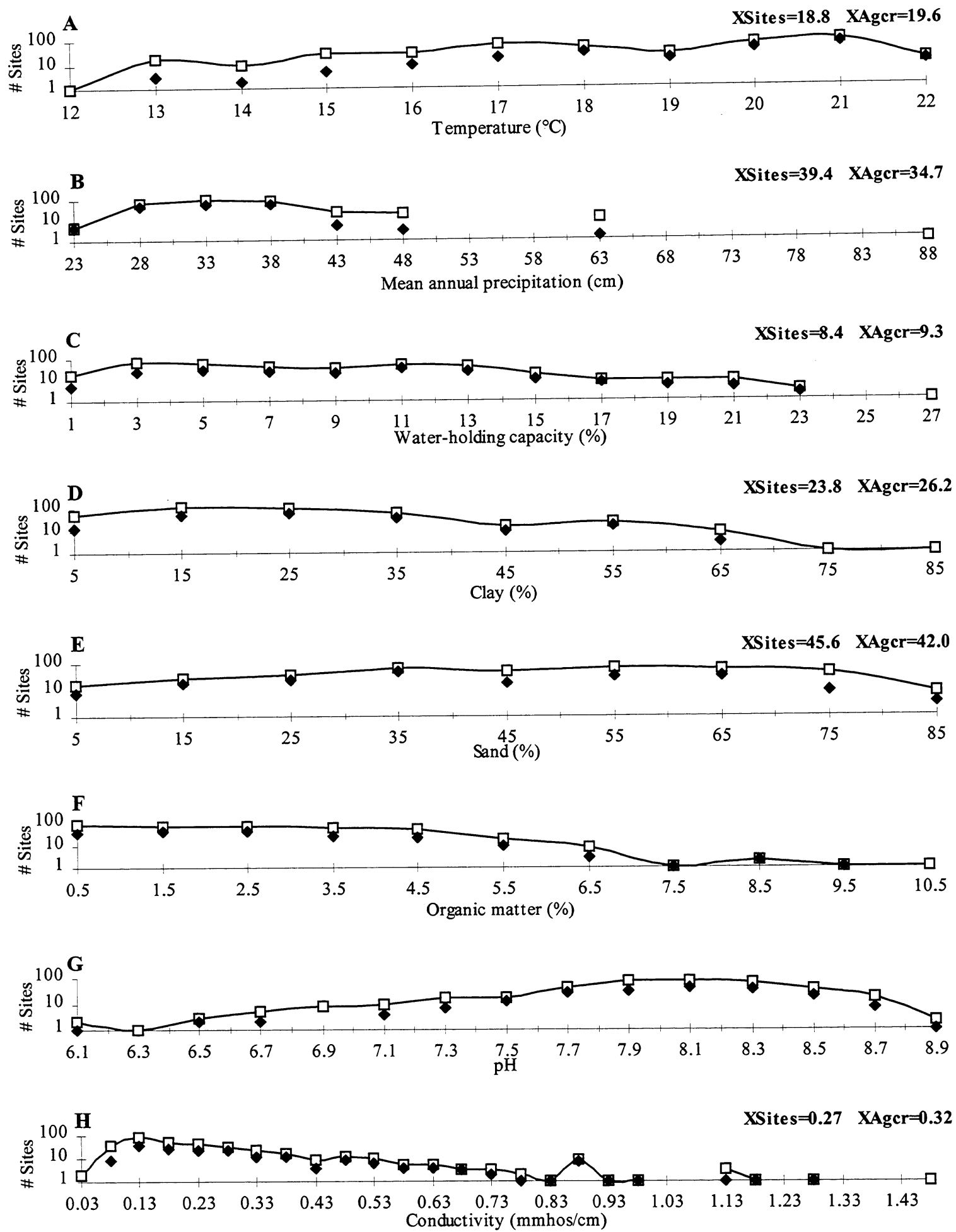

Figure 2.2. The distribution of Agropyron cristatum sites (solid diamonds) and all roadside sites (open squares) across nine site characteristics. Where the mean of sites occupied by Agropyron cristatum is significantly $(\mathrm{p}<0.05)$ different from the mean of all sites, both are shown in the upper right of the graph. 


\section{Agropyron dasystachyum (Agda)}

Common name: thickspike wheatgrass

Family: Poaceae

Invasiveness: Native

Duration and Habit ${ }^{1}$ : Perennial Grass, vegetatively reproducing.

Environmental Type ${ }^{2}$ : Agda cover (\%) is highest in the PIPO, PSME and AGSP types and lowest in the BOGR and ANSC types (Fig. 3.1A).

Temperature ${ }^{2}$ : Summer temperature at average Agda sites is lower than at average roadside sites (Fig 3.2A).

Precipitation²: Annual ppt at average Agda sites is higher than at average roadside sites (Fig 3.2B).

Water-holding capacity ${ }^{2}$ : WHC at average Agda sites is lower than at average roadside sites , (Fig. $3.2 \mathrm{C})$.

Clay $^{2}$ : Clay at average Agda sites is lower than at average roadside sites (Fig. 3.2D).

Sand $^{2}$ : Sand at average Agda sites is higher than at average roadside sites (Fig. 3.2E).

Organic matter: OM does not differ between average Agda sites and average roadside sites (Fig. 3.2F).

pH: pH does not differ between average Agda sites and average roadside sites (Fig. 3.2G).

Conductivity: Conductivity does not differ between average Agda sites and average roadside sites (Fig. $3.2 \mathrm{H})$.

Position $^{2,3}$ : Agda performs better on inslopes than backslopes.

Aspect: Though Agda cover does not vary significantly with slope orientation, WE slopes may favor it (Fig 3.1B).

\footnotetext{
${ }^{1}$ Refer to the introduction (p37) for a brief discussion (elaborated in Part 1) of each factor.

${ }^{2}$ Species presence varies significantly with this factor.

${ }^{3}$ Inslope/backslope effects cannot be determined from Figure 3.1B below.
}
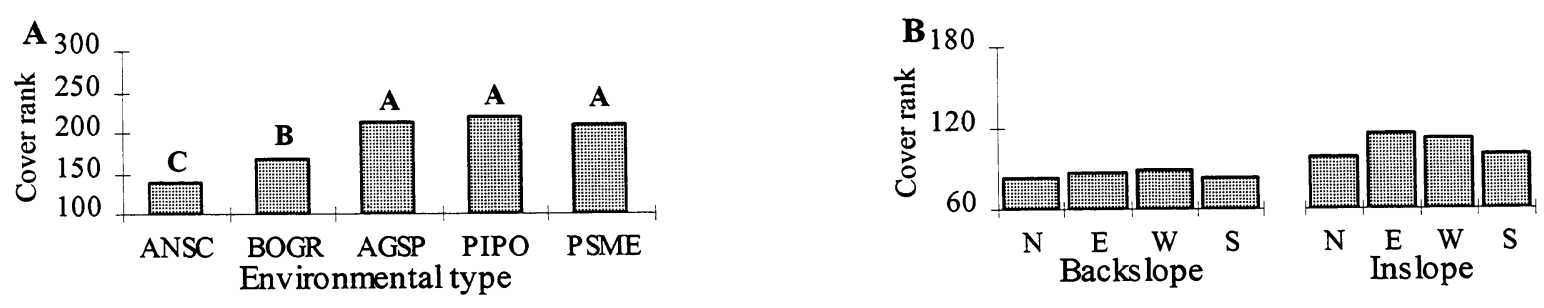

Figure 3.1. A) Relative performance of Agropyron dasystachyum in five environmental types. B) Effect of position and aspect on the performance of Agropyron dasystachyum. Categories sharing a letter are not significantly $(\mathrm{p}<0.05)$ different. 

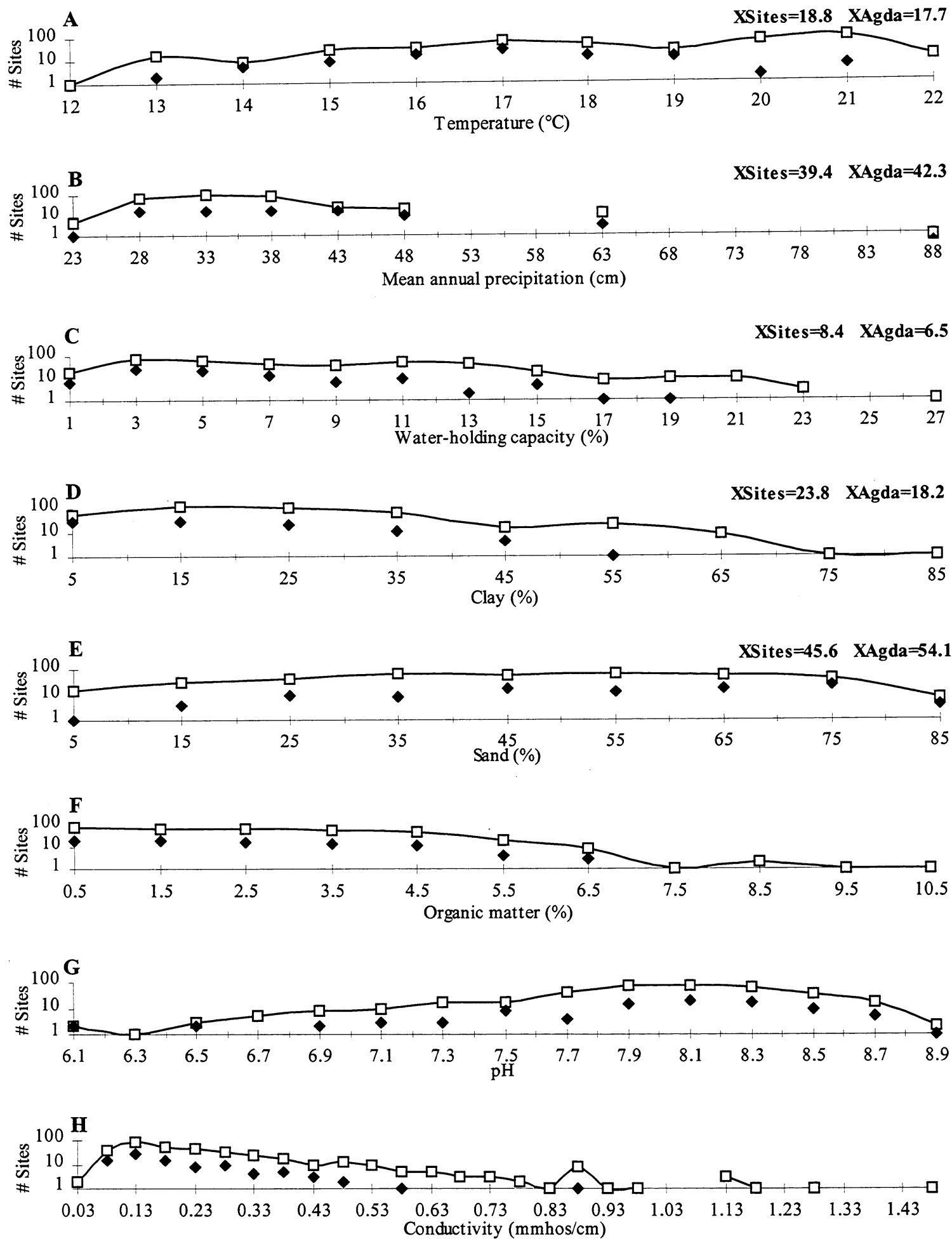

Figure 3.2. The distribution of Agropyron dasystachyum sites (solid diamonds) and all roadside sites (open squares) across nine site characteristics. Where the mean of sites occupied by Agropyron dasystachyum is significantly $(\mathrm{p}<0.05)$ different from the mean of all sites, both are shown in the upper right of the graph. 


\section{Agropyron smithii (Agsm)}

Common name: western wheatgrass

Family: Poaceae

Invasiveness: Native.

Duration and Habit' ${ }^{1}$ : Perennial grass, vegetatively reproducing.

Environmental Type ${ }^{2}$ : Agsm cover (\%) is higher in the BOGR type than any other type (Fig. 4.1A).

Temperature ${ }^{2}$ : July temperature at average Agsm sites is higher than at average roadside sites, (Fig. 4.2A).

Precipitation ${ }^{2}$ : Precipitation at average Agda sites is lower than at average roadside sites (Fig. 4.2B).

Water-holding capacity: WHC does not differ between average Agsm and average roadside sites (Fig. 4.2C).

Clay $^{2}$ : Clay at average Agsm sites is higher than at average roadside sites (Fig. 4.2D)

Sand ${ }^{2}$ : Sand at average Agsm sites is lower than at average roadside sites (Fig. 4.2E)

Organic matter: OM does not differ between average Agsm sites and average roadside sites (Fig. 4.2F)

pH: $\mathrm{pH}$ does not differ between average Agsm sites and average roadside sites (Fig. 4.2G)

Conductivity $^{2}$ Conductivity at average Agsm sites is higher than at average roadside sites (Fig. 4.2H).

Position ${ }^{3}$ : Performance of Agsm does not vary significantly with position.

Aspect $^{2}$ : Agsm performance declines from NS to EW facing slopes (Fig. 4.1B).

\footnotetext{
${ }^{1}$ Refer to the introduction (p37) for a brief discussion (elaborated in Part 1) of each factor.

${ }^{2}$ Species presence varies significantly with this factor.

${ }^{3}$ Inslope/backslope effects cannot be determined from Figure 4.1B below
}
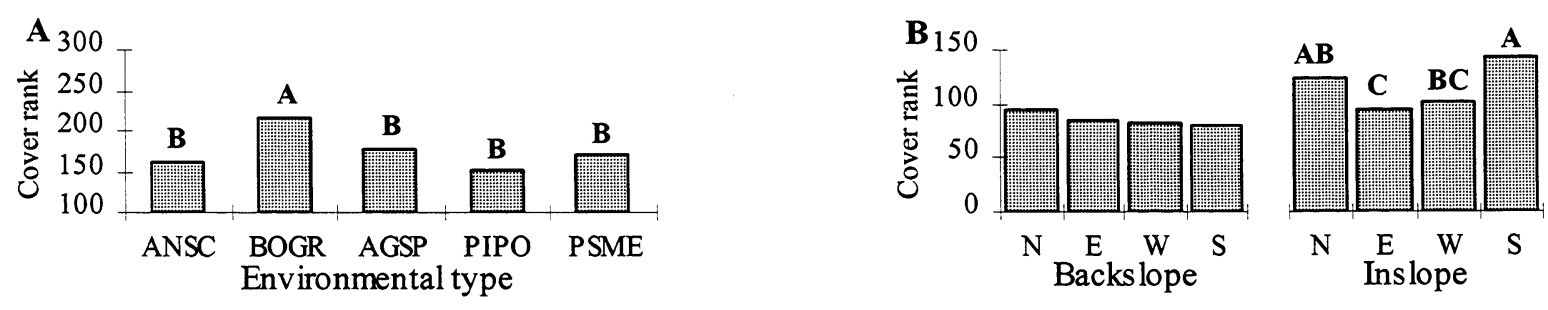

Figure 4.1. A) Relative performance of Agropyron smithii in five environmental types. B) Effect of position and aspect on the performance of Agropyron smithii. Categories sharing a letter are not significantly $(p<0.05)$ different. 

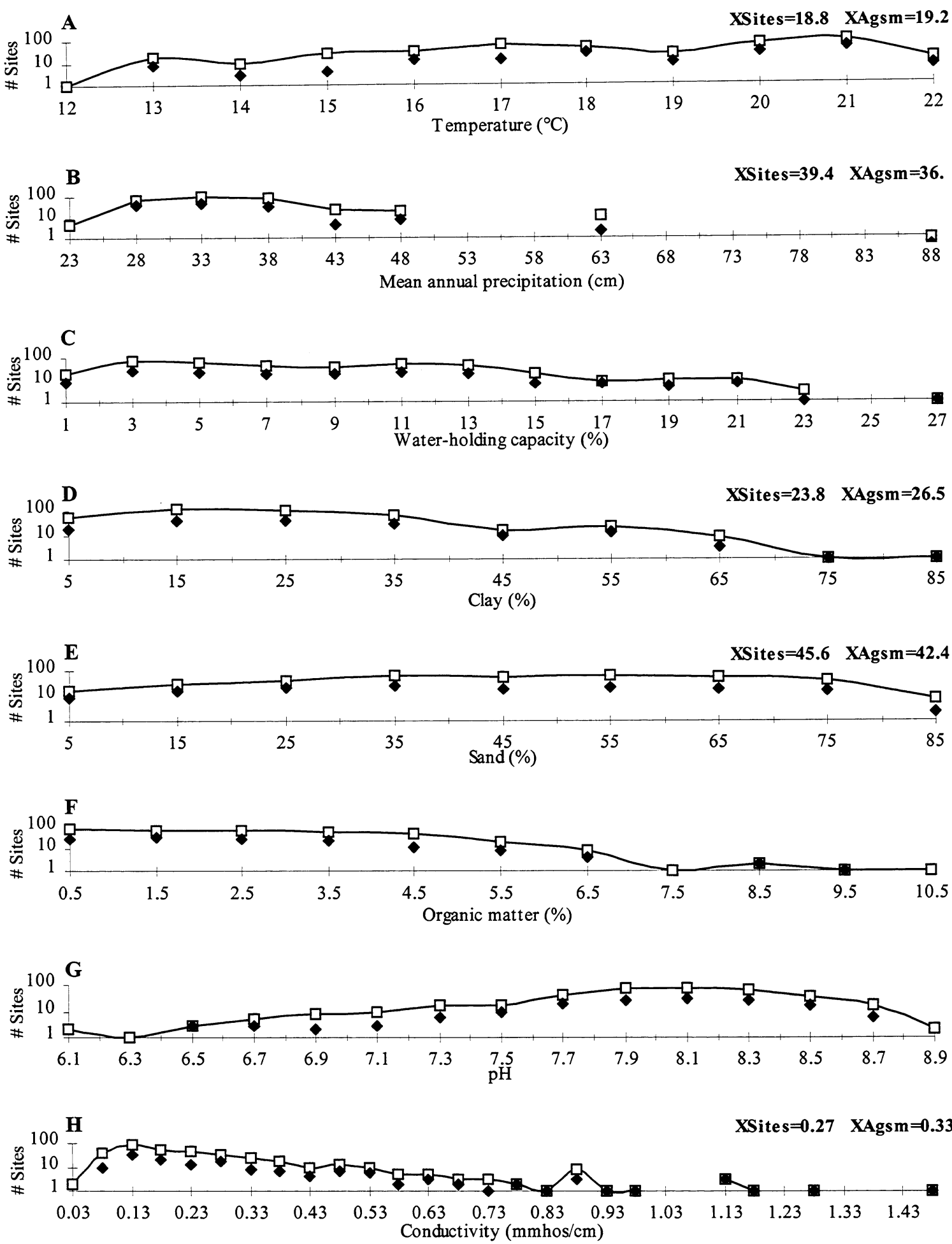

Figure 4.2. The distribution of Agropyron smithii sites (solid diamonds) and all roadside sites (open squares) across nine site characteristics. Where the mean of sites occupied by Agropyron smithii is significantly $(\mathrm{p}<0.05)$ different from the mean of all sites, both are shown in the upper right of the graph. 


\section{Agropyron spicatum (Agsp)}

Common name: bluebunch wheatgrass

Family: Poaceae

Invasiveness: Native.

Duration and Habit ${ }^{1}$ : Perennial Grass, not vegetatively reproducing.

Environmental type: Agsp cover (\%) does not differ among types (Fig. 5.1A)

Temperature: Summer temperature at average Agsp sites does not differ from average roadside sites (Fig. 5.2A).

Precipitation: Annual precipitation at average Agsp sites does not differ from average roadside sites (Fig. 5.2B).

Water-holding capacity: WHC does not differ between average Agsp sites and average roadside sites (Fig. 5.2C).

Clay: Clay does not differ between average Agsp sites and average roadside sites (Fig. 5.2D).

Sand: Sand does not differ between average Agsp sites and average roadside sites (Fig. 5.2E).

Organic matter: OM does not differ between average Agsp sites and average roadside sites (Fig. 5.2F).

pH: pH does not differ between average Agsp sites and average roadside sites (Fig. 5.2G).

Conductivity: Conductivity does not differ between average Agsp sites and average roadside sites (Fig. $5.2 \mathrm{H})$.

Position $^{2,3}$ : Agsp performs better on backslopes than inslopes.

Aspect: Aspect does not affect the performance of Agsp (Fig 5.1B).

\footnotetext{
${ }^{1}$ Refer to the introduction (p37) for a brief discussion (elaborated in Part 1) of each factor.

${ }^{2}$ Species presence varies significantly with this factor.

${ }^{3}$ Inslope/backslope effects cannot be determined from Figure 5.1B below
}
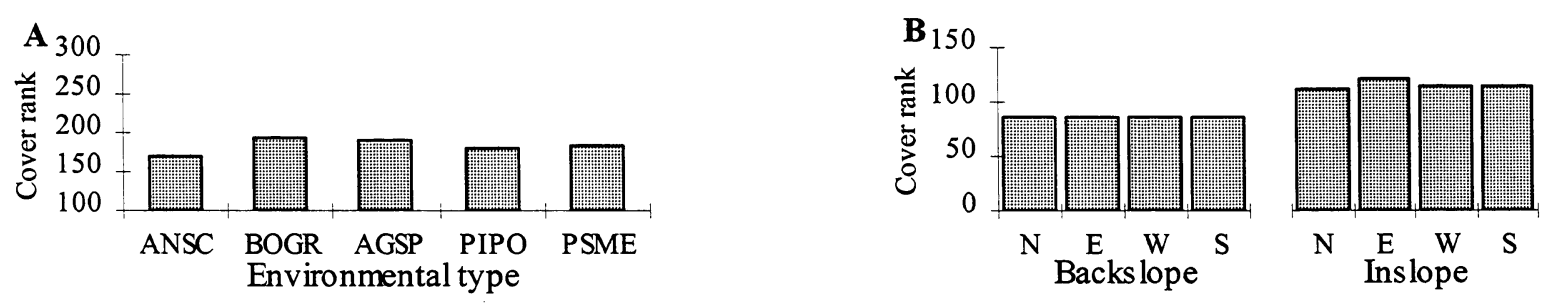

Figure 5.1. A) Relative performance of Agropyron spicatum in five environmental types. B) Effect of position and aspect on the performance of Agropyron spicatum. Categories sharing a letter are not significantly $(\mathrm{p}<0.05)$ different. 

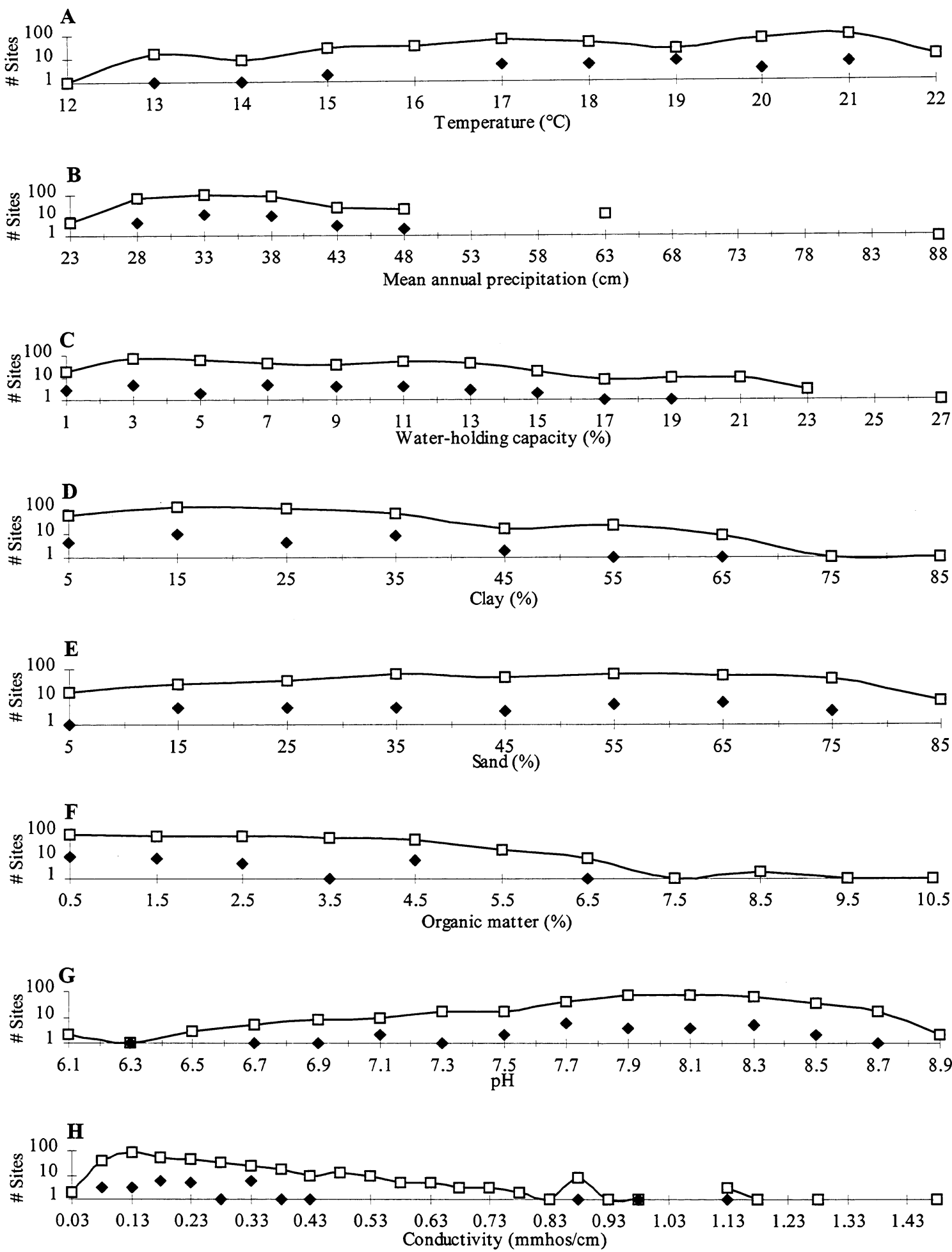

Figure 5.2 The distribution of Agropyron spicatum sites (solid diamonds) and all roadside sites (open squares) across nine site characteristics. Where the mean of sites occupied by Agropyron spicatum is significantly $(p<0.05)$ different from the mean of all sites, both are shown in the upper right of the graph. 


\section{Agrostis stolonifera (Agst)}

Common name: redtop bentgrass

Family: Poaceae

Invasiveness: Exotic. Invading wetlands extensively, probably BOGR-ABLA.

Duration and Habit ${ }^{1}$ : Perennial grass, vegetatively reproducing.

Environmental Type²: Agst cover (\%) is higher in the BOGR type than in any other type (Fig. 6.1A).

Temperature: Summer temperature does not differ between average Agst sites and average roadside sites (Fig. 6.2A).

Precipitation: Annual precipitation at average Agst sites does not differ from that of average roadside sites. (Fig. 6.2B).

Water-holding capacity: WHC does not differ between average Agst sites and average roadside sites (Fig. 6.2C).

Clay: Clay does not differ between average Agst sites and average roadside sites (Fig. 6.2D).

Sand: Sand does not differ between average Agst sites and average roadside sites (Fig. 6.2E).

Organic matter: OM does not differ between average Agst sites and average roadside sites (Fig. 6.2F).

pH: $\mathrm{pH}$ does not differ between average Agst sites and average roadside sites (Fig. 6.2G).

Conductivity ${ }^{2}$ : Conductivity is higher on average Agst sites than average roadside sites (Fig. $6.2 \mathrm{H}$ )

Position $^{3}$ : Performance of Agst does not vary significantly with position.

Aspect': Agst may perform slightly better on EW than NS slopes (Fig 6.1B).

\footnotetext{
${ }^{1}$ Refer to the introduction (p37) for a brief discussion (elaborated in Part 1) of each factor.

${ }^{2}$ Species presence varies significantly with this factor.

${ }^{3}$ Inslope/backslope effects cannot be determined from Figure 6.1B below
}
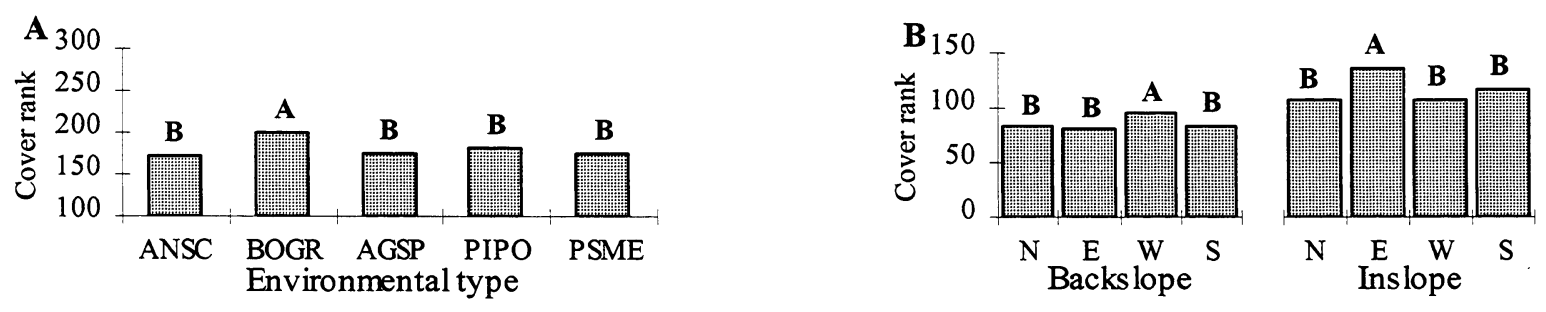

Figure 6.1. A) Relative performance of Agrostis stolonifera in five environmental types. B) Effect of position and aspect on the performance of Agrostis stolonifera. Categories sharing a letter are not significantly $(\mathrm{p}<0.05)$ different. 

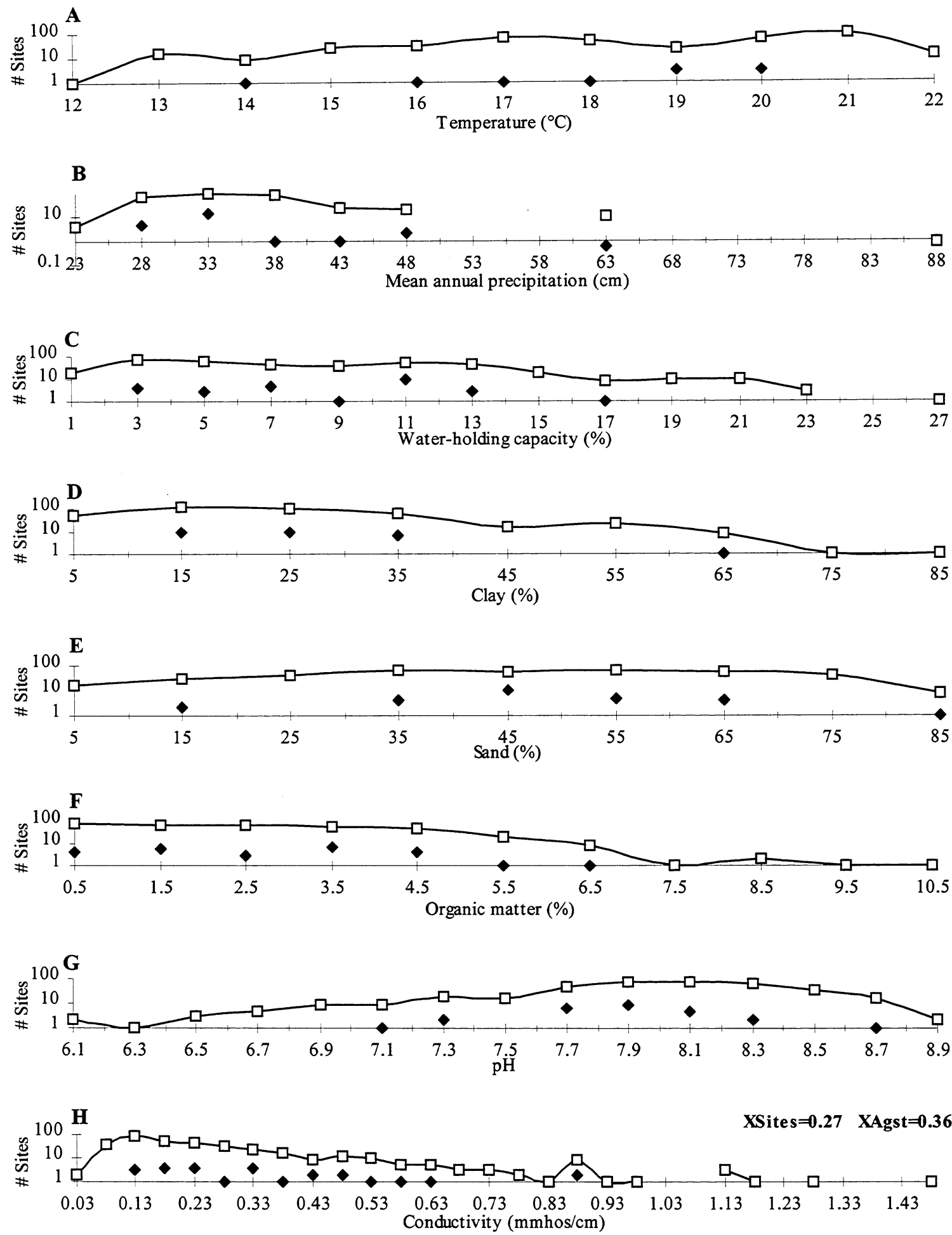

Figure 6.2. The distribution of Agrostis stolonifera sites (solid diamonds) and all roadside sites (open squares) across nine site characteristics. Where the mean of sites occupied by Agrostis stolonifera is significantly $(\mathrm{p}<0.05)$ different from the mean of all sites, both are shown in the upper right of the graph. 


\section{Alyssum alyssoides (Alal)}

Common name: pale alyssum

Family: Brassicaceae

Origin: Exotic. On roadsides BOGR-PSME. Escaping BOGR-AGSP.

Duration and Habit ${ }^{1}$ : Annual Forb, not vegetatively reproducing.

Environmental type: Alal cover (\%) does not differ between types (Fig. 7.1A).

Temperature: Summer temperature does not differ between average Alal sites and average roadside sites (Fig. 7.2A).

Precipitation ${ }^{2}$ : Annual precipitation at average Alal sites is less than at average roadside sites (Fig. 7.2B).

Water-holding capacity: WHC does not differ between average Alal sites and average roadside sites (Fig. 7.2C).

Clay: Clay does not differ between average Alal sites and average roadside sites (Fig. 7.2D).

Sand: Sand does not differ between average Alal sites and average roadside sites (Fig. 7.2E).

Organic matter: OM does not differ between average Alal sites and average roadside sites (Fig. 7.2F).

pH$^{2}: \mathrm{pH}$ at average Alal sites is lower than at average roadside sites (Fig. 7.2G).

Conductivity: Conductivity does not differ between average Alal sites and average roadside sites (Fig. 7.2H).

Position ${ }^{3}$ : Performance of Alal does not vary significantly with position.

Aspect $^{2}$ : Alal may perform slightly better on NS than EW slopes (Fig 7.1B).

\footnotetext{
${ }^{1}$ Refer to the introduction (p37) for a brief discussion (elaborated in Part 1) of each factor.

${ }^{2}$ Species presence varies significantly with this factor.

${ }^{3}$ Inslope/backslope effects cannot be determined from Figure 7.1B below
}
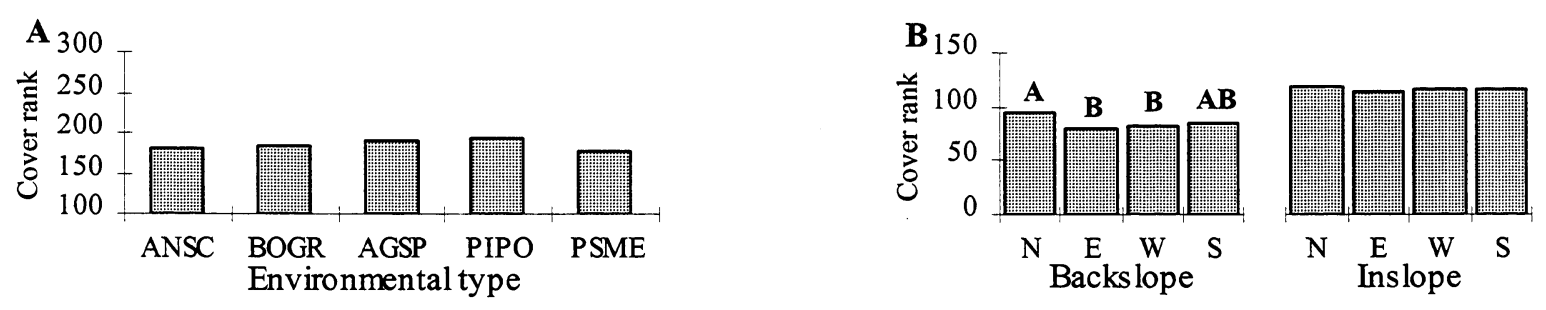

Figure 7.1. A) Relative performance of Alyssum alyssoides in five environmental types. B) Effect of position and aspect on the performance of Alyssum alyssoides. Categories sharing a letter are not significantly $(\mathrm{p}<0.05)$ different. 

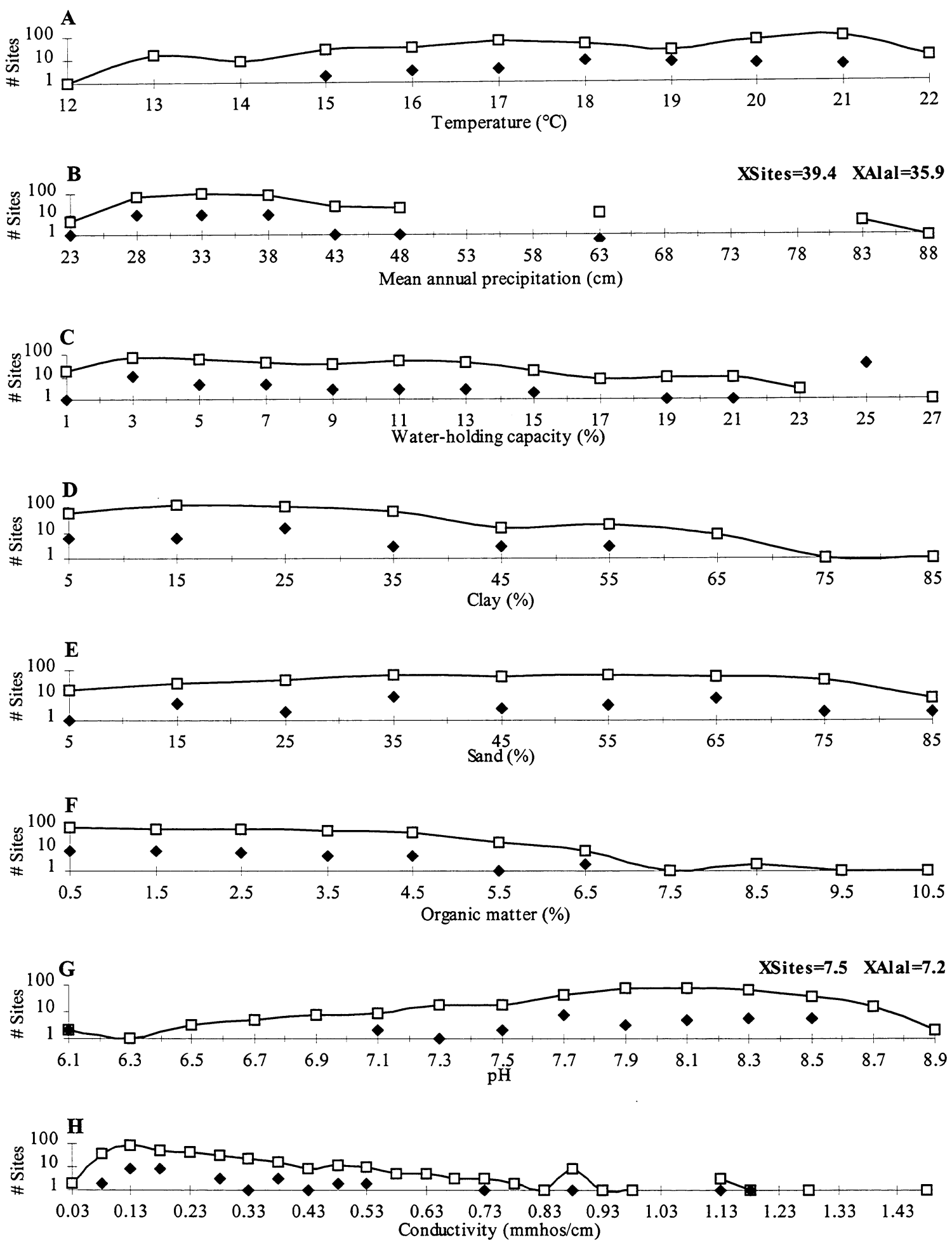

Figure 7.2. The distribution of Alyssum alyssoides sites (solid diamonds) and all roadside sites (open squares) across nine site characteristics. Where the mean of sites occupied by Alyssum alyssoides is significantly $(p<0.05)$ different from the mean of all sites, both are shown in the upper right of the graph. 


\section{Artemisia cana (Arca)}

Common name: silver sagebrush

Family: Asteraceae

Origin: Native.

Duration and Habit': Perennial Shrub, not vegetatively reproducing.

Environmental type: Arca cover (\%) does not differ between types (Fig. 8.1A).

Temperature: Summer temperature does not differ between average Arca and average roadside sites (Fig. 8.2A).

Precipitation ${ }^{2}$ : Annual precipitation at average Arca sites is less than at the average roadside sites (Fig. 8.2B).

Water-holding capacity: WHC does not differ between average Arca sites and average roadside sites (Fig. 8.2C).

Clay $^{2}$ : Clay at average Arca sites is higher than at average roadside sites (Fig. 8.2D).

Sand': Sand at average Arca sites is lower than at average roadside sites (Fig. 8.2E).

Organic matter: OM does not differ between average Arca sites and average roadside sites (Fig. 8.2F).

pH: $\mathrm{pH}$ does not differ between average Arca sites and average roadside sites (Fig. 8.2G).

Conductivity $^{2}$ : Conductivity in average Arca sites is higher than average roadside sites (Fig. 8.2H).

Position $^{3}$ : Performance of Arca does not vary significantly with position

Aspect $^{2}$ : On inslopes, Arca performs best, slightly, on north facing slopes (Fig. 8.1B).

\footnotetext{
${ }^{1}$ Refer to the introduction (p37) for a brief discussion (elaborated in Part 1) of each factor.

${ }^{2}$ Species presence varies significantly with this factor.

${ }^{3}$ Inslope/backslope effects cannot be determined from Figure $8.1 \mathrm{~B}$ below
}
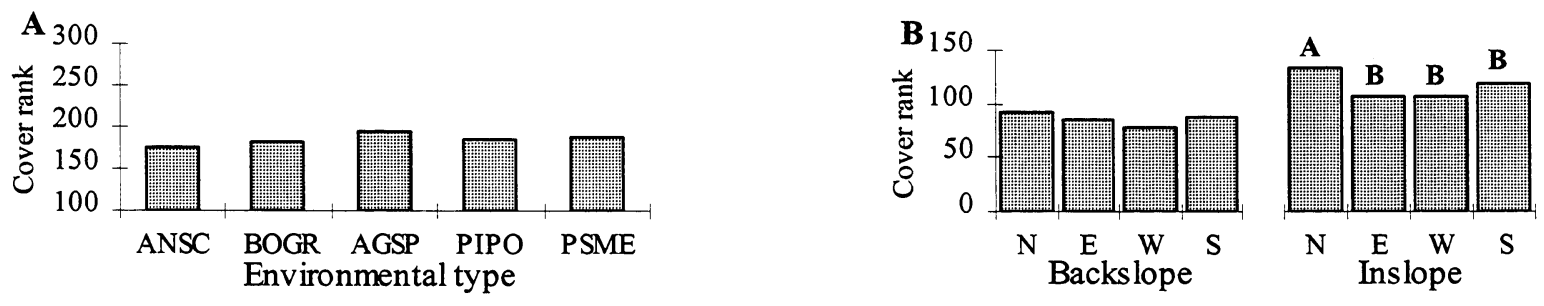

Figure 8.1. A) Relative performance of Artemisia cana in five environmental types. B) Effect of position and aspect on the performance of Artemisia cana. Categories sharing a letter are not significantly $(\mathrm{p}<0.05)$ different. 

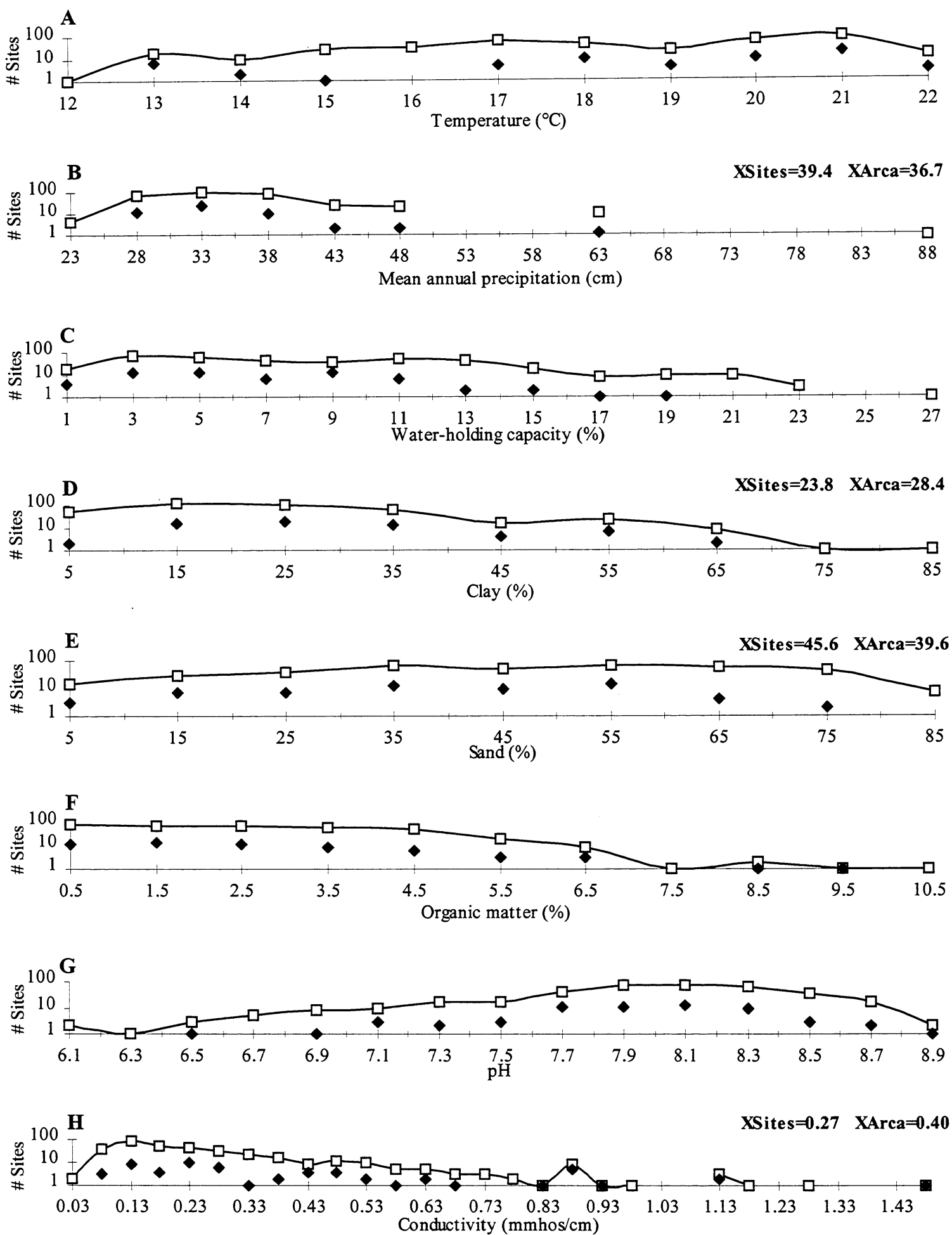

Figure 8.2. The distribution of Artemisia cana sites (solid diamonds) and all roadside sites (open squares) across nine site characteristics. Where the mean of sites occupied by Artemisia cana is significantly $(p<0.05)$ different from the mean of all sites, both are shown in the upper right of the graph. 


\section{Artemisia frigida (Arfr)}

Common name: fringed sagebrush

Family: Asteraceae

Origin: Native.

Duration and Habit' ${ }^{1}$ : Perennial Forb, vegetatively reproducing.

Environmental Type ${ }^{2}$ : Arfr cover (\%) is highest in AGSP and BOGR types and lowest in the ANSC type. PIPO and PSME types are intermediate (Fig. 9.1A).

Temperature ${ }^{2}$ : Summer temperature at average Arfr sites is higher than at average roadside sites (Fig. 9.2A).

Precipitation ${ }^{2}$ : Annual precipitation at average Arfr sites is less than at average roadside sites. (Fig. 9.2B).

Water-holding capacity ${ }^{2}$ : WHC at average Arfr sites is higher than at average roadside sites (Fig. 9.2C).

Clay $^{2}$ : Clay in average Arfr sites is lower than at average roadside sites (Fig. 9.2D).

Sand ${ }^{2}$ : Sand at average Arfr sites is lower than at average roadside sites (Fig. 9.2E).

Organic matter: OM does not differ between average Arfr sites and average roadside sites (Fig. 9.2F).

$\mathbf{p H}^{2}: \mathrm{pH}$ at average Arfr sites is higher than at average roadside sites (Fig. 9.2G).

Conductivity $^{2}$ : Conductivity at average Arfr sites is higher than at average roadside sites (Fig. 9.2H).

Position $^{2,3}$ : Arfr performs better on backslopes than inslopes.

Aspect $^{2}$ : Arfr performance varies little with slope orientation (Fig. 9.1B).

\footnotetext{
${ }^{1}$ Refer to the introduction (p37) for a brief discussion (elaborated in Part 1) of each factor.

${ }^{2}$ Species presence varies significantly with this factor.

${ }^{3}$ Inslope/backslope effects cannot be determined from Figure 22.1B below
}
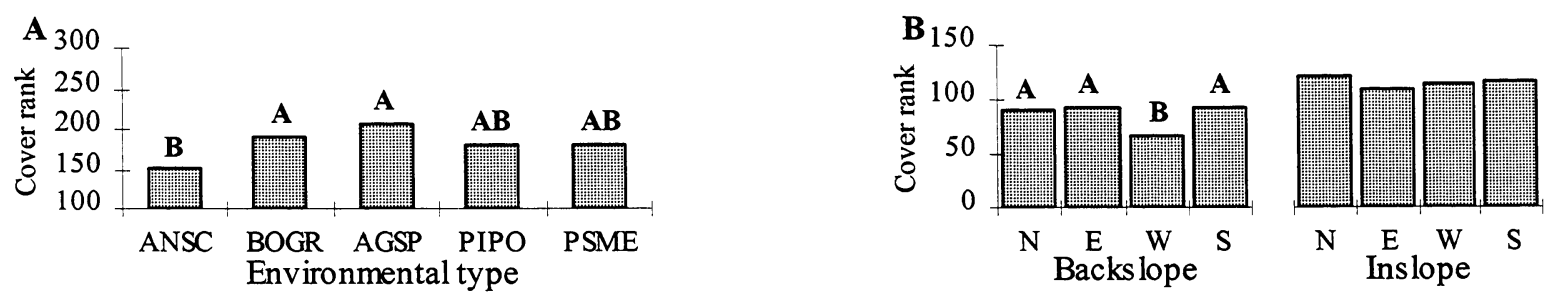

Figure 9.1. A) Relative performance of Artemisia frigida in five environmental types. B) Effect of position and aspect on the performance of Artemisia frigida. Categories sharing a letter are not significantly $(p<0.05)$ different. 

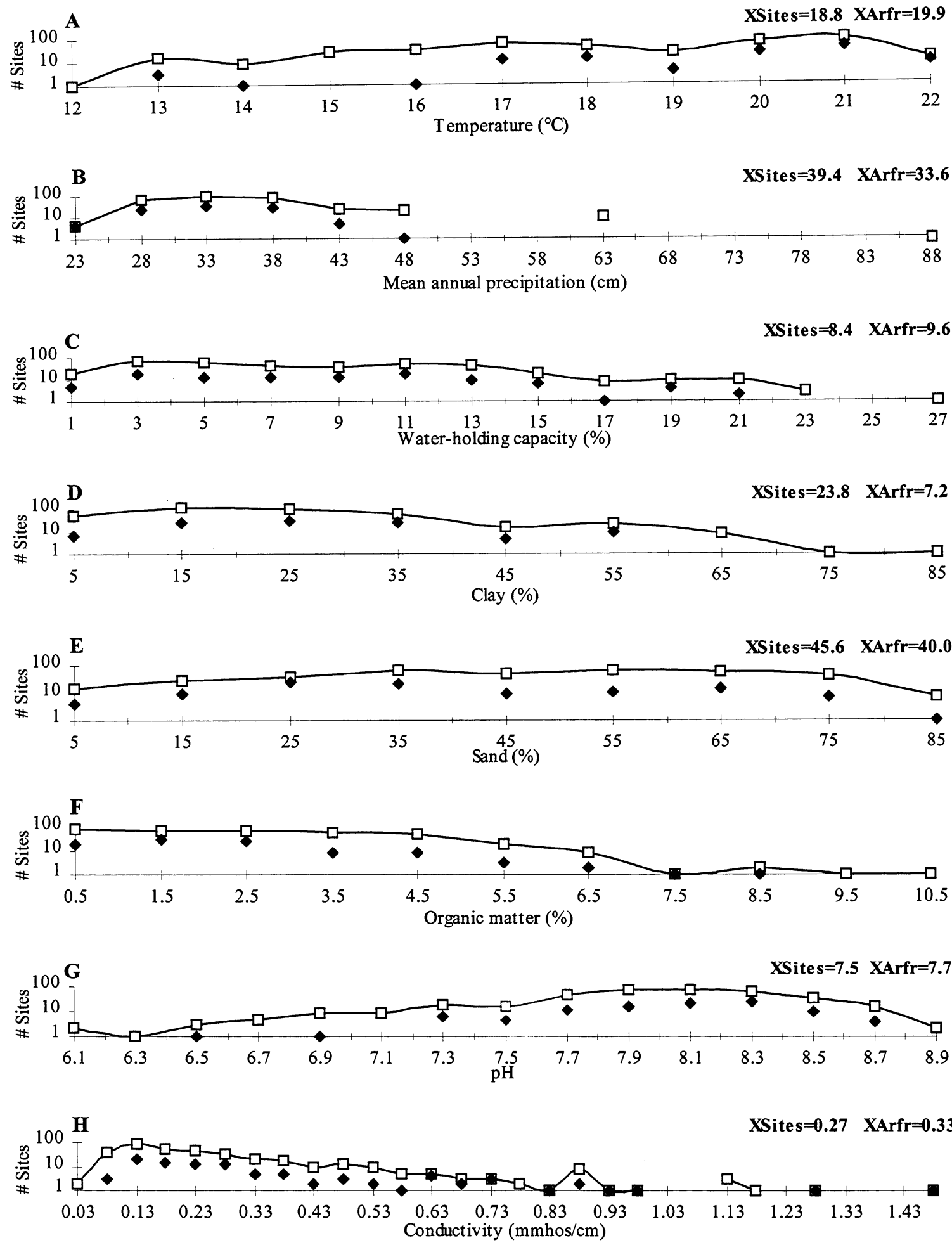

Figure 9.2. The distribution of Artemisia frigida sites (solid diamonds) and all roadside sites (open squares) across nine site characteristics. Where the mean of sites occupied by Artemisia frigida is significantly $(p<0.05)$ different from the mean of all sites, both are shown in the upper right of the graph. 


\section{Artemisia tridentada (Artr)}

Common name: mountain sagebrush

Family: Asteraceae

Origin: Native.

Duration and Habit': Perennial Shrub, not vegetatively reproducing.

Environmental type: Artr cover (\%) does not differ between types (Fig. 10.1A).

Temperature: Summer temperature does not differ between average Artr sites and average roadside sites (Fig. 10.2A).

Precipitation: Annual precipitation does not differ between average Artr and average roadside sites (Fig. 10.2B).

Water-holding capacity: WHC does not differ between average Artr sites and average roadside sites (Fig. 10.2C).

Clay: Clay content does not differ between average Artr sites and average roadside sites (Fig. 10.2D).

Sand $^{2}$ : Sand at average Artr sites is lower than at average roadside sites (Fig. 10.2E).

Organic matter: OM does not differ between average Artr sites and average roadside sites (Fig. 10.2F).

pH: $\mathrm{pH}$ does not differ between average Artr sites and average roadside sites (Fig. 10.2G).

Conductivity: Conductivity does not differ between average Artr and average roadside sites (Fig. $10.2 \mathrm{H})$.

Position $^{2,3}$ : Artr performs better on backslopes than inslopes.

Aspect: Aspect has no effect on Artr performance (Fig. 10.1B).

\footnotetext{
${ }^{1}$ Refer to the introduction (p37) for a brief discussion (elaborated in Part 1) of each factor.

${ }^{2}$ Species presence varies significantly with this factor.

${ }^{3}$ Inslope/backslope effects cannot be determined from Figure 10.1B below.
}
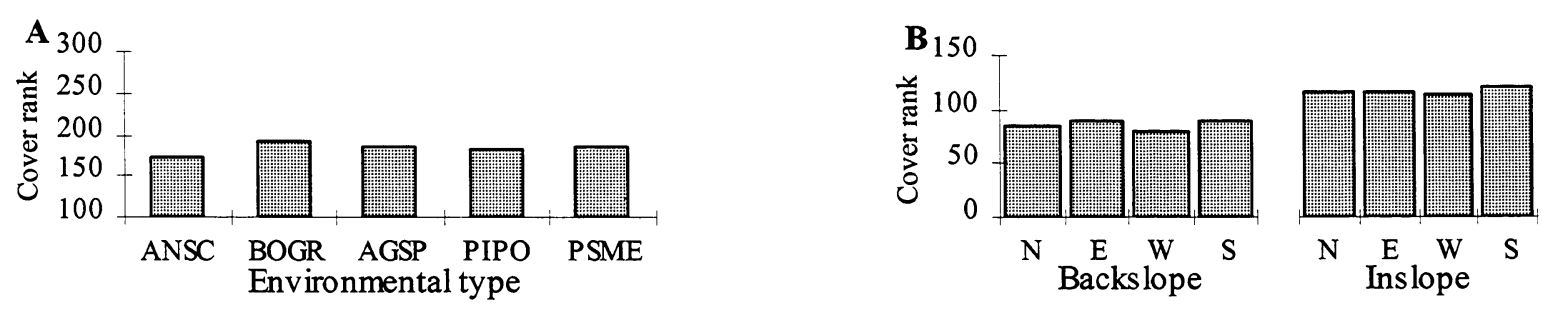

Figure 10.1. A) Relative performance of Artemisa tridentata in five environmental types. B) Effect of position and aspect on the performance of Artemisa tridentata. Categories sharing a letter are not significantly $(\mathrm{p}<0.05)$ different. 

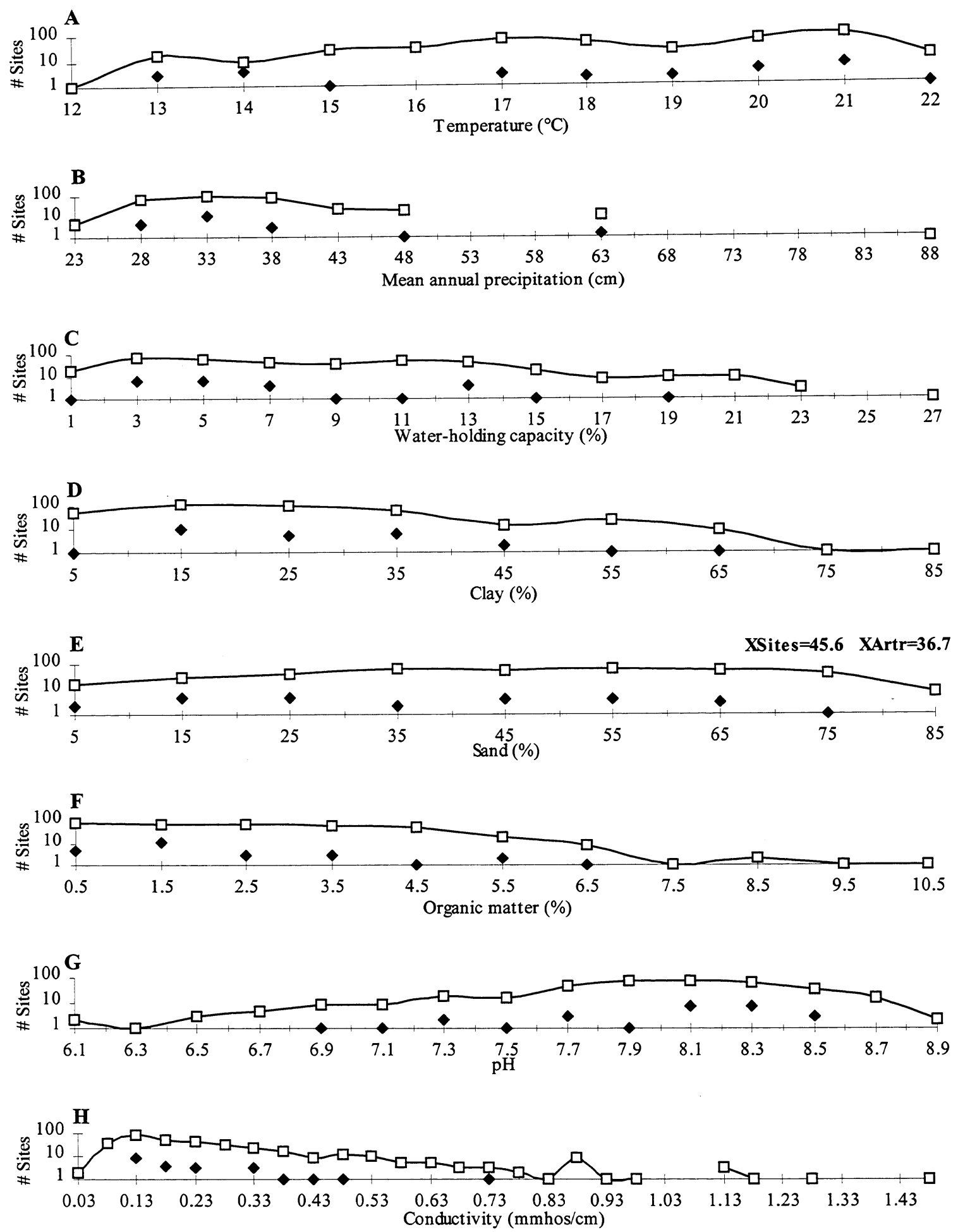

Figure 10.2. The distribution of Artemisia tridentada sites (solid diamonds) and all roadside sites (open squares) across nine site characteristics. Where the mean of sites occupied by Artemisia tridentada is significantly $(\mathrm{p}<0.05)$ different from the mean of all sites, both are shown in the upper right of the graph. 


\section{Avena sativa (Avsa)}

Common name: common oat

Family: Poaceae

Origin: Exotic. On roadsides BOGR-PSME. Not escaping.

Duration and Habit ${ }^{1}$ : Grass, not vegetatively reproducing.

Environmental Type ${ }^{2}$ : Avsa cover (\%) is higher in the ANSC than any other type (Fig. 11.1A).

Temperature $^{2}$ : Summer temperature on average Avsa sites is higher than on average roadside sites (Fig. 11.2A).

Precipitation: Annual precipitation does not differ between average Avsa and average roadside sites (Fig. 11.2B).

Water-holding capacity: WHC does not differ between average Avsa and average roadside sites (Fig. 11.2C).

Clay: Clay content does not differ between average Avsa and average roadside sites (Fig. 11.2D).

Sand: Sand \% does not differ between average Avsa and average roadside sites (Fig. 11.2E).

Organic matter: OM does not differ between average Avsa and average roadside sites (Fig. 11.2F).

pH: $\mathrm{pH}$ does not differ between average Avsa and average roadside sites (Fig. 11.2G).

Conductivity: Conductivity does not differ between average Avsa and average roadside sites (Fig. 11.2H).

Position ${ }^{3}$ : On roadsides, Avsa cover does not respond to position.

Aspect $^{2}$ : Avsa may perform slightly better on EW than NS inslopes (Fig. 11.1B).

\footnotetext{
${ }^{1}$ Refer to the introduction (p37) for a brief discussion (elaborated in Part 1) of each factor.

${ }^{2}$ Species presence varies significantly with this factor.

${ }^{3}$ Inslope/backslope effects cannot be determined from Figure 11.1B below
}
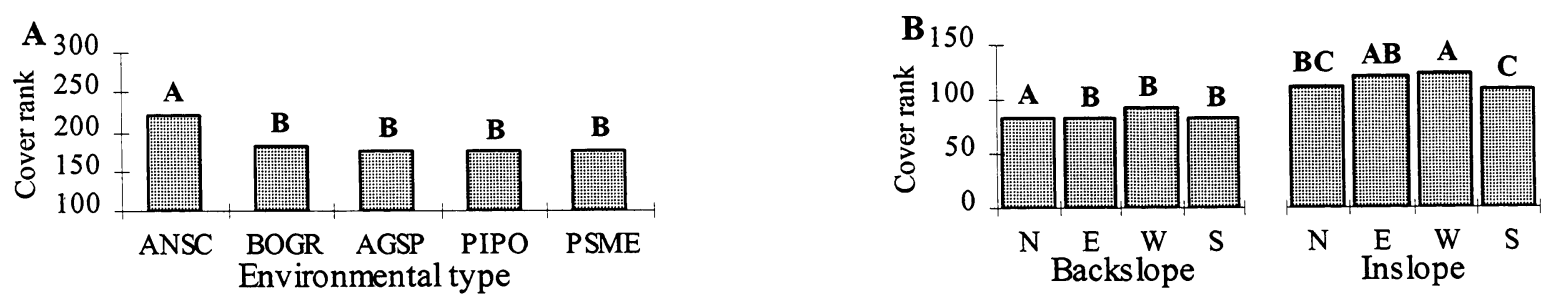

Figure 11.1. A) Relative performance of Avena sativa in five environmental types. B) Effect of position and aspect on the performance of Avena sativa. Categories sharing a letter are not significantly $(\mathrm{p}<0.05)$ different. 

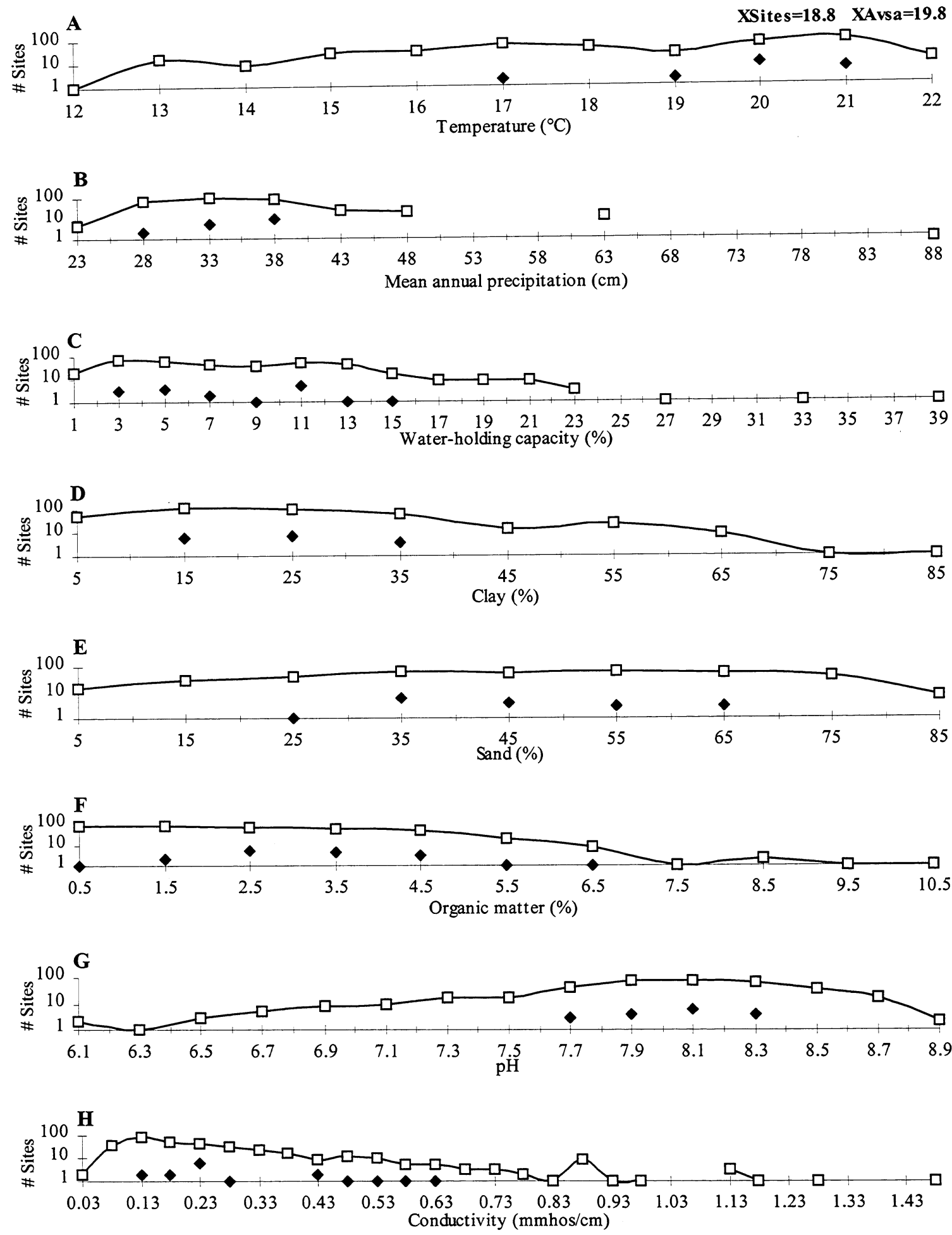

Figure 11.2. The distribution of Avena sativa sites (solid diamonds) and all roadside sites (open squares) across nine site characteristics. Where the mean of sites occupied by Avena sativa is significantly $(p<0.05)$ different from the mean of all sites, both are shown in the upper right of the graph. 


\section{Bouteloua gracilis (Bogr)}

Common name: blue gramma

Family: Poaceae

Origin: Native.

Duration and Habit' ${ }^{1}$ : Perennial Grass, vegetatively reproducing.

Environmental type: Bogr cover (\%) is the same in all types (Fig. 12.1A).

Temperature ${ }^{2}$ : Summer temperature at average Bogr sites is higher than at average roadside sites (Fig. 12.2A).

Precipitation²: Bogr cover (\%) is highest in the driest sites (20-25cm) (Fig. 12.2B).

Water-holding capacity: WHC does not differ between average Bogr and average roadside sites (Fig. 12.2C).

Clay: Clay does not differ between average Bogr sites and average roadside sites (Fig. 12.2D).

Sand: Sand does not differ between average Bogr sites and average roadside sites (Fig. 12.2E).

Organic matter: OM does not differ between average Bogr sites and average roadside sites (Fig. 12.2F).

pH: $\mathrm{pH}$ does not differ between average Bogr sites and average roadside sites (Fig. 12.2G).

Conductivity: Conductivity does not differ between average Bogr and average roadside sites (Fig. $12.2 \mathrm{H})$.

Position $^{3}$ : On roadsides, Bogr cover does not respond to position.

Aspect $^{2}$ : Despite statistics, Bogr does seems not to respond to aspect (Fig. 12.1B).

\footnotetext{
${ }^{1}$ Refer to the introduction (p37) for a brief discussion (elaborated in Part 1) of each factor.

${ }^{2}$ Species presence varies significantly with this factor.

${ }^{3}$ Inslope/backslope effects cannot be determined from Figure 12.1B below.
}
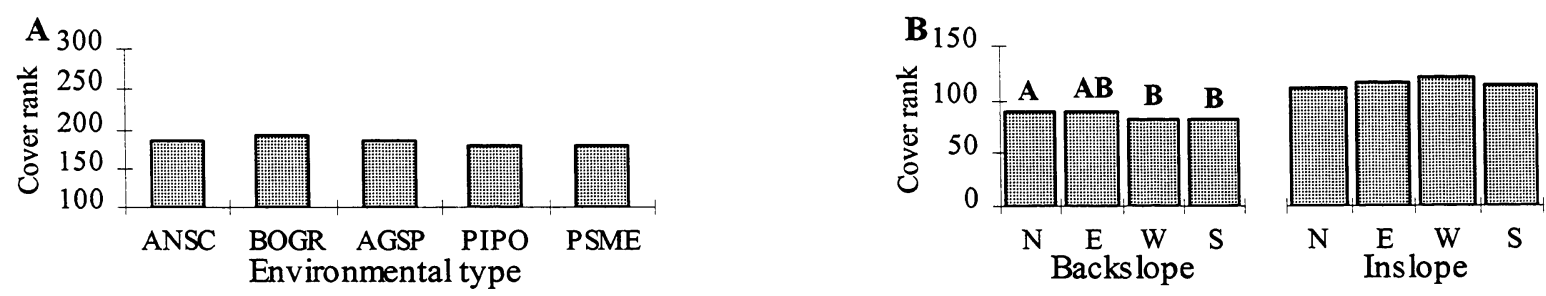

Figure 12.1. A) Relative performance of Bouteloua gracilis in five environmental types. B) Effect of position and aspect on the performance of Bouteloua gracilis. Categories sharing a letter are not significantly $(\mathrm{p}<0.05)$ different. 

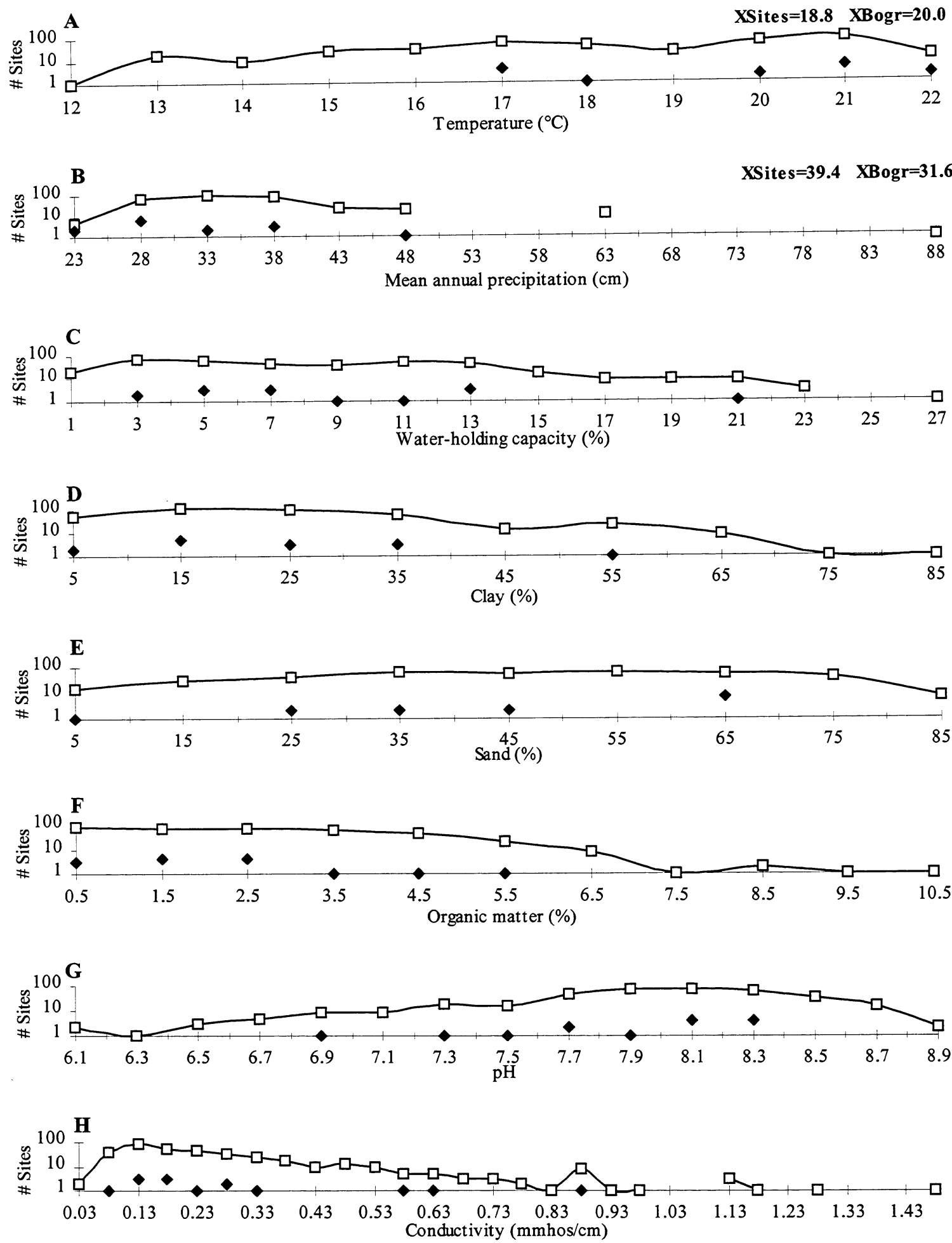

Figure 12.2. The distribution of Bouteloua gracilis sites (solid diamonds) and all roadside sites (open squares) across nine site characteristics. Where the mean of sites occupied by Bouteloua gracilis is significantly $(p<0.05)$ different from the mean of all sites, both are shown in the upper right of the graph. 


\section{Bromus inermis (Brin)}

Common name: smooth brome

Family: Poaceae

Origin: Exotic. On roadsides, BOGR-ALPN. Escaping PSME-POTR.

Duration and Habit ${ }^{1}$ Perennial Grass, vegetative reproducing.

Environmental Type ${ }^{2}$ : Brin cover (\%) is highest in the ANSC and PSME types and lowest in the PIPO type (Fig. 13.1A).

Temperature: Summer temperature does not differ between average Brin sites and average roadside sites (Fig. 13.2A).

Precipitation: Annual precipitation does not differ between Brin sites and average roadside sites (Fig. 13.2B).

Water-holding capacity: WHC does not differ between average Brin sites and average roadside sites (Fig. 13.2C).

Clay: Clay does not differ between average Brin sites and average roadside sites (Fig. 13.2D).

Sand: Sand does not differ between average Brin sites and average roadside sites (Fig. 13.2E).

Organic matter: OM does not differ between average Brin sites and average roadside sites (Fig. 13.2F).

pH: pH does not differ between average Brin sites and average roadside sites (Fig. 13.2G).

Conductivity: Conductivity does not differ between average Brin sites and average roadside sites (Fig. 13.2H).

Position $^{2,3}$ : Brin performs better on inslopes than backslopes

Aspect $^{2}$ : Brin seems to perform slightly worse on W inslopes than other slopes (Fig. 13.1B).

\footnotetext{
${ }^{1}$ Refer to the introduction (p37) for a brief discussion (elaborated in Part 1) of each factor.

${ }^{2}$ Species presence varies significantly with this factor.

${ }^{3}$ Inslope/backslope effects cannot be determined from Figure 13.1B below.
}
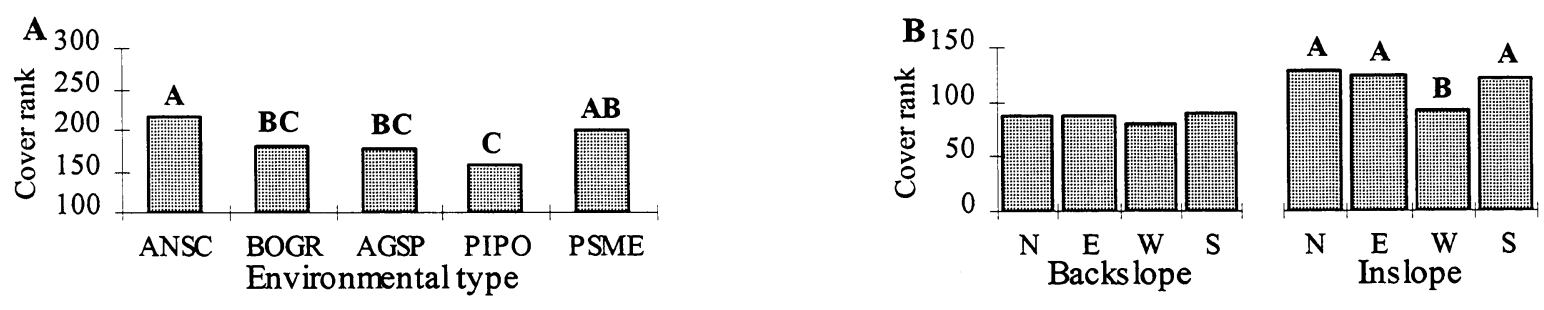

Figure 13.1. A) Relative performance of Bromus inermis in five environmental types. B) Effect of position and aspect on the performance of Bromus inermis. Categories sharing a letter are not significantly $(\mathrm{p}<0.05)$ different. 

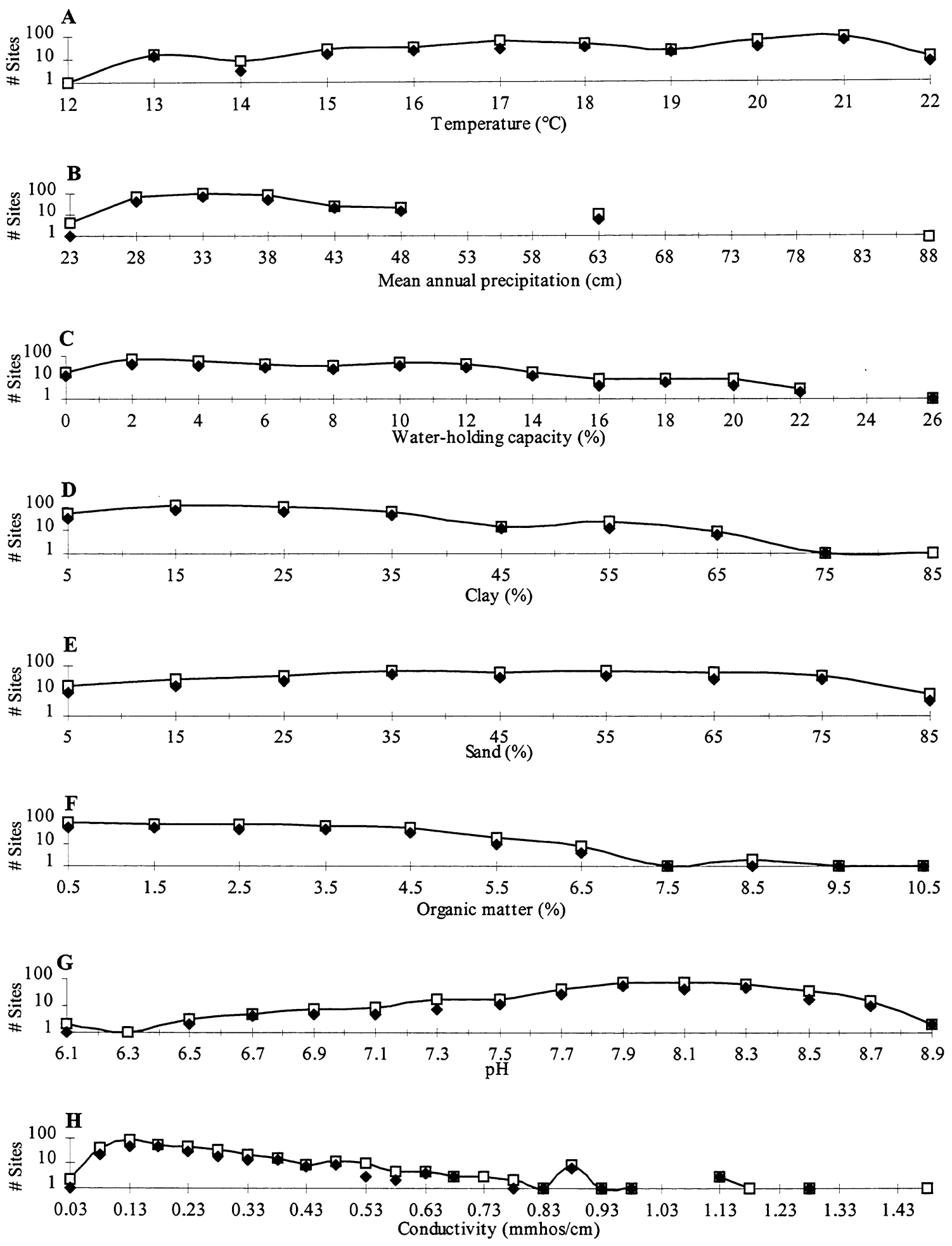

Figure 13.2. The distribution of Bromus inermis sites (solid diamonds) and all roadside sites (open squares) across nine site characteristics. Where the mean of sites occupied by Bromus inermis is significantly $(\mathrm{p}<0.05)$ different from the mean of all sites, both are shown in the upper right of the graph. 


\section{Bromus tectorum (Brte)}

Common name: cheatgrass

Family: Poaceae

Origin: Exotic. On roadsides from BOGR to PSME. Escaping BOGR to PSME.

Duration and Habit ${ }^{1}$ : Annual Grass, not vegetatively reproducing.

Environmental Type ${ }^{2}$ : Brte cover (\%) is highest in the BOGR, AGSP and PIPO types than the PSME type (Fig. 14.1A).

Temperature: Summer temperature does not differ between average Brte sites and average roadside sites (Fig. 14.2A).

Precipitation: Annual precipitation does not differ between average Brte sites and average roadside sites (Fig. 14.2B).

Water-holding capacity ${ }^{2}$ : WHC of average Brte sites is lower than average roadside sites (Fig. 14.C).

Clay: Clay does not differ between average Brte sites and average roadside sites (Fig. 14.2D).

Sand: Sand does not differ between average Brte sites and average roadside sites (Fig. 14.2E).

Organic matter: OM does not differ between average Brte sites and average roadside sites (Fig. 14.2F)

pH: pH does not differ between average Brte sites and average roadside sites (Fig. 14.2G).

Conductivity: Conductivity does not differ between average Brte sites and average roadside sites (Fig. 14.2H).

Position ${ }^{3}$ : On roadsides, Brte cover does not respond to position.

Aspect: Aspect has no effect on the performance of Brte (Fig. 14.1B).

\footnotetext{
${ }^{1}$ Refer to the introduction (p37) for a brief discussion (elaborated in Part 1) of each factor.

${ }^{2}$ Species presence varies significantly with this factor.

${ }^{3}$ Inslope/backslope effects cannot be determined from Figure 14.1B below.
}
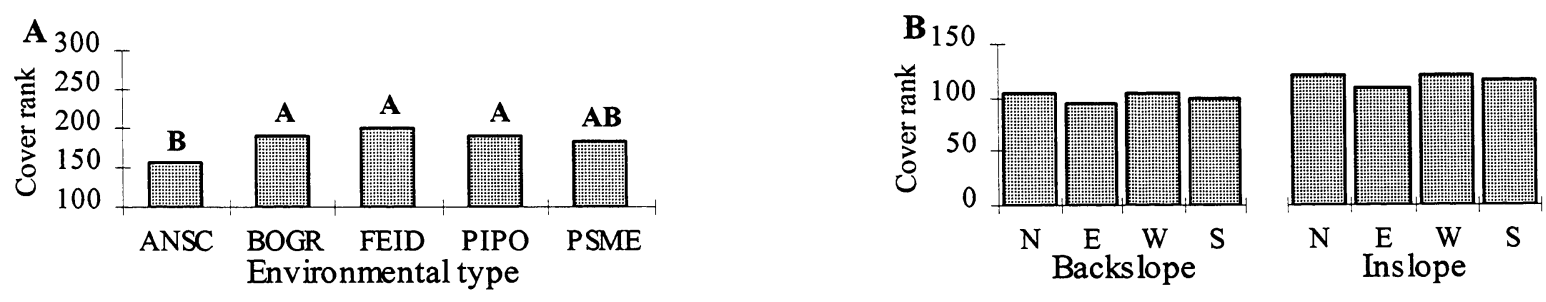

Figure 14.1. A) Relative performance of Bromus tectorum in five environmental types. B) Effect of position and aspect on the performance of Bromus tectorum. Categories sharing a letter are not significantly $(p<0.05)$ different. 

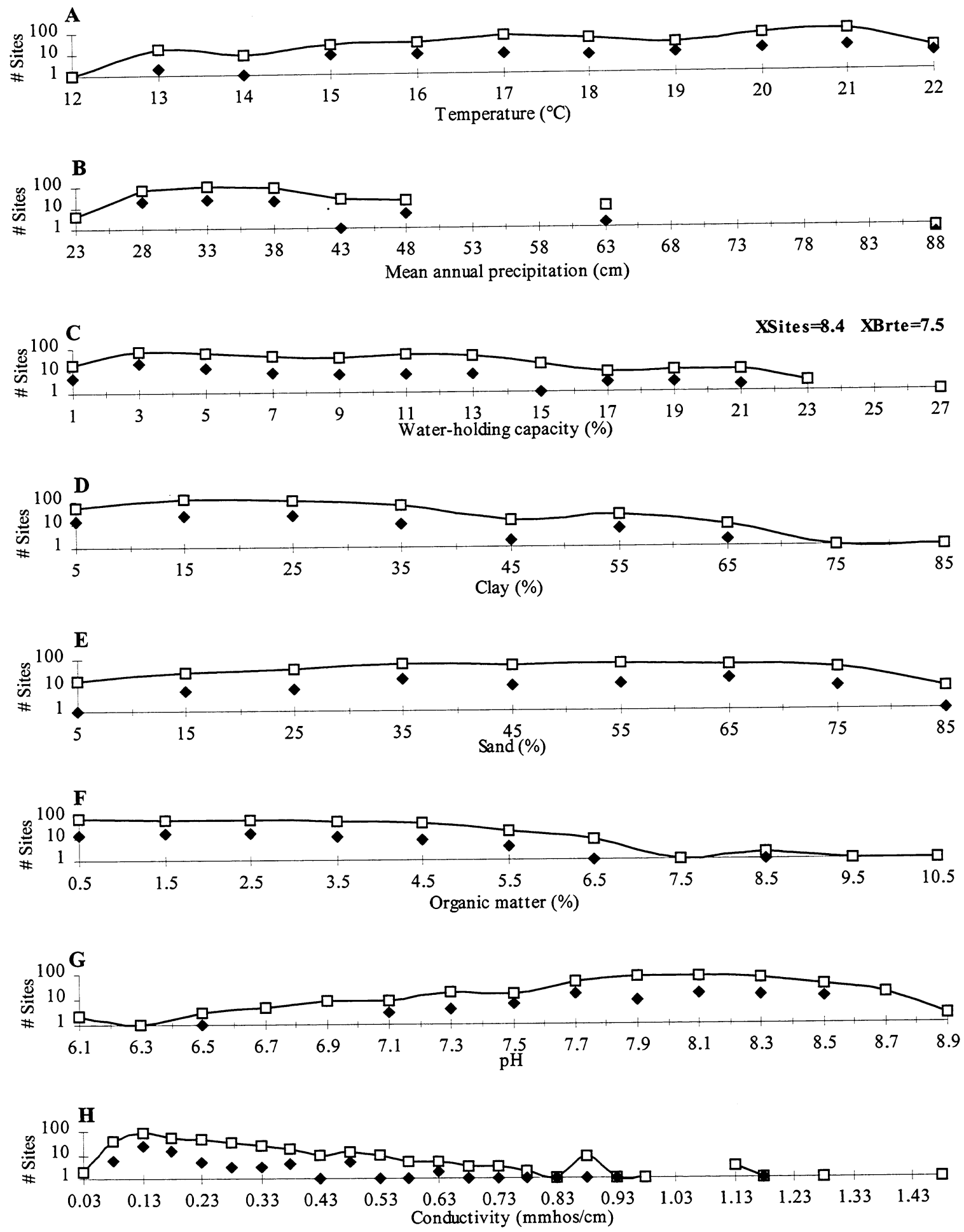

Figure 14.2. The distribution of Bromus tectorum sites (solid diamonds) and all roadside sites (open squares) across nine site characteristics. Where the mean of sites occupied by Bromus tectorum is significantly $(\mathrm{p}<0.05)$ different from the mean of all sites, both are shown in the upper right of the graph. 


\section{Centaurea maculosa (Cema)}

Common name: spotted knapweed

Family: Asteraceae

Origin: Exotic. On roadsides BOGR- low ABLA. Escaping BOGR-AGSP.

Duration and Habit ${ }^{1}$ : Bienniel Forb, not vegetatively reproducing.

Environmental type: Cema cover (\%) does not differ among types (Fig. 15.1A).

Temperature ${ }^{2}$ : Summer temperature at average Cema sites is lower than in average roadside sites (Fig. 15.2A).

Precipitation ${ }^{2}$ : Annual precipitation is higher at average Cema sites than at average roadside sites (Fig. 15.2B).

Water-holding capacity ${ }^{2}$ : WHC at average Cema sites is lower than at average roadside sites (Fig. 15.2C).

Clay $^{2}$ : Clay at average Cema sites is lower than average roadside sites (Fig. 15.2D).

Sand $^{2}$ : Sand at average Cema sites is higher than at average roadside sites (Fig. 15.2E).

Organic matter: OM does not differ between average Cema sites and average roadside sites (Fig. 15.2F).

$\mathbf{p H}^{2}: \mathrm{pH}$ in average Cema sites is lower than average roadside sites (Fig. 15.2G).

Conductivity $^{2}$ : Conductivity at average Cema sites is lower than average roadside sites (Fig. 15.2H).

Position ${ }^{3}$ : Cema performance seems not to respond to position.

Aspect: Cema performance seems not to respond to aspect (Fig. 15.1B)

\footnotetext{
${ }^{1}$ Refer to the introduction (p37) for a brief discussion (elaborated in Part 1) of each factor.

${ }^{2}$ Species presence varies significantly with this factor.

${ }^{3}$ Inslope/backslope effects cannot be determined from Figure 15.1B below
}
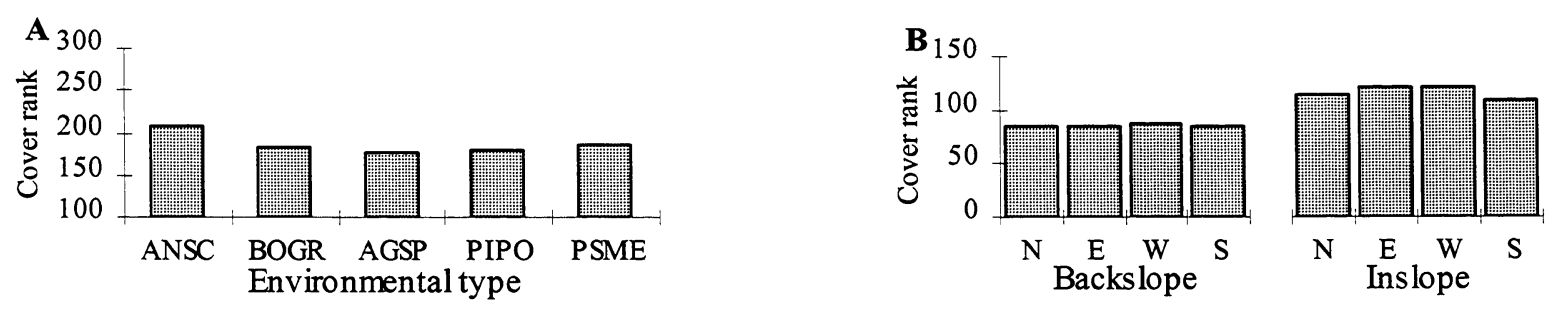

Figure 15.1. A) Relative performance of Centaurea maculosa in five environmental types. B) Effect of position and aspect on the performance of Centaurea maculosa. Categories sharing a letter are not significantly $(\mathrm{p}<0.05)$ different. 

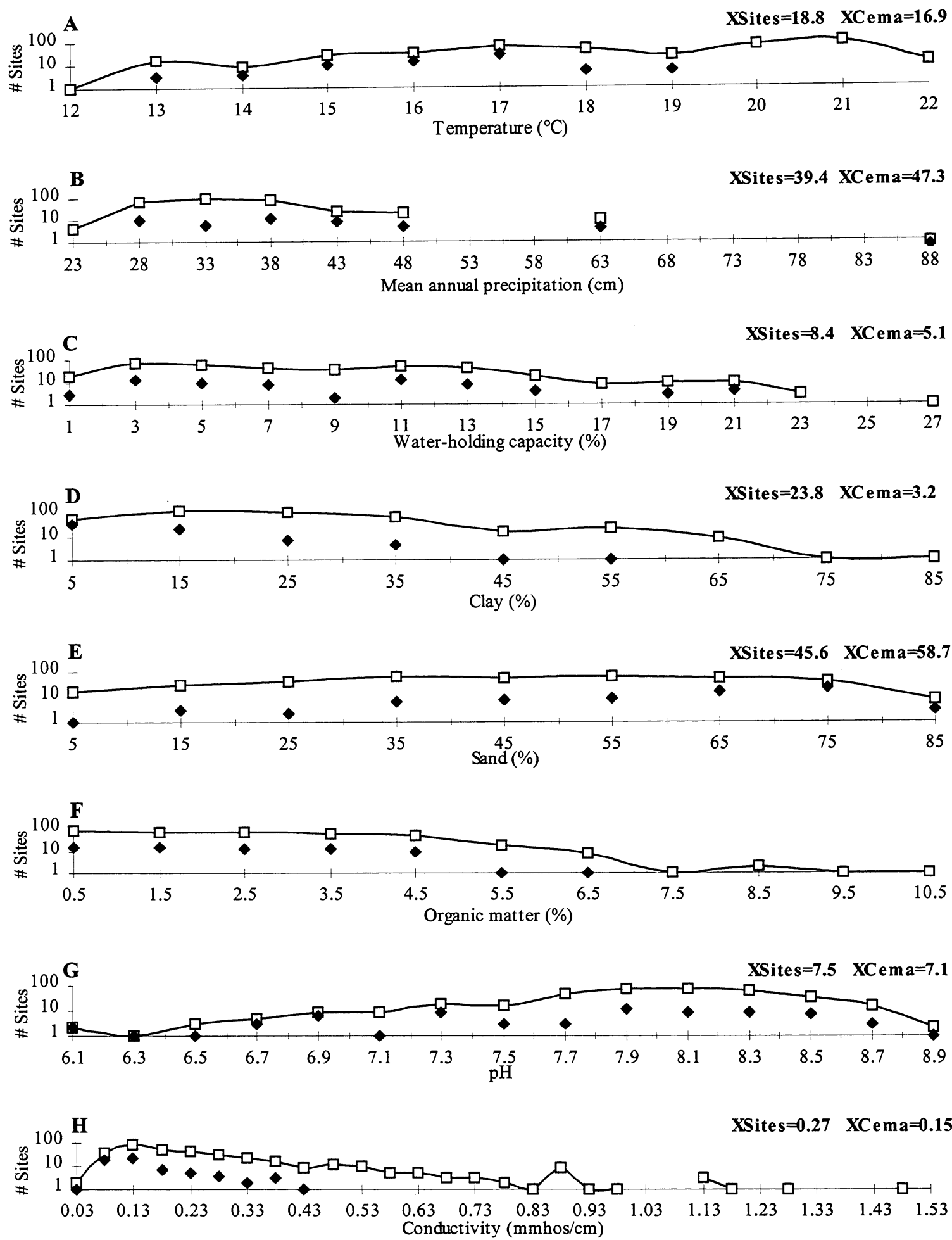

Figure 15.2. The distribution of Centaurea maculosa sites (solid diamonds) and all roadside sites (open squares) across nine site characteristics. Where the mean of sites occupied by Centaurea maculosa is significantly $(p<0.05)$ different from the mean of all sites, both are shown in the upper right of the graph. 


\section{Cirsium arvense (Ciar)}

Common name: Canada thistle

Family: Asteraceae

Origin: Exotic. On roadsides, AGSP- low ABLA. Escaping, high AGSP-POTR.

Duration and Habit ${ }^{1}$ : Perennial Forb, vegetatively reproducing.

Environmental type: Ciar cover (\%) does not differ between types (Fig. 16.1A)

Temperature: Summer temperature in average Ciar sites does not differ from average roadside sites (Fig. 16.2A).

Precipitation: Annual precipitation at average Ciar sites does not differ from average roadside sites (Fig. 16.2B)

Water-holding capacity: WHC does not differ between average Ciar sites and average roadside sites (Fig. 16.2C).

Clay: Clay does not differ between average Ciar sites and average roadside sites (Fig. 16.2D).

Sand: Sand does not differ between average Ciar sites and average roadside sites (Fig. 16.2E).

Organic matter: OM does not differ between average Ciar sites and average roadside sites (Fig. 16.2F).

pH: pH does not differ between average Ciar sites and average roadside sites (Fig. 16.2G).

Conductivity: Conductivity does not differ between average Ciar sites and average roadside sites (Fig. 16.2H).

Position ${ }^{3}$ : On roadsides, Ciar cover does not respond to position.

Aspect: Ciar performance is not affected by aspect (Fig 16.1B)

\footnotetext{
${ }^{1}$ Refer to the introduction (p37) for a brief discussion (elaborated in Part 1) of each factor.

${ }^{2}$ Species presence varies significantly with this factor.

${ }^{3}$ Inslope/backslope effects cannot be determined from Figure 16.1B below
}
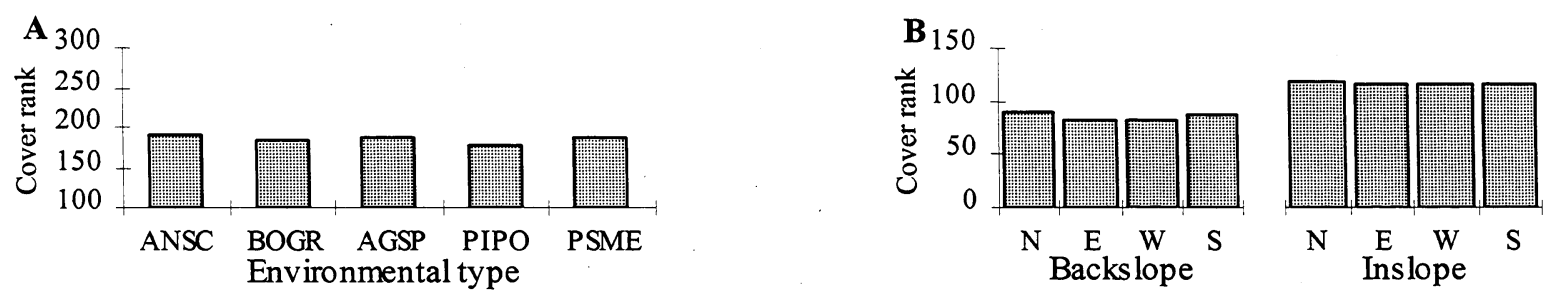

Figure 16.1. A) Relative performance of Cirsium arvense in five environmental types. B) Effect of position and aspect on the performance of Cirsium arvense. Categories sharing a letter are not significantly $(\mathrm{p}<0.05)$ different. 

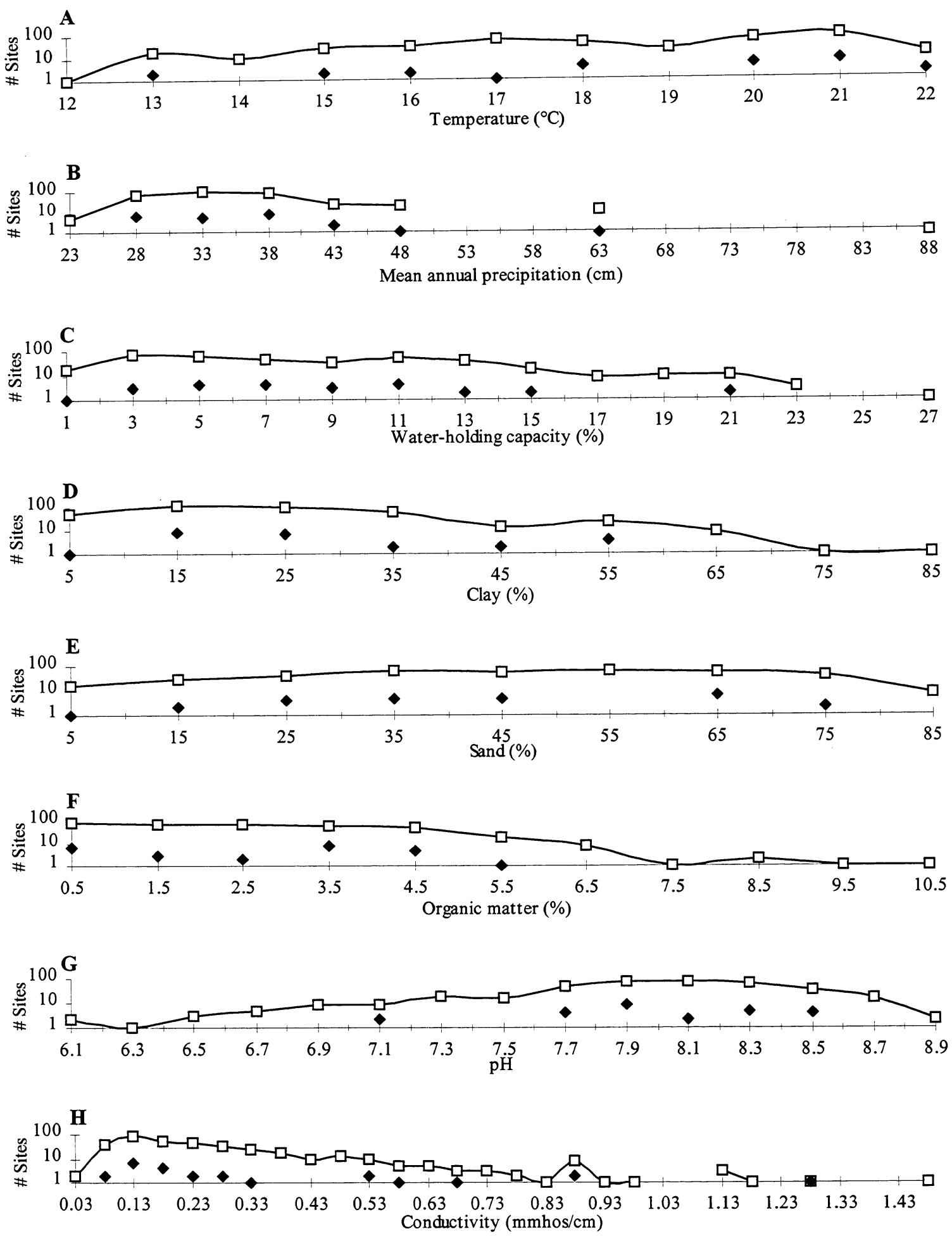

Figure 16.2. The distribution of Cirsium arvense sites (solid diamonds) and all roadside sites (open squares) across nine site characteristics. Where the mean of sites occupied by Cirsium arvense is significantly $(p<0.05)$ different from the mean of all sites, both are shown in the upper right of the graph. 


\section{Dactylis glomerata (Dagl)}

Common name: orchard-grass

Family: Poaceae

Origin: Exotic. On roadsides, AGSP-ABLA. Escaping PSME.

Duration and Habit ${ }^{1}$ : Perennial Grass, not vegetatively reproducing.

Environmental Type ${ }^{2}$ : Dagl cover (\%) is highest in the AGSP, PIPO and PSME types and lowest on ANSC and BOGR types (Fig. 17.1A)

Temperature ${ }^{2}$ : Summer temperature at average Dagl sites is lower than in average roadside sites (Fig. 17.2A).

Precipitation²: Annual precipitation at average Dagl sites is higher than at average roadside sites (Fig. 17.2B)

Water-holding capacity ${ }^{2}$ : WHC at average Dagl sites is lower than at average roadside sites (Fig. 17.2C).

Clay $^{2}$ : Clay at average Dagl sites is lower than at average roadside sites (Fig. 17.2D).

Sand $^{2}$ : Sand at average Dagl sites is higher than at average roadside sites (Fig. 17.2E).

Organic matter: OM does not differ between average Dagl sites and average roadside sites (Fig. 17.2F).

pH: $\mathrm{pH}$ does not differ between average Dagl sites and average roadside sites (Fig. 17.2G).

Conductivity: Conductivity at average Dagl sites does not differ from average roadside sites (Fig. 17.2H).

Position $^{2,3}$ : Dagl performs better on inslopes than backslopes.

Aspect: Though insignificant, Dagl may perform better on EW than NS slopes (Fig. 17.1B).

\footnotetext{
${ }^{1}$ Refer to the introduction (p37) for a brief discussion (elaborated in Part 1) of each factor.

${ }^{2}$ Species presence varies significantly with this factor.

${ }^{3}$ Inslope/backslope effects cannot be determined from Figure 17.1B below.
}
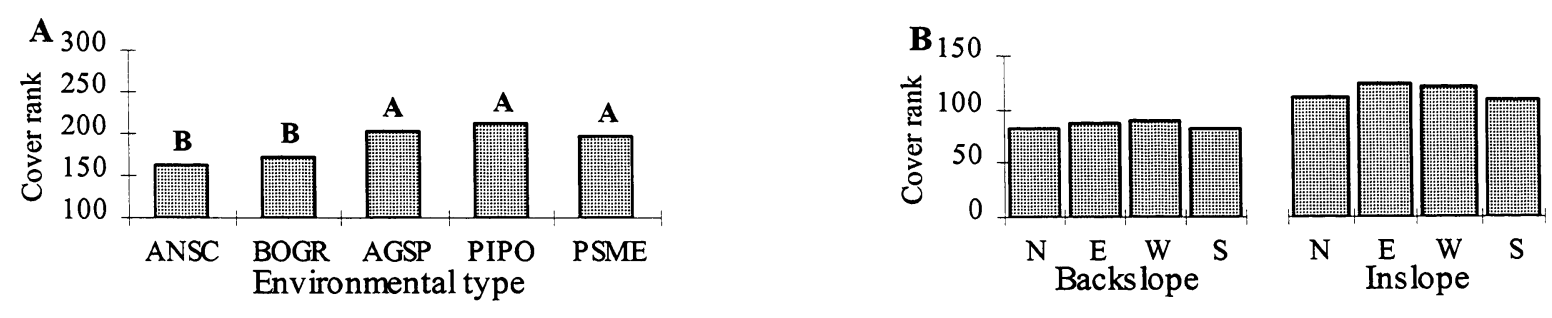

Figure 17.1. A) Relative performance of Dactylis glomerata in five environmental types. B) Effect of position and aspect on the performance of Dactylis glomerata. Categories sharing a letter are not significantly $(\mathrm{p}<0.05)$ different. 

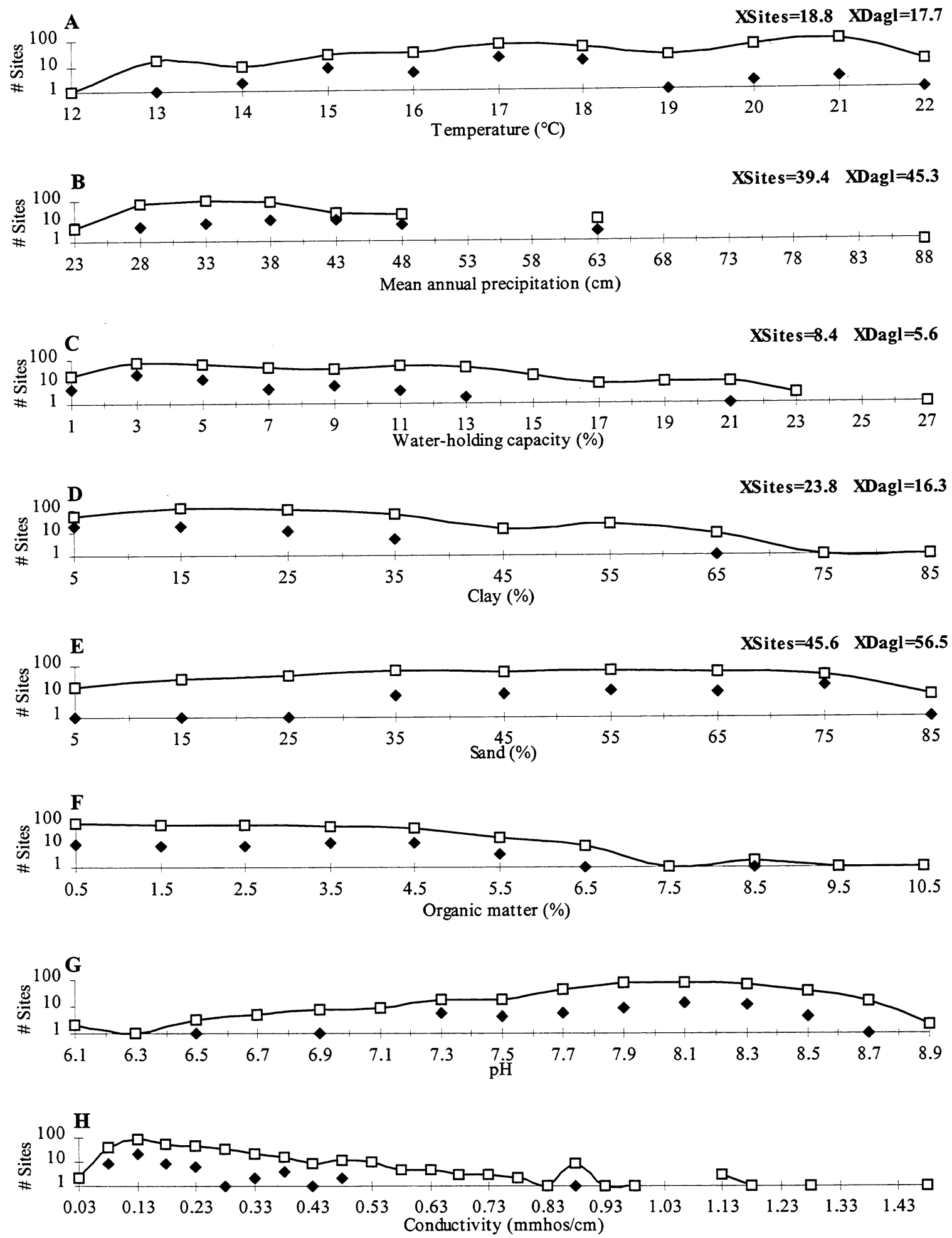

Figure 17.2. The distribution of Dactylis glomerata sites (solid diamonds) and all roadside sites (open squares) across nine site characteristics. Where the mean of sites occupied by Dactylis glomerata is significantly $(\mathrm{p}<0.05)$ different from the mean of all sites, both are shown in the upper right of the graph. 


\section{Dalea purpurea (Dapu)}

Common name: purple prairie flower

Family: Asteraceae

Origin: Native.

Duration and Habit' ${ }^{1}$ : Perennial Forb, not vegetatively reproducing.

Environmental type: Dapu cover (\%) does not differ among types (Fig. 18.1A).

Temperature: Summer temperature does not differ between average Dapu sites and average roadside sites (Fig. 18.2A).

Precipitation: Annual precipitation does not differ between average Dapu sites and average roadside sites (Fig. 18.2B).

Water-holding capacity: WHC does not differ between average Dapu sites and average roadside sites (Fig. 18.2C)

Clay: Clay does not differ between average Dapu sites and average roadside sites (Fig. 18.2D).

Sand $^{2}$ : Sand at average Dapu sites is lower than at average roadside sites (Fig. 18.2E).

Organic matter: OM does not differ between average Dapu sites and average roadside sites (Fig. 18.2F).

$\mathbf{p H}^{2}: \mathrm{pH}$ at average Dapu sites is higher than at average roadside sites (Fig. 18.2G).

Conductivity: Conductivity does not differ between average Dapu sites and average roadside sites (Fig. 18.2H).

Position $^{2,3}$ : Dapu performs better on backslopes than inslopes.

Aspect: Dapu has no aspect preference (Fig. 18.1B)

\footnotetext{
${ }^{1}$ Refer to the introduction (p37) for a brief discussion (elaborated in Part 1) of each factor.

${ }^{2}$ Species presence varies significantly with this factor.

${ }^{3}$ Inslope/backslope effects cannot be determined from Figure 18.1B below
}
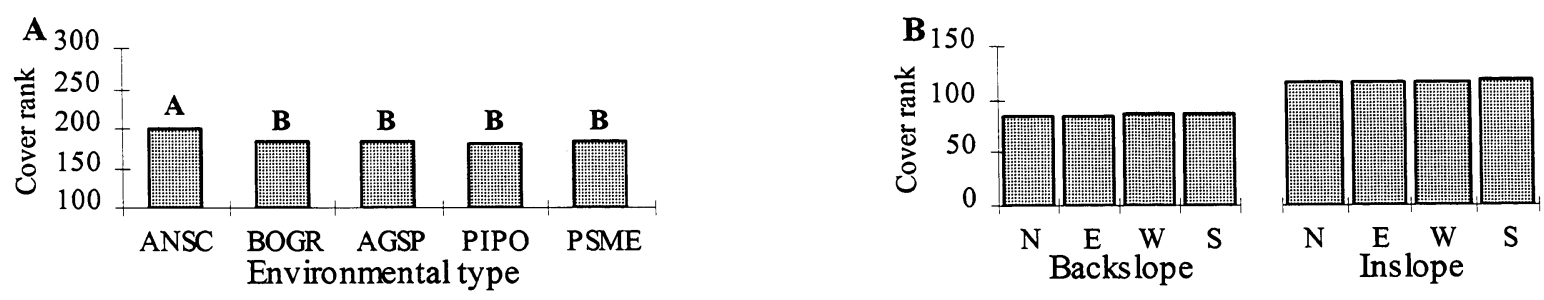

Figure 18.1. A) Relative performance of Dalea purpurea in five environmental types. B) Effect of position and aspect on the performance of Dalea purpurea. Categories sharing a letter are not significantly $(p<0.05)$ different 

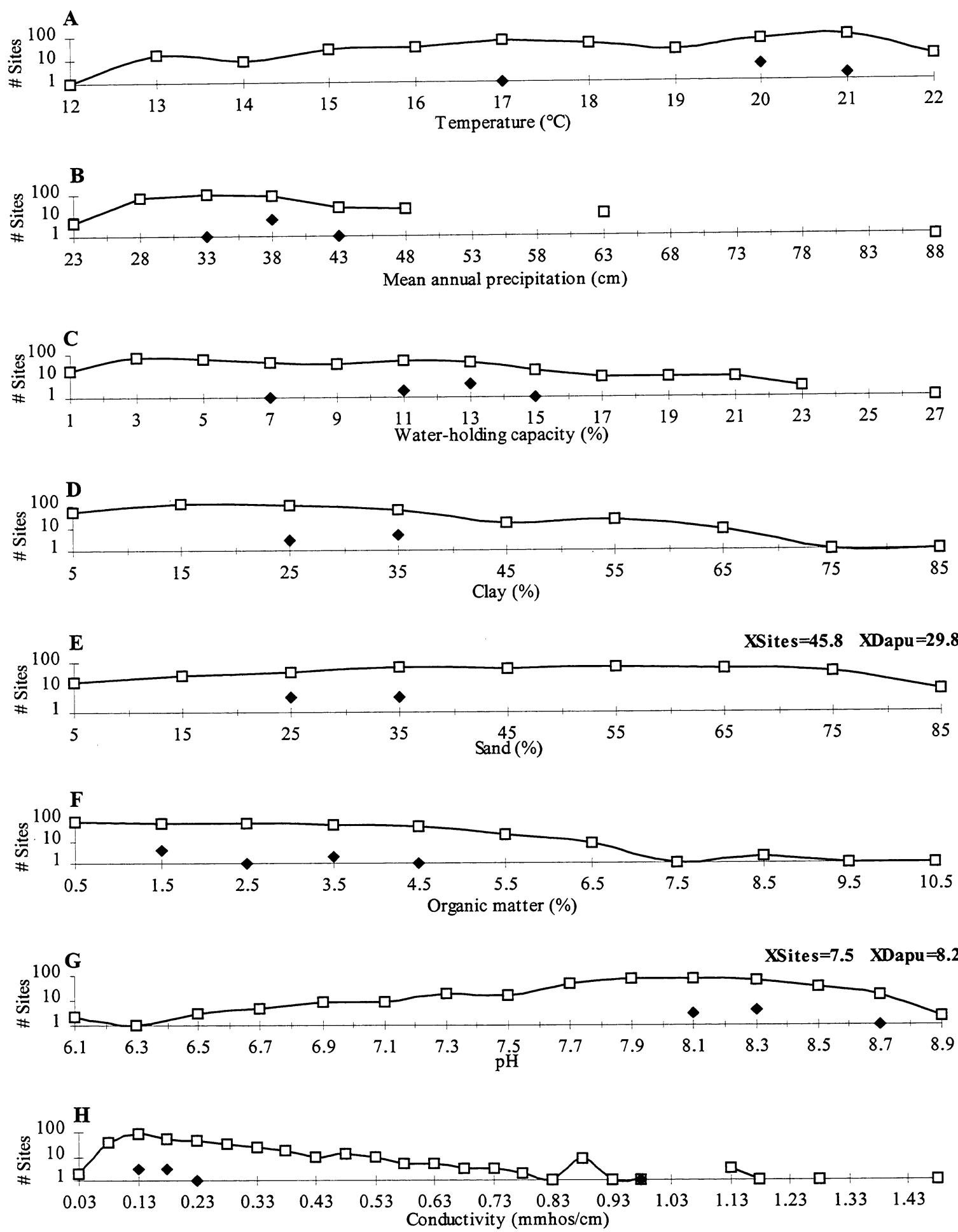

Figure 18.2. The distribution of Dalea purpurea sites (solid diamonds) and all roadside sites (open squares) across nine site characteristics. Where the mean of sites occupied by Dalea purpurea is significantly $(\mathrm{p}<0.05)$ different from the mean of all sites, both are shown in the upper right of the graph. 


\section{Festuca idahoensis (Feid)}

Common name: Idaho fescue

Family: Poaceae

Origin: Native.

Duration and Habit': Perennial Grass, not vegetatively reproducing.

Environmental type ${ }^{2}$ : Feid cover (\%) is highest in PIPO and PSME sites and lowest in ANSC and BOGR types (Fig. 19.1A).

Temperature ${ }^{2}$ : Summer temperature at average Feid sites is lower than at average roadside sites (Fig. 19.2A).

Precipitation $^{2}$ : Annual precipitation at average Feid sites is higher than at average roadside sites (Fig. 19.2B).

Water-holding capacity ${ }^{2}$ : WHC at average Feid sites is lower than at average roadside sites (Fig. 19.2C).

Clay² $^{2}$ Clay at average Feid sites is lower than at average roadside sites (Fig. 19.2D).

Sand $^{2}$ : Sand at average Feid sites is higher than at average roadside sites (Fig. 19.2E).

Organic matter: OM does not differ between average Feid sites and average roadside sites (Fig. 19.2F).

pH: $\mathrm{pH}$ does not differ between average Feid sites and average roadside sites (Fig. 19.2G).

Conductivity $^{2}$ : Conductivity at average Feid sites is lower than in average roadside sites (Fig. 19.2H).

Position $^{2,3}$ : Feid performs better on inslopes than backslopes.

Aspect: Feid does not respond differentially to aspect (Fig. 19.1B).

\footnotetext{
${ }^{1}$ Refer to the introduction (p37) for a description of each factor.

${ }^{2}$ Species presence varies significantly with this factor.

${ }^{3}$ Inslope/backslope effects cannot be determined from Figure 19.1B below.
}
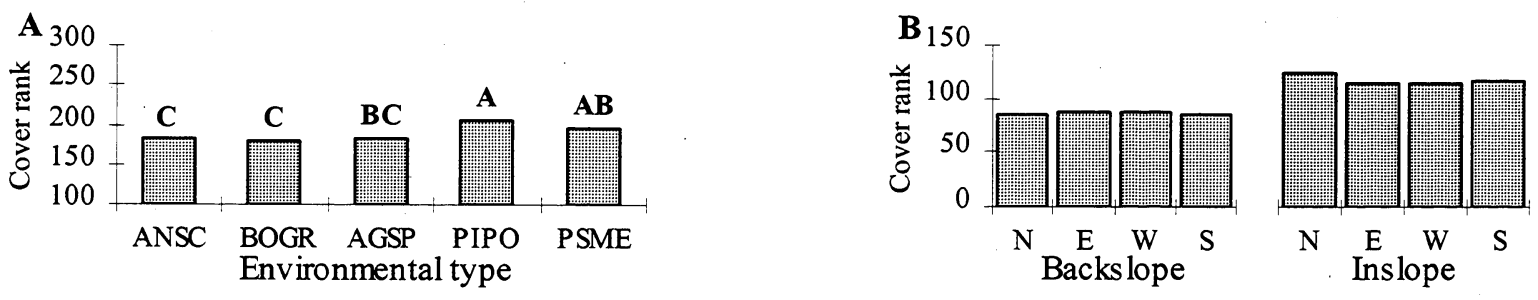

Figure 19.1. A) Relative performance of Festuca idahoensis in five environmental types. B) Effect of position and aspect on the performance of Festuca idahoensis. Categories sharing a letter are not significantly $(\mathrm{p}<0.05)$ different. 

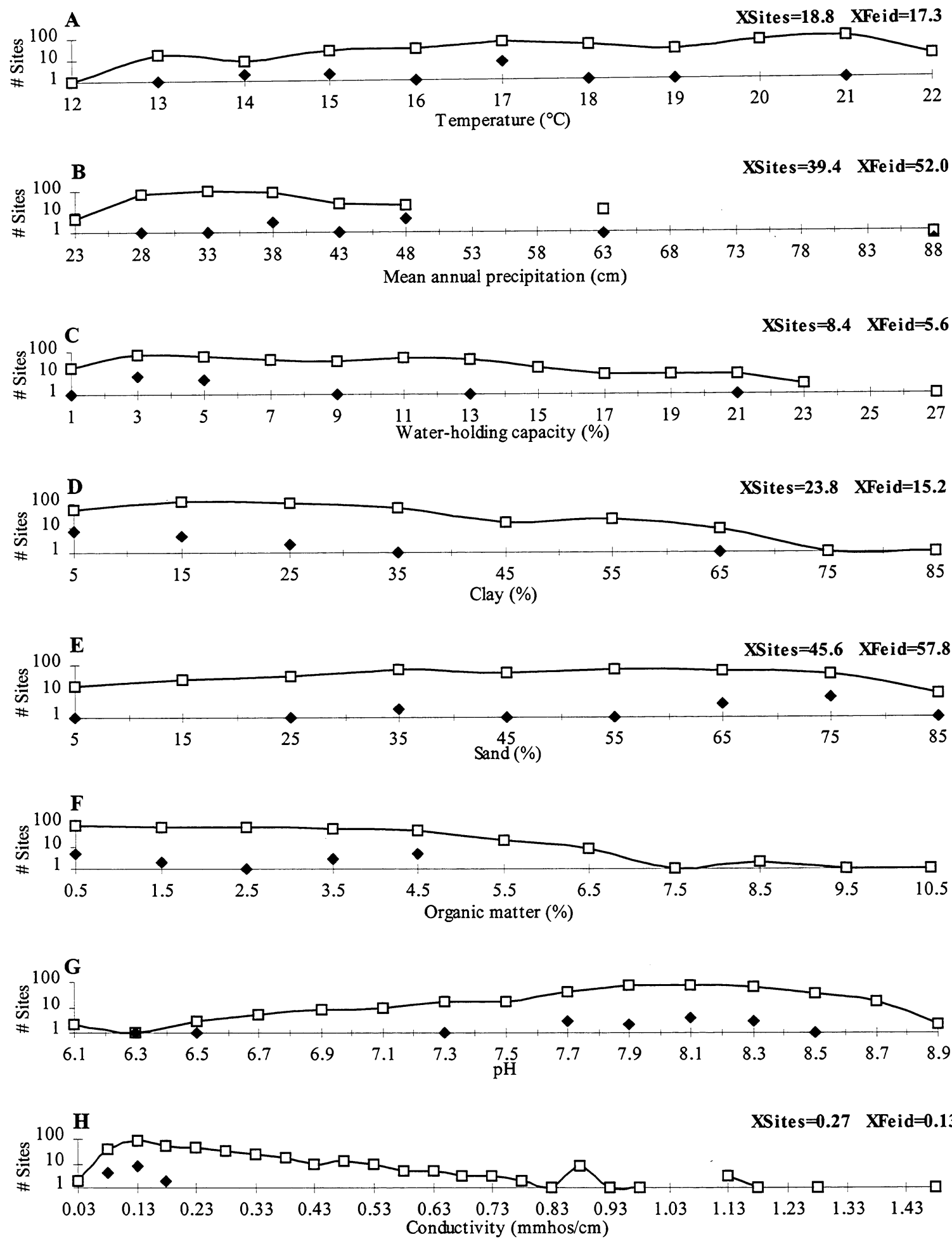

Figure 19.2. The distribution of Festuca idahoensis sites (solid diamonds) and all roadside sites (open squares) across nine site characteristics. Where the mean of sites occupied by Festuca idahoensis is significantly $(\mathrm{p}<0.05)$ different from the mean of all sites, both are shown in the upper right of the graph. 


\section{Festuca ovina (Feov)}

Common name: sheep fescue

Family: Poaceae

Origin: Native.

Duration and Habit': Perennial Grass, not vegetatively reproducing.

Environmental type: Feov cover (\%) is highest in PIPO types and lowest in the ANSC type (Fig. 20.1A).

Temperature ${ }^{2}$ : Summer temperature at average Feov sites is lower than at average roadside sites (Fig. 20.2A).

Precipitation $^{2}$ : Annual precipitation at average Feov sites is greater than at average roadside sites (Fig. 20.2B).

Water-holding capacity ${ }^{2}$ : WHC at average Feov sites is lower than at average roadside sites (Fig. 20.2C).

Clay $^{2}$ : Clay at average Feov sites is lower than at average roadside sites (Fig. 20.2D).

Sand $^{2}$ : Sand at average Feov sites is higher than at average roadside sites (Fig. 20.2E).

Organic matter ${ }^{2}: \mathrm{OM}$ in average Feov sites is lower than at average roadside sites (Fig. 20.2F).

pH: $\mathrm{pH}$ does not differ between average Feov sites and average roadside sites (Fig. 20.2G).

Conductivity ${ }^{2}$ : Conductivity at average Feov sites is lower than at average roadside sites (Fig. 20.2H).

Position': On roadsides, Feov cover does not respond to position.

Aspect ${ }^{2}$ : Feov cover is slightly higher on EW than NS slopes (20.1B).

${ }^{1}$ Refer to the introduction (p37) for a description of each factor.

${ }^{2}$ Species presence varies significantly with this factor.

${ }^{3}$ Inslope/backslope effects cannot be determined from Figure 20.1B below.
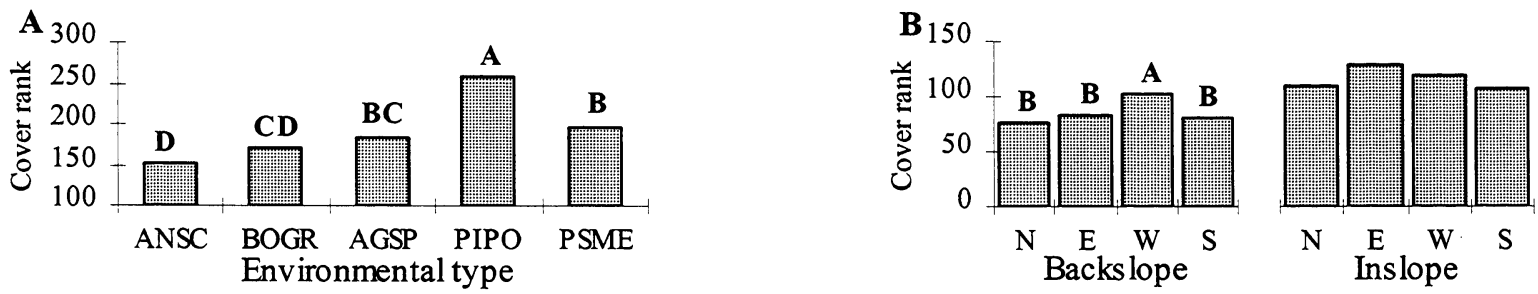

Figure 20.1. A) Relative performance of Festuca ovina in five environmental types. B) Effect of position and aspect on the performance of Festuca ovina. Categories sharing a letter are not significantly $(\mathrm{p}<0.05)$ different. 

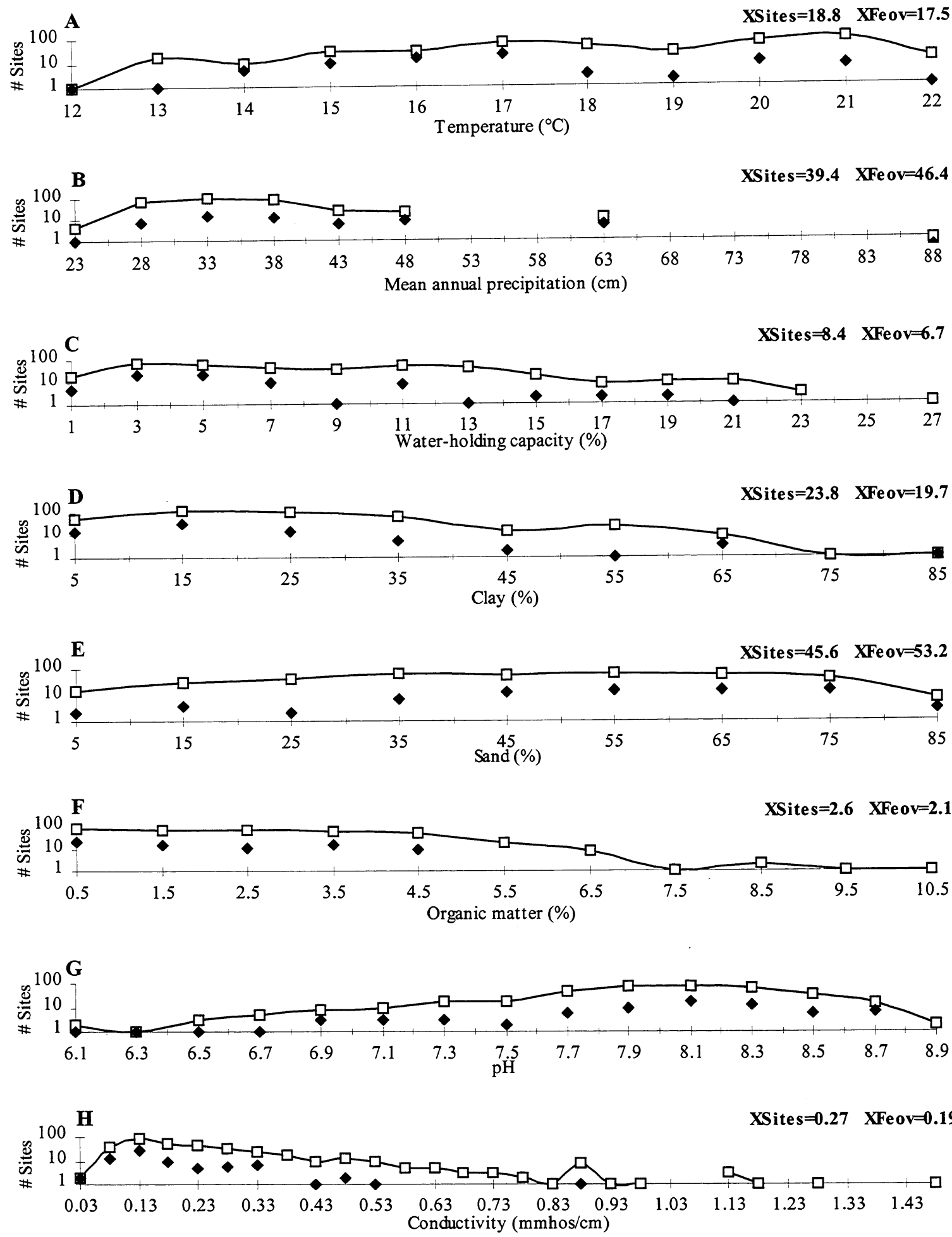

Figure 20.2. The distribution of Festuca ovina sites (solid diamonds) and all roadside sites (open squares) across nine site characteristics. Where the mean of sites occupied by Festuca ovina is significantly $(\mathrm{p}<0.05)$ different from the mean of all sites, both are shown in the upper right of the graph. 


\section{Festuca scabrella (Fesc)}

Common name: rough fescue

Family: Poaceae

Origin: Native.

Duration and Habit ${ }^{1}$ : Perennial Grass, not vegetatively reproducing.

Environmental Type²: Fesc cover (\%) is highest in the AGSP type (Fig. 21.1A).

Temperature: Summer temperature does not differ between average Fesc sites and average roadside sites (Fig. 21.2A).

Precipitation: Annual precipitation at average Fesc sites does not differ from precipitation at average roadside sites (Fig. 21.2B).

Water-holding capacity: WHC does not differ between average Fesc sites and average roadside sites (Fig. 21.2C).

Clay: Clay does not differ between average Fesc sites and average roadside sites (Fig. 21.2D).

Sand: Sand does not differ between average Fesc sites and average roadside sites (Fig. 21.2E).

Organic matter: OM does not differ between average Fesc sites and average roadside sites (Fig. 21.2F).

pH: pH does not differ between average Fesc sites and average roadside sites (Fig. 21.2G).

Conductivity: Conductivity does not differ between average Fesc sites and average roadside sites (Fig. $21.2 \mathrm{H})$.

Position $^{3}$ : On roadsides, Fesc cover does not respond to position.

Aspect: Fesc does not respond differentially to aspect (Fig 21.1B).

\footnotetext{
${ }^{1}$ Refer to the introduction (p37) for a description of each factor.

${ }^{2}$ Species presence varies significantly with this factor.

${ }^{3}$ Inslope/backslope effects cannot be determined from Figure 21.1B below.
}
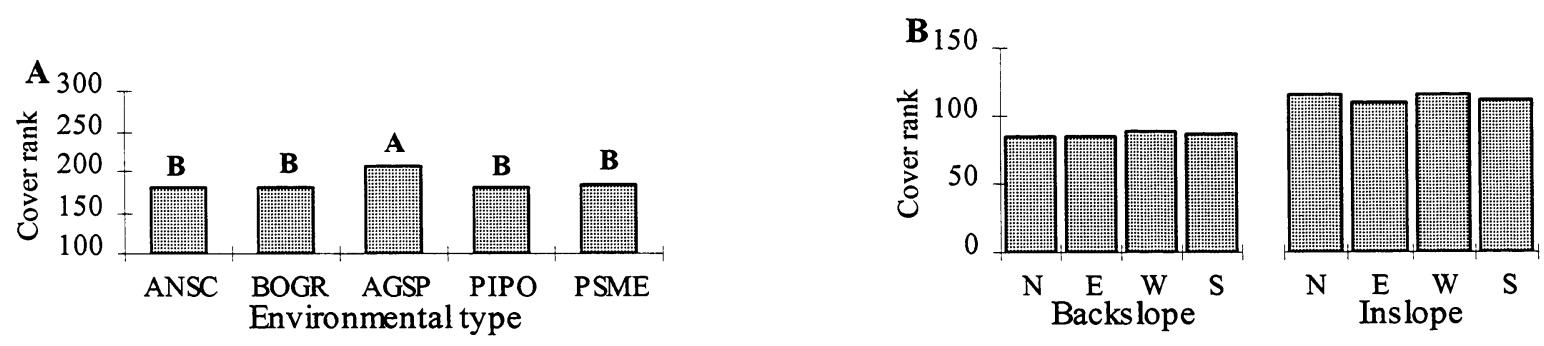

Figure 21.1. A) Relative performance of Festuca scabrella in five environmental types. B) Effect of position and aspect on the performance of Festuca scabrella. Categories sharing a letter are not significantly $(p<0.05)$ different. 

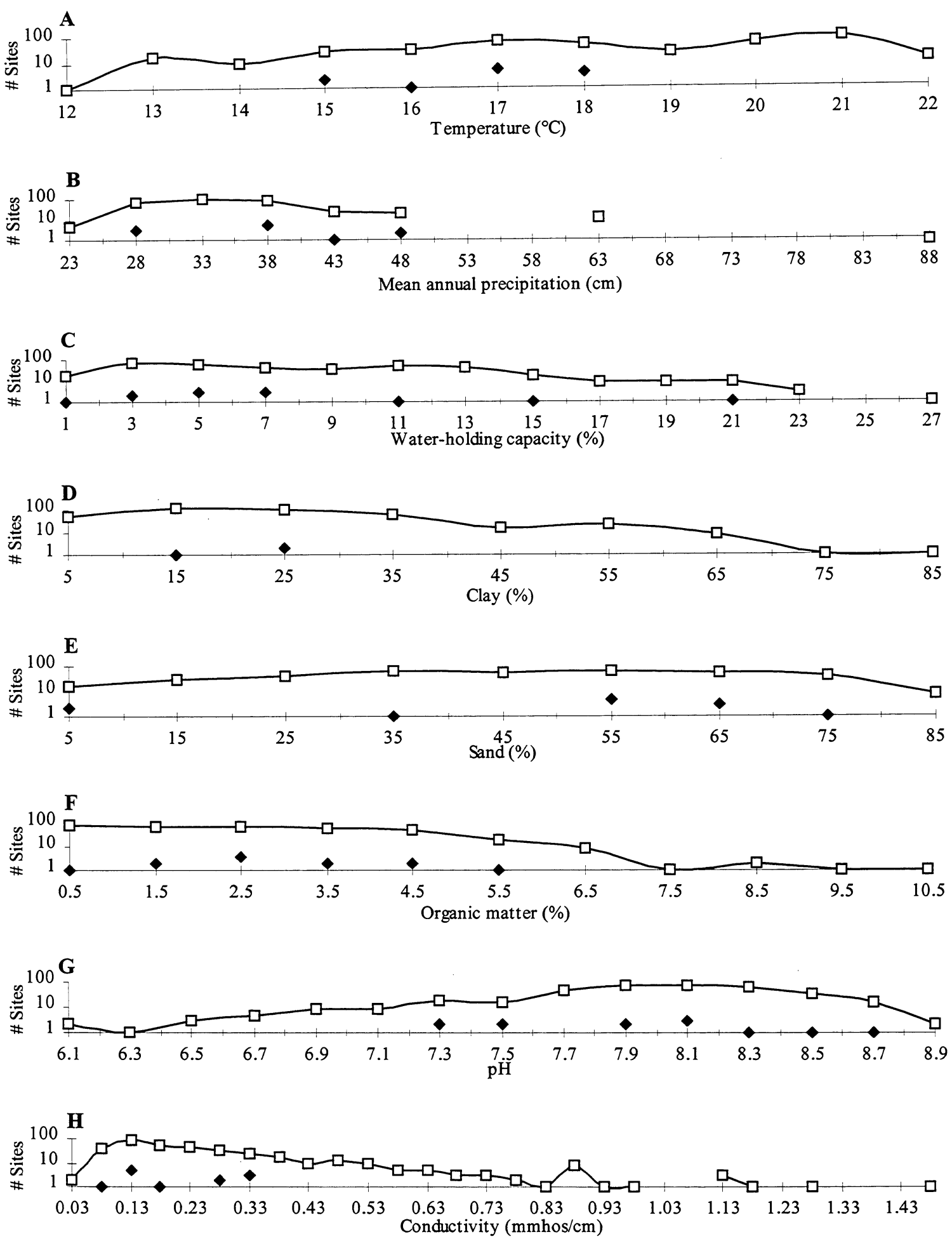

Figure 21.2. The distribution of Festuca scabrella sites (solid diamonds) and all roadside sites (open squares) across nine site characteristics. Where the mean of sites occupied Festuca scabrella is significantly $(p<0.05)$ different from the mean of all sites, both are shown in the upper right of the graph. 


\section{Gaura coccinea (Gaco)}

Common name: scarlet gaura

Family: Onagraceae

Origin: Native.

Duration and Habit ${ }^{1}$ : Perennial Forb, not vegetatively reproducing.

Environmental type: Gaco cover (\%) does not differ among types (Fig. 22.1A).

Temperature: Summer temperature does not differ between average Gaco sites and average roadside sites (Fig. 22.2A).

Precipitation: Annual precipitation at average Gaco sites does not differ from average roadside sites (Fig. 22.2B).

Water-holding capacity: WHC does not differ between average Gaco sites and average roadside sites (Fig. 22.2C).

Clay: Clay does not differ between average Gaco sites and average roadside sites (Fig. 22.2D).

Sand: Sand does not differ between average Gaco sites and average roadside sites (Fig. 22.2E).

Organic matter: OM at average Gaco sites does not differ from average roadside sites (Fig. 22.2F).

pH: pH in average Gaco sites does not differ from average roadside sites (Fig. 22.2G).

Conductivity: Conductivity at average Gaco sites does not differ from average roadside sites (Fig. 22.2H).

Position $^{2,3}$ : Gaco performs better on backslopes than inslopes.

Aspect: Gaco does not respond differentially to aspect (Fig 22.1B)

\footnotetext{
${ }^{1}$ Refer to the introduction (p37) for a description of each factor.

${ }^{2}$ Species presence varies significantly with this factor.

${ }^{3}$ Inslope/backslope effects cannot be determined from Figure 22.1B below
}
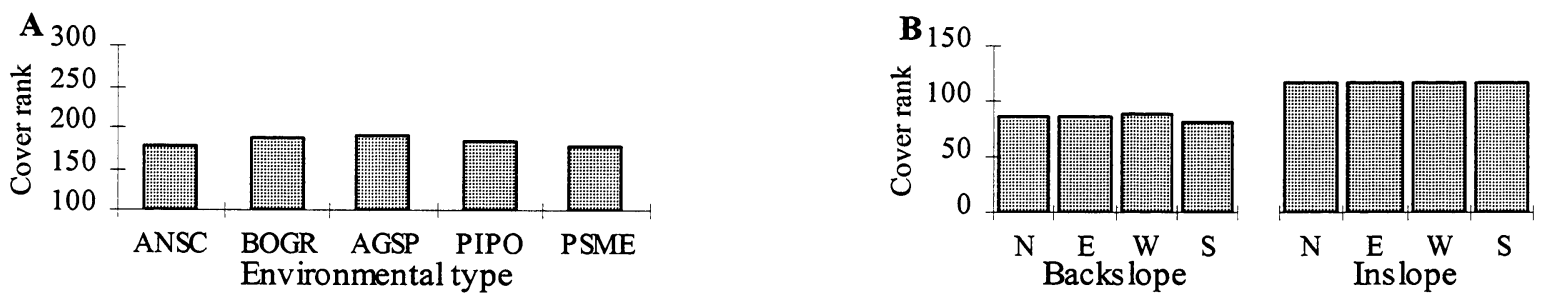

Figure 22.1. A) Relative performance of Gaura coccinea in five environmental types. B) Effect of position and aspect on the performance of Gaura coccinea. Categories sharing a letter are not significantly $(\mathrm{p}<0.05)$ different. 

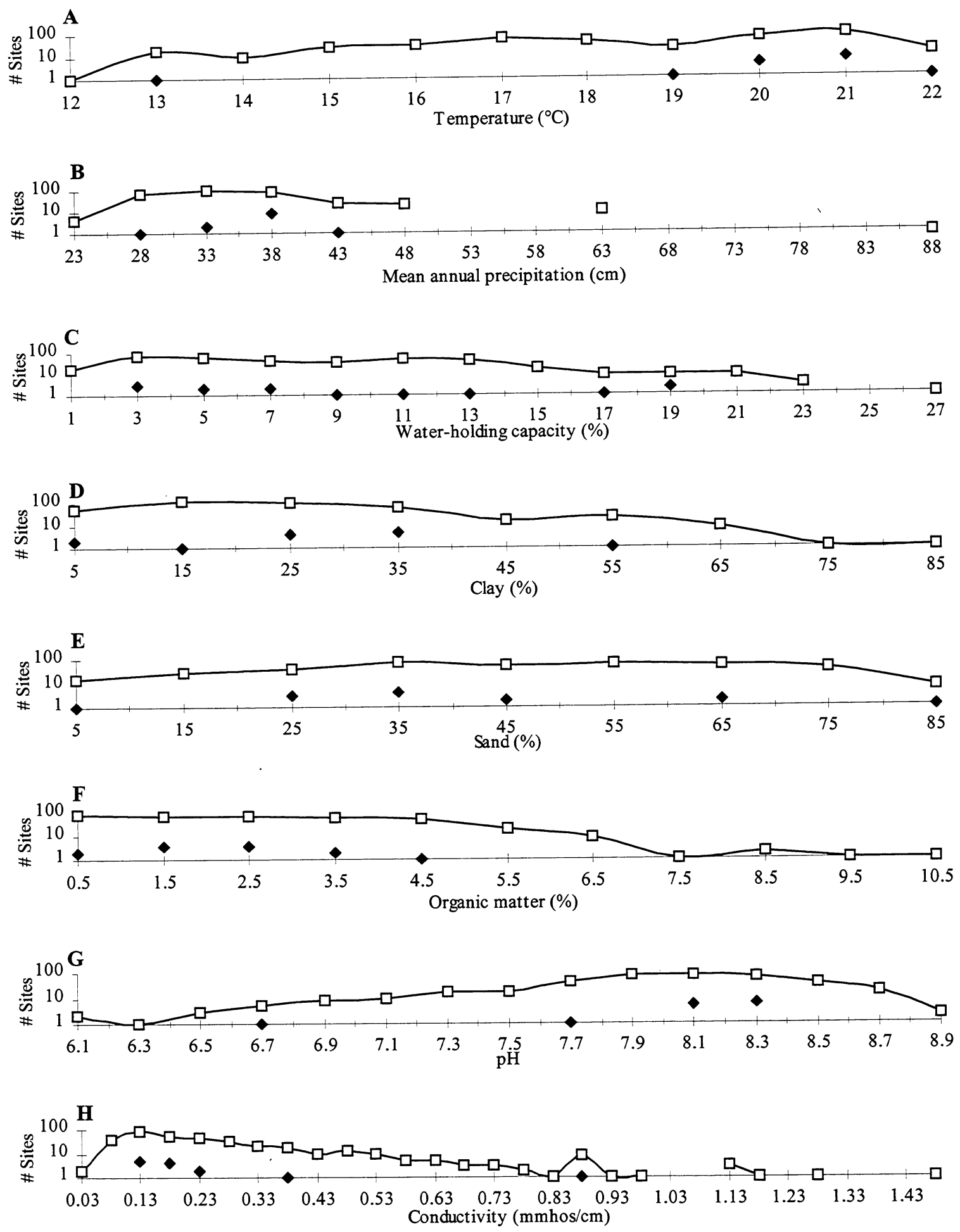

Figure 22.2 The distribution of Gaura coccinea sites (solid diamonds) and all roadside sites (open squares) across nine site characteristics. Where the mean of sites occupied by Gaura coccinea is significantly $(p<0.05)$ different from the mean of all sites, both are shown in the upper right of the graph. 


\section{Gutierrezia sarothrae (Gusa)}

Common name: broom snakeweed

Family: Asteraceae

Origin: Native.

Duration and Habit': Perennial Shrub, not vegetatively reproducing.

Environmental type: Gusa cover (\%) does not differ between types (Fig. 23.1A)

Temperature: Summer temperature does not differ between average Gusa sites and average roadside sites (Fig. 23.2A).

Precipitation ${ }^{2}$ : Annual precipitation was less at average Gusa sites than at average roadside sites (Fig. 23.2B).

Water-holding capacity: WHC does not differ between average Gusa sites and average roadside sites (Fig. 23.2C).

Clay $^{2}$ : Clay at average Gusa sites is higher than at average roadside sites (Fig. 23.2D).

Sand $^{2}$ : Sand at average Gusa sites is lower than at average roadside sites (Fig. 23.2E).

Organic matter': ${ }^{2} \mathrm{OM}$ at average Gusa sites is lower than at average roadside sites (Fig. 23.2F).

pH: $\mathrm{pH}$ does not differ between average Gusa sites and average roadside sites (Fig. 23.2G).

Conductivity: Conductivity does not differ between average Gusa and average roadside sites (Fig. 23.2H).

Position ${ }^{2,3}$ : Gusa performs better on backslopes than inslopes.

Aspect $^{2}$ : On backslopes, Gusa performance is slightly better on NS than EW slopes (Fig. 23.1B)

\footnotetext{
${ }^{1}$ Refer to the introduction (p37) for a description of each factor.

${ }^{2}$ Species presence varies significantly with this factor.

${ }^{3}$ Inslope/backslope effects cannot be determined from Figure 23.1B below
}
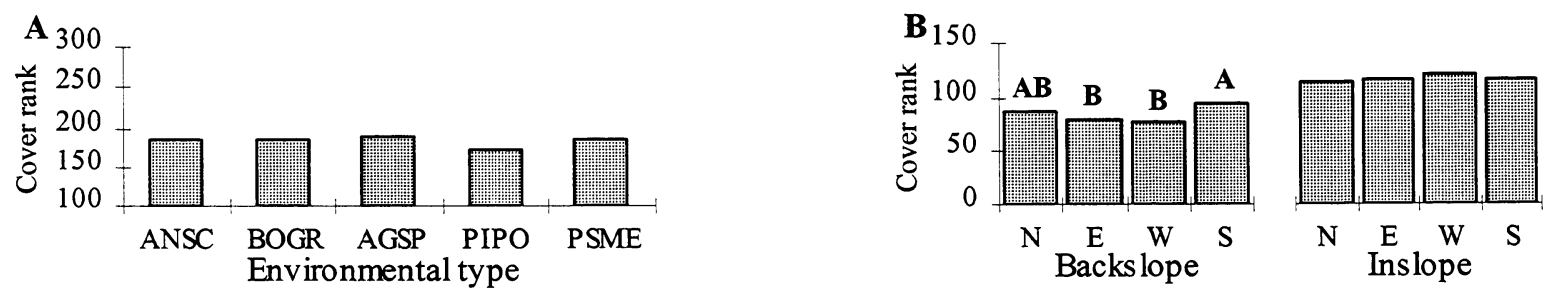

Figure 23.1. A) Relative performance of Gutierrezia sarothrae in five environmental types. B) Effect of position and aspect on the performance of Gutierrezia sarothrae. Categories sharing a letter are not significantly $(p<0.05)$ different. 

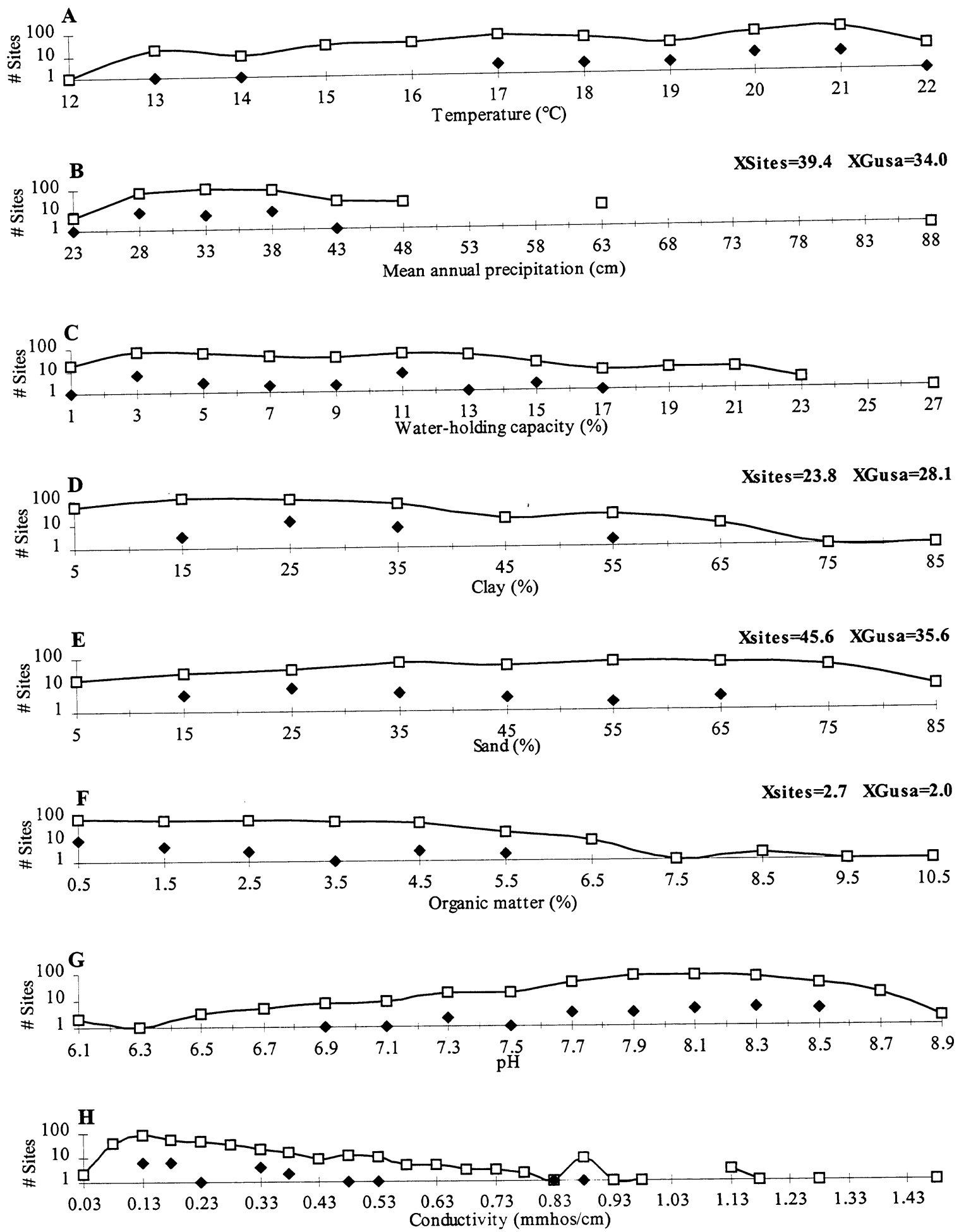

Figure 23.2. The distribution of Gutierrezia sarothrae sites (solid diamonds) and all roadside sites (open squares) across nine site characteristics. Where the mean of sites occupied by Gutierrezia sarothrae is significantly $(\mathrm{p}<0.05)$ different from the mean of all sites, both are shown in the upper right of the graph. 


\section{Heterotheca villosa (Hevi)}

Common name: hairy gold-aster

Family: Asteraceae

Origin: Native.

Duration and Habit ${ }^{1}$ : Perennial Forb, not vegetatively reproducing.

Environmental type: Hevi cover (\%) does not differ between types (Fig. 24.1A)

Temperature ${ }^{2}$ : Summer temperature at average Hevi sites is higher than at average roadside sites (Fig. 24.2A).

Precipitation ${ }^{2}$ : Annual precipitation at average Hevi sites is less than that at average roadside sites (Fig. 24.2B).

Water-holding capacity: WHC does not differ between average Hevi sites and average roadside sites (Fig. 24.2C).

Clay: Clay does not differ between average Hevi sites and average roadside sites (Fig. 24.2D).

Sand: Sand does not differ between average Hevi sites and average roadside sites (Fig. 24.2E).

Organic matter: OM does not differ between average Hevi sites and average roadside sites (Fig. 24.2F).

pH: $\mathrm{pH}$ does not differ between average Hevi and average roadside sites (Fig. 24.2G).

Conductivity: Conductivity does not differ between average Hevi sites and average roadside sites (Fig. 24.2H).

Position ${ }^{3}$ : On roadsides, Hevi cover does not respond to position.

Aspect $^{2}$ : On inslopes, Hevi may perform slightly better on NS than EW slopes (Fig 24.1B).

\footnotetext{
${ }^{1}$ Refer to the introduction (p37) for a description of each factor.

${ }^{2}$ Species presence varies significantly with this factor.

${ }^{3}$ Inslope/backslope effects cannot be determined from Figure 24.1B below.
}
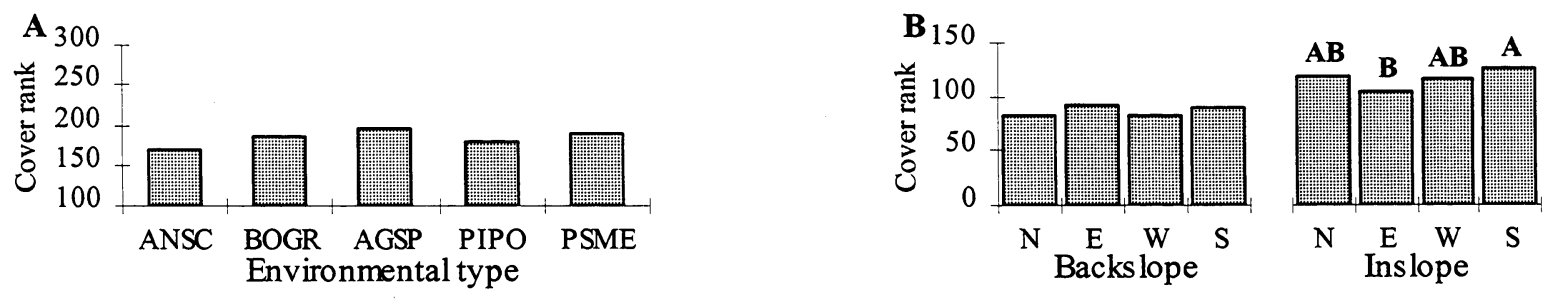

Figure 24.1. A) Relative performance of Heterotheca villosa in five environmental types. B) Effect of position and aspect on the performance of Heterotheca villosa. Categories sharing a letter are not significantly $(\mathrm{p}<0.05)$ different. 

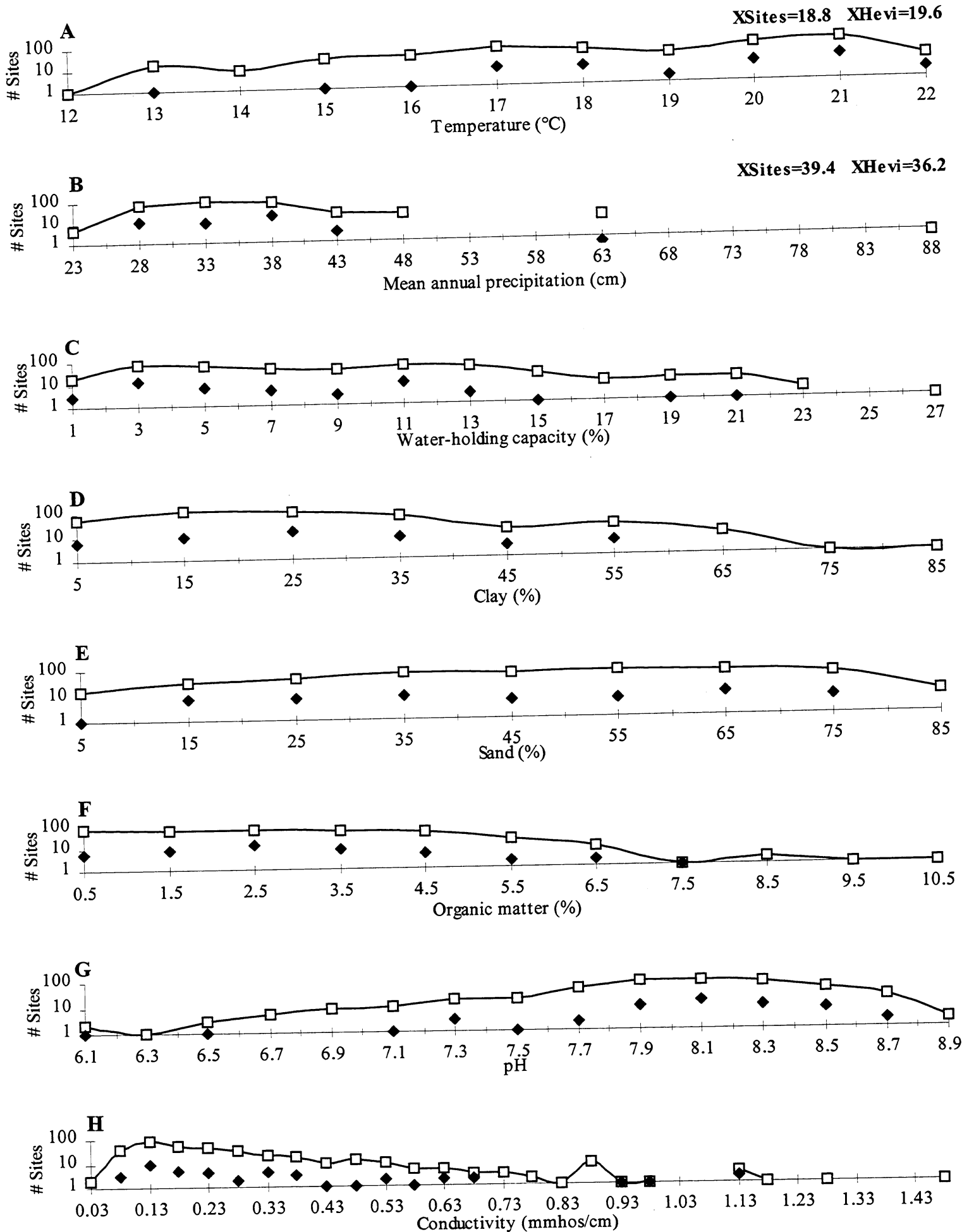

Figure 24.2. The distribution of Heterotheca villosa sites (solid diamonds) and all roadside sites (open squares) across nine site characteristics. Where the mean of sites occupied by Heterotheca villosa is significantly $(\mathrm{p}<0.05)$ different from the mean of all sites, both are shown in the upper right of the graph. 


\section{Hordeum jubatum (Hoju)}

Common name: foxtail barley

Family: Poaceae

Origin: Native.

Duration and Habit ${ }^{1}$ : Perennial Grass, not vegetatively reproducing.

Environmental Type ${ }^{2}$ : Hoju cover (\%) is highest in the BOGR and PIPO types, and lower in ANSC, AGSP and PSME types (Fig. 25.1A)

Temperature ${ }^{2}$ : Summer temperature at average Hoju sites is higher than at average roadside sites (Fig. 25.2A)

Precipitation: Annual precipitation at average Hoju sites is not different from average roadside sites (Fig. 25.2B).

Water-holding capacity: WHC does not differ between average Hoju sites and average roadside sites (Fig. 25.2C).

Clay: Clay does not differ between average Hoju sites and average roadside sites (Fig. 25.2D).

Sand: Sand does not differ between average Hoju sites and average roadside sites (Fig. 25.2E).

Organic matter: OM does not differ between Hoju sites and average roadside sites (Fig. 25.2F).

pH: pH does not differ between average Hoju sites and average roadside sites (Fig. 25.2G).

Conductivity $^{2}$ : Conductivity at average Hoju sites is higher than at average roadside sites (Fig. 25.2H).

Position ${ }^{3}$ : On roadsides, Hoju cover does not respond to position.

Aspect: Hoju does not respond differentially to aspect (Fig. 25.1B).

\footnotetext{
${ }^{1}$ Refer to the introduction (p37) for a description of each factor.

${ }^{2}$ Species presence varies significantly with this factor.

${ }^{3}$ Inslope/backslope effects cannot be determined from Figure 25.1B below
}
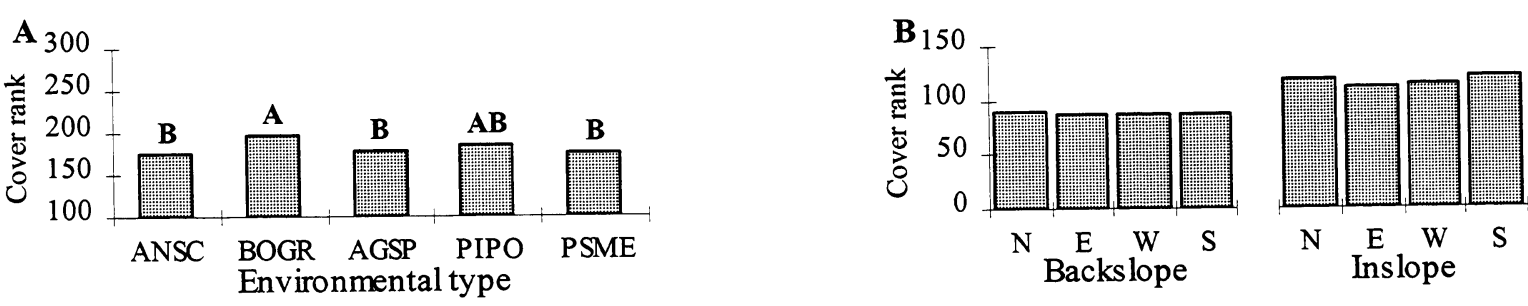

Figure 25.1. A) Relative performance of Hordeum jubatum in five environmental types. B) Effect of position and aspect on the performance of Horduem jubatum. Categories sharing a letter are not significantly $(\mathrm{p}<0.05)$ different. 

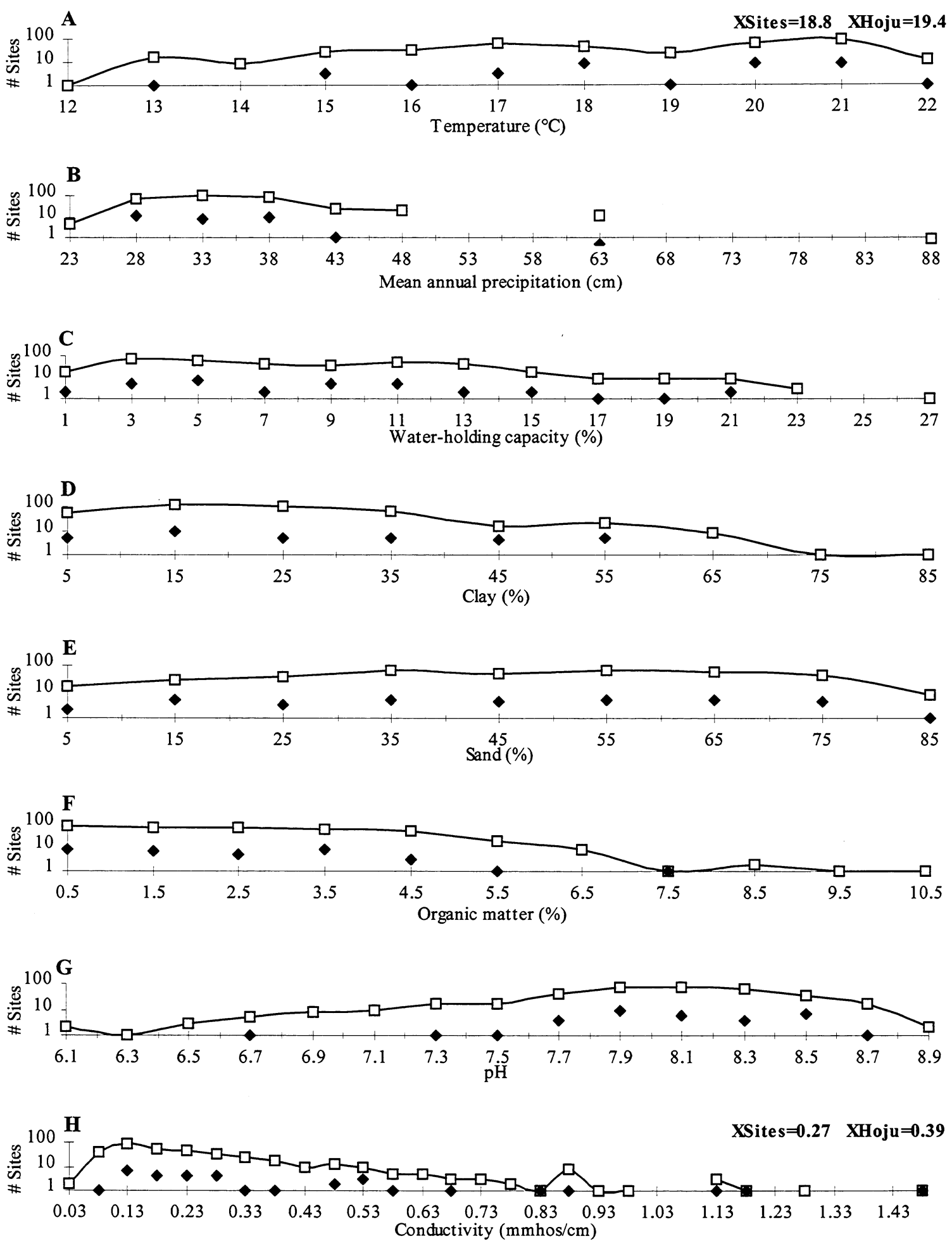

Figure 25.2. The distribution of Hordeum jubatum sites (solid diamonds) and all roadside sites (open squares) across nine site characteristics. Where the mean of sites occupied by Hordeum jubatum is significantly $(p<0.05)$ different from the mean of all sites, both are shown in the upper right of the graph. 


\section{Koelera nitida (Koni)}

Common name: prairie junegrass

Family: Poaceae

Origin: Native.

Duration and Habit ${ }^{1}$ : Perennial Grass, not vegetatively reproducing.

Environmental Type ${ }^{2}$ : Koni cover (\%) is highest in the BOGR and PSME types and lowest in ANSC, AGSP and PIPO (Fig. 26.1A)

Temperature: Summer temperature at average Koni sites does not differ from average roadside sites (Fig. 26.2A).

Precipitation²: Annual precipitation at average Koni sites is less than that at average roadside sites (Fig. 26.2B).

Water-holding capacity: WHC does not differ between average Koni sites and average roadside sites (Fig. 26.2C).

Clay: Clay does not differ between average Koni sites and average roadside sites (Fig. 26.2D).

Sand: Sand does not differ between average Koni sites and average roadside sites (Fig. 26.2E).

Organic matter: OM does not differ between average Koni sites and average roadside sites (Fig. 26.2F).

pH: pH does not differ between average Koni sites and average roadside sites (Fig. 26.2G).

Conductivity $^{2}$ : Conductivity at average Koni sites is higher than at average roadside sites (Fig. 26.2H).

Position $^{2,3}$ : Koni performs better on backslopes than on inslopes.

Aspect $^{2}$ : Despite statistics, Koni shows little response to aspect (Fig. 26.1B)

\footnotetext{
${ }^{1}$ Refer to the introduction (p37) for a description of each factor.

${ }^{2}$ Species presence varies significantly with this factor.

${ }^{3}$ Inslope/backslope effects cannot be determined from Figure 26.1B below
}
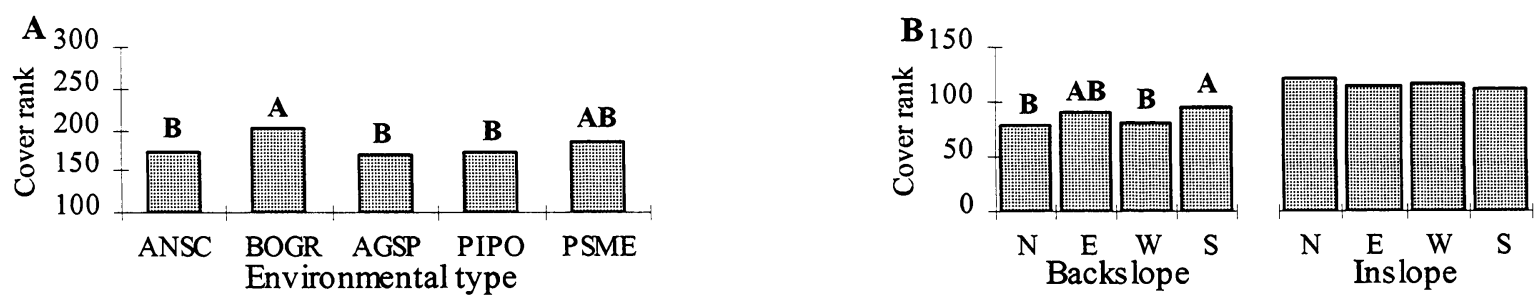

Figure 26.1. A) Relative performance of Koeleri nitida in five environmental types. B) Effect of position and aspect on the performance of Koeleri nitida. Categories sharing a letter are not significantly $(\mathrm{p}<0.05)$ different 

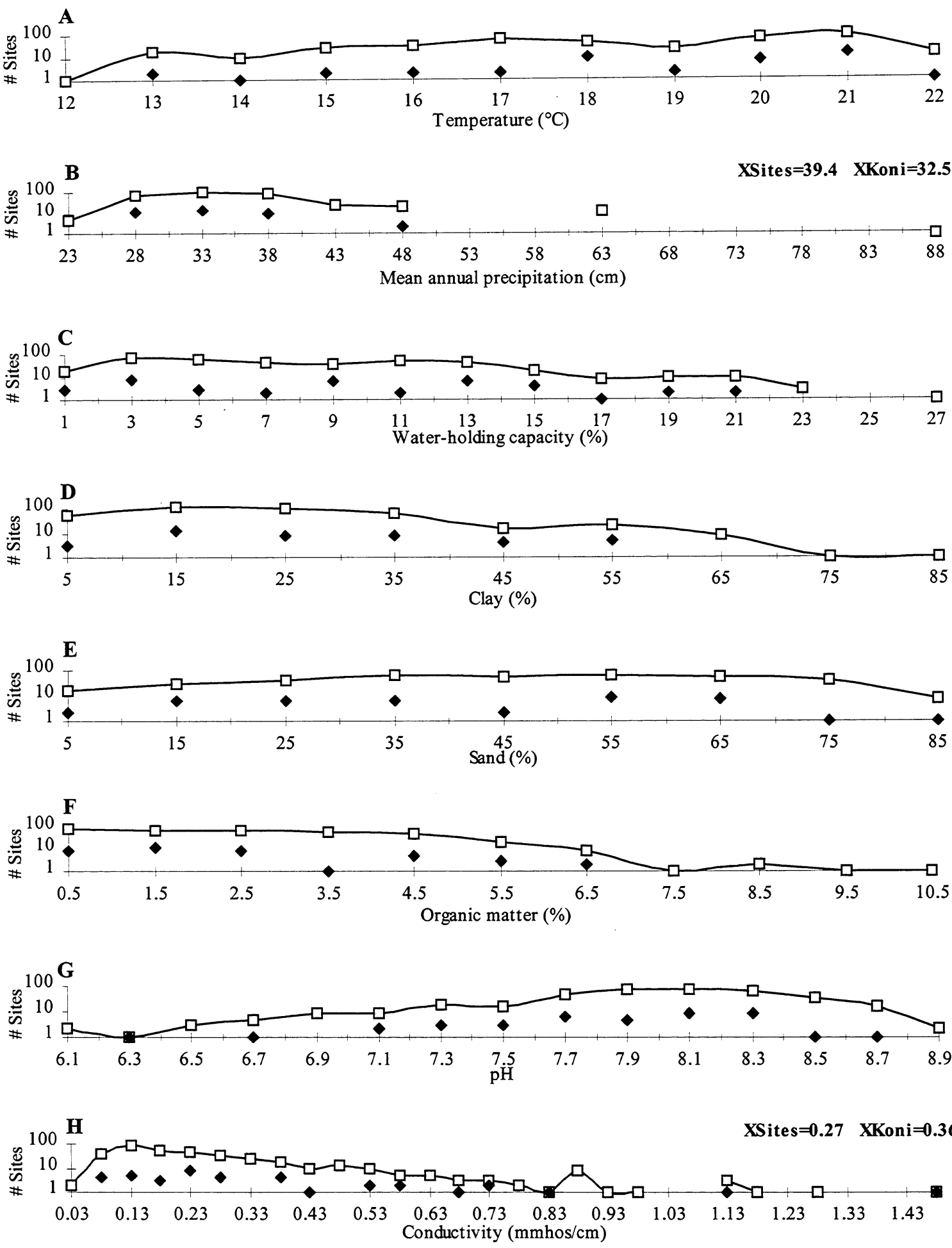

Figure 26.2. The distribution of Koeleri nitida sites (solid diamonds) and all roadside sites (open squares) across nine site characteristics. Where mean of sites occupied by Koeleri nitida is significantly $(p<0.05)$ different from the mean of all sites, both are shown in the upper right of the graph. 


\section{Kochia scoparia (Kosc)}

Common name: summer cypress

Family: Chenopodiaceae

Origin: Exotic. On roadsides, BOGR and PSME. Escaping in BOGR.

Duration and Habit ${ }^{1}$ : Forb, not vegetatively reproducing.

Environmental Type ${ }^{2}$ : Kosc cover (\%) is highest in the AGSP type (Fig. 27.1A)

Temperature: Summer temperature does not differ between average Kosc sites and average roadside sites (Fig. 27.2A).

Precipitation ${ }^{2}$ : Annual precipitation at average Kosc sites is lower than at average roadside sites (Fig. 27.2B).

Water-holding capacity: WHC does not differ between average Kosc sites and average roadside sites (Fig. 27.2C).

Clay: Clay does not differ between average Kosc sites and average roadside sites (Fig. 27.2D).

Sand: Sand does not differ between average Kosc sites and average roadside sites (Fig. 27.2E).

Organic matter: OM does not differ between average Kosc sites and average roadside sites (Fig. 27.2F).

pH: $\mathrm{pH}$ does not differ between average Kosc sites and average roadside sites (Fig. 27.2G).

Conductivity: Conductivity at average Kosc sites does not differ from average roadside sites (Fig. 27.2H).

Position ${ }^{3}$ : On roadsides, Kosc cover does not respond to position.

Aspect: Kosc performance is not affected by aspect (Fig 27.1B).

\footnotetext{
${ }^{1}$ Refer to the introduction (p37) for a description of each factor.

${ }^{2}$ Species presence varies significantly with this factor.

${ }^{3}$ Inslope/backslope effects cannot be determined from Figure 27.1B below
}
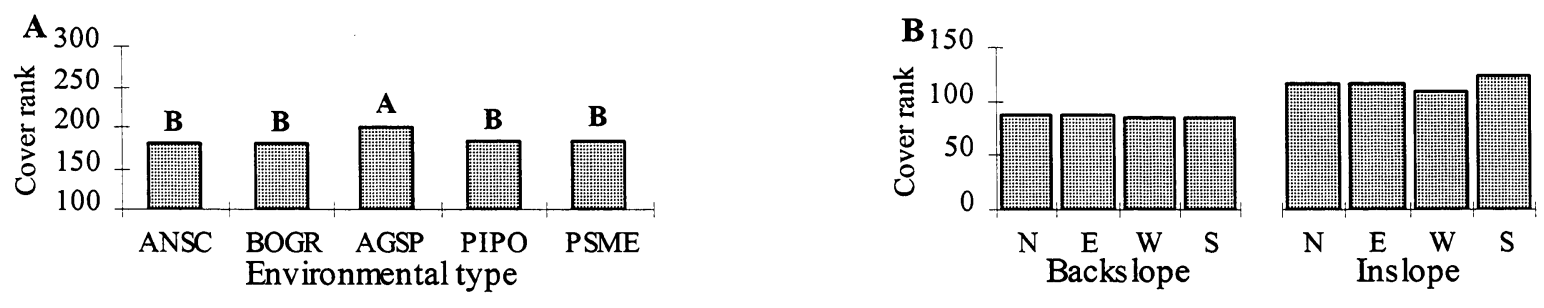

Figure 27.1. A) Relative performance of Kochia scoparia in five environmental types. B) Effect of position and aspect on the performance of Kochia scoparia. Categories sharing a letter are not significantly $(\mathrm{p}<0.05)$ different 

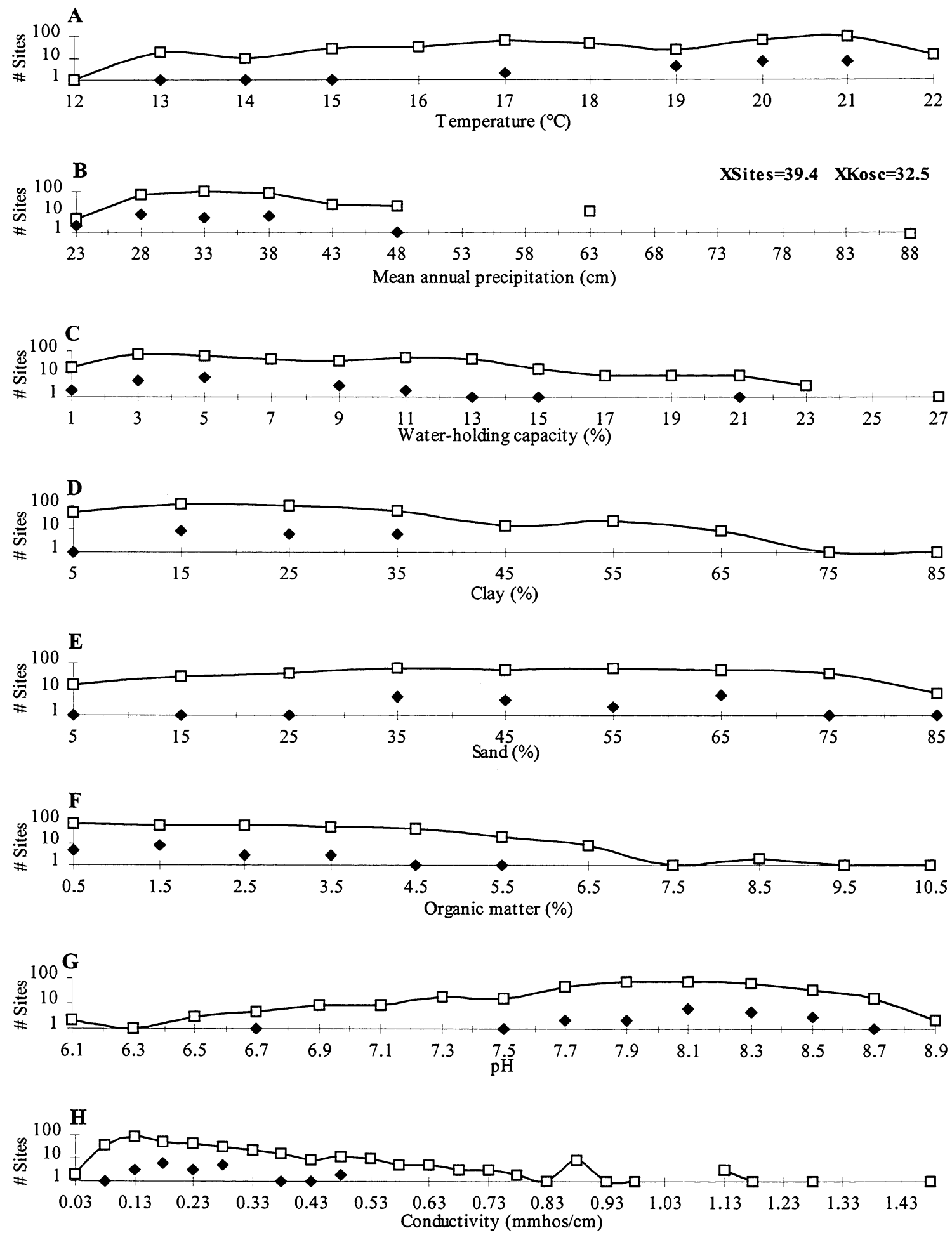

Figure 27.2. The distribution of Kochia scoparia sites (solid diamonds) and all roadside sites (open squares) across nine site characteristics. Where the mean of sites occupied by Kochia scoparia is significantly $(p<0.05)$ different from the mean of all sites, both are shown in the upper right of the graph. 


\section{Lactuca serriola (Lase)}

Common name: prickly lettuce

Family: Asteraceae

Origin: Exotic. On roadsides, BOGR and PSME. Escaping in BOGR.

Duration and Habit ${ }^{1}$ : Exotic Annual Forb, not vegetatively reproducing.

Environmental Type': Lase cover (\%) is highest in the ANSC type (Fig. 28.1A).

Temperature: Summer temperature does not differ between average Lase sites and average roadside sites (Fig. 28.2A).

Precipitation: Annual precipitation does not differ between average Lase sites and average roadside sites (Fig. 28.2B).

Water-holding capacity: WHC does not differ between average Lase sites and average roadside sites (Fig. 28.2C).

Clay: Clay does not differ between average Lase sites and average roadside sites (Fig. 28.2D).

Sand: Sand does not differ between average Lase sites and average roadside sites (Fig. 28.2E).

Organic matter: OM does not differ between average Lase sites and average roadside sites (Fig. 28.2F).

pH: $\mathrm{pH}$ does not differ between average Lase sites and average roadside sites (Fig. 28.2G).

Conductivity: Conductivity does not differ between average Lase and average roadside sites (Fig. 28.2H).

Position $^{2,3}$ : Lase performs better on inslopes than backslopes.

Aspect: Lase performance does not vary with aspect (Fig 28.1B).

\footnotetext{
${ }^{1}$ Refer to the introduction (p37) for a description of each factor.

${ }^{2}$ Species presence varies significantly with this factor.

${ }^{3}$ Inslope/backslope effects cannot be determined from Figure 28.1B below
}
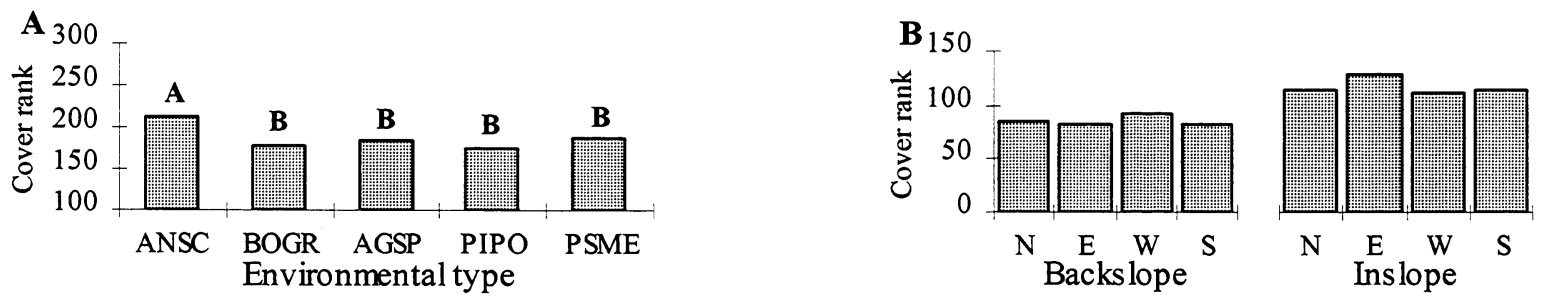

Figure 28.1 A) Relative performance of Lactuca serriola in five environmental types. B) Effect of position and aspect on the performance of Lactuca serriola. Categories sharing a letter are not significantly $(\mathrm{p}<0.05)$ different. 

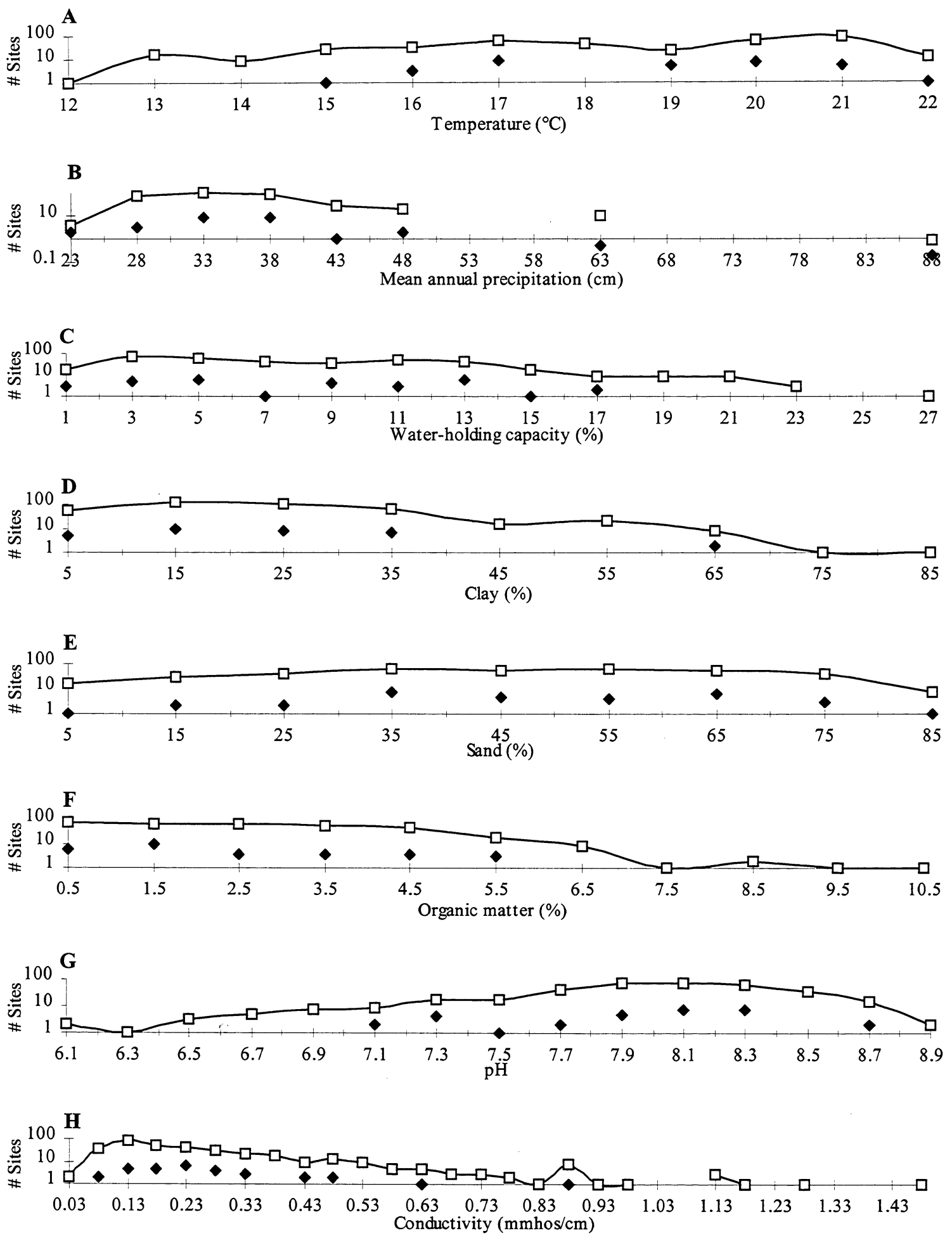

Figure 28.2. The distribution of Lactuca serriola sites (solid diamonds) and all roadside sites (open squares) across nine site characteristics. Where the mean of sites occupied by Lactuca serriola is significantly $(\mathrm{p}<0.05)$ different from the mean of all sites, both are shown in the upper right of the graph. 


\section{Liatris punctata (Lipu)}

Common name: dotted grayfeather

Family: Asteraceae

Origin: Native.

Duration and Habit ${ }^{1}$ : Perennial Forb, not vegetatively reproducing.

Environmental type: Lipu cover (\%) does not differ between types (Fig. 29.1A)

Temperature: Summer temperature does not differ between average Lipu sites and average roadside sites (Fig. 29.2A).

Precipitation: Annual precipitation does not differ between average Lipu and average roadside sites (Fig. 29.2B).

Water-holding capacity: WHC does not differ between average Lipu sites and average roadside sites (Fig. 29.2C).

Clay: Clay does not differ between average Lipu sites and average roadside sites (Fig. 29.2D).

Sand: Sand does not differ between average Lipu sites and average roadside sites (Fig. 29.2E).

Organic matter: OM does not differ between average Lipu sites and average roadside sites (Fig. 29.2F).

pH: $\mathrm{pH}$ does not differ between average Lipu sites and average roadside sites (Fig. 29.2G).

Conductivity: Conductivity does not differ between average Lipu sites and average roadside sites (Fig. 29.2H).

Position $^{3}$ : On roadsides, Lipu cover does not respond to position.

Aspect: Lipu performance does not vary with aspect (Fig. 29.1B).

\footnotetext{
${ }^{1}$ Refer to the introduction (p37) for a description of each factor.

${ }^{2}$ Species presence varies significantly with this factor.

${ }^{3}$ Inslope/backslope effects cannot be determined from Figure 29.1B below
}
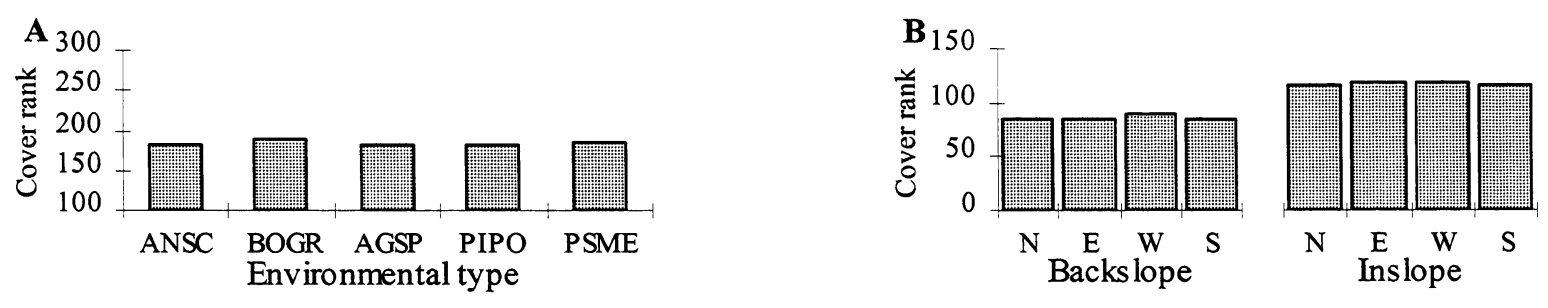

Figure 29.1. A) Relative performance of Liatris punctata in five environmental types. B) Effect of position and aspect on the performance of Liatris punctata. Categories sharing a letter are not significantly $(\mathrm{p}<0.05)$ different. 

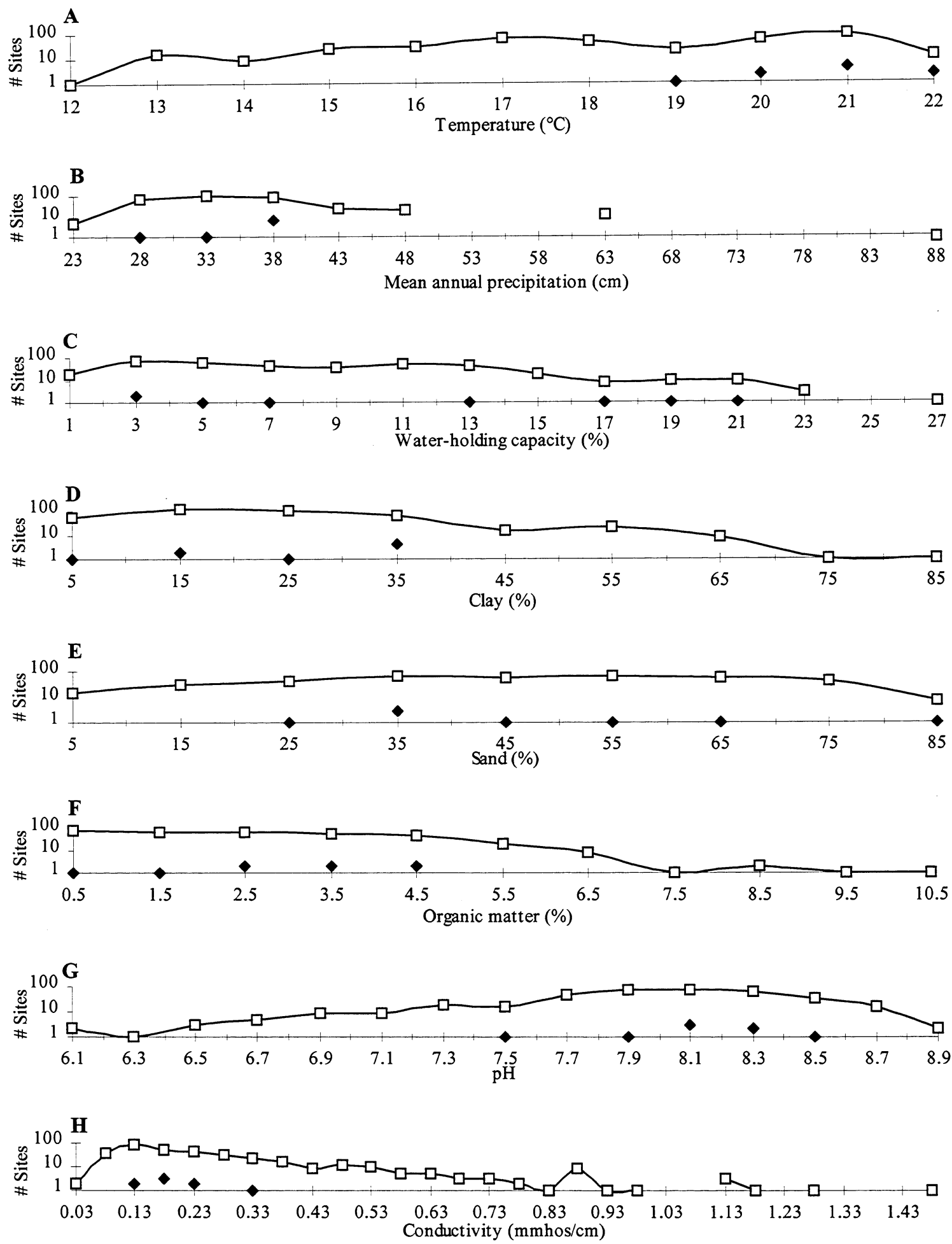

Figure 29.2. The distribution of Liatris punctata sites (solid diamonds) and all roadside sites (open squares) across nine site characteristics. Where the mean of sites occupied by Liatris punctata is significantly $(p<0.05)$ different from the mean of all sites, both are shown in the upper right of the graph. 


\section{Lupinus argenteus (Luar)}

Common name: silvery lupine

Family: Fabaceae

Origin: Native.

Duration and Habit ${ }^{1}$ : Perennial Forb, not vegetatively reproducing.

Environmental type: Luar cover (\%) does not differ between types (Fig. 30.1A)

Temperature ${ }^{2}$ : Summer temperature at average Luar sites is lower than average roadside sites (Fig. 30.2A).

Precipitation': Annual precipitation at average Luar sites is less than at average roadside sites (Fig. 30.2B).

Water-holding capacity: WHC does not differ between average Luar sites and average roadside sites (Fig. 30.2C).

Clay: Clay does not differ between average Luar sites and average roadside sites (Fig. 30.2D).

Sand: Sand does not differ between average Luar sites and average roadside sites (Fig. 30.2E).

Organic matter: OM does not differ between average Luar sites and average roadside sites (Fig. 30.2F).

$\mathbf{p H}^{2}: \mathrm{pH}$ at average Luar sites is lower than at average roadside sites (Fig. 30.2G).

Conductivity: Conductivity does not differ between average Luar sites and average roadside sites (Fig. $30.2 \mathrm{H})$.

Position $^{2,3}$ : Luar performs better on backslopes than on inslopes.

Aspect: On roadside sites Luar performance does not vary with aspect (Fig. 30.1B).

\footnotetext{
${ }^{1}$ Refer to the introduction (p37) for a description of each factor.

${ }^{2}$ Species presence varies significantly with this factor.

${ }^{3}$ Inslope/backslope effects cannot be determined from Figure 30.1B below
}
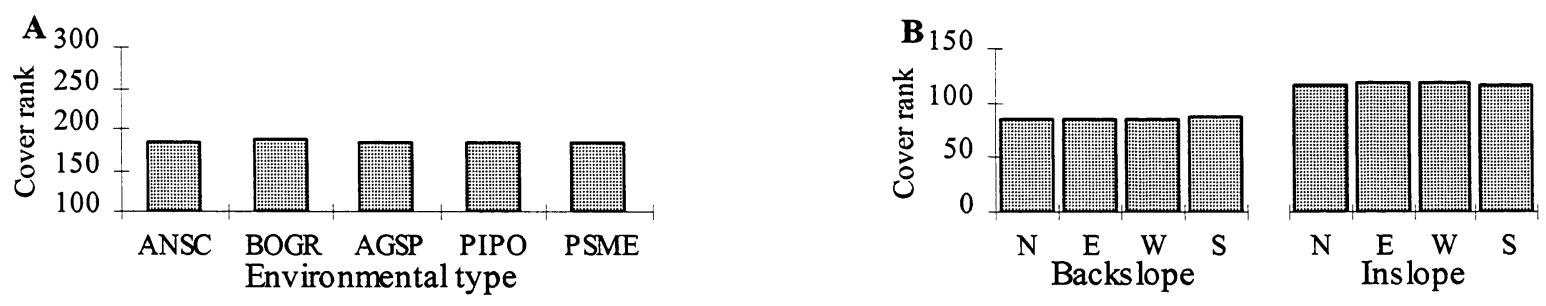

Figure 30.1. A) Relative performance of Lupinus argenteus in five environmental types. B) Effect of position and aspect on the performance of Lupinus argenteus. Categories sharing a letter are not significantly $(\mathrm{p}<0.05)$ different. 

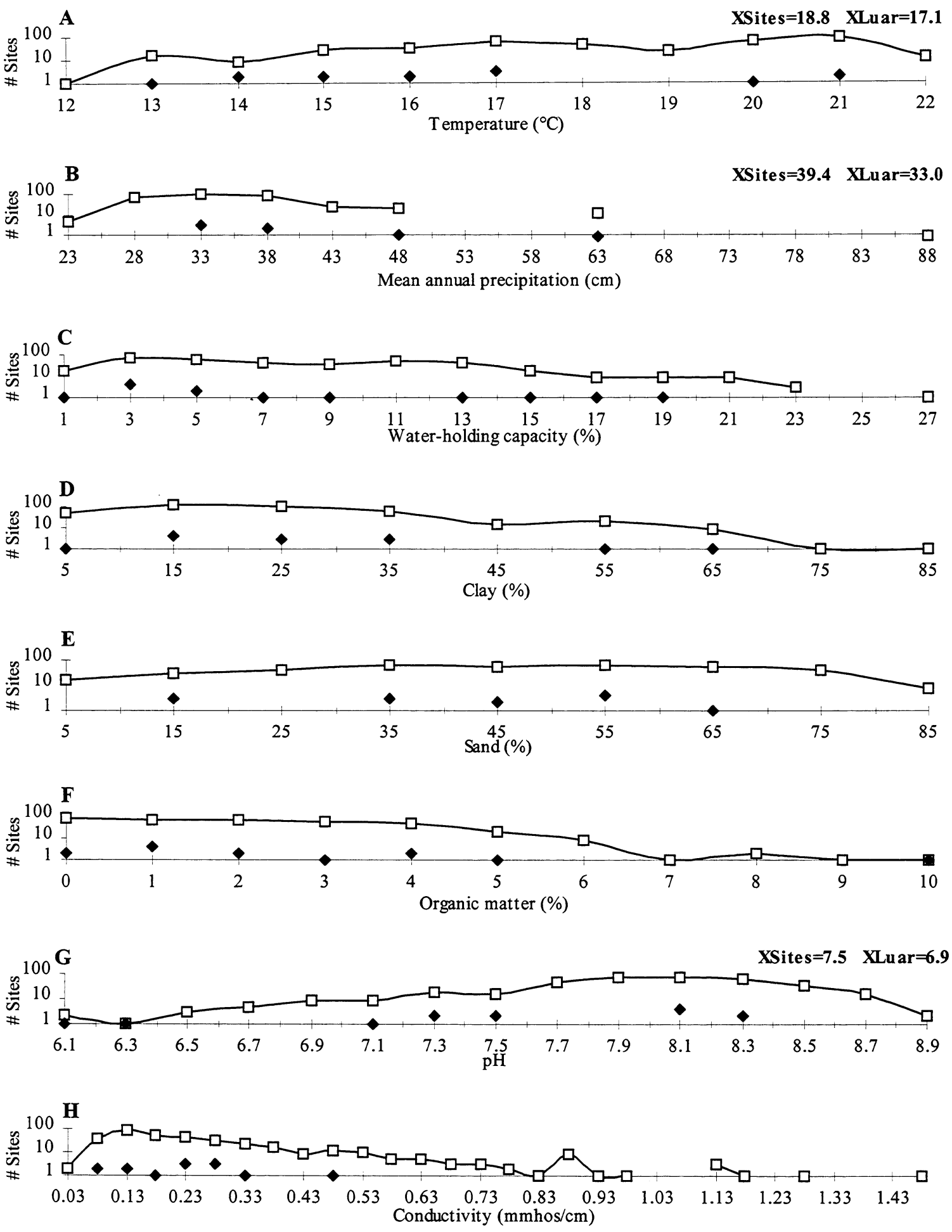

Figure 30.2. The distribution of Lupinus argenteus sites (solid diamonds) and all roadside sites (open squares) across nine site characteristics. Where the mean of sites occupied by Lupinus argenteus is significantly $(p<0.05)$ different from the mean of all sites, both are shown in the upper right of the graph. 


\section{Medicago polymorpha (Mepo)}

Common name: burclover

Family: Fabaceae

Origin: Exotic. On roadsides, AGSP-ABLA. Not escaping.

Duration and Habit ${ }^{1}$ : Exotic Annual Forb, not vegetatively reproducing.

Environmental type: Mepo cover (\%) does not differ among types (Fig. 31.1A).

Temperature ${ }^{2}$ : Summer temperature at average Mepo sites is lower than at average roadside sites (Fig. 31.2A).

Precipitation²: Annual precipitation at average Mepo sites is greater than at average roadside sites (Fig. 31.2B).

Water-holding capacity ${ }^{2}$ : WHC at average Mepo sites is lower than at average roadside sites (Fig. $31.2 \mathrm{C})$.

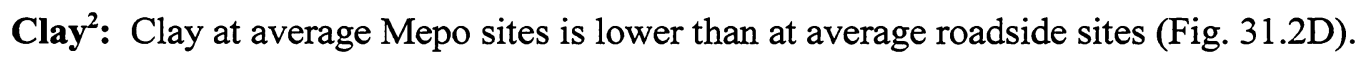

Sand $^{2}$ : Sand at average Mepo sites is higher than at average roadside sites (Fig. 31.2E).

Organic matter: OM does not differ between average Mepo sites and average roadside sites (Fig. 31.2F).

pH: pH does not differ between average Mepo sites and average roadside sites (Fig. 31.2G).

Conductivity $^{2}$ : Conductivity in average Mepo sites is lower than average roadside sites (Fig. 31.2H).

Position $^{3}$ : On roadsides, Mepo cover does not respond to position.

Aspect: On roadsides, Mepo performance does not vary with aspect (Fig. 31.1B)

\footnotetext{
${ }^{1}$ Refer to the introduction (p37) for a description of each factor.

${ }^{2}$ Species presence varies significantly with this factor.

${ }^{3}$ Inslope/backslope effects cannot be determined from Figure 32.1B below
}
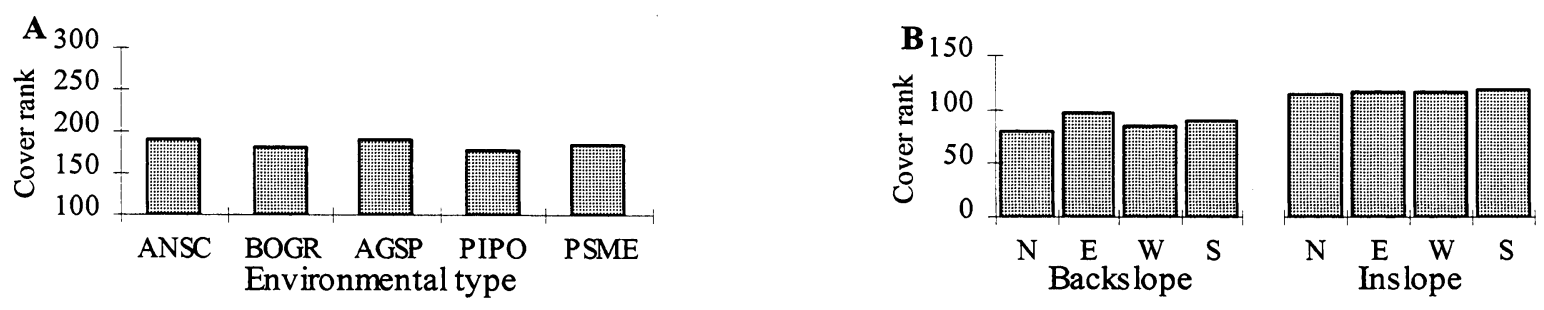

Figure 31.1. A) Relative performance of Medicago polymorpha in five environmental types. B) Effect of position and aspect on the performance of Medicago polymorpha. Categories sharing a letter are not significantly $(\mathrm{p}<0.05)$ different. 

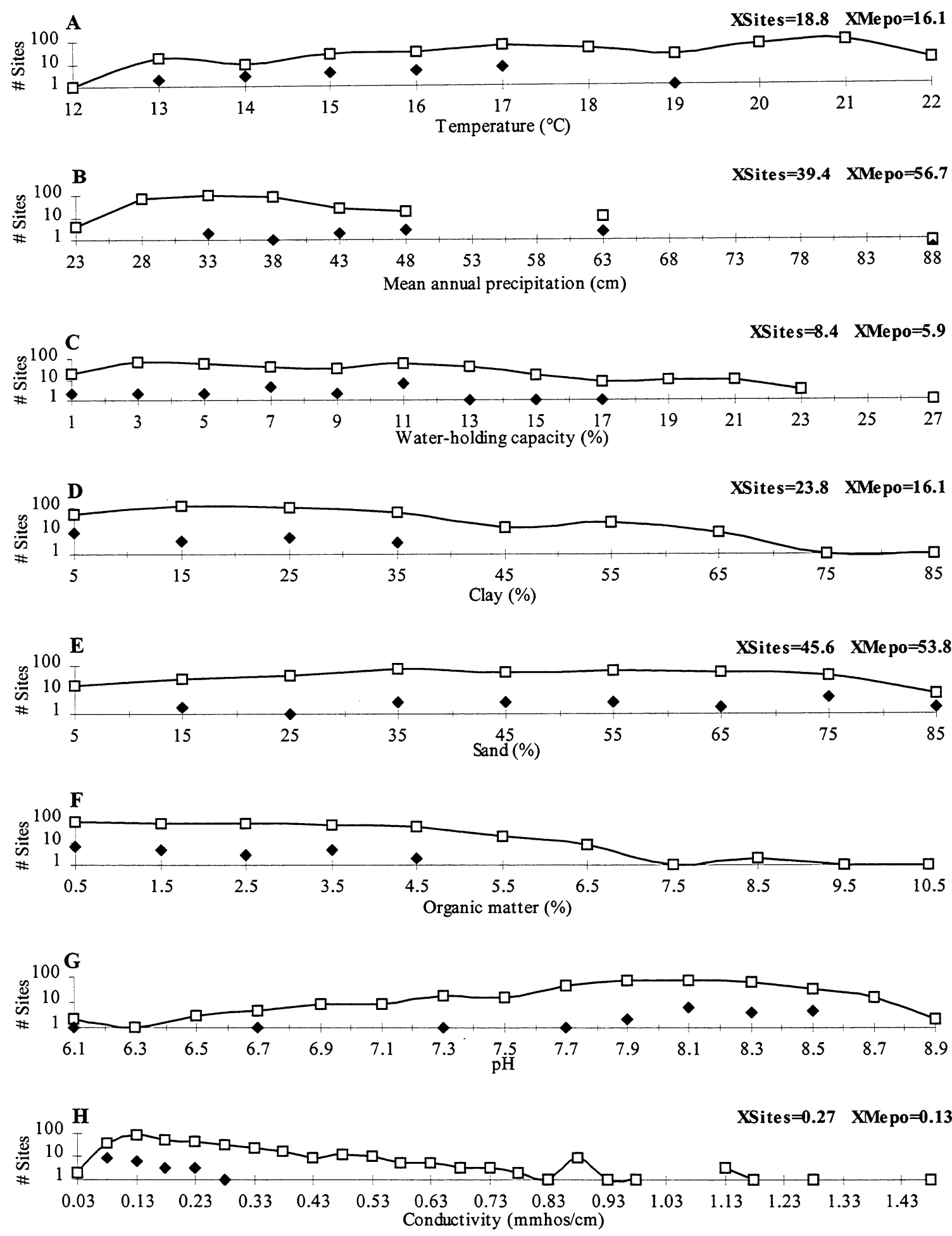

Figure 31.2. The distribution of Medicago polymorpha sites (solid diamonds) and all roadside sites (open squares) across nine site characteristics. Where the mean of sites occupied by Medicago polymorpha is significantly $(\mathrm{p}<0.05)$ different from the mean of all sites, both are shown in the upper right of the graph. 


\section{Medicago sativa (Mesa)}

Common name: alfalfa

Family: Fabaceae

Origin: Exotic. On roadsides, PSME-POTR. Not escaping.

Duration and Habit ${ }^{1}$ : Exotic Perennial Forb, not vegetatively reproducing.

Environmental type: Mesa cover (\%) does not differ among types (Fig. 32.1A).

Temperature ${ }^{2}$ : Summer temperature at average Mesa sites is lower than at average roadside sites (Fig. 32.2A).

Precipitation ${ }^{2}$ : Annual precipitation at average Mesa sites is less than at average roadside sites (Fig. 32.2B).

Water-holding capacity ${ }^{2}$ : WHC at average Mesa sites is higher than at average roadside sites (Fig. 32.2C).

Clay $^{2}$ : Clay at average Mesa sites is higher than at average roadside sites (Fig. 32.2D).

Sand $^{2}$ : Sand at average Mesa sites is lower than at average roadside sites (Fig. 32.2E).

Organic matter: OM does not differ between average Mesa sites and average roadside sites (Fig. 32.2F).

pH: $\mathrm{pH}$ does not differ between average Mesa sites and average roadside sites (Fig. 32.2G).

Conductivity $^{2}$ : Conductivity at average Mesa sites is higher than at average roadside sites (Fig. 32.2H).

Position ${ }^{3}$ : On roadsides, Mesa cover does not respond to position.

Aspect: On roadsides, Mesa performance does not vary with aspect (Fig 32.1B).

\footnotetext{
${ }^{1}$ Refer to the introduction (p37) for a description of each factor.

${ }^{2}$ Species presence varies significantly with this factor.

${ }^{3}$ Inslope/backslope effects cannot be determined from Figure 32.1B below
}
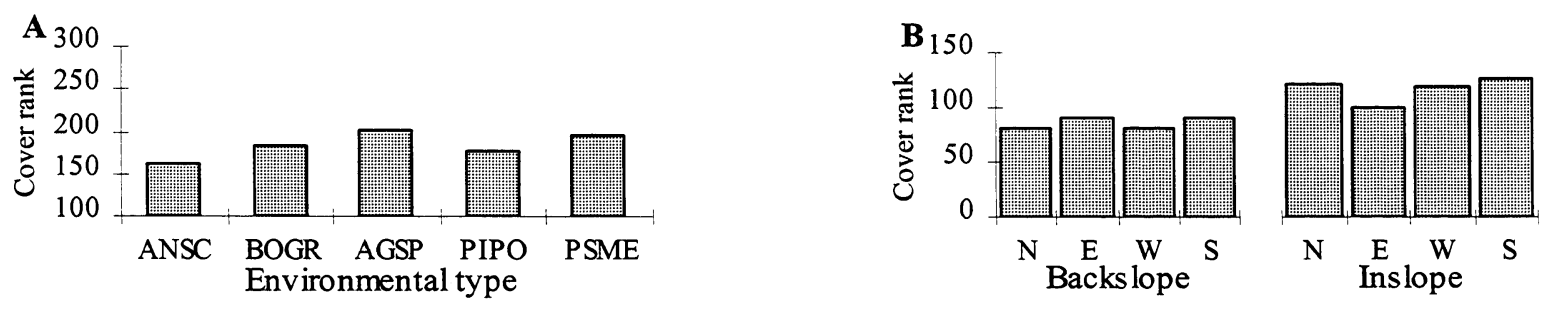

Figure 32.1. A) Relative performance of Medicago sativa in five environmental types. B) Effect of position and aspect on the performance of Medicago sativa. Categories sharing a letter are not significantly $(\mathrm{p}<0.05)$ different. 


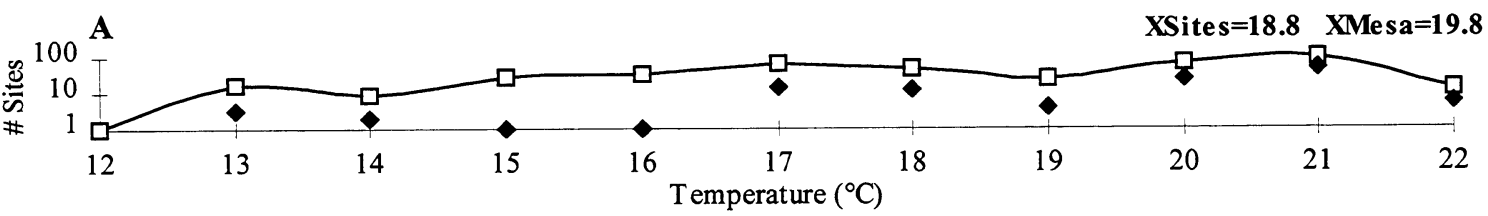

B
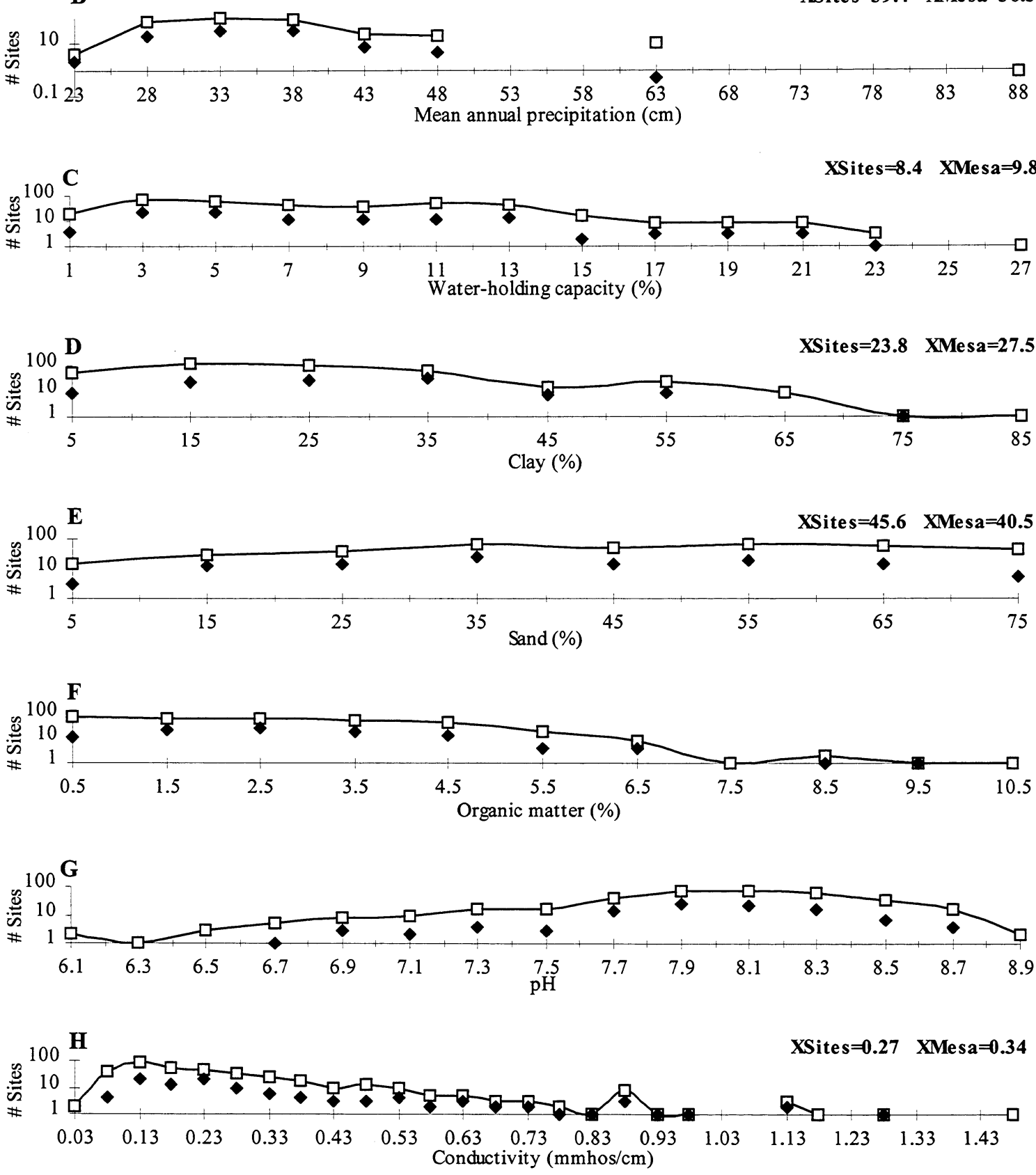

Figure 32.2. The distribution of Medicago sativa sites (solid diamonds) and all roadside sites (open squares) across nine site characteristics. Where the mean of sites occupied by Medicago sativa is significantly $(\mathrm{p}<0.05)$ different from the mean of all sites, both are shown in the upper right of the graph. 


\section{Melilotus officinalis (Meof)}

Common name: yellow sweet-clover

Family: Fabaceae

Origin: Exotic. On roadsides, BOGR-ABLA. Escaping primarily BOGR-AGSP.

Duration and Habit ${ }^{1}$ : Biennial Forb, not vegetatively reproducing.

Environmental Type ${ }^{2}$ : Meof cover (\%) is highest in the AGSP and PSME sites, slightly lower in the PIPO and BOGR types and lowest in the ANSC type (Fig. 33.1A).

Temperature: Summer temperature does not differ between average Meof sites and average roadside sites (Fig. 33.2A).

Precipitation': Annual precipitation at average Meof sites is greater than at the average roadside site (Fig. 33.2B).

Water-holding capacity: WHC does not differ between average Meof sites and average roadside sites (Fig. 33.2C).

Clay: Clay does not differ between average Meof sites and average roadside sites (Fig. 33.2D).

Sand: Sand does not differ between average Meof sites and average roadside sites (Fig. 33.2E).

Organic matter': $\mathrm{OM}$ at average Meof sites is lower than at average roadside sites (Fig. 33.2F).

pH: $\mathrm{pH}$ does not differ between average Meof sites and average roadside sites (Fig. 33.2G).

Conductivity: Conductivity does not differ between average Meof and average roadside sites (Fig. $33.2 \mathrm{H})$.

Position $^{3}$ : On roadsides, Meof cover does not respond to position.

Aspect: On roadsides there is no consistent linkage of Meof performance with aspect (Fig 33.1B).

\footnotetext{
${ }^{1}$ Refer to the introduction (p37) for a description of each factor.

${ }^{2}$ Species presence varies significantly with this factor.

${ }^{3}$ Inslope/backslope effects cannot be determined from Figure 33.1B below
}
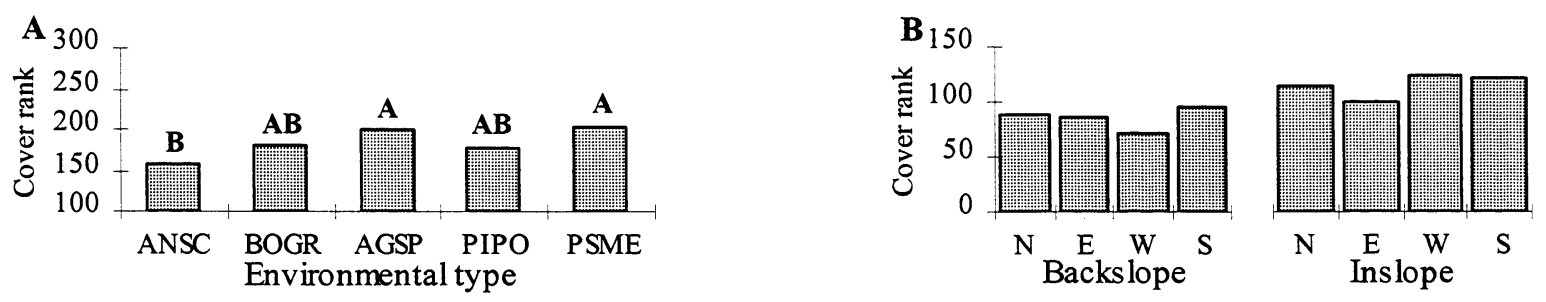

Figure 33.1. A) Relative performance of Melilotus offincinalis in five environmental types. B) Effect of position and aspect on the performance of Melilotus offincinalis. Categories sharing a letter are not significantly $(\mathrm{p}<0.05)$ different. 

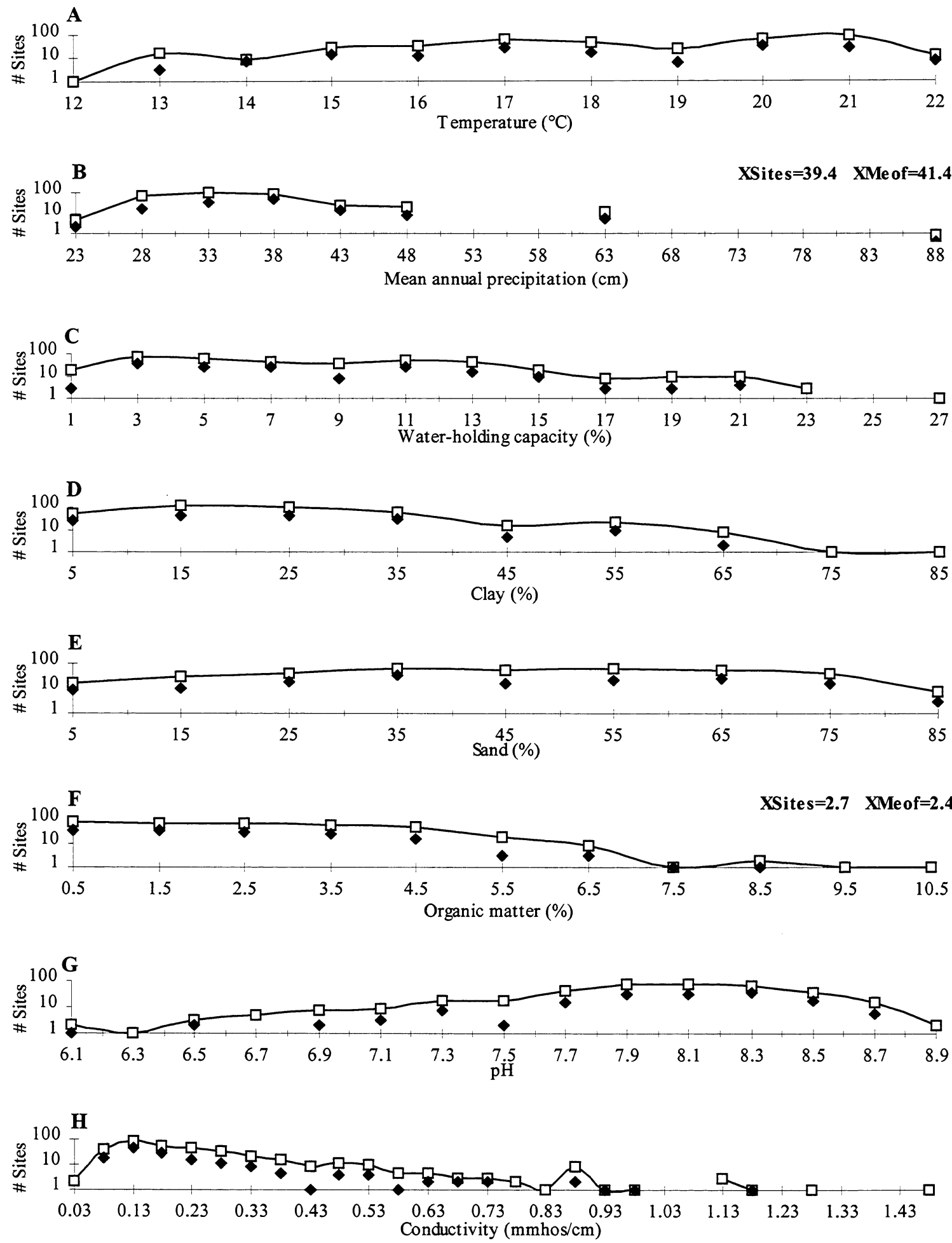

Figure 33.2. The distribution of Melilotus offincinalis sites (solid diamonds) and all roadside sites (open squares) across nine site characteristics. Where the mean of sites occupied by Melilotus offincinalis is significantly $(p<0.05)$ different from the mean of all sites, both are shown in the upper right of the graph. 


\section{Opuntia polycantha (Oppo)}

Common name: plains prickly pear

Family: Cactaceae

Origin: Native.

Duration and Habit ${ }^{1}$ : Perennial Forb, vegetatively reproducing.

Environmental type: Oppo cover (\%) does not differ between types (Fig. 34.1A)

Temperature: Summer temperature does not differ between average Oppo and average roadside sites (Fig. 34.2A).

Precipitation $^{2}$ : Annual precipitation at average Oppo sites is less than at average roadside sites (Fig. 34.2B).

Water-holding capacity: WHC does not differ between average Oppo sites and average roadside sites (Fig. 34.2C).

Clay $^{2}$ : Clay at average Oppo sites is higher than at average roadside sites (Fig. 34.2D).

Sand $^{2}$ : Sand at average Oppo sites is lower than average roadside sites (Fig. 34.2E).

Organic matter': OM at average Oppo sites is lower than at average roadside sites (Fig. 34.2F).

pH: $\mathrm{pH}$ does not differ between average Oppo sites and average roadside sites (Fig. 34.2G).

Conductivity $^{2}$ : Conductivity at average Oppo sites is higher than at average roadside sites (Fig. $34.2 \mathrm{H}$ ).

Position $^{2,3}$ : Oppo performs better on backslopes than inslopes.

Aspect: Oppo performance does not vary significantly with aspect (Fig 34.1B)

\footnotetext{
${ }^{1}$ Refer to the introduction (p37) for a description of each factor.

${ }^{2}$ Species presence varies significantly with this factor.

${ }^{3}$ Inslope/backslope effects cannot be determined from Figure 34.1B below
}
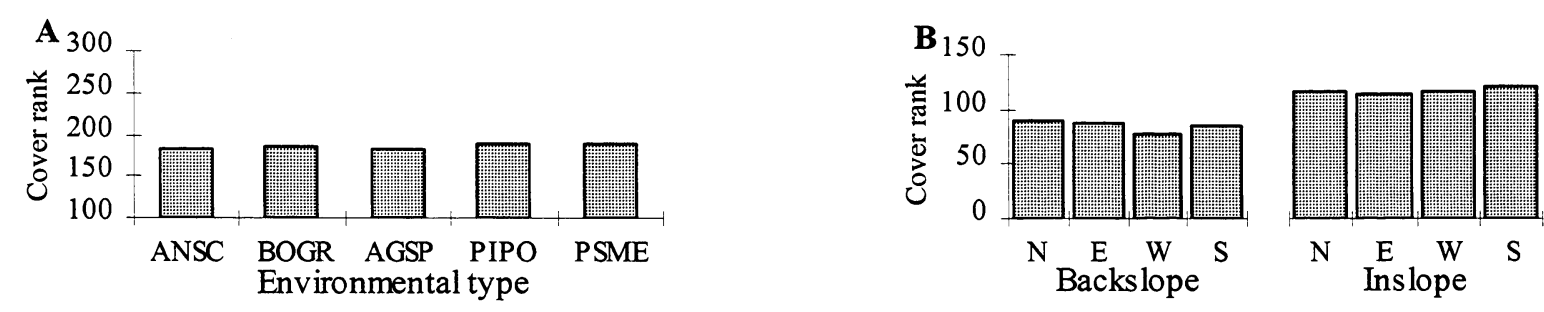

Figure 34.1. A) Relative performance of Opuntia polycantha in five environmental types. B) Effect of position and aspect on the performance of Opuntia polycantha. Categories sharing a letter are not significantly $(\mathrm{p}<0.05)$ different. 

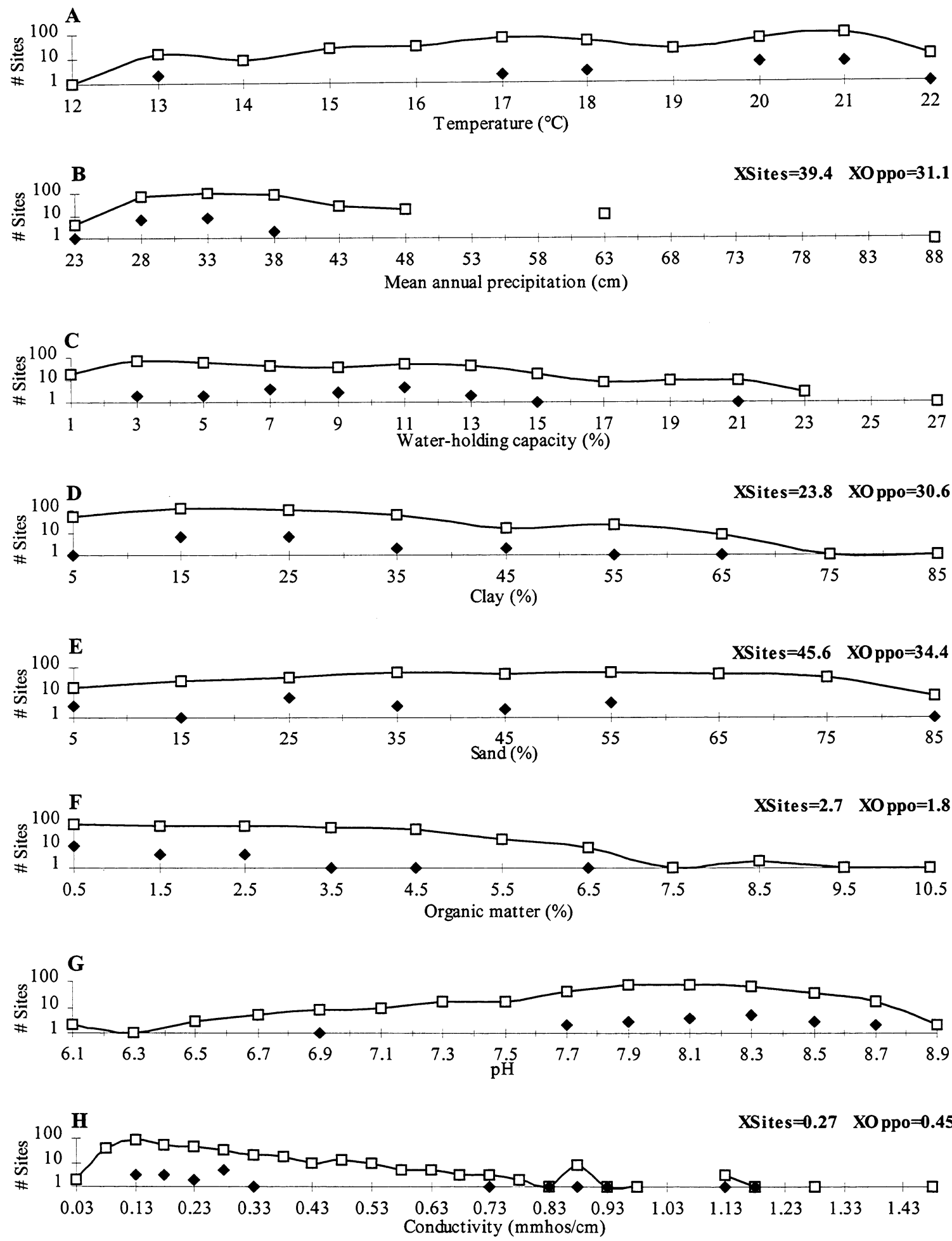

Figure 34.2. The distribution of Opuntia polycantha sites (solid diamonds) and all roadside sites (open squares) across nine site characteristics. Where the mean of sites occupied by Opuntia polycantha is significantly $(p<0.05)$ different from the mean of all sites, both are shown in the upper right of the graph. 


\section{Phalaris arundinacea (Phar)}

Common name: reed canary-grass

Family: Poaceae

Origin: Native. On roadsides, BOGR-ABLA. Increasing on wetlands throughout. Many to most roadside populations are seeded with exotic (European) seeds.

Duration and Habit ${ }^{1}$ : Perennial Grass, vegetatively reproducing.

Environmental Type ${ }^{2}$ : Phar cover (\%) is highest in the PIPO type and slightly lower in PSME and lowest in ANSC and BOGR (Fig. 35.1A).

Temperature ${ }^{2}$ : Summer temperature at average Phar sites is lower than at average roadside sites (Fig. 35.2A).

Precipitation': Annual precipitation at average Phar sites is higher than precipitation at average roadside sites (Fig. 35.2B).

Water-holding capacity ${ }^{2}$ : WHC in average Phar sites is lower than average roadside sites (Fig. 35.2C).

Clay $^{2}$ : Clay at average Phar sites is lower than average roadside sites (Fig. 35.2D).

Sand²: Sand in average Phar sites is higher than at average roadside sites (Fig. 35.2E).

Organic matter: OM does not differ between average Phar sites and average roadside sites (Fig. 35.2F).

pH: $\mathrm{pH}$ does not differ between average Phar sites and average roadside sites (Fig. 35.2G).

Conductivity: Conductivity does not differ between average Phar and average roadside sites (Fig. $35.2 \mathrm{H})$.

Position $^{2,3}$ : Phar performs better on inslopes than backslopes

Aspect: Phar performance does not vary significantly with aspect (note EW/NS inslopes) (Fig. 35.1B)

\footnotetext{
${ }^{1}$ Refer to the introduction (p37) for a description of each factor.

${ }^{2}$ Species presence varies significantly with this factor.

${ }^{3}$ Inslope/backslope effects cannot be determined from Figure 35.1B below
}
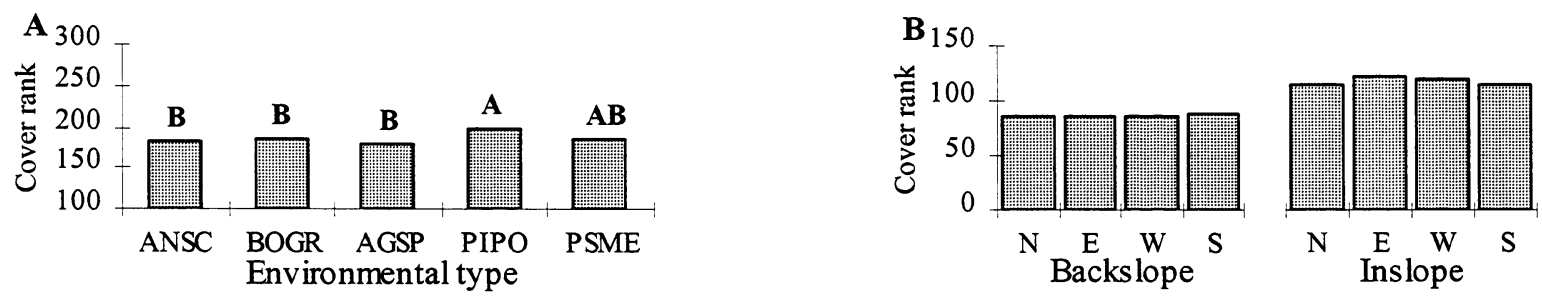

Figure 35.1. A) Relative performance of Phalaris arundinacea in five environmental types. B) Effect of position and aspect on the performance of Phalaris arundinacea. Categories sharing a letter are not significantly $(\mathrm{p}<0.05)$ different. 

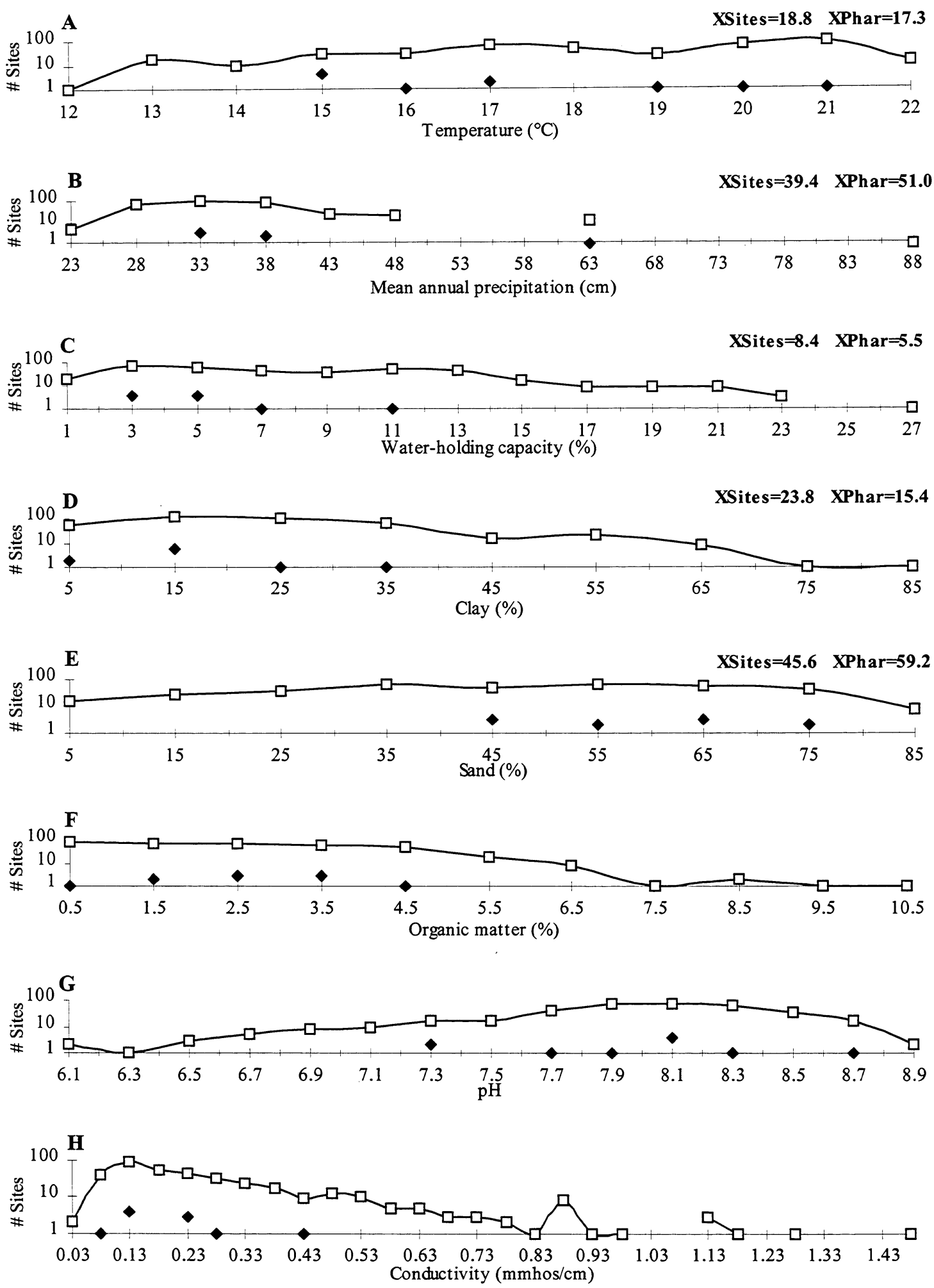

Figure 35.2. The distribution of Phalaris arundinacea sites (solid diamonds) and all roadside sites (open squares) across nine site characteristics. Where the mean of sites occupied Phalaris arundinacea is significantly $(\mathrm{p}<0.05)$ different from the mean of all sites, both are shown in the upper right of the graph. 


\section{Phleum pratense (Phpr)}

Common name: timothy

Family: Poaceae

Origin: Exotic. On roadsides, BOGR-ALPN. Escaping AGSP-ABLA.

Duration and Habit ${ }^{1}$ : Exotic Perennial Grass, not vegetatively reproducing.

Environmental type: Phpr cover (\%) is highest in the PSME type, lower in the PIPO type and lowest in the ANSC, AGSP and BOGR types (Fig. 36.1A)

Temperature ${ }^{2}$ : Summer temperature at average Phpr sites is lower than at average roadside sites (Fig. 36.2A).

Precipitation': Annual precipitation at average Phpr sites is greater than at average roadside sites (Fig. 36.2B).

Water-holding capacity ${ }^{2}$ : WHC at average Phpr sites is lower than at average roadside sites (Fig. 36.2C).

Clay: Clay does not differ between average Phpr sites and average roadside sites (Fig. 36.2D).

Sand $^{2}$ : Sand at average Phpr sites is higher than at average roadside sites (Fig. 36.2E).

Organic matter: OM does not differ between average Phpr sites and average roadside sites (Fig. 36.2F).

pH: $\mathrm{pH}$ at average Phpr sites does not differ from average roadside sites (Fig. 36.2G).

Conductivity ${ }^{2}$ : Conductivity at average Phpr sites is lower than at average roadside sites (Fig. 36.2H).

Position $^{\mathbf{2} 3}$ : Performance of Phpr is better on inslopes than backslopes.

Aspect: Performance of Phpr does not vary with aspect (note EW/NS inslopes) (Fig. 36.1B).

\footnotetext{
${ }^{1}$ Refer to the introduction (p37) for a description of each factor.

${ }^{2}$ Species presence varies significantly with this factor.

${ }^{3}$ Inslope/backslope effects cannot be determined from Figure 36.1B below
}
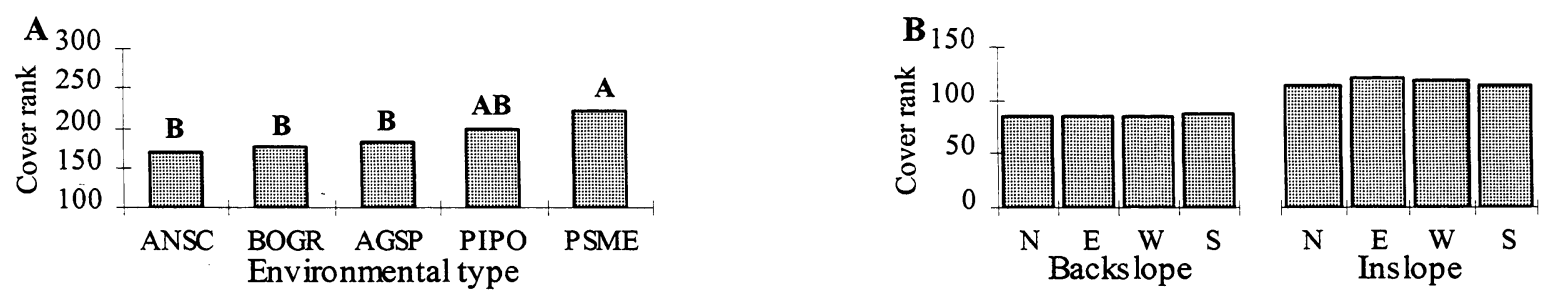

Figure 36.1. A) Relative performance of Phleum pratense in five environmental types. B) Effect of position and aspect on the performance of Phleum pratense. Categories sharing a letter are not significantly $(\mathrm{p}<0.05)$ different. 

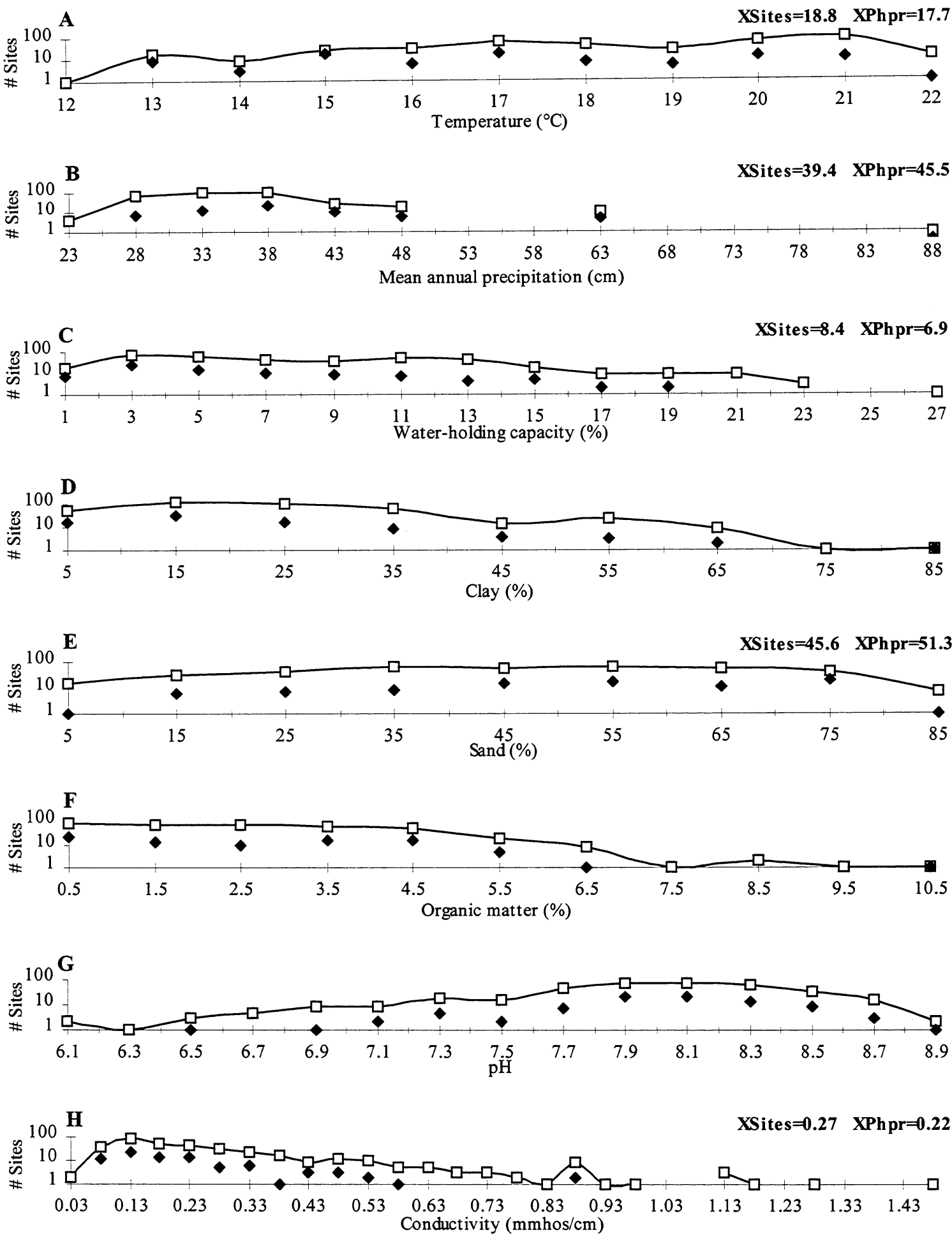

Figure 36.2. The distribution of Phleum pratense sites (solid diamonds) and all roadside sites (open squares) across nine site characteristics. Where the mean of sites occupied by Phleum pratense is significantly $(\mathrm{p}<0.05)$ different from the mean of all sites, both are shown in the upper right of the graph. 


\section{Pinus ponderosa (Pipo)}

Common name: ponderosa pine

Family: Pinaceae

Origin: Native.

Duration and Habit ${ }^{1}$ : Perennial Tree, not vegetatively reproducing.

Environmental type: Pipo cover (\%) does not differ between types (Fig. 37.1A)

Temperature $^{2}$ : Summer temperature at average Pipo sites is lower than at average roadside sites (Fig. 37.2A).

Precipitation²: Annual precipitation at average Pipo sites is greater than at average roadside sites (Fig. 37.2B).

Water-holding capacity: WHC does not differ between average Pipo sites and average roadside sites (Fig. 37.2C).

Clay $^{2}$ : Clay at average Pipo sites is lower than at average roadside sites (Fig. 37.2D).

Sand: Sand does not differ between average Pipo sites and average roadside sites (Fig. 37.2E).

Organic matter: OM does not differ between average Pipo sites and average roadside sites (Fig. 37.2F).

pH: pH does not differ between average Pipo sites and average roadside sites (Fig. 37.2G).

Conductivity $^{2}$ : Conductivity at average Pipo sites is lower than at average roadside sites (Fig. 37.2H).

Position $^{3}$ : On roadsides, Pipo cover does not respond to position.

Aspect: Performance of Pipo does not vary with aspect (Fig 37.1B).

\footnotetext{
${ }^{1}$ Refer to the introduction (p37) for a description of each factor.

${ }^{2}$ Species presence varies significantly with this factor.

${ }^{3}$ Inslope/backslope effects cannot be determined from Figure 22.1B below
}
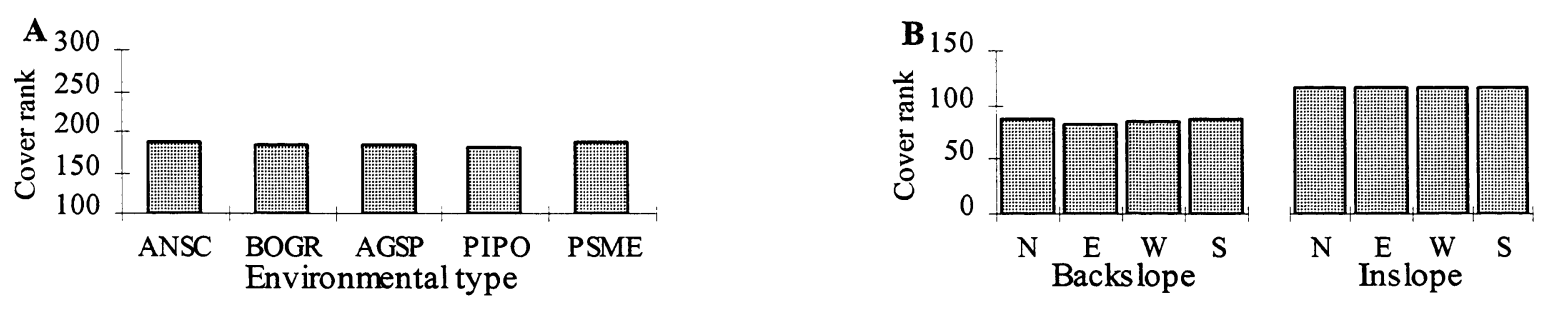

Figure 37.1. A) Relative performance of Pinus ponderosa in five environmental types. B) Effect of position and aspect on the performance of Pinus ponderosa. Categories sharing a letter are not significantly $(\mathrm{p}<0.05)$ different. 

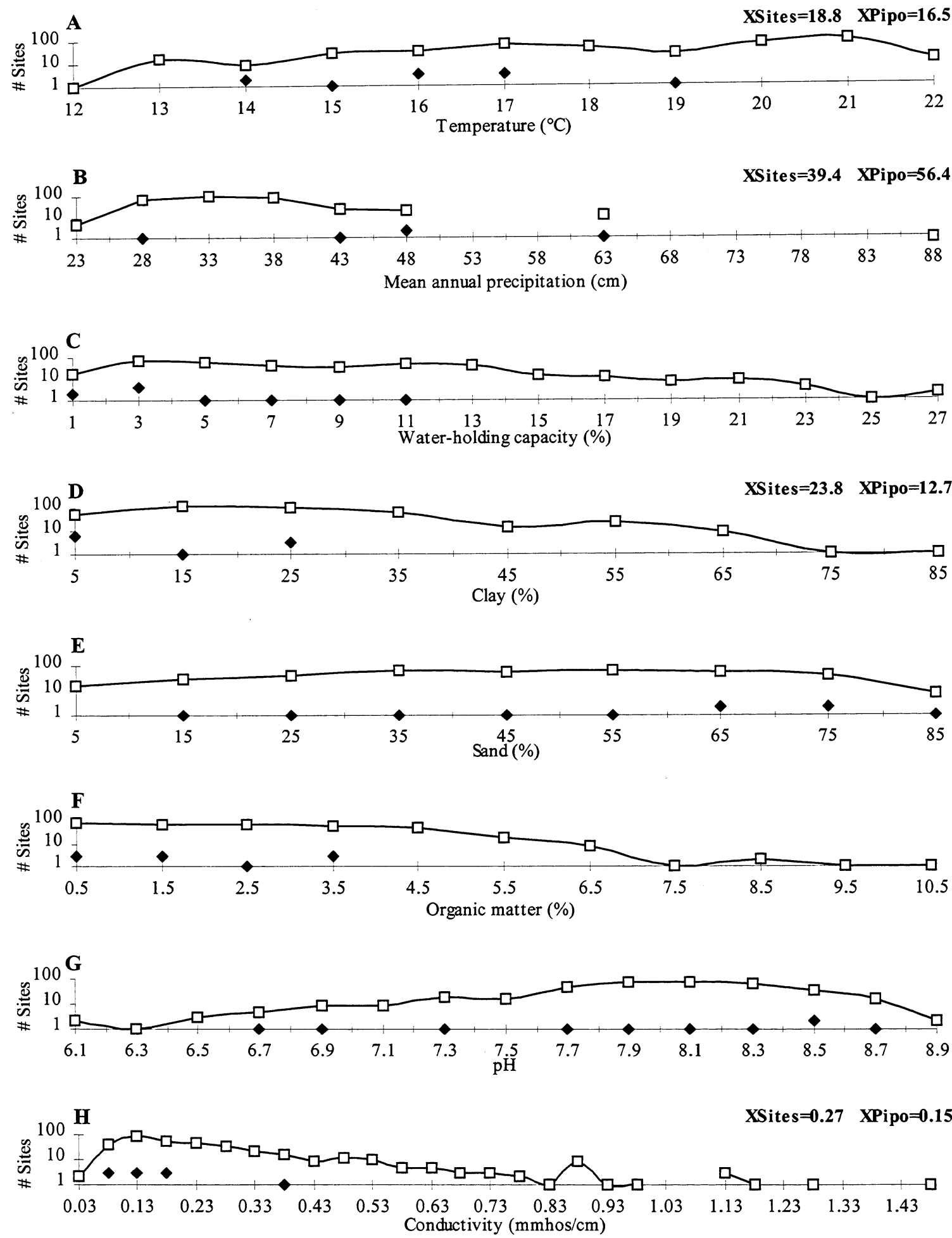

Figure 37.2. The distribution of Pinus ponderosa sites (solid diamonds) and all roadside sites (open squares) across nine site characteristics. Where the mean of sites occupied by Pinus ponderosa is significantly $(\mathrm{p}<0.05)$ different from the mean of all sites, both are shown in the upper right of the graph. 


\section{Poa compressa (Poco)}

Common name: Canada bluegrass

Family: Poaceae

Origin: Exotic. On roadsides, AGSP- ALPN. Escaping AGSP, PSME, ALPN.

Duration and Habit ${ }^{1}$ : Perennial Forb, vegetatively reproducing.

Environmental Type ${ }^{2}$ : Poco cover (\%) is highest in the PIPO type, slightly lower in the PSME and AGSP types and lowest in BOGR and ANSC (Fig. 38.1A).

Temperature ${ }^{2}$ : Summer temperature at average Poco sites is lower than at average roadside sites (Fig. 38.2A).

Precipitation²: Annual precipitation at average Poco sites is greater than at average roadside sites (Fig. 38.2B).

Water-holding capacity ${ }^{2}$ : WHC at average Poco sites is less than at average roadside sites (Fig. 38.2C).

Clay²: Clay at average Poco sites is less than at average roadside sites (Fig. 38.2D).

Sand $^{2}$ : Sand in average Poco sites is greater than at average roadside sites (Fig. 38.2E).

Organic matter: OM does not differ between average Poco sites and average roadside sites (Fig. 38.2F).

pH: pH does not differ between average Poco sites and average roadside sites (Fig. 38.2G).

Conductivity $^{2}$ : Conductivity at Poco sites is less than average roadside sites (Fig. 38.2H).

Position $^{2,3}$ : Poco performs better on inslopes than on backslopes.

Aspect: Aspect does not affect Poco performance (Fig. 38.1B).

\footnotetext{
${ }^{1}$ Refer to the introduction (p37) for a description of each factor.

${ }^{2}$ Species presence varies significantly with this factor.

${ }^{3}$ Inslope/backslope effects cannot be determined from Figure 38.1B below
}
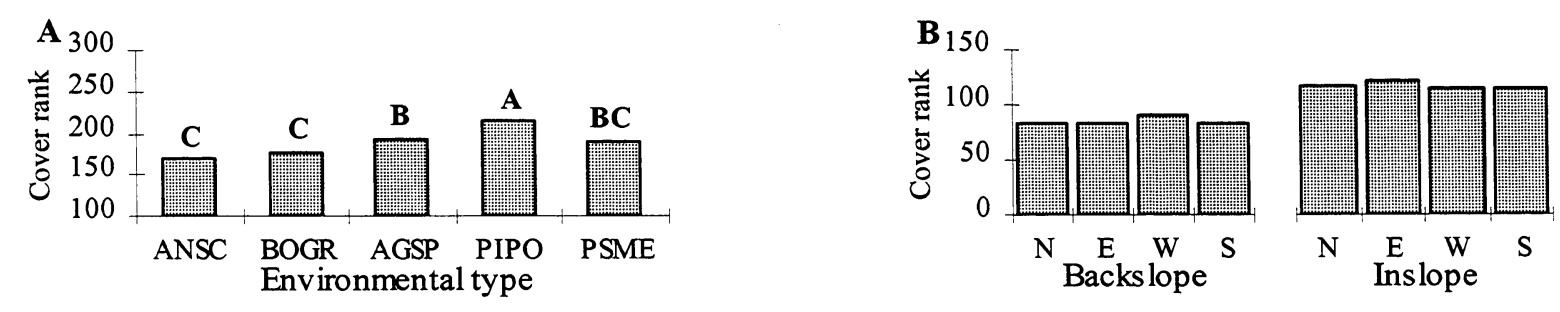

Figure 38.1. A) Relative performance of Poa compressa in five environmental types. B) Effect of position and aspect on the performance of Poa compressa. Categories sharing a letter are not significantly $(p<0.05)$ different. 

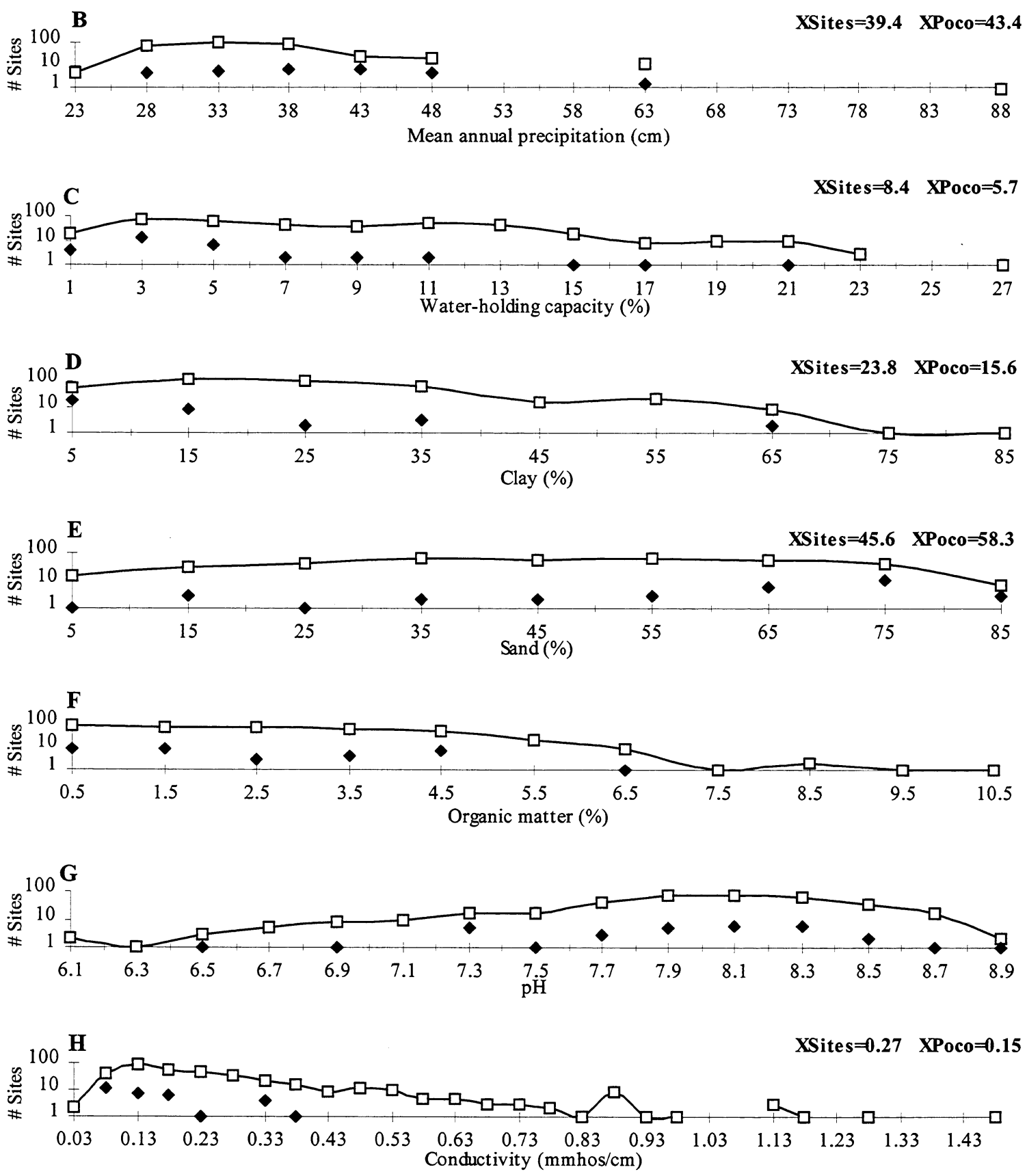

Figure 38.2. The distribution of Poa compressa sites (solid diamonds) and all roadside sites (open squares) across nine site characteristics. Where the mean of sites occupied by Poa compressa is significantly $(\mathrm{p}<0.05)$ different from the mean of all sites, both are shown in the upper right of the graph. 


\section{Poa pratensis (Popr)}

Common name: Kentucky bluegrass

Family: Poaceae

Origin: Exotic. On roadsides, BOGR-ABLA. Escaping BOGR-PSME/POTR.

Duration and Habit ${ }^{1}$ : Perennial Grass, vegetatively reproducing.

Environmental Type ${ }^{2}$ : Popr cover (\%) is higher in the ANSC, AGSP, BOGR and PSME types than in the PIPO type (Fig. 39.1A).

Temperature: Summer temperature does not differ between average Popr and average roadside sites (Fig. 39.2A).

Precipitation: Annual precipitation at average Popr sites does not differ from precipitation at average roadside sites (Fig. 39.2B).

Water-holding capacity: WHC does not differ between average Popr and average roadside sites (Fig. 39.2C).

Clay: Clay does not differ between average Popr sites and average roadside sites (Fig. 39.2D).

Sand: Sand does not differ between average Popr sites and average roadside sites (Fig. 39.2E).

Organic matter: OM does not differ between average Popr sites and average roadside sites (Fig. 39.2F).

pH: pH does not differ between average Popr sites and average roadside sites (Fig. 39.2G).

Conductivity: Conductivity does not differ between average Popr and average roadside sites (Fig. 39.2H).

Position $^{2,3}$ : Popr performance is better on inslopes than backslopes.

Aspect: Despite statistics, variation in Popr performance with aspect seems insignificant (Fig. 39.1B).

${ }^{1}$ Refer to the introduction (p37) for a description of each factor.

${ }^{2}$ Species presence varies significantly with this factor.

${ }^{3}$ Inslope/backslope effects cannot be determined from Figure 39.1B below
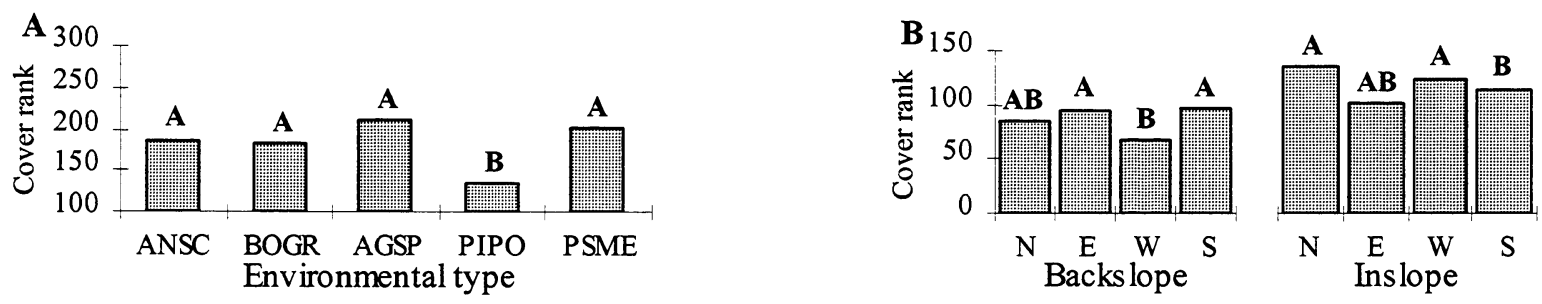

Figure 39.1. A) Relative performance of Poa pratensis in five environmental types. B) Effect of position and aspect on the performance of Poa pratensis. Categories sharing a letter are not significantly $(\mathrm{p}<0.05)$ different. 

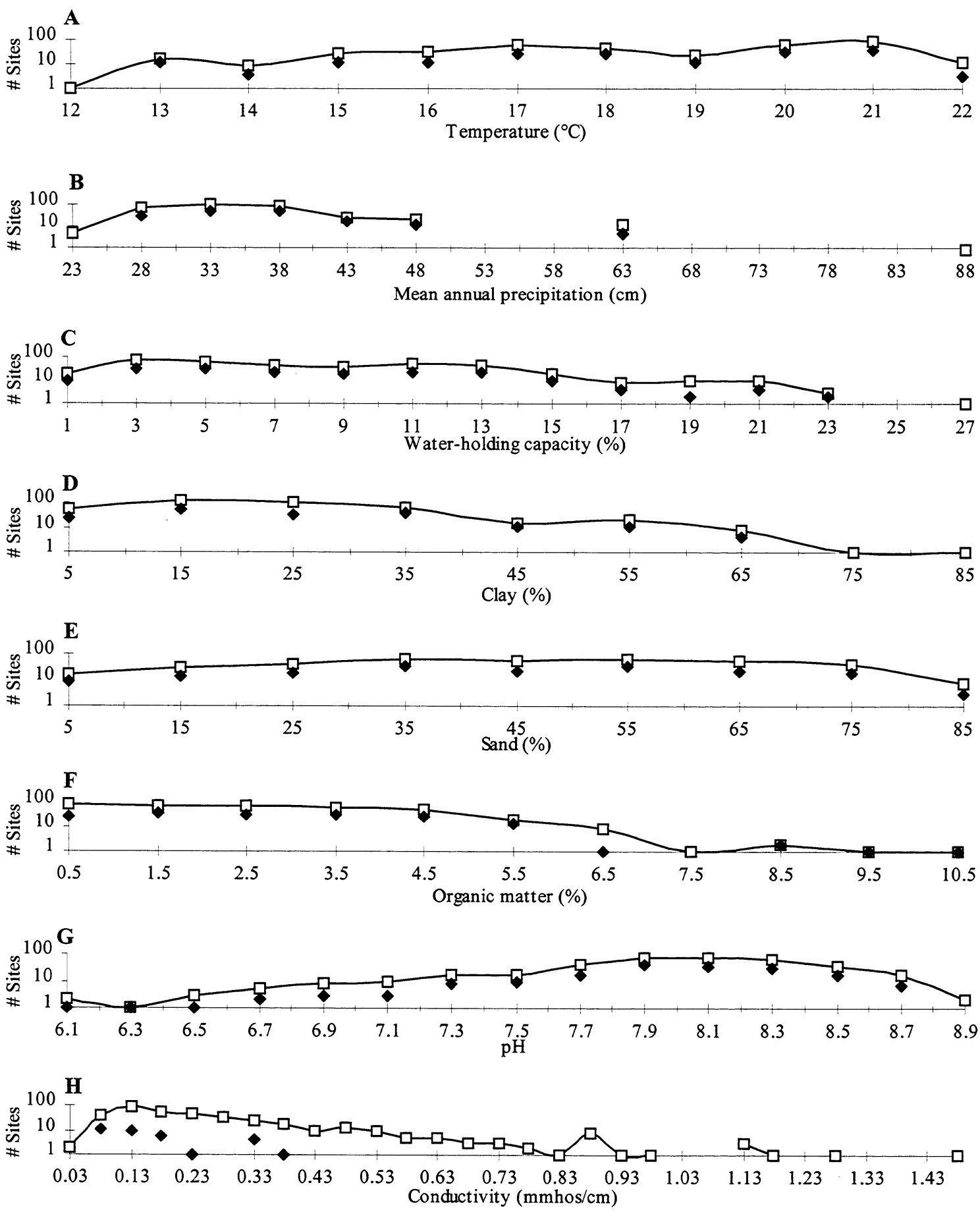

Figure 39.2. The distribution of Poa pratensis sites (solid diamonds) and all roadside sites (open squares) across nine site characteristics. Where the mean of sites occupied by Poa pratensis is significantly $(\mathrm{p}<0.05)$ different from the mean of all sites, both are shown in the upper right of the graph. 


\section{Poa sandbergii (Posa)}

Common name: Sandberg bluegrass

Family: Poaceae

Origin: Native.

Duration and Habit ${ }^{1}$ : Perennial Grass, not vegetatively reproducing.

Environmental type: Posa cover (\%) does not differ from between types (Fig. 40.1A).

Temperature: Summer temperature does not differ between average Posa sites and average roadside sites (Fig. 40.2A).

Precipitation': Annual precipitation at average Posa sites is less than at average roadside sites (Fig. 40.2B).

Water-holding capacity: WHC does not differ between average Posa sites and average roadside sites (Fig. 40.2C).

Clay: Clay does not differ between average Posa sites and average roadside sites (Fig. 40.2D).

Sand: Sand does not differ between Posa sites and average roadside sites (Fig. 40.2E).

Organic matter: OM does not differ between average Posa sites and average roadside sites (Fig. 40.2F).

pH: $\mathrm{pH}$ does not differ between average Posa sites and average roadside sites (Fig. 40.2G).

Conductivity $^{2}$ : Conductivity at average Posa sites is higher than average roadside sites (Fig. 40.2H).

Position $^{3}$ : On roadsides, Posa cover does not respond to position.

Aspect: The performance of Posa, on roadsides, is not affected by aspect (Fig 40.1B).

\footnotetext{
${ }^{1}$ Refer to the introduction (p37) for a description of each factor.

${ }^{2}$ Species presence varies significantly with this factor.

${ }^{3}$ Inslope/backslope effects cannot be determined from Figure $40.1 \mathrm{~B}$ below
}
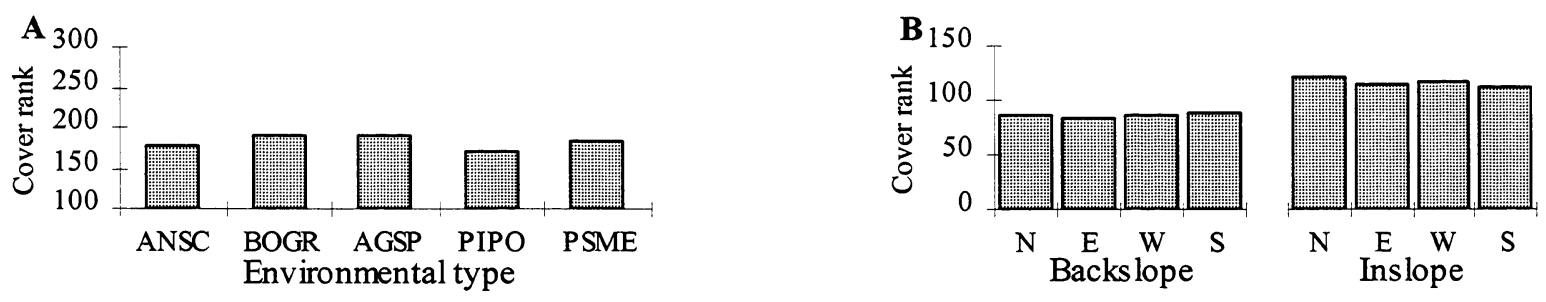

Figure 40.1. A) Relative performance of Poa sandbergii in five environmental types. B) Effect of position and aspect on the performance of Poa sandbergii. Categories sharing a letter are not significantly $(\mathrm{p}<0.05)$ different. 

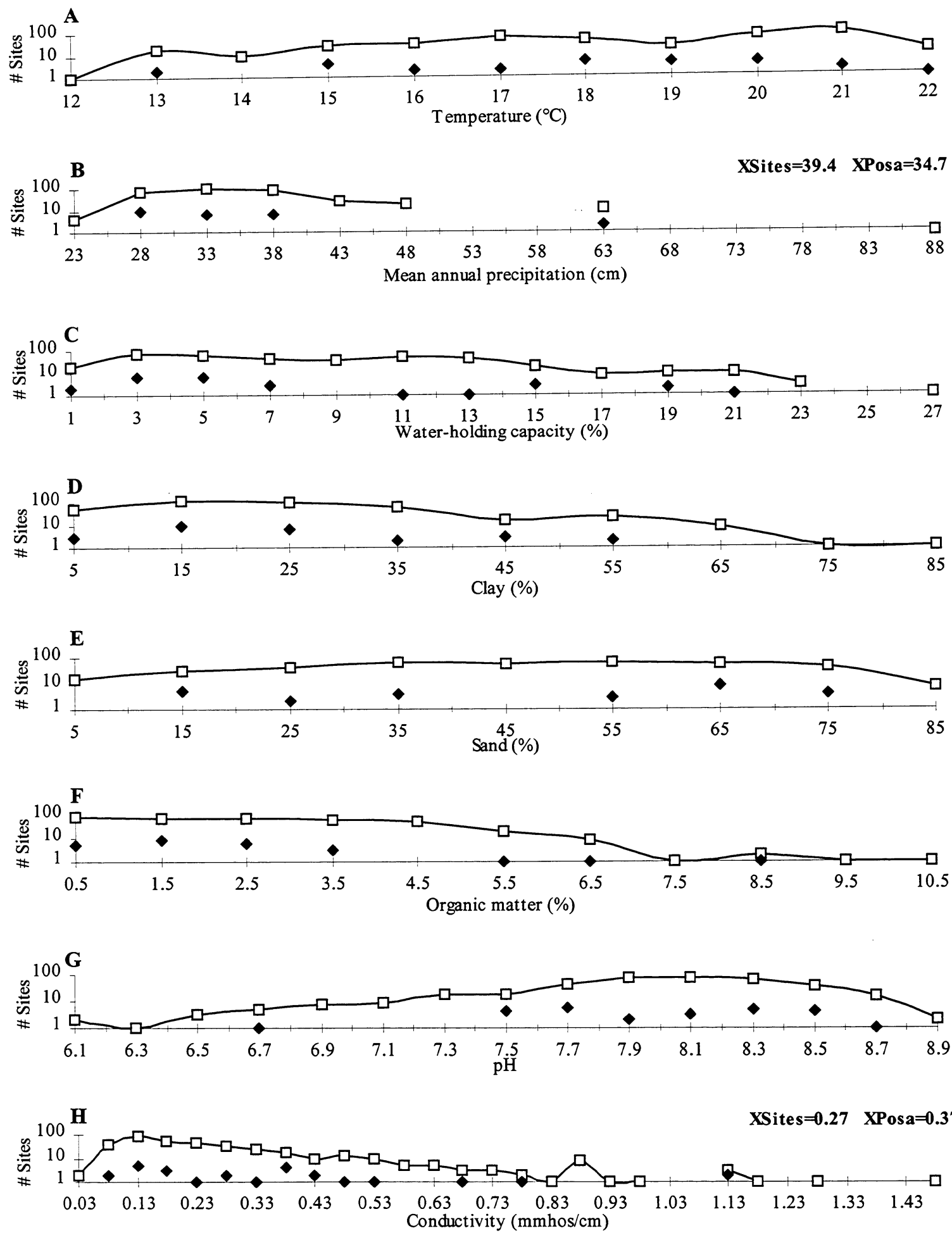

Figure 40.2. The distribution of Poa sandbergii sites (solid diamonds) and all roadside sites (open squares) across nine site characteristics. Where the mean of sites occupied by Poa sandbergii is significantly $(p<0.05)$ different from the mean of all sites, both are shown in the upper right of the graph 


\section{Ratibida columnifera (Raco)}

Common name: upright prairie-coneflower

Family: Asteraceae

Origin: Native.

Duration and Habit ${ }^{1}$ : Perennial Forb, not vegetatively reproducing.

Environmental type: Raco cover (\%) does not differ between types (Fig. 41.1A).

Temperature: Summer temperature does not differ between average Raco sites and average roadside sites (Fig. 41.2A).

Precipitation: Annual precipitation at average Raco sites does not differ from the average sites (Fig. 41.2B).

Water-holding capacity: WHC does not differ between average Raco sites and average roadside sites (Fig. 41.2C).

Clay: Clay does not differ between average Raco sites and average roadside sites (Fig. 41.2D).

Sand: Sand does not differ between average Raco sites and average roadside sites (Fig. 41.2E).

Organic matter: OM does not differ between average Raco sites and average roadside sites (Fig. 41.2F).

pH: $\mathrm{pH}$ does not differ between average Raco sites and average roadside sites (Fig. 41.2G).

Conductivity: Conductivity does not differ between average Raco sites and average roadside sites (Fig. $41.2 \mathrm{H})$.

Position ${ }^{3}$ : On roadsides, Raco cover does not respond to position.

Aspect: Performance of Raco does not vary with aspect (Fig 41.1B).

\footnotetext{
${ }^{1}$ Refer to the introduction (p37) for a description of each factor.

${ }^{2}$ Species presence varies significantly with this factor.

${ }^{3}$ Inslope/backslope effects cannot be determined from Figure 41.1B below
}
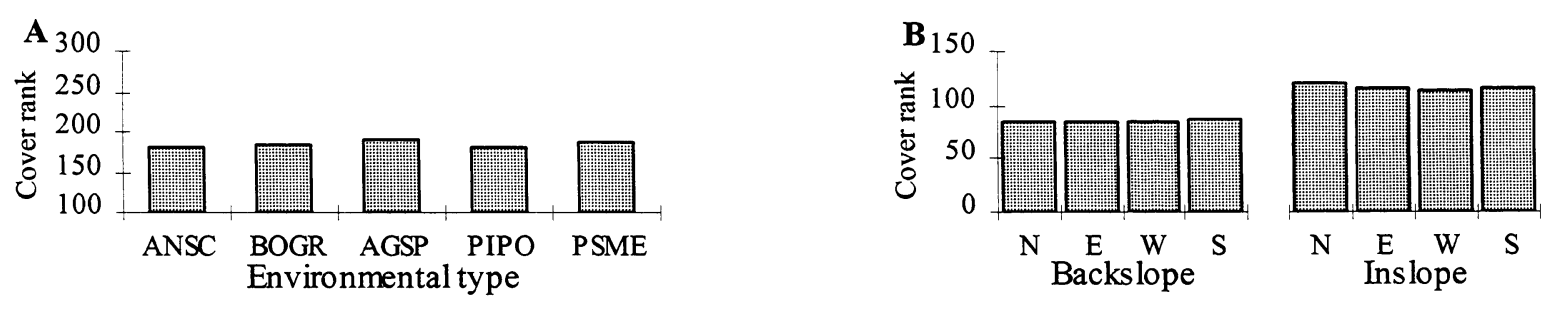

Figure 41.1. A) Relative performance of Ratibida columnifera in five environmental types. B) Effect of position and aspect on the performance of Ratibida columnifera. Categories sharing a letter are not significantly $(\mathrm{p}<0.05)$ different. 

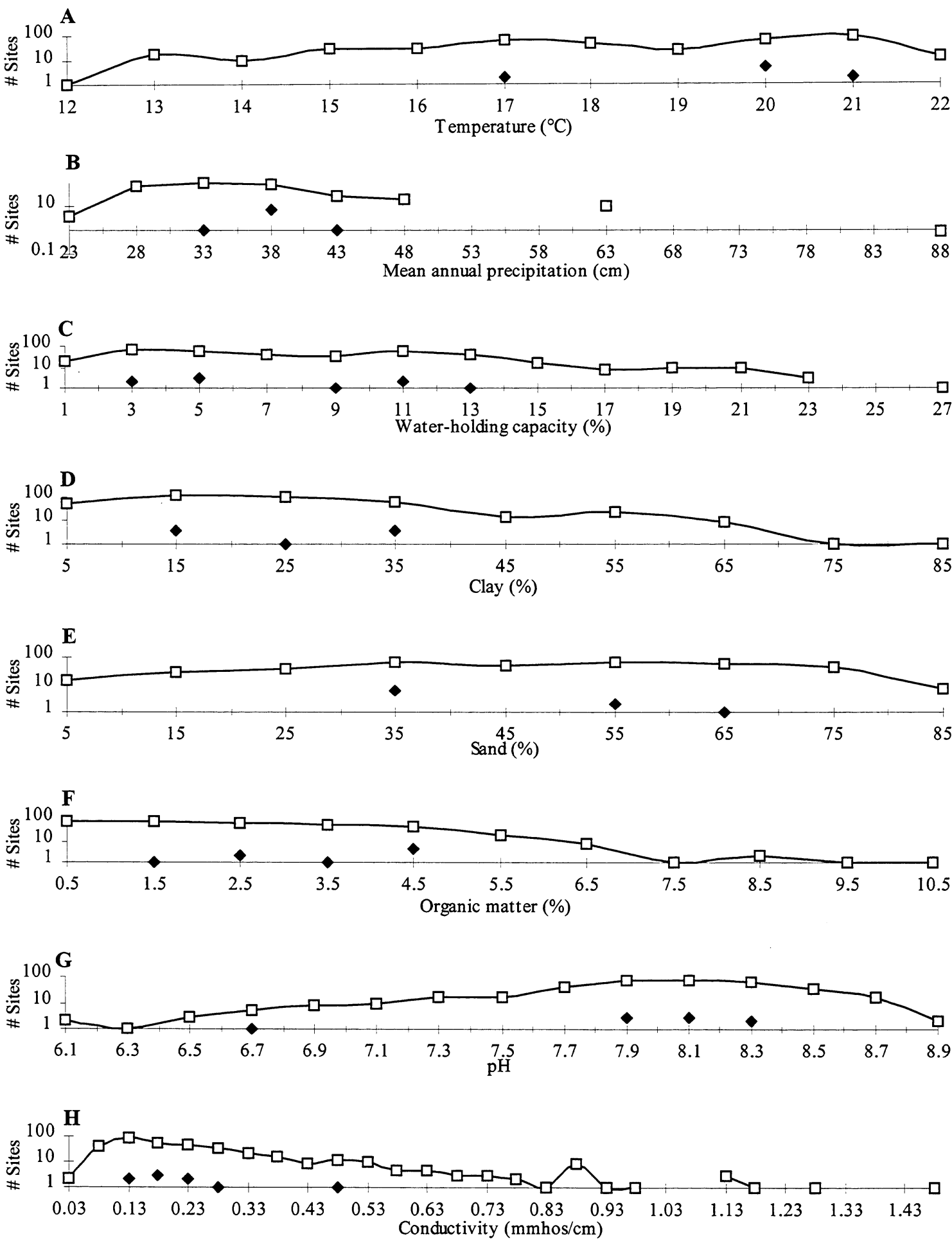

Figure 41.2. The distribution of Ratibida columnifera sites (solid diamonds) and all roadside sites (open squares) across nine site characteristics. Where the mean of sites occupied by Ratibida columnifera is significantly $(\mathrm{p}<0.05)$ different from the mean of all sites, both are shown in the upper right of the graph. 


\section{Rosa woodsii (Rowo)}

Common name: wood's rose

Family: Rosaeceae

Origin: Native.

Duration and Habit ${ }^{1}$ : Perennial Shrub, vegetatively reproducing.

Environmental type: Rowo cover (\%) does not differ between types (Fig. 42.1A).

Temperature: Summer temperature does not differ between average Rowo sites and average roadside sites (Fig. 42.2A).

Precipitation: Annual precipitation at average Rowo sites does not differ from average roadside sites (Fig. 42.2B).

Water-holding capacity: WHC does not differ between average Rowo sites and average roadside sites (Fig. 42.2C).

Clay: Clay does not differ between average Rowo sites and average roadside sites (Fig. 42.2D).

Sand: Sand does not differ between average Rowo sites and average roadside sites (Fig. 42.2E).

Organic matter: OM does not differ between average Rowo sites and average roadside sites (Fig. 42.2F).

pH: pH does not differ between average Rowo sites and average roadside sites (Fig. 42.2G).

Conductivity: Conductivity does not differ between average Rowo sites and average roadside sites (Fig. $42.2 \mathrm{H})$.

Position ${ }^{3}$ : Performance of Rowo does not vary with position.

Aspect: On roadsides, the performance of Rowo does not vary with aspect (Fig. 42.1B).

\footnotetext{
${ }^{1}$ Refer to the introduction (p37) for a description of each factor.

${ }^{2}$ Species presence varies significantly with this factor.

${ }^{3}$ Inslope/backslope effects cannot be determined from Figure 42.1B below
}
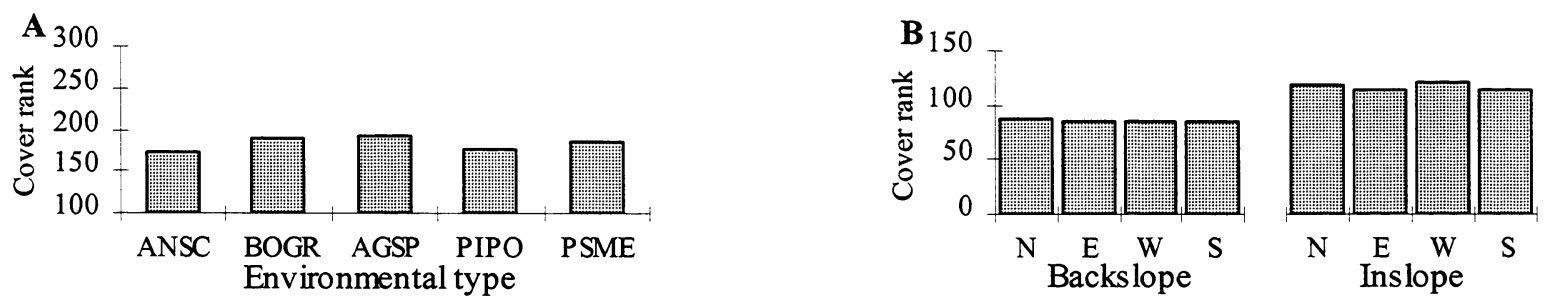

Figure 42.1. A) Relative performance of Rosa woodsii in five environmental types. B) Effect of position and aspect on the performance of Rosa woodsii. Categories sharing a letter are not significantly $(\mathrm{p}<0.05)$ different. 

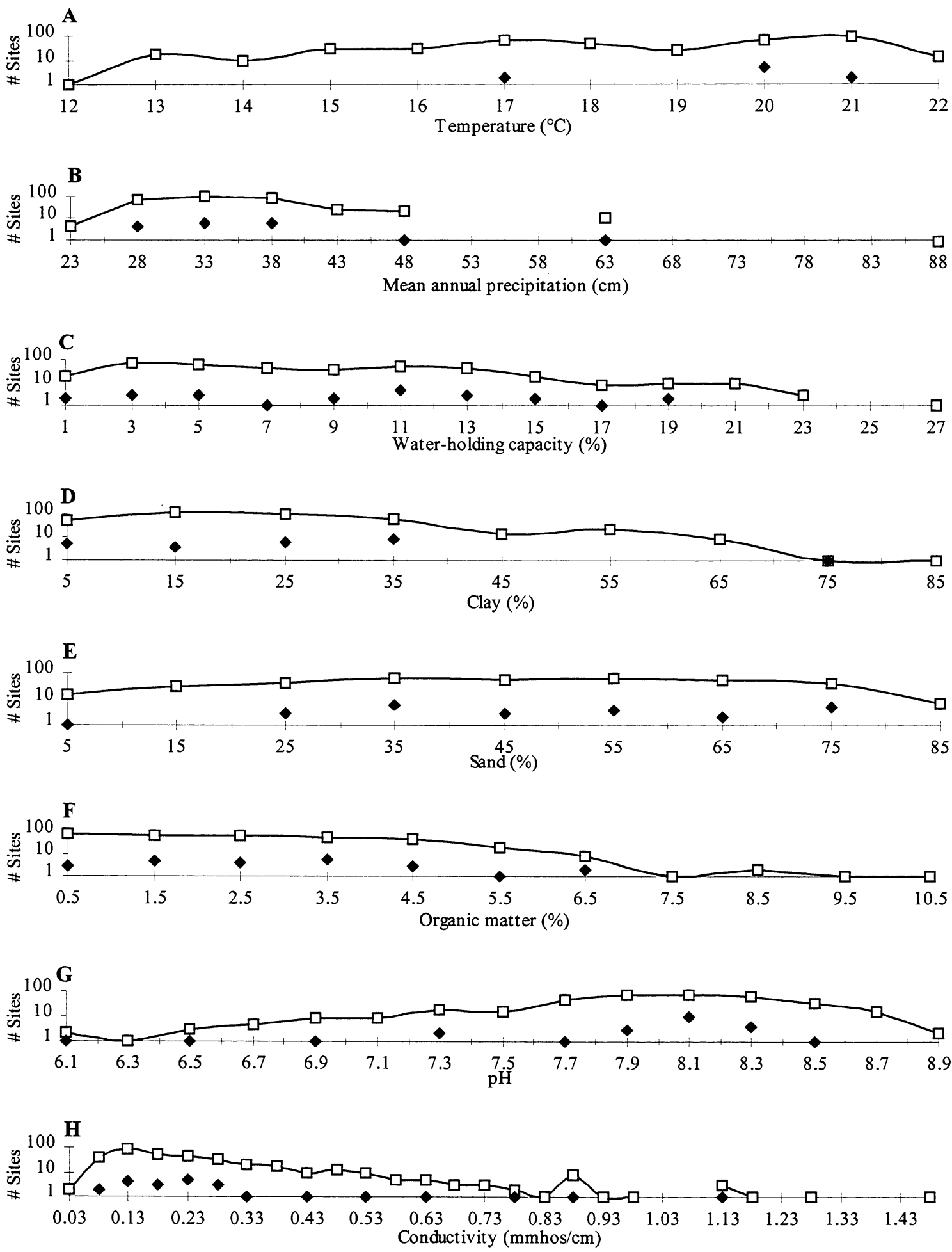

Figure 42.2 The distribution of Rosa woodsii sites (solid diamonds) and all roadside sites (open squares) across nine site characteristics. Where the mean of sites occupied by Rosa woodsii is significantly $(p<0.05)$ different from the mean of all sites, both are shown in the upper right of the graph. 


\section{Sphaeralcea coccinea (Spco)}

Common name: scarlett globe-mallow

Family: Malvaceae

Origin: Native.

Duration and Habit ${ }^{1}$ : Perennial Forb, vegetatively reproducing.

Environmental type: Spco cover (\%) does not differ between types (Fig. 43.1A).

Temperature: Summer temperature does not differ between average Spco sites and average roadside sites (Fig. 43.2A).

Precipitation ${ }^{2}$ : Annual precipitation at average Spco sites is less than at average roadside sites (Fig. 43.2B).

Water-holding capacity: WHC does not differ between average Spco sites and average roadside sites (Fig. 43.2C).

Clay: Clay does not differ between average Spco sites and average roadside sites (Fig. 43.2D).

Sand: Sand does not differ between average Spco sites and average roadside sites (Fig. 43.2E).

Organic matter: OM does not differ between average Spco sites and average roadside sites (Fig. 43.2F).

pH: $\mathrm{pH}$ does not differ between average Spco sites and average roadside sites (Fig. 43.2G).

Conductivity: Conductivity does not differ between average Spco sites and average roadside sites (Fig. 43.2H).

Position $^{2,3}$ : Spco performs better on backslopes than inslopes.

Aspect: Spco cover does not vary with aspect (Fig 43.1B).

\footnotetext{
${ }^{1}$ Refer to the introduction (p37) for a description of each factor.

${ }^{2}$ Species presence varies significantly with this factor.

${ }^{3}$ Inslope/backslope effects cannot be determined from Figure 43.1B below
}
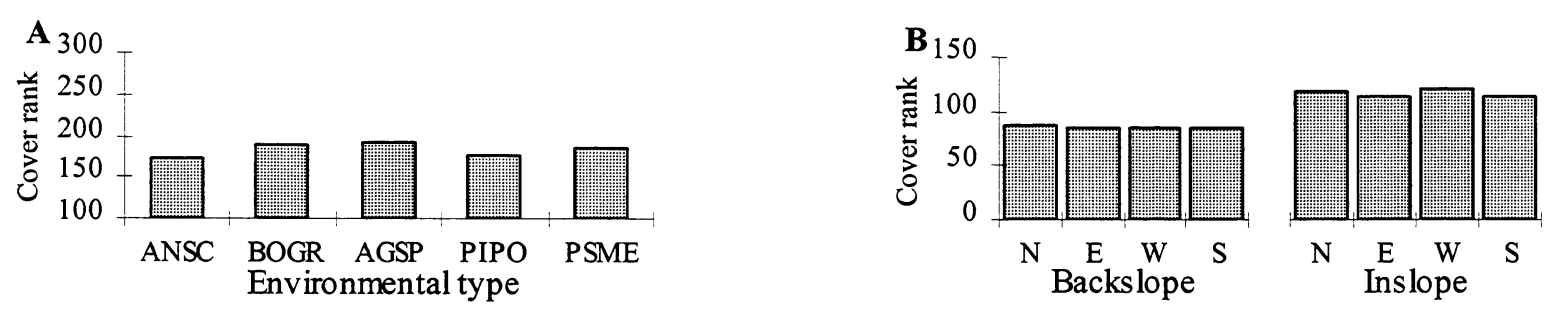

Figure 43.1. A) Relative performance of Sphaeralcea coccinea in five environmental types. B) Effect of position and aspect on the performance of Sphaeralcea coccinea. Categories sharing a letter are not significantly $(\mathrm{p}<0.05)$ different 

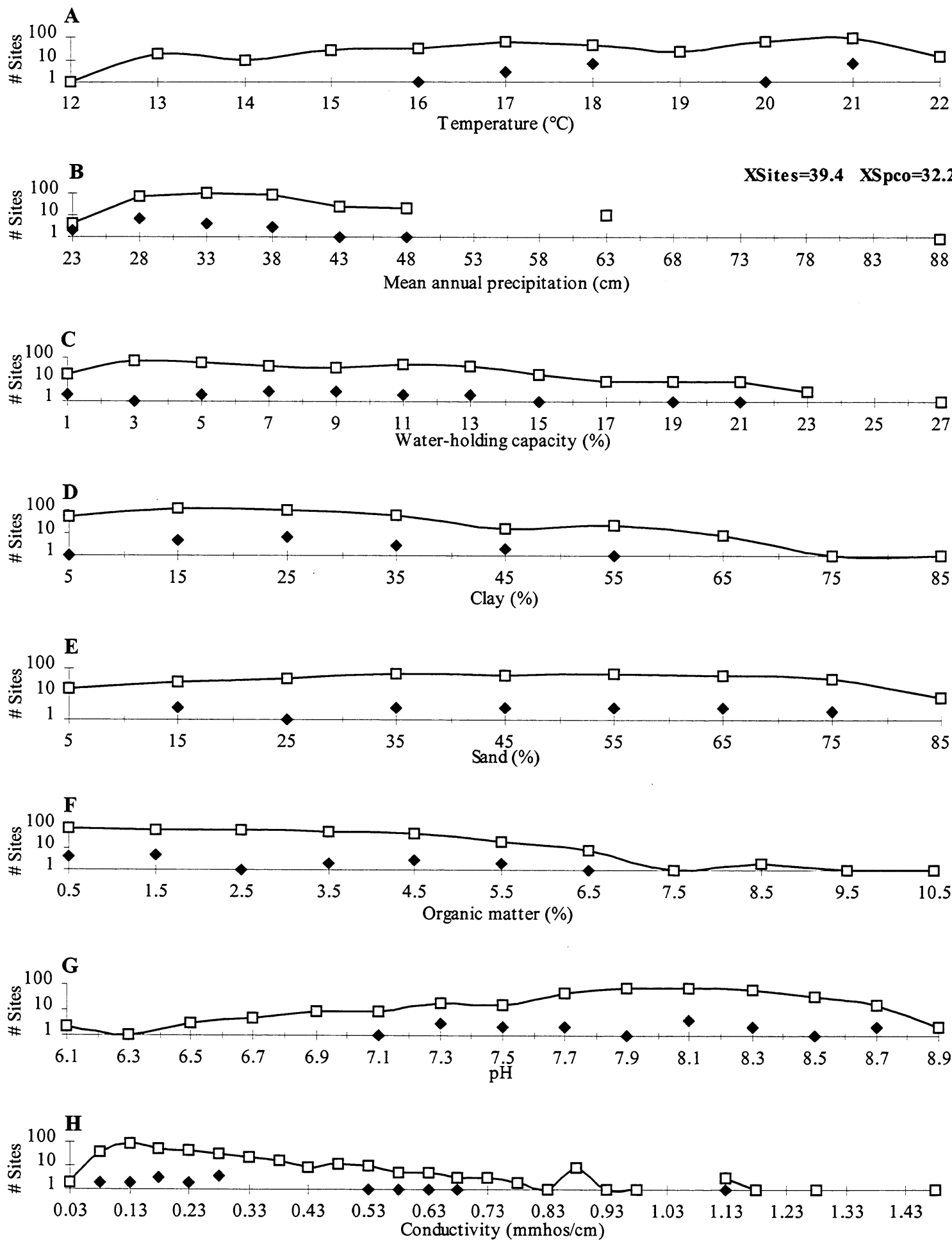

Figure 43.2. The distribution of Sphaeralcea coccinea sites (solid diamonds) and all roadside sites (open squares) across nine site characteristics. Where the mean of sites occupied by Sphaeralcea coccinea is significantly $(\mathrm{p}<0.05)$ different from the mean of all sites, both are shown in the upper right of the graph. 


\section{Stipa comata (Stco)}

Common name: needle and thread grass

Family: Poaceae

Origin: Native.

Duration and Habit ${ }^{1}$ : Perennial Grass, not vegetatively reproducing.

Environmental Type ${ }^{2}$ : Stco cover (\%) is highest in the AGSP and BOGR types, lower the ANSC and PSME types and lowest in the PIPO type (Fig. 44.1A).

Temperature: Summer temperature does not differ between average Stco sites and average roadside sites (Fig. 44.2A).

Precipitation ${ }^{2}$ : Summer precipitation at average Stco sites is less than at the average roadsides site (Fig. 44.2B).

Water-holding capacity: WHC does not differ between average Stco sites and an average roadside sites (Fig. 44.2C).

Clay: Clay does not differ between average Stco sites and average roadside sites (Fig. 44.2D).

Sand: Sand does not differ between average Stco sites and average roadside sites (Fig. 44.2E).

Organic matter: OM does not differ between average Stco sites and average roadside sites (Fig. 44.2F).

pH: $\mathrm{pH}$ does not differ between average Stco sites and average roadside sites (Fig. 44.2G).

Conductivity: Conductivity does not differ between average Stco sites and average roadside sites (Fig. 44.2H).

Position $^{2,3}$ : Stco performance on backslopes is better than on inslopes.

Aspect $^{2}$ : On backslopes, Stco performs worst on SW slopes (Fig 44.1B).

\footnotetext{
${ }^{1}$ Refer to the introduction (p37) for a description of each factor.

${ }^{2}$ Species presence varies significantly with this factor.

${ }^{3}$ Inslope/backslope effects cannot be determined from Figure 22.1B below
}
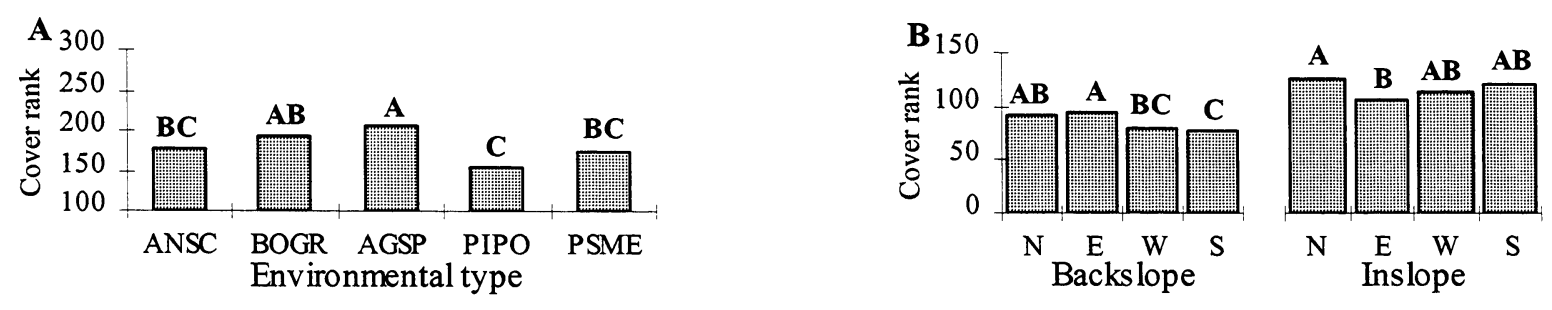

Figure 44.1. A) Relative performance of Stipa comata in five environmental types. B) Effect of position and aspect on the performance of Stipa comata. Categories sharing a letter are not significantly $(\mathrm{p}<0.05)$ different. 

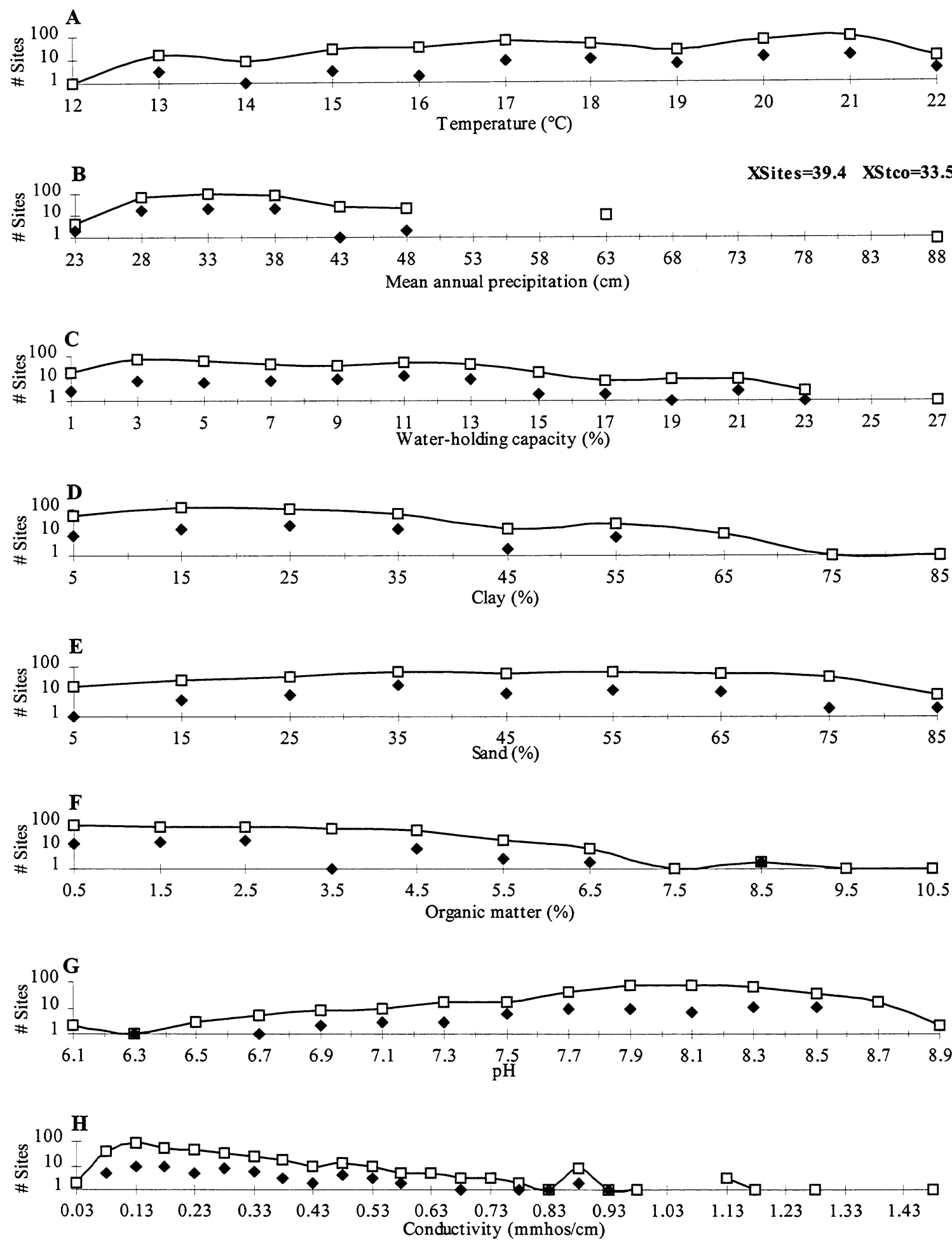

Figure 44.2. The distribution of Stipa comata sites (solid diamonds) and all roadside sites (open squares) across nine site characteristics. Where the mean of sites occupied by Stipa comata is significantly $(p<0.05)$ different from the mean of all sites, both are shown in the upper right of the graph. 


\section{Stipa viridula (Stvi)}

Common name: green needle grass

Family: Poaceae

Origin: Native.

Duration and Habit ${ }^{1}$ : Perennial Grass, not vegetatively reproducing.

Environmental Type ${ }^{2}$ : Stvi cover (\%) is the highest in the ANSC, BOGR and PSME types and lower in the PIPO and AGSP types (Fig. 45.1A).

Temperature: Summer temperature does not differ between average Stvi sites and average roadside sites (Fig. 45.2A).

Precipitation: Annual precipitation at average Stvi sites does not differ from average roadside sites (Fig. 45.2B).

Water-holding capacity: WHC does not differ between average Stvi sites and average roadside sites (Fig. 45.2C).

Clay: Clay does not differ between average Stvi sites and average roadside sites (Fig. 45.2D).

Sand: Sand does not differ between average Stvi sites and average roadside sites (Fig. 45.2E).

Organic matter: OM does not differ between average Stvi sites and average roadside sites (Fig. 45.2F).

pH: pH does not differ between average Stvi sites and average roadside sites (Fig. 45.2G).

Conductivity: Conductivity does not differ between average Stvi sites and average roadside sites (Fig. 45.2H).

Position $^{3}$ : On roadsides, Stvi cover does not respond to position.

Aspect: Stvi performance does not vary with aspect (Fig 45.1B).

\footnotetext{
${ }^{1}$ Refer to the introduction (p37) for a description of each factor.

${ }^{2}$ Species presence varies significantly with this factor.

${ }^{3}$ Inslope/backslope effects cannot be determined from Figure 45.1B below
}
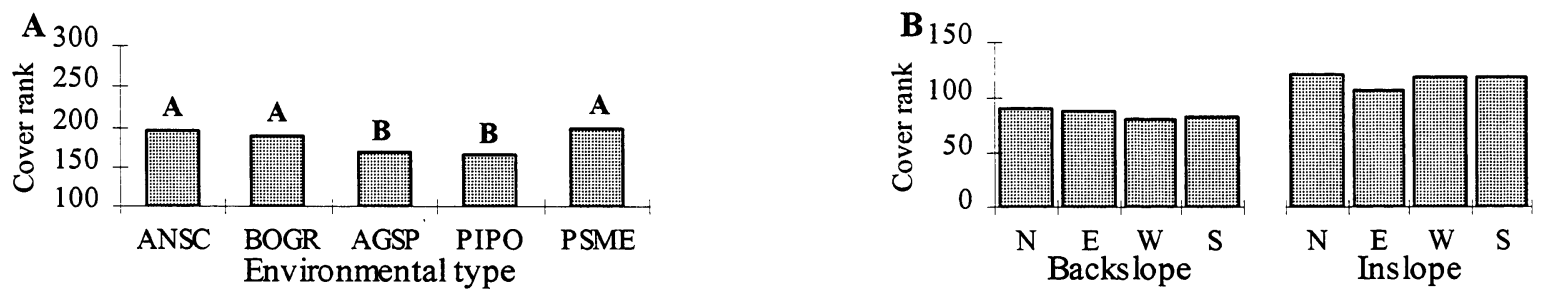

Figure 45.1. A) Relative performance of Stipa viridula in five environmental types. B) Effect of position and aspect on the performance of Stipa viridula. Categories sharing a letter are not significantly $(\mathrm{p}<0.05)$ different. 

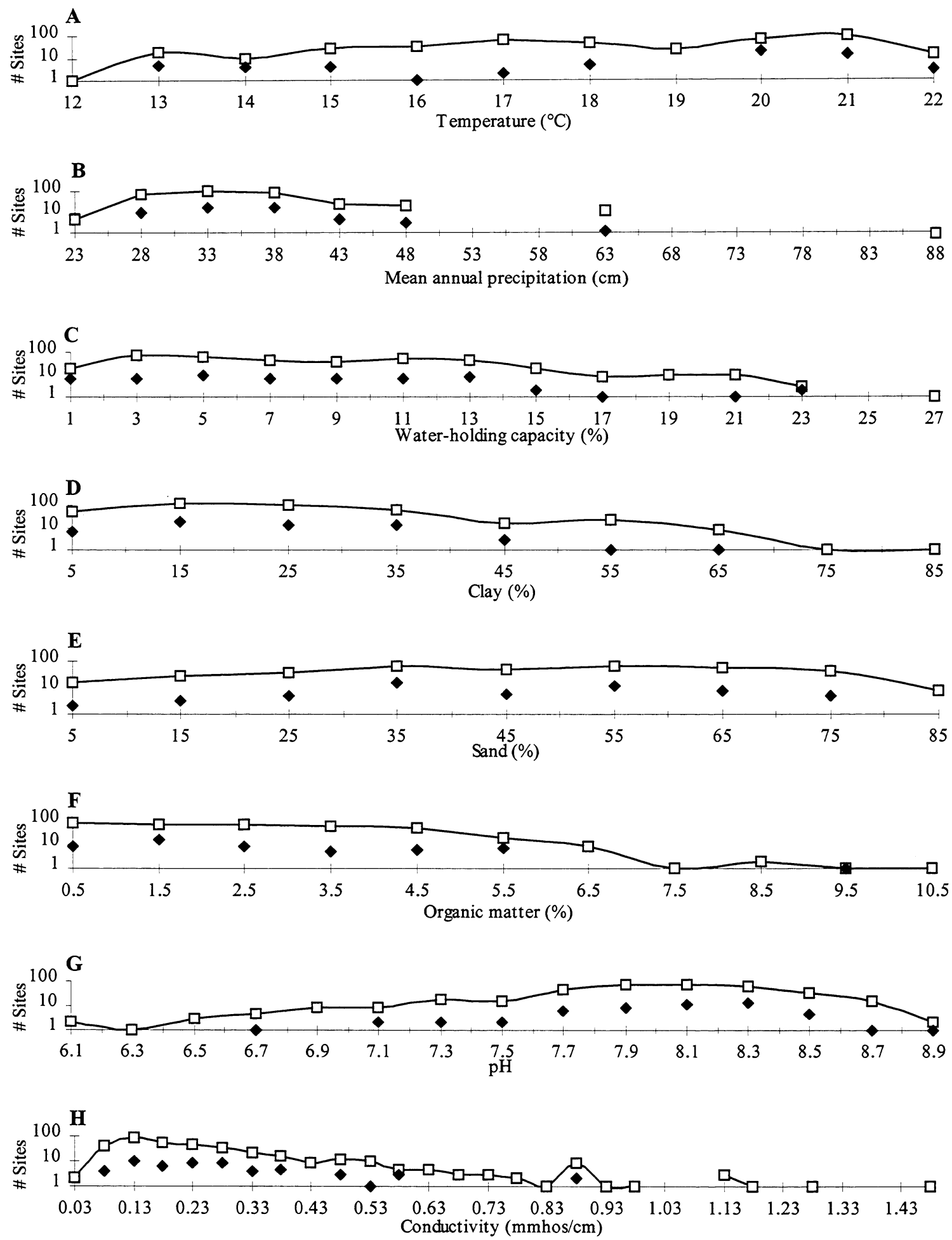

Figure 45.2. The distribution of Stipa viridula sites (solid diamonds) and all roadside sites (open squares) across nine site characteristics. Where the mean of sites occupied by Stipa viridula is significantly $(p<0.05)$ different from the mean of all sites, both are shown in the upper right of the graph. 


\section{Symphoricarpos albus (Syal)}

Common name: common snowberry

Family: Caprifoliaceae

Origin: Native.

Duration and Habit ${ }^{1}$ : Perennial Shrub, vegetatively reproducing.

Environmental type: Syal cover (\%) does not differ between types (Fig. 46.1A).

Temperature: Summer temperature does not differ between average Syal sites and average roadside sites (Fig. 46.2A).

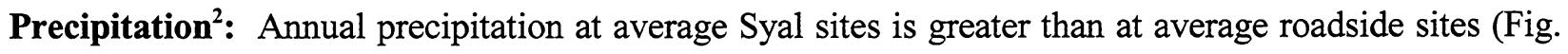
46.2B).

Water-holding capacity: WHC does not differ between average Syal sites and average roadside sites (Fig. 46.2C).

Clay: Clay does not differ between average Syal sites and average roadside sites (Fig. 46.2D).

Sand: Sand does not differ between average Syal sites and average roadside sites (Fig. 46.2E).

Organic matter: OM does not differ between average Syal sites and average roadside sites (Fig. 46.2F).

pH: $\mathrm{pH}$ does not differ between average Syal sites and average roadside sites (Fig. 46.2G).

Conductivity: Conductivity does not differ between average Syal sites and average roadside sites (Fig. 46.2H).

Position $^{3}$ : On roadsides, Syal cover does not respond to position.

Aspect: On roadsides Syal cover does not respond to aspect (Fig 46.1B).

\footnotetext{
${ }^{1}$ Refer to the introduction (p37) for a description of each factor.

${ }^{2}$ Species presence varies significantly with this factor.

${ }^{3}$ Inslope/backslope effects cannot be determined from Figure 46.1B. below
}
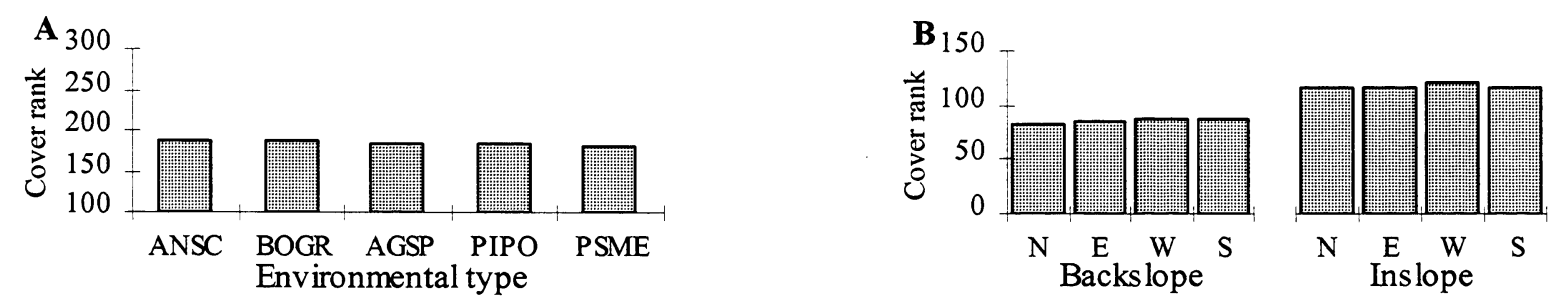

Figure 46.1. A) Relative performance of Symphoricarpos albus in five environmental types. B) Effect of position and aspect on the performance of Symphoricarpos albus. Categories sharing a letter are not significantly $(\mathrm{p}<0.05)$ different. 

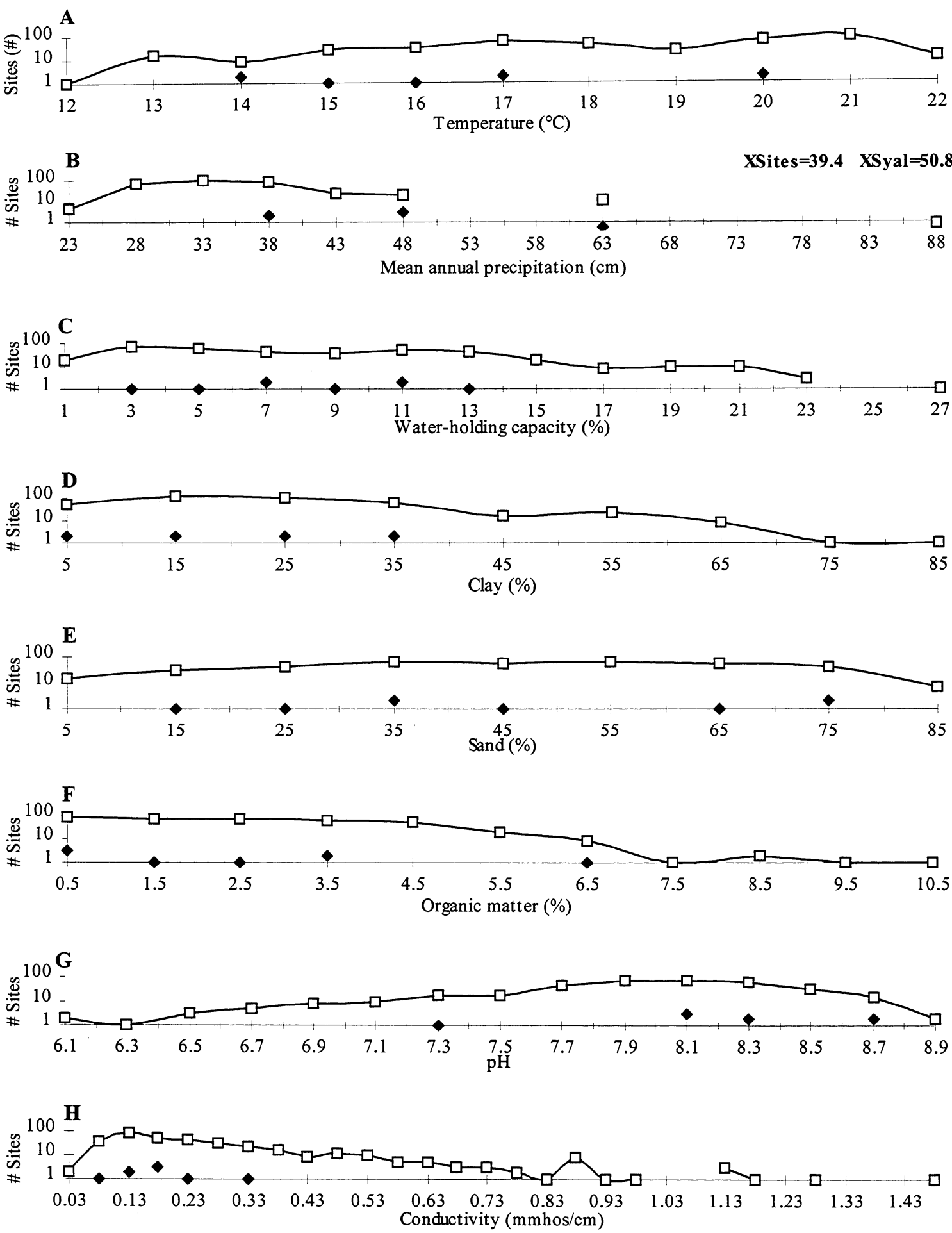

Figure 46.2. The distribution of Symphoricarpos albus sites (solid diamonds) and all roadside sites (open squares) across nine site characteristics. Where the mean of sites occupied by Symphoricarpos albus is significantly $(\mathrm{p}<0.05)$ different from the mean of all sites, both are shown in the upper right of the graph. 


\section{Thlaspi arvense (Thar)}

Common name: field pennycress

Family: Brassicaeae

Origin: Exotic.

Duration and Habit ${ }^{1}$ : Annual Forb, vegetatively reproducing.

Environmental Type ${ }^{2}$ : Thar cover (\%) is highest in the PSME type and BOGR type and lowest in the ANSC type (Fig. 47.1A).

Temperature: Summer temperature does not differ between average Thar sites and average roadside sites (Fig. 47.2A).

Precipitation: Annual precipitation at average Thar sites is not different from precipitation at average roadside sites (Fig. 47.2B).

Water-holding capacity ${ }^{2}$ : WHC in average Thar sites is higher than at average roadside sites (Fig. 47.2C).

Clay: Clay does not differ between average Thar sites and average roadside sites (Fig. 47.2D).

Sand: Sand does not differ between average Thar sites and average roadside sites (Fig. 47.2E).

Organic matter: OC does not differ between average Thar sites and average roadside sites (Fig. 47.2F).

pH: pH does not differ between average Thar sites and average roadside sites (Fig. 47.2G).

Conductivity: Conductivity does not differ between average Thar sites and average roadside sites (Fig. 47.2H).

Position $^{2,3}$ : Thar performance on backslopes is better than on inslopes.

Aspect: On roadsides, Thar cover does not respond to aspect (Fig 47.1B).

\footnotetext{
${ }^{1}$ Refer to the introduction (p37) for a description of each factor.

${ }^{2}$ Species presence varies significantly with this factor.

${ }^{3}$ Inslope/backslope effects cannot be determined from Figure 47.1B below
}
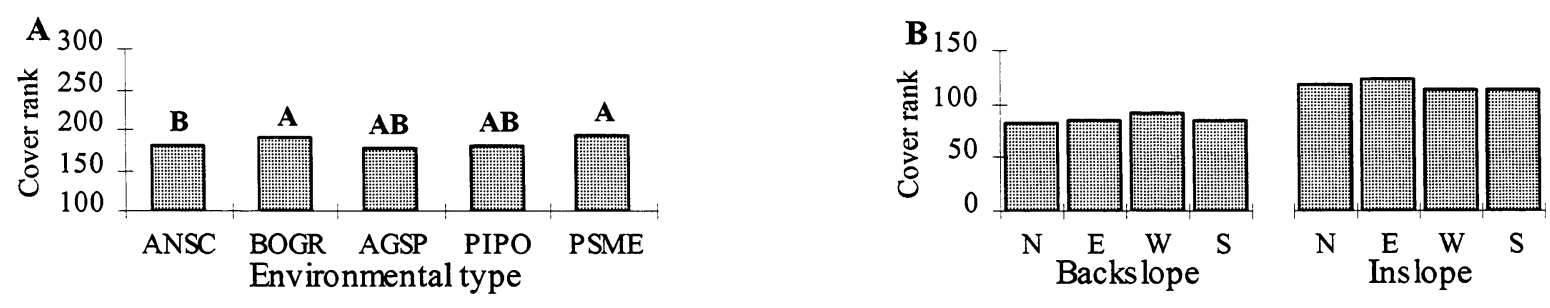

Figure 47.1. A) Relative performance of Thlaspi arvense in five environmental types. B) Effect of position and aspect on the performance of Thlaspi arvense. Categories sharing a letter are not significantly $(p<0.05)$ different 

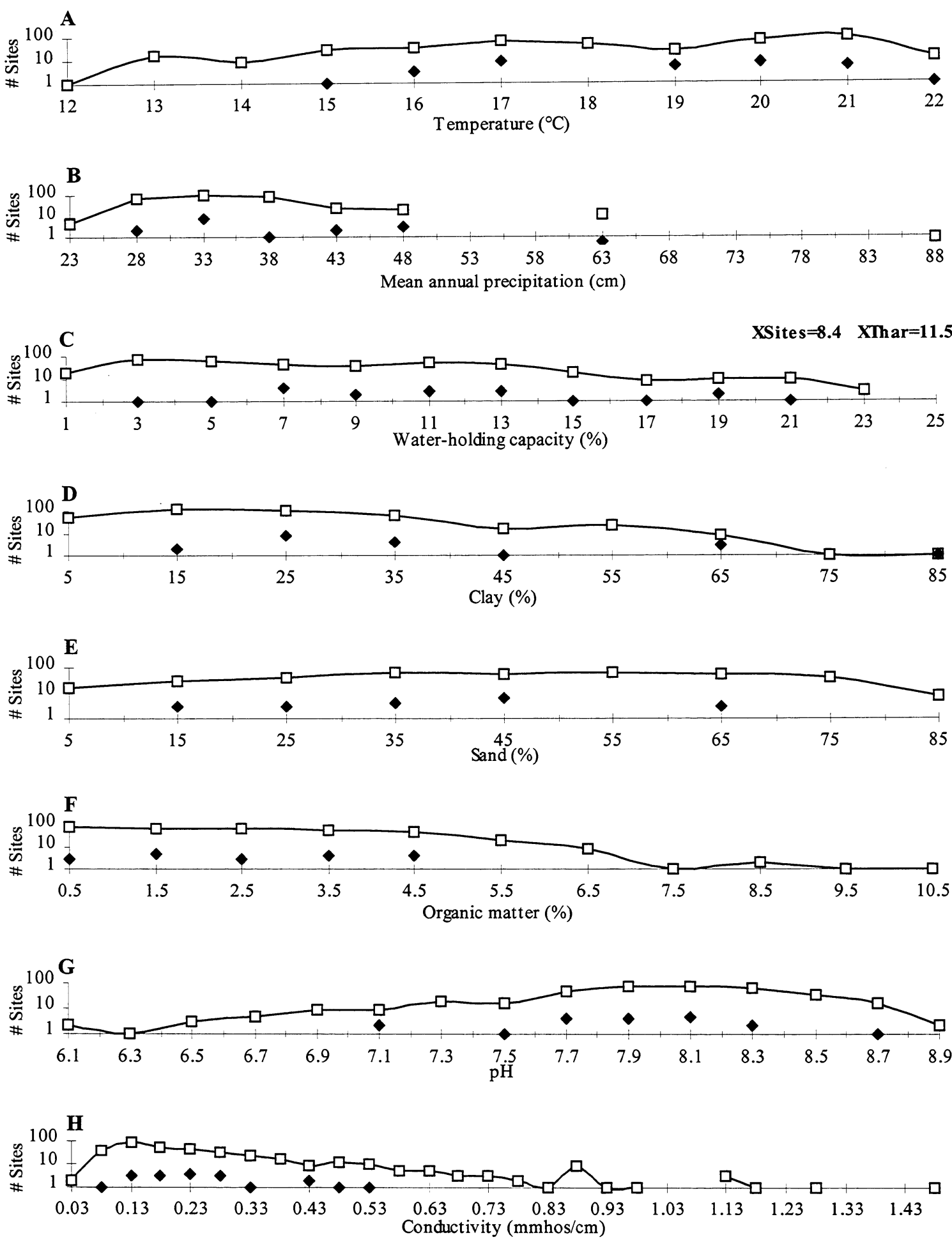

Figure 47.2. The distribution of Thlaspi arvense sites (solid diamonds) and all roadside sites (open squares) across nine site characteristics. Where the mean of sites occupied by Thlaspi arvense is significantly $(\mathrm{p}<0.05)$ different from the mean of all sites, both are shown in the upper right of the graph. 


\section{Tragopogon dubius (Trdu)}

Common name: western salsify

Family: Asteraceae

Origin: Exotic.

Duration and Habit ${ }^{1}$ : Biennial Forb, not vegetatively reproducing.

Environmental type: Trdu cover (\%) does not differ between types (Fig. 48.1A).

Temperature: Summer temperature does not differ between average Trdu sites and average roadside sites (Fig. 48.2A).

Precipitation: Annual precipitation at average Trdu sites does not differ from average roadside sites (Fig. 48.2B).

Water-holding capacity: WHC does not differ between average Trdu sites and average roadside sites (Fig. 48.2C).

Clay: Clay does not differ between average Trdu sites and average roadside sites (Fig. 48.2D).

Sand: Sand does not differ between average Trdu sites and average roadside sites (Fig. 48.2E).

Organic matter: OM does not differ between average Trdu sites and average roadside sites (Fig. 48.2F).

pH: $\mathrm{pH}$ does not differ between average Trdu sites and average roadside sites (Fig. 48.2G).

Conductivity: Conductivity does not differ between average Trdu sites and average roadside sites (Fig. $48.2 \mathrm{H})$.

Position $^{3}$ : On roadsides, Trdu cover does not respond to position.

Aspect: Trdu cover is insignificantly lower on EW than NS slopes (Fig. 48 1B).

\footnotetext{
${ }^{1}$ Refer to the introduction (p37) for a description of each factor.

${ }^{2}$ Species presence varies significantly with this factor.

${ }^{3}$ Inslope/backslope effects cannot be determined from Figure 48.1B below
}
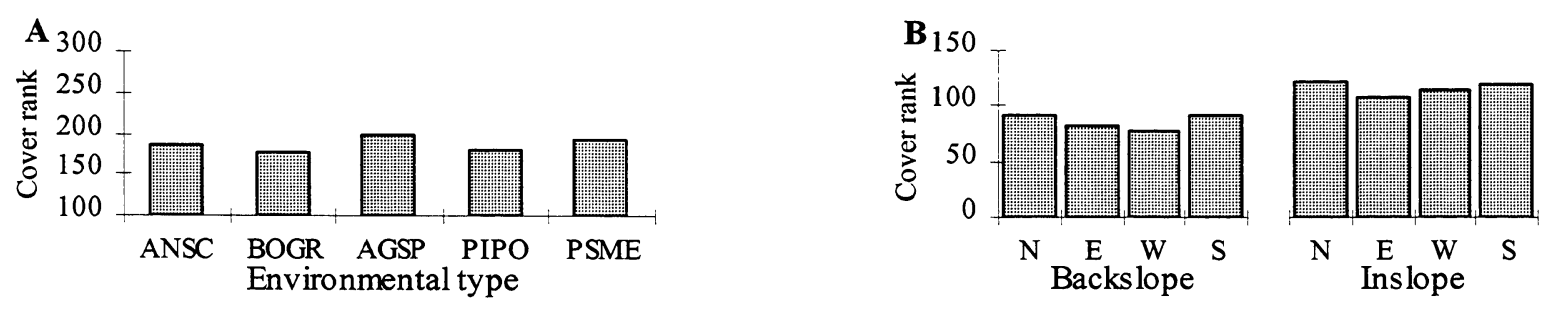

Figure 48.1. A) Relative performance of Tragopogon dubius in five environmental types. B) Effect of position and aspect on the performance of Tragopogon dubius. Categories sharing a letter are not significantly $(p<0.05)$ different. 

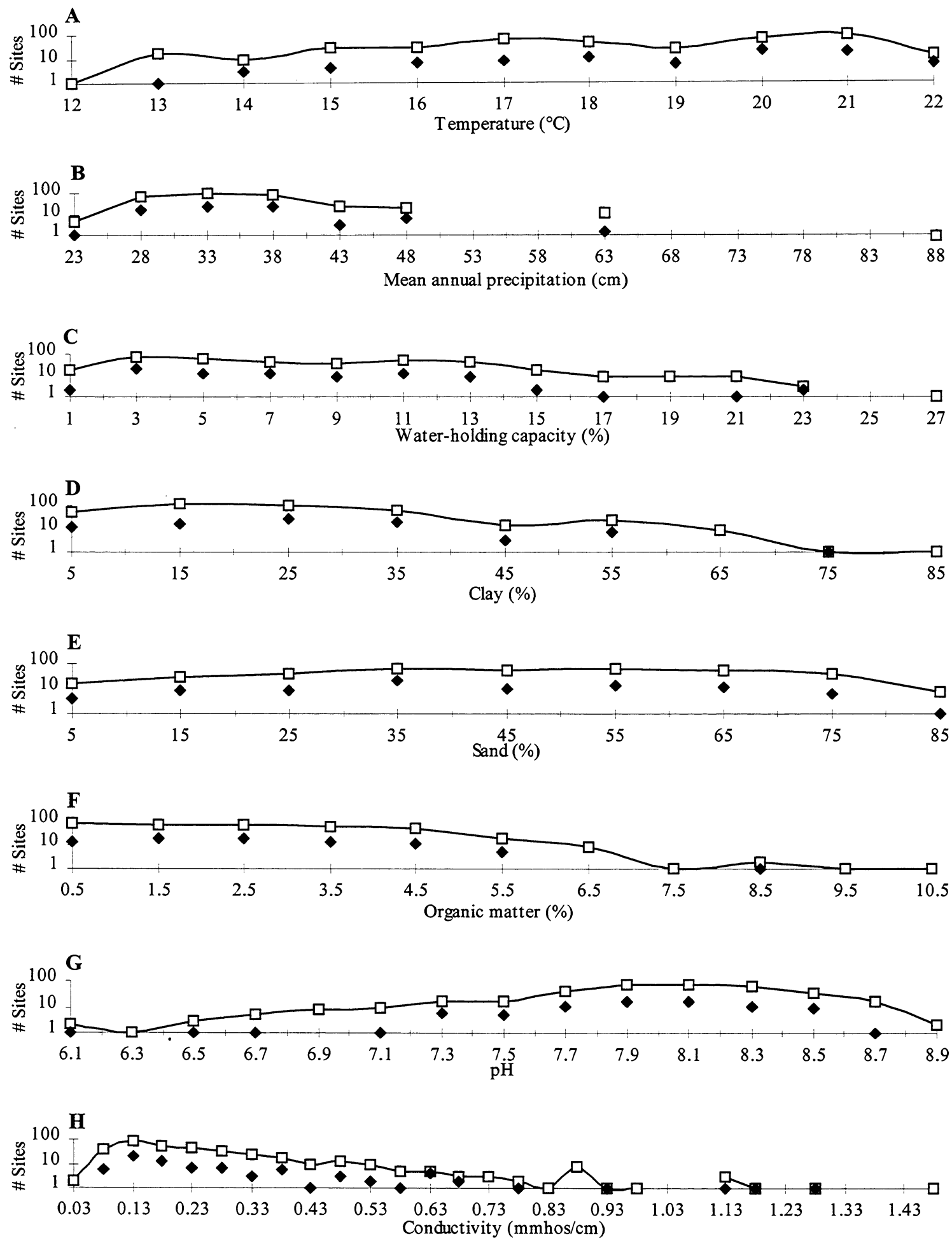

Figure 48.2. The distribution of Tragopogon dubius sites (solid diamonds) and all roadside sites (open squares) across nine site characteristics. Where the mean of sites occupied by Tragopogon dubius is significantly $(\mathrm{p}<0.05)$ different from the mean of all sites, both are shown in the upper right of the graph. 


\section{Trifolium hybridum (Trhy)}

Common name: alsike clover

Family: Fabaceae

Origin: Exotic.

Duration and Habit ${ }^{1}$ : Perennial Forb, vegetatively reproducing.

Environmental Type': Trhy cover (\%) is highest in the PSME type (Fig. 49.1A).

Temperature ${ }^{2}$ : Summer temperature at average Trhy sites is lower than at average roadside sites (Fig. 49.2A).

Precipitation²: Annual precipitation at average Trhy sites is greater than at average roadside sites (Fig. 49.2B).

Water-holding capacity: WHC does not differ between average Trhy sites and average roadside sites (Fig. 49.2C).

Clay: Clay does not differ between average Trhy sites and average roadside sites (Fig. 49.2D).

Sand: Sand does not differ between average Trhy sites and average roadside sites (Fig. 49.2E).

Organic matter: OM does not differ between average Trhy sites and average roadside sites (Fig. 49.2F).

$\mathbf{p H}^{2}: \mathrm{pH}$ in average Trhy sites is lower than average roadside sites (Fig. 49.2G).

Conductivity $^{2}$ : Conductivity at average Trhy sites is lower than at average roadside sites (Fig. 49.2H).

Position ${ }^{3}$ : On roadsides, Trhy cover does not respond to position.

Aspect: On roadsides, Trhy cover does not respond to aspect (Fig 49.1B).

\footnotetext{
${ }^{1}$ Refer to the introduction (p37) for a description of each factor.

${ }^{2}$ Species presence varies significantly with this factor.

${ }^{3}$ Inslope/backslope effects cannot be determined from Figure 49.1B below.
}
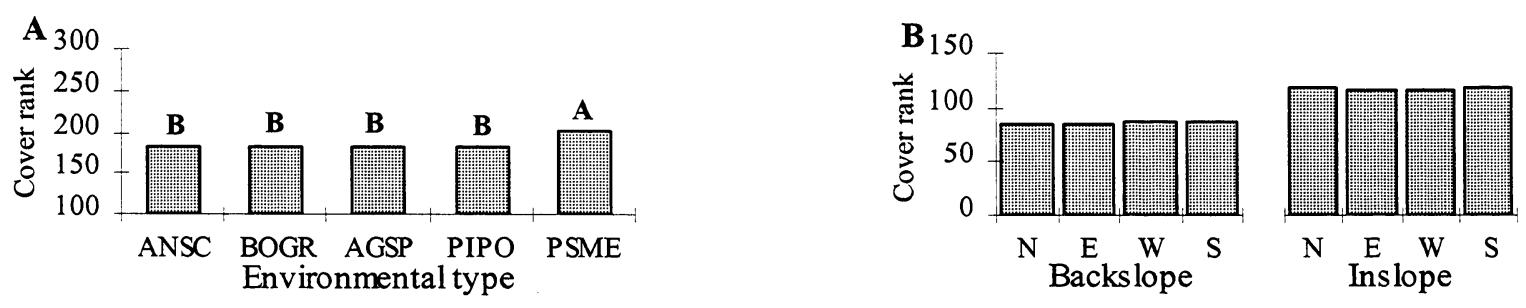

Figure 49.1 A) Relative performance of Trifolium hybridum in five environmental types. B) Effect of position and aspect on the performance of Trifolium hybridum. Categories sharing a letter are not significantly $(\mathrm{p}<0.05)$ different. 

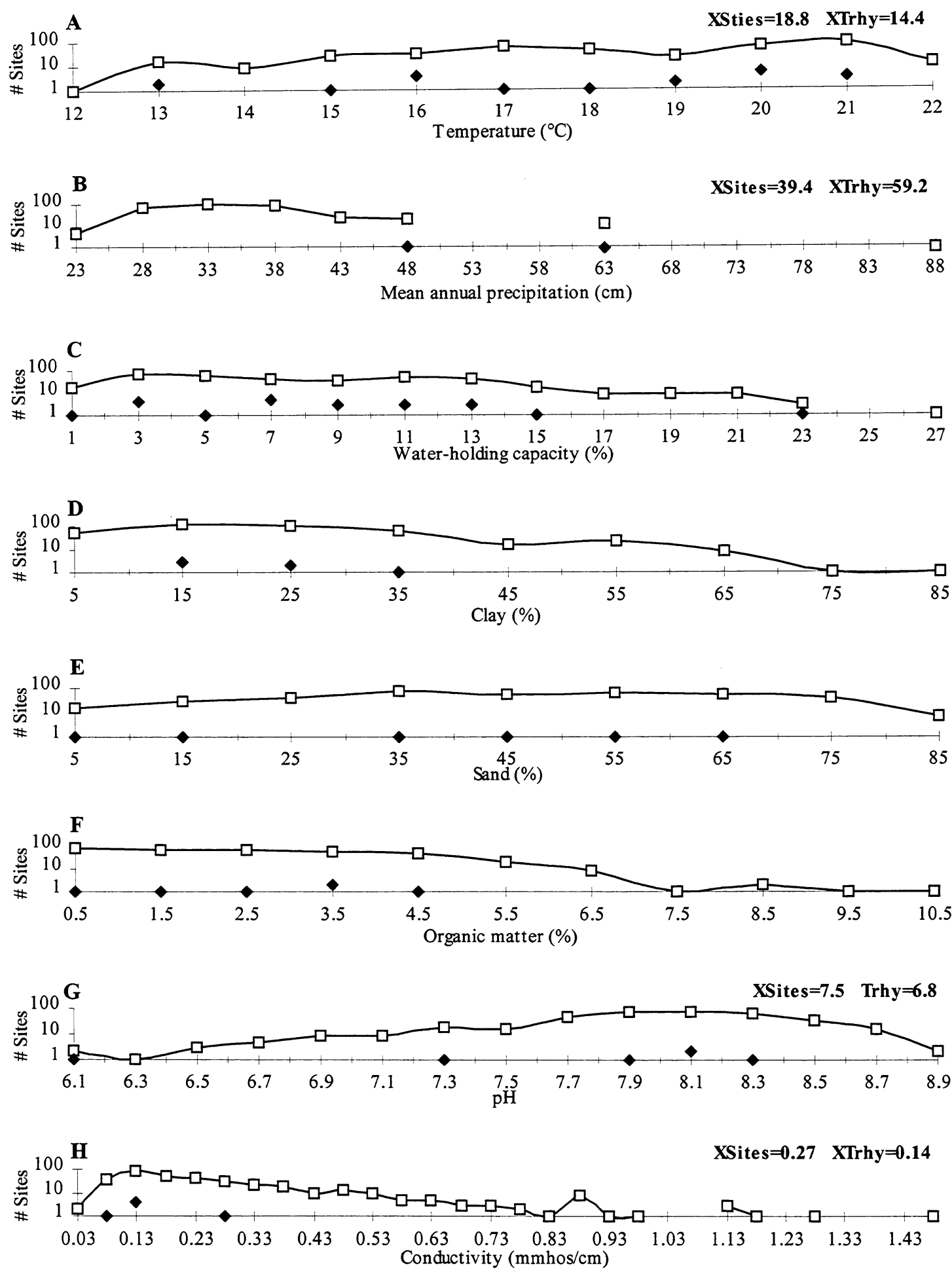

Figure 49.2. The distribution of Trifolium hybridum sites (solid diamonds) and all roadside sites (open squares) across nine site characteristics. Where the mean of sites occupied by Trifolium hybridum is significantly $(\mathrm{p}<0.05)$ different from the mean of all sites, both are shown in the upper right of the graph. 


\section{Verbascum thapsus (Veth)}

Common name: flannel mullein

Family: Scrophulariaceae

Origin: Exotic.

Duration and Habit' ${ }^{1}$ : Biennial Forb, not vegetatively reproducing.

Environmental Type: Veth cover (\%) does not differ between types (Fig. 50.1A).

Temperature ${ }^{2}$ : Summer temperature at average Veth sites is lower than at average roadside sites (Fig. 50.2A).

Precipitation ${ }^{2}$ : Annual precipitation at average Veth sites is higher than at average roadside sites (Fig. 50.2B).

Water-holding capacity ${ }^{2}$ : WHC in average Veth sites is lower than in average roadside sites (Fig. 50.2C).

Clay: Clay does not differ between average Veth sites and average roadside sites (Fig. 50.2D).

Sand $^{2}$ : Sand in average Veth sites is higher than average roadside sites (Fig. 50.2E).

Organic matter: OM does not differ between average Veth sites and average roadside sites (Fig. 50.2F).

pH: $\mathrm{pH}$ does not differ between average Veth sites and average roadside sites (Fig. 50.2G).

Conductivity $^{2}$ : Conductivity in average Veth sites is lower than in average roadside sites (Fig. 50.2H).

Position ${ }^{3}$ : Veth performance does not vary with position.

Aspect: On roadsides, Veth performance does not vary with aspect (Fig. 50.1B).

\footnotetext{
${ }^{1}$ Refer to the introduction (p37) for a description of each factor.

${ }^{2}$ Species presence varies significantly with this factor.

${ }^{3}$ Inslope/backslope effects cannot be determined from Figure 50.1B below.
}
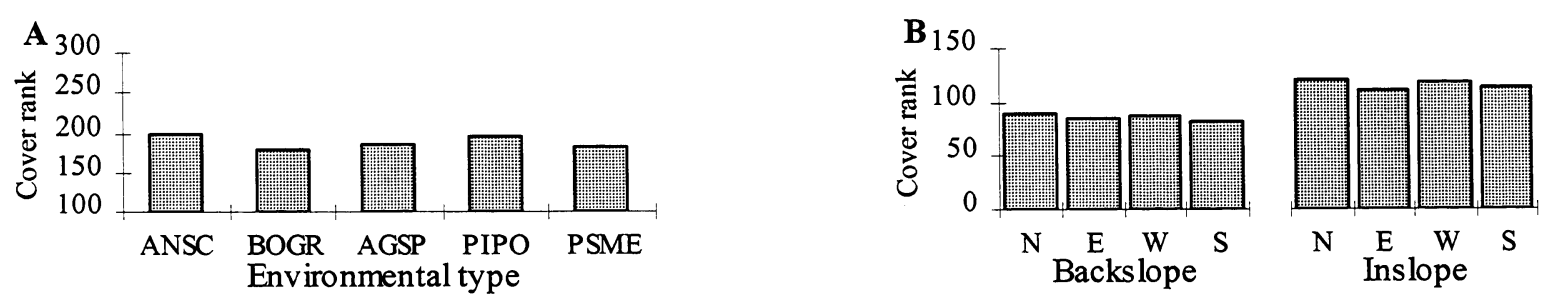

Figure 50.1. A) Relative performance of Verbascum thapsus. in five environmental types. B) Effect of position and aspect on the performance of Verbascum thapsus. Categories sharing a letter are not significantly $(\mathrm{p}<0.05)$ different. 

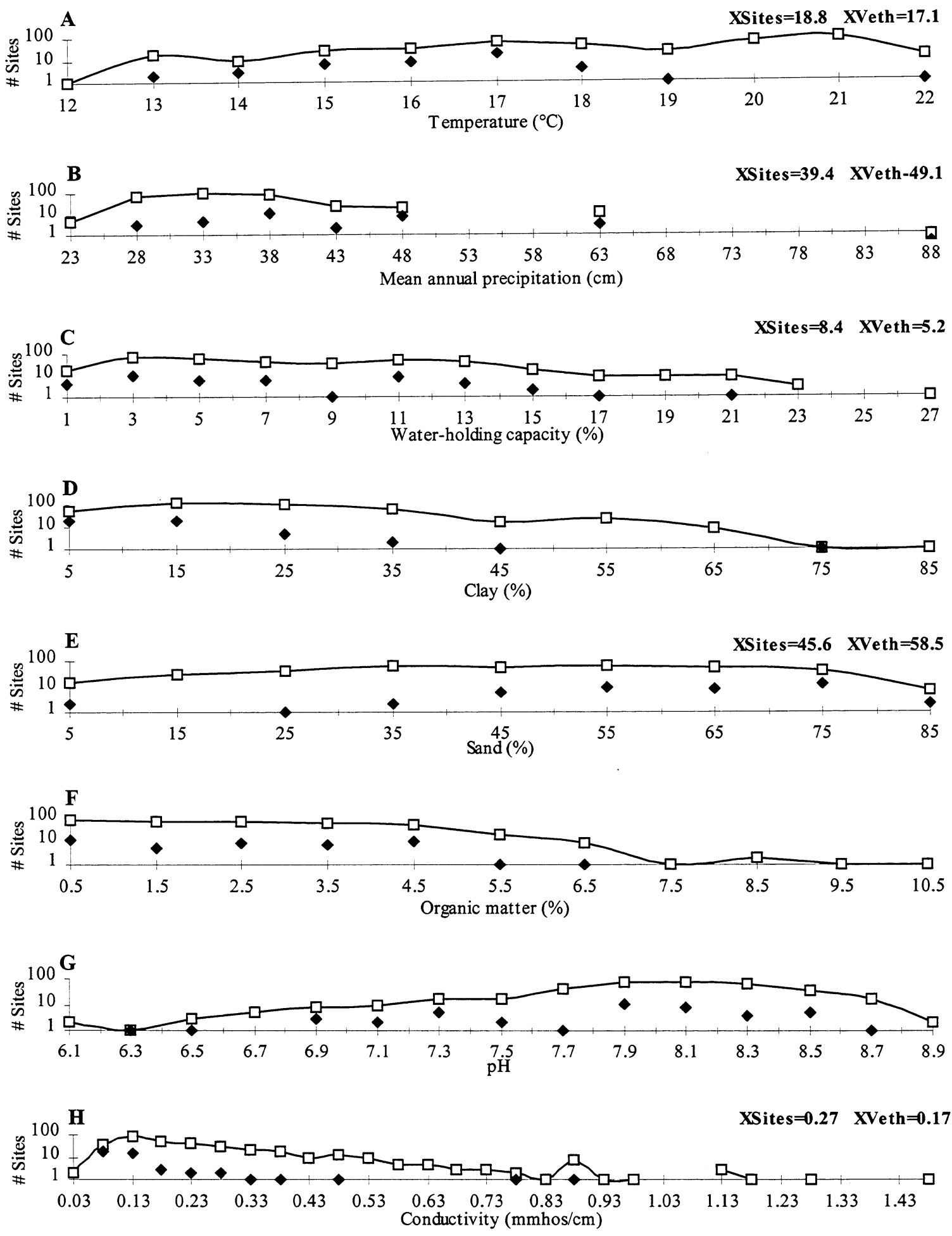

Figure 50.2. The distribution of Verbascum thapsus sites (solid diamonds) and all roadside sites (open squares) across nine site characteristics. Where the mean of sites occupied by Verbascum thapsus is significantly $(p<0.05)$ different from the mean of all site, both are shown in the upper right of the graph. 


\section{INDEX I}

\section{common names}

This index has three functions. It translates common names to both Latin names and acronyms. In addition, it locates articles on the environmental requirements of the species. The index does not locate items in Part I.

\author{
Common name \\ alfalfa \\ alyssum, pale \\ barley, foxtail \\ bentgrass, redtop \\ bluegrass, Canada \\ bluegrass, Kentucky \\ bluegrass, Sandberg \\ brome, snooth \\ canary-grass, reed \\ cheatgrass \\ clover, alsike \\ cyprus, summer \\ fescue, Idaho \\ fescue, sheep \\ fescue, rough \\ gaura, scarlet \\ grayfeather, dotted \\ globe-mallow, scarlet \\ gold-aster, hairy \\ grama, blue \\ junegrass, praire \\ knapweed, spotted \\ lettuce, prickly \\ lupine, silvery \\ medic, black \\ mullein, flannel \\ needle \& thread grass \\ needlegrass, green \\ oats, common \\ orchard-grass
}

Latin name

Medicago sativa

Alyssum alyssoides

Hordeum jubatum

Agrostis stolonifera

Poa compressa

Poa pratensis

Poa sandbergii

Bromus inermis

Phalaris arundinace

Bromus tectorum

Trifolium hybridum

Kochia scoparia

Festuca idahoensis

Festuca ovina

Festuca scabrella

Gaura coccinea

Liatris punctata

Sphaleraceae coccinea

Heterotheca villosa

Bouteloua gracilis

Koeleria nitida

Centaurea maculosa

Lactuca serriola

Lupinus argenteus

Medicago lupulina*

Verbascum thapsus

Stipa comata

Stipa viridula

Avena sativa

Dactylis glomerata
Acronym

MESA

ALAL

HOJU

AGST

POCO

POPR

POSA

BRIN

PHAR

BRTE

TRHY

KOSC

FEID

FEOV

FESC

GACO

LIPU

SPCO

HEVI

BOGR

KONI

CEMA

LASE

LUAR

MEPO

VETH

STCO

STVI

AVSA

DAGL
Page

109 
pennycress, field

prairie-clover, purple

prairie-coneflower, upright

pine, ponderosa

prickly-pear, plains

rose, wood's

salsify, western

sagebrush, fringed

sagebrush, mountain

sagebrush, silver

snakeweed, broom

snowberry, common

sweet-clover, yellow

thistle, Canada

timothy

wheatgrass, bluebunch

wheatgrass, crested

wheatgrass, thickspike

wheatgrass, western
Thlaspi arvensea

Dalea purpurea

Ratibida columnifera

Pinus ponderosa

Opuntia polyacantha

Rosa woodsii

Tragopogon dubius

Artemisia frigida

Artemisia tridentata

Artemisia cana

Guterriezia sarothrae

Symphoricarpos albus

Melilous officinalis

Cirsium arvense

Phleum pratense

Agropyron spicatum

Agropyron cristatum

Agropyron dasystachyum

Agropyron smithii

Achillea millefolium
THAR

DAPR

133

75

RACO 121

PIPO 113

$\begin{array}{ll}\text { OPPO } & 107\end{array}$

ROWO 123

TRDU 135

ARFR 57

ARTR 59

ARCA 55

GUSA 85

SYAL 131

MEOF 105

CIAR 71

PHPR 111

AGSP 49

AGCR 43

AGDA 45

AGSM 47

ACMI 41

yarrow, western

*Medicago lupulina $=$ Medicago polymorpha 


\section{INDEX II}

acronyms \& proper names.

This index has three functions. It translates acronyms to proper names. It translates both to common names. And it locates species articles from their proper names or their acronymns - however, since these are arranged alphabetically it may be quicker to turn directly to them. [Note that acronyms are formed from the first two letters of the genus name and the species epithet.] The index does not locate items in Part I.

$\begin{array}{ll}\text { Acronym } & \text { Latin name } \\ \text { ACMI } & \text { Achillea millefolium } \\ \text { AGCR } & \text { Agropyron cristatum } \\ \text { AGDA } & \text { Agropyron dasystachym } \\ \text { AGSM } & \text { Agropyron smithii } \\ \text { AGSP } & \text { Agropyron spicatum } \\ \text { AGST } & \text { Agrostis stolonifera } \\ \text { ALAL } & \text { Alyssum alyssoides } \\ \text { ARCA } & \text { Artemisia cana } \\ \text { ARFR } & \text { Artemisia frigida } \\ \text { ARTR } & \text { Artemisia tridentata } \\ \text { AVSA } & \text { Avena sativa } \\ \text { BOGR } & \text { Bouteloua gracilis } \\ \text { BRIN } & \text { Bromus inermis } \\ \text { BRTE } & \text { Bromus tectorum } \\ \text { CEMA } & \text { Centaurea maculosa } \\ \text { CIAR } & \text { Cirsium arvense } \\ \text { DAGL } & \text { Dactylis } \text { glomerata } \\ \text { DAPR } & \text { Dalea purpurea } \\ \text { FEID } & \text { Festuca idahoensis } \\ \text { FEOV } & \text { Festuca ovina } \\ \text { FESC } & \text { Festuca scabrella } \\ \text { GACO } & \text { Gaura coccinea } \\ \text { GUSA } & \text { Guterriezia sarothrae } \\ \text { HEVI } & \text { Heterotheca villosa } \\ \text { HOJU } & \text { Hordeum jubatum } \\ \text { KONI } & \text { Koeleria nitida } \\ \text { KOSC } & \text { Kochia scoparia } \\ \text { LASE } & \text { Lactuca serriola } \\ \text { LIPU } & \text { Liatris punctata } \\ \text { LUAR } & \text { Lupinus argenteus } \\ \text { MEPO } & \text { Medicago lupulina* } \\ \text { MESA } & \text { Medicago sativa } \\ \text { MEOF } & \text { Melilous officinalis } \\ \text { OPPO } & \text { Opuntia polyacantha } \\ \text { PHAR } & \text { Phalaris arundinace } \\ \text { PHPR } & \text { Phleum pratense } \\ \text { PIPO } & \text { Pinus ponderosa } \\ \text { POCO } & \\ & \text { Pompressa } \\ & \end{array}$

\begin{tabular}{|c|c|}
\hline Common name & Page \\
\hline western yarrow & 41 \\
\hline crested wheatgrass & 43 \\
\hline thickspike wheatgrass & 45 \\
\hline western wheatgrass & 47 \\
\hline bluebunch wheatgrass & 49 \\
\hline redtop bentgrass & 51 \\
\hline pale alyssum & 53 \\
\hline silver sagebrush & 55 \\
\hline fringed sagebrush & 57 \\
\hline mountain sagebrush & 59 \\
\hline common oats & 61 \\
\hline blue grama & 63 \\
\hline smooth brome & 65 \\
\hline cheatgrass & 67 \\
\hline spotted knapweed & 69 \\
\hline Canada thistle & 71 \\
\hline orchard-grass & 73 \\
\hline purple prairie-clover & 75 \\
\hline Idaho fescue & 77 \\
\hline sheep fescue & 79 \\
\hline rough fescue & 81 \\
\hline scarlet gaura & 83 \\
\hline broom snakeweed & 85 \\
\hline hairy gold-aster & 87 \\
\hline foxtail barley & 89 \\
\hline prairie junegrass & 91 \\
\hline summer cyprus & 93 \\
\hline prickly lettuce & 95 \\
\hline dotted gayfeather & 97 \\
\hline silvery lupine & 99 \\
\hline black medic & 101 \\
\hline alfalfa & 103 \\
\hline yellow sweet-clover & 105 \\
\hline plains prickly-pear & 107 \\
\hline reed canary-grass & 109 \\
\hline timothy & 111 \\
\hline ponderosa pine & 113 \\
\hline Canada bluegrass & 115 \\
\hline
\end{tabular}




\begin{tabular}{llll} 
POPR & Poa pratensis & Kentucky bluegrass & 117 \\
POSA & Poa sandbergii & Sandburg bluegrass & 119 \\
RACO & Ratibida columnifera & upright prairie-coneflower & 121 \\
ROWO & Rosa woodsii & wood's rose & 123 \\
SPCO & Sphaleraceae coccinea & scarlet globe-mallow & 125 \\
STCO & Stipa comata & needle \& thread grass & 127 \\
STVI & Stipa viridula & green needlegrass & 129 \\
SYAL & Symphoricarpos albus & common snowberry & 131 \\
THAR & Thlaspi arvensea & field pennycress & 133 \\
TRDU & Tragopogon dubius & western salsify & 135 \\
TRHY & Trifolium hybridum & alsike clover & 137 \\
VETH & Verbascum thapsus & flannel mullein & 139 \\
& & & \\
\hline
\end{tabular}

*Medicago lupulina $=M$. polymorpha 


\section{APPENDIX A}

\section{METRIC-ENGLISH CONVERSIONS}

Table 10. Conversion of metric and English measures.

LENGTH.

$\begin{array}{lll}1 \mathrm{~mm} & 0.1 \mathrm{~cm} & 0.04 \text { inch } \\ 10 \mathrm{~mm} & 1.0 \mathrm{~cm} & 0.39 \text { inch } \\ 100 \mathrm{~cm} & 1.0 \mathrm{~m} & 39.4 \text { inch } \\ & & \text { or } 3.38 \mathrm{ft} \\ 1000 \mathrm{~m} & 1 \mathrm{~km} & 0.62 \text { miles } \\ 1609 \mathrm{~m} & & 1.00 \text { miles }\end{array}$

AREA

$\begin{array}{lll}10,000 \mathrm{~m}^{2} & 1 \text { hectare } & 2.741 \text { acres } \\ (1000)^{2} \mathrm{~m}^{2} & \text { 1square kilometer } & 0.3861 \mathrm{mi}^{2}\end{array}$

MASS

$\begin{array}{lll}1 \mathrm{gm} & & 0.002 \text { pound } \\ 1000 \mathrm{gm} & 1 \mathrm{~kg} & 2.2 \text { pounds } \\ 1000 \mathrm{~kg} & 1 \mathrm{M} \text { ton } & 2205 \text { pounds }\end{array}$

TEMPERATURE ${ }^{1}$

$100 \mathrm{C}$

$212 \mathrm{~F}$

$25 \mathrm{C}$

$77 \mathrm{~F}$

$20 \mathrm{C}$

$68 \mathrm{~F}$

$15 \mathrm{C}$

$59 \mathrm{~F}$

$10 \mathrm{C}$

$50 \mathrm{~F}$

$5 \mathrm{C}$

$40 \mathrm{~F}$

$0 \mathrm{C}$

$32 \mathrm{~F}$

Temperature conversions can be calculated degree by degree with the following formulae: $\mathrm{C}=(\mathrm{F}-32)(5 / 9) \mathrm{F}=\mathrm{C}(9 / 5)+32$. 